DEVELOPMENT OF A PREDICTIVE MODEL FOR CARBON DIOXIDE SEQUESTRATION IN DEEP SALINE CARBONATE AQUIFERS

\author{
A THESIS SUBMITTED TO \\ THE GRADUATE SCHOOL OF NATURAL AND APPLIED SCIENCES \\ OF \\ MIDDLE EAST TECHNICAL UNIVERSITY
}

BY

SULTAN ANBAR

IN PARTIAL FULFILLMENT OF THE REQUIREMENTS FOR

THE DEGREE MASTER OF SCIENCE IN PETROLEUM AND NATURAL GAS ENGINEERING 
Approval of the thesis:

\section{DEVELOPMENT OF A PREDCTVE MODEL FOR CARBON DIOXIDE SEQUESTRATION IN DEEP SALINE CARBONATE AQUIFERS}

submitted by Sultan ANBAR in partial fulfillment of the requirements for the degree of Master of Science in Petroleum and Natural Gas Engineering Department, Middle East Technical University by,

Prof. Dr. Canan ÖZGEN

Dean, Graduate School of Natural and Applied Sciences

Prof. Dr. Mahmut PARLAKTUNA

Head of Department, Petroleum and Natural Gas Engineering

Prof. Dr. Serhat AKIN

Supervisor, Petroleum and Natural Gas Engineering Dept., METU

Examining Committee Members

Prof. Dr. Mahmut PARLAKTUNA

Petroleum and Natural Gas Dept., METU

Prof. Dr. Serhat AKIN

Petroleum and Natural Gas Dept., METU

Prof. Dr. Mustafa Verşan KÖK

Petroleum and Natural Gas Dept., METU

Assoc. Prof. Evren ÖZBAYOĞLU

Petroleum and Natural Gas Dept., METU

Yıldız KARAKEÇE, M.Sc

Turkish Petroleum Corporation

Date: $24 / 06 / 2009$ 
I hereby declare that all information in this document has been obtained and presented in accordance with academic rules and ethical conduct. I also declare that, as required by these rules and conduct, I have fully cited and referenced all material and results that are not original to this work.

Name, Last name: Sultan ANBAR

Signature: 


\title{
ABSTRACT
}

\section{DEVELOPMENT OF A PREDICTIVE MODEL FOR CARBON DIOXIDE SEQUESTRATION IN DEEP SALINE CARBONATE AQUIFERS}

\author{
Anbar, Sultan \\ M.S., Department of Petroleum and Natural Gas Engineering \\ Supervisor: Prof. Dr. Serhat Akın
}

June 2009, 184 pages

Although deep saline aquifers are found in all sedimentary basins and provide very large storage capacities, a little is known about them because they are rarely a target for the exploration. Furthermore, nearly all the experiments and simulations made for $\mathrm{CO}_{2}$ sequestration in deep saline aquifers are related to the sandstone formations. The aim of this study is to create a predictive model to estimate the $\mathrm{CO}_{2}$ storage capacity of the deep saline carbonate aquifers since a little is known about them. To create a predictive model, the variables which affect the $\mathrm{CO}_{2}$ storage capacity and their ranges are determined from published literature data. They are rock properties (porosity, permeability, vertical to horizontal permeability ratio), fluid properties (irreducible water saturation, gas permeability end point, Corey water and gas coefficients), reaction properties (forward and backward reaction rates) and reservoir properties (depth, pressure gradient, 
temperature gradient, formation dip angle, salinity), diffusion coefficient and Kozeny-Carman Coefficient. Other parameters such as pore volume compressibility and density of brine are calculated from correlations found in literature. To cover all possibilities, Latin Hypercube Space Filling Design is used to construct 100 simulation cases and CMG STARS is used for simulation runs. By using least squares method, a linear correlation is found to calculate $\mathrm{CO}_{2}$ storage capacity of the deep saline carbonate aquifers with a correlation coefficient 0.81 by using variables found from literature and simulation results. Numerical dispersion effects have been considered by increasing the grid dimensions. It has been found that correlation coefficient decreased to 0.77 when the grid size was increased from $250 \mathrm{ft}$ to $750 \mathrm{ft}$. The sensitivity analysis shows that the most important parameter that affects $\mathrm{CO}_{2}$ storage capacity is depth since the pressure difference between formation pressure and fracture pressure increases with depth. Also, $\mathrm{CO}_{2}$ storage mechanisms are investigated at the end of 300 years of simulation. Most of the gas (up to $90 \%$ ) injected into formation dissolves into the formation water and negligible amount of $\mathrm{CO}_{2}$ reacts with carbonate. This result is consistent with sensitivity analysis results since the variables affecting the solubility of $\mathrm{CO}_{2}$ in brine have greater affect on storage capacity of aquifers. Dimensionless linear and nonlinear predictive models are constructed to estimate the $\mathrm{CO}_{2}$ storage capacity of all deep saline carbonate aquifers and it is found that the best dimensionless predictive model is linear one independent of bulk volume of the aquifer.

Keywords: $\mathrm{CO}_{2}$ sequestration, deep saline aquifers, predictive model construction 


\title{
KARBONDIOKSITIN DERIN TUZLU KARBONAT AKIFERLERE DEPOLANMASI İÇIN TAHMINI MODELIN GELIŞTIRMESi
}

\author{
Anbar, Sultan \\ Yüksek Lisans, Petrol ve Doğal Gaz Mühendisliği Bölümü \\ Tez Yöneticisi: Prof. Dr. Serhat Akın
}

Haziran 2009, 184 sayfa

Derin tuzlu akiferler her tortul havzada bulunmasına ve geniş depolama kapasiteleri olmasına rağmen, nadir araştırma alanları olduğu için çok az özellikleri bilinmektedir. Ayrıca, derin tuzlu akiferlere $\mathrm{CO}_{2}$ depolama amaçlı yapılan birçok deney ve modelleme çalışmaları kumtaşı formasyonları ile ilgilidir. Bu çalışmanın amacı, derin tuzlu karbonat akiferlerin depolama kapasitelerinin bulunabilmesi için bir tahmini modelin oluşturulmasıdır. $\mathrm{Bu}$ modeli oluşturmak için $\mathrm{CO}_{2}$ depolama kapasitelerini etkileyen değişkenler ve değişken aralıkları literatürden tespit edilmiştir. Bu değişkenler kayaç özellikleri (gözeneklilik, geçirgenlik, yatay/dikey geçirgenlik oranı), akışkan özellikleri (indirgenemez su doygunluğu, gaz geçirgenliğinin son noktası, Corey su ve Corey gaz katsayıları), reaksiyon özellikleri (ileri ve geri reaksiyon hızı), akifer özellikleri (derinlik, basınç gradyanı, sıcaklık gradyanı, formasyon eğim açısı, tuzluluk), difüzyon katsayısı, Kozeny-Carman 
katsayısıdır. Gözenek hacmi sıkıştırılabilirliği ve tuzlu suyun özkütlesi gibi diğer değişkenler literatürden bulunan korelâsyonlardan hesaplanmıştır. Tüm olasılıkları göz önünde bulundurmak için Latin Hiperküp Uzaysal Dağılım Tasarım yöntemi kullanılarak 100 modelleme çalışması hazırlanmış ve CMG STARS kullanılarak modelleme yapılmıştır. Derin tuzlu karbonat akiferlerin $\mathrm{CO}_{2}$ depolama kapasitesini hesaplamak için literatürden bulunan değişkenler ve model sonuçları kullanılarak en küçük kareler metodu ile doğrusal korelâsyon katsayısı 0.81 olan bir korelâsyon elde edilmiştir. Izgara bloklarının boyutları arttırılarak sayısal dağıım etkisi incelenmiştir. Izgara blok boyutları 250 ft'den $(76 \mathrm{~m}) 750$ ft'e $(228 \mathrm{~m})$ arttırıldığında korelâsyon katsayısının 0.77'ye düştüğü görülmüştür. Ayrıca hassasiyet analizi yapılarak hangi değişkenin akifer $\mathrm{CO}_{2}$ depolama kapasitesini nasıl etkilediği incelenmiştir. Hassasiyet analizi depolama kapasitesini etkileyen en önemli değişkenin derinlik olduğunu göstermiştir, çünkü formasyon basıncı ile çatlatma basıncı arasındaki fark derinlikle artmaktadır. Ayrıca, $\mathrm{CO}_{2}$ depolama mekanizmaları 300 yıllık modelleme sonrası incelenmiş ve enjekte edilen $\mathrm{CO}_{2}$ gazının büyük bir kısmının (\%90 kadar) formasyon suyunda çözündüğü ve inmal edilebilecek bir kısmının da karbonat ile tepkimeye girdiği görülmüştür. Bu sonuç hassasiyet analizi sonuçları ile uyumludur; çünkü $\mathrm{CO}_{2}$ çözünürlüğünü etkileyen değişkenlerin akiferlerin $\mathrm{CO}_{2}$ depolama kapasiteleri üzerinde daha çok etkisi bulunmaktadır. Derin tuzlu karbonat akiferlerin $\mathrm{CO}_{2}$ depolama kapasitesini hesaplamak için boyutsuz doğrusal ve doğrusal olmayan tahmini modeller oluşturulmuştur ve en iyi boyutsuz tahmini modelin doğrusal akifer hacminden bağımsız olan tahmini model olduğu görülmüştür.

Anahtar Kelimeler: $\mathrm{CO}_{2}$ depolama, derin tuzlu akiferler, tahmini modelin oluşturulması 
To My Family

viii 


\section{ACKNOWLEDGMENTS}

The author wishes to express her deepest gratitude to her supervisor Prof.

Dr. Serhat AKIN for his guidance, advice, criticism, encouragement, insight and especially his patience throughout the research.

The author would also like to thank her sisters, her brother and her parents, Saniye ANBAR and Mithat ANBAR, for their continuous encouragement.

This study was supported by The Scientific and Technological Research Council of Turkey. 


\section{TABLE OF CONTENTS}

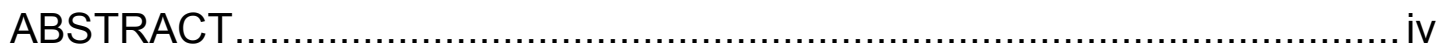

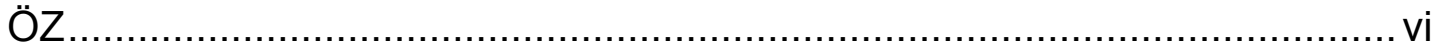

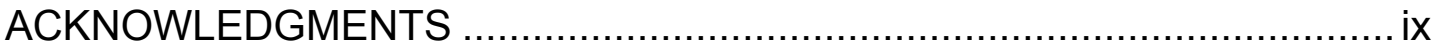

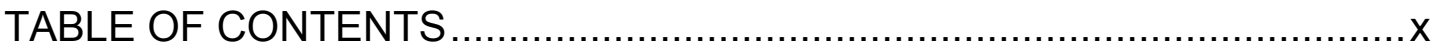

LIST OF FIGURES .................................................................... xvi

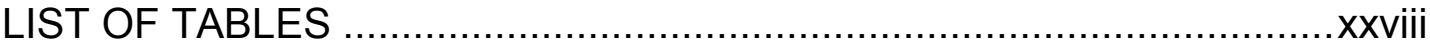

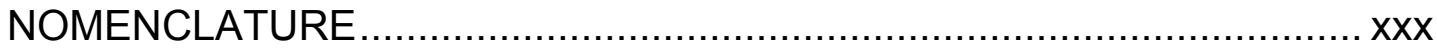

CHAPTERS

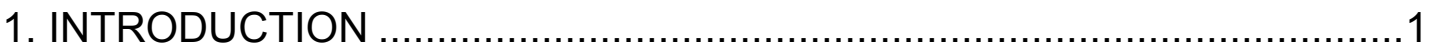

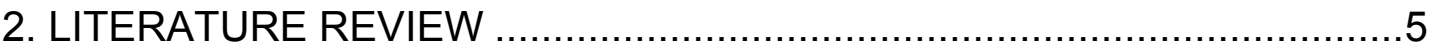

2.1. $\mathrm{CO}_{2}$ Mitigation Alternatives ..................................................... 5

2.1.1. Terrestrial Ecosystem ........................................................6

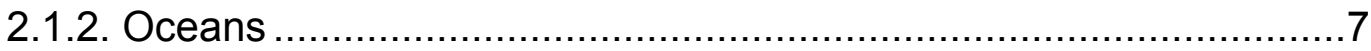

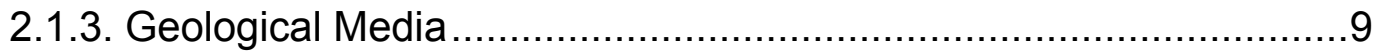

2.1.3.1. Oil and Gas Reservoirs ................................................ 10 
2.1.3.3.1. $\mathrm{CO}_{2}$ Storage Projects

2.1.3.3.1.1. The Sleipner Field and SACS Project. .14

2.1.3.3.1.2. Frio Brine Pilot .17

2.1.3.3.2. $\mathrm{CO}_{2}$ Trapping Mechanism 19

2.1.3.3.2.1. Hydrodynamic Trapping 19

2.1.3.3.2.2. Solubility Trapping .20

2.1.3.3.2. Mineral Trapping. .20

2.1.3.3.3. Physical Properties of the Supercritical $\mathrm{CO}_{2}$ .21

2.1.3.3.4. Dissolved $\mathrm{CO}_{2}$ Chemistry. .27

2.1.3.3.4.1. Reactivity of the Dissolved $\mathrm{CO}_{2}$ .28

2.1.3.3.5. Previous Works Related to the Deep Saline Aquifers .30

2.2. Design of Experiment 35

2.2.1. Experiment Design Characteristics 35

2.2.1.1. Orthogonality 36

2.2.1.2. Space-Filling Property 36

2.2.2. Space-Filling Design. .38

2.2.2.1. Latin Hypercube Sampling. 39

2.2.2.2 Latin Hypercube Design. 40 
2.3.2. Solution of Basic Equations .50

2.3.2.1. Newton's Method .51

2.3.2.2. Gauss Elimination Method .52

2.3.2.3. LU Decomposition. .54

2.3.2.4. Adaptive Implicit Method (AIM) and Implicit Pressure Explicit

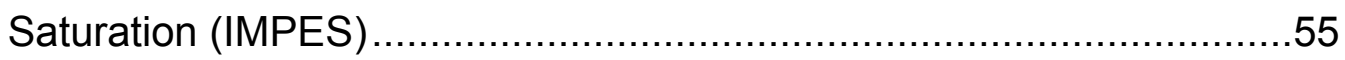

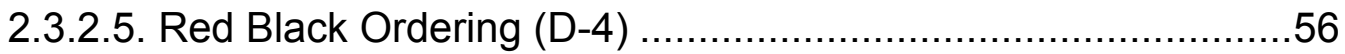

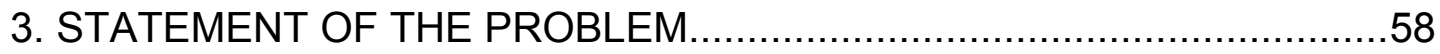

4. METHODOLOGY

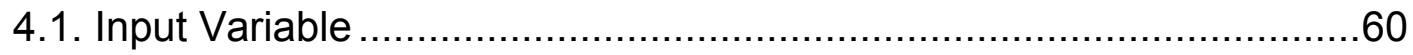

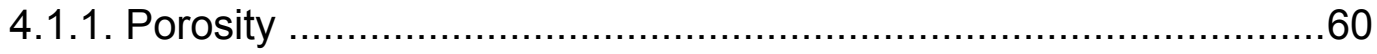

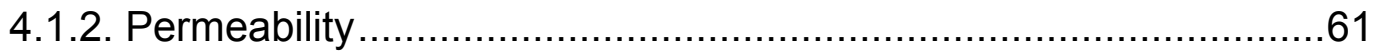

4.1.3. Ratio of Vertical Permeability to Horizontal Permeability ..............62

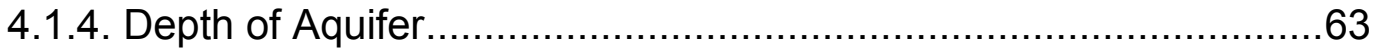

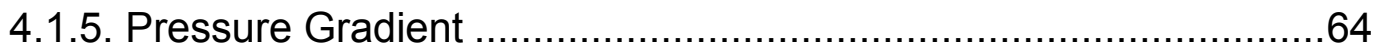

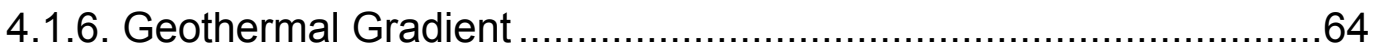

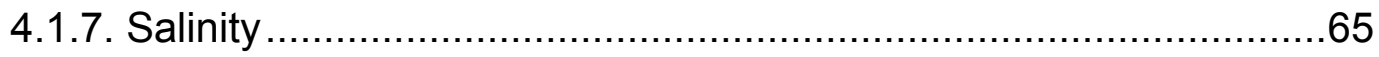


4.1.8. Relative Permeability .

4.1.9. Kozeny-Carman Coefficient.

4.1.10. $\mathrm{CO}_{2}-$ Water Diffusion Coefficient

4.1.11. Reaction Rates .68

4.1.12. Formation Dip .68

4.2. Latin Hypercube Space Filling Design .68

4.3. Simulation Model .74

4.3.1. Input-Output Control .74

4.3.2. Aquifer Description .75

4.3.3. Other Aquifer Properties .76

4.3.4. Component Properties. 79

4.3.5. Rock-Fluid Data .84

4.3.6. Initial Conditions .86

4.3.7. Numerical Control 89

4.3.8. Well and Recurrent Data .89

4.4. Predictive Models and Sensitivity Analysis. .93

5. RESULTS AND DISCUSSIONS. .96

5.1. Predictive Model Construction for $\mathrm{CO}_{2}$ Sequestration in Deep Saline Carbonate Aquifers .96 
5.2. Sensitivity Analysis of the Predictive Model Constructed for $\mathrm{CO}_{2}$ Sequestration in Deep Saline Carbonate Aquifers ..................................106

5.2.1. Reference Depth of the Aquifer .........................................107

5.2.2. Aquifer Pressure @ Reference Depth ......................................109

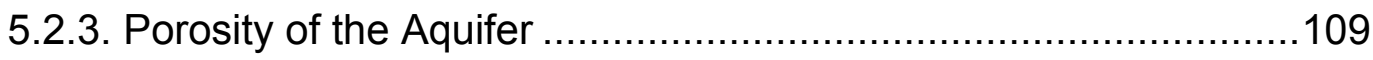

5.2.4. Aquifer Temperature and Formation Water Salinity....................110

5.2.5. Irreducible Water Saturation ................................................111

5.2.6. Horizontal Permeability of the Aquifer …..............................112

5.2.7. Vertical Permeability and Dip of the Aquifer ............................113

5.2.8. Gas Relative Permeability End Point, Corey Water and Corey Gas Exponents 114

5.2.9. Diffusion Coefficient of $\mathrm{CO}_{2}$ in Water.....................................116

5.2.10. Forward and Backward Reaction Rates ...............................117

5.2.11. Kozeny-Carman Coefficient................................................118

5.2.12. Overall Discussion of Sensitivity Analysis ............................120

5.2.13. Reduced Form of the Predictive Model ................................123

5.3. Predictive Models for $\mathrm{CO}_{2}$ Trapping Mechanisms in Deep Saline

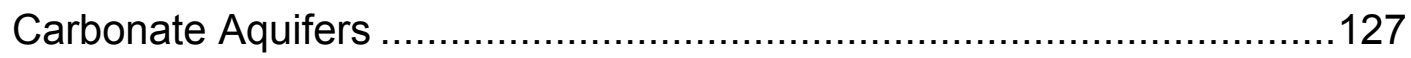

5.4. Dimensionless Predictive Model Construction for $\mathrm{CO}_{2}$ Sequestration in Deep Saline Carbonate Aquifers 133

6. CONCLUSION 140 
7. RECOMMENDATIONS

REFERENCES

APPENDICES

A. CORRELATION COEFFICIENTS OF DESIGN VARIABLES

B. DISTRIBUTION OF SIMULATION INPUT VARIABLES

C. PROJECTED DISTRIBUTION OF DESIGN POINTS .156

D. SIMULATION TEXT FILE. .176

E. M FILE FOR GAS COMPRESSIBILITY FACTOR CALCULATION. 183 


\section{LIST OF FIGURES}

Figure 2.1: Long Range Fossil Energy Supply and Associated Carbon Emission

Figure 2.2: The Sleipner Gas Field and $\mathrm{CO}_{2}$ Injection 15

Figure 2.3: Repeated Seismic Surveys and Position of Injected $\mathrm{CO}_{2}$ 16

Figure 2.4: Overview of Monitoring Strategy at the Frio Brine Storage Experiment

Figure 2.5: Modeled $\mathrm{CO}_{2}$ Distribution After 0.1, 0.5, 1.0 and 2.0 Years of Injection 19

Figure 2.6: Phase Diagram for Pure $\mathrm{CO}_{2}$ .21

Figure 2.7: $\mathrm{CO}_{2}$ Solubility as a Function of Molarity. .26

Figure 2.8: $\mathrm{CO}_{2}$ Solubility as a Function of Pressure .26

Figure 2.9: $\mathrm{CO}_{2}$ Solubility as a Function of Temperature. 27

Figure 2.10: Dissolution of $\mathrm{CO}_{2}$ as a function of $\mathrm{pH}$ .28

Figure 2.11: Comparison of Diagnostic for Three Eight-Run Space Filling Design From Output of JMP.... 39

Figure 2.12: Operation Mechanism of STARS .43

Figure 2.13: Red-Black Ordering .56

Figure 2.14: Red-Black Ordering Resulting Matrix .57 
Figure 2.15: Resulting Matrix after Elimination Stage

Figure 4.1: Porosity versus Pore Volume Compressibility from the Literature

Figure 4.2: Porosity (\%) Design Data Distribution

Figure 4.3: Correlation Coefficient Distribution

Figure 4.4: Porosity vs. Permeability Projected Distribution. .73

Figure 4.5: Euclidean Maximum Minimum Distance Distribution .73

Figure 4.6: Reservoir Appearance .75

Figure 4.7: Pore Volume Compressibility from the Literature and Mod-Horne Curve .77

Figure 4.8: Relative Permeability Curves .86

Figure 4.9: Solubility of $\mathrm{CaCO}_{3}$ with temperature .87

Figure 4.10: Solubility of $\mathrm{NaCl}$ with temperature .88

Figure 4.11: Formation and Fracture Pressure Gradient .91

Figure 5.1: Case 1, Analysis 1, Linear Predictive Model Fit (Function of Design Input Variables). 100

Figure 5.2: Case 1, Analysis 2, Linear Predictive Model Fit (Function of Simulation Input Variables) 100

Figure 5.3: Case 1, Analysis 1, Absolute Percent Error between Simulated and Predicted Results 101

Figure 5.4: Case 1, Analysis 2, Absolute Percent Error between Simulated and Predicted Results 102 
Figure 5.5: Case 2, Linear Predictive Model Fit .104

Figure 5.6: Case 3, Linear Predictive Model Fit .105

Figure 5.7: Case 2, Absolute Percent Error between Simulated and Predicted Results 105

Figure 5.8: Case 3, Absolute Percent Error between Simulated and Predicted Results 106

Figure 5.9: Case1, Analysis 1, Pareto Plot 107

Figure 5.10: Aquifer Reference Depth Sensitivity Analysis 108

Figure 5.11: Aquifer Pressure Sensitivity Analysis. 109

Figure 5.12: Aquifer Porosity Sensitivity Analysis 110

Figure 5.13: Aquifer Temperature Sensitivity Analysis 111

Figure 5.14: Formation Water Salinity Sensitivity Analysis 111

Figure 5.15: Irreducible Water Saturation Sensitivity Analysis 112

Figure 5.16: Aquifer Permeability Sensitivity Analysis 112

Figure 5.17: Aquifer Dip Sensitivity Analysis. 113

Figure 5.18: Aquifer Vertical Permeability Sensitivity Analysis 114

Figure 5.19: Corey Gas Exponent Sensitivity Analysis 115

Figure 5.20: Gas Relative Permeability End Point Sensitivity Analysis 115

Figure 5.21: Corey Water Exponent Sensitivity Analysis 116

Figure 5.22: Diffusion Coefficient of $\mathrm{CO}_{2}$ Sensitivity Analysis .117 
Figure 5.23: Forward Reaction Rate Sensitivity Analysis

Figure 5.24: Backward Reaction Rate Sensitivity Analysis .118

Figure 5.25: Kozeny-Carman Coefficient Sensitivity Analysis. 119

Figure 5.26: Reduced Form, Case 1, Linear Predictive Model Fit .125

Figure 5.27: Reduced Form, Case 2,Linear Predictive Model Fit 125

Figure 5.28: Reduced Form, Case 1, Absolute Percent Error between Simulated and Predicted Results .126

Figure 5.29: Reduced Form, Case 2, Absolute Percent Error between Simulated and Predicted Results .126

Figure 5.30: Injected $\mathrm{CO}_{2}$ Moles Number, Linear Predictive Model Fit .......128

Figure 5.31: Mineralization Trapping, Linear Predictive Model Fit 129

Figure 5.32: Hydrodynamic Trapping, Linear Predictive Model Fit 129

Figure 5.33: Solubility Trapping, Linear Predictive Model Fit 130

Figure 5.34: $\mathrm{CO}_{2}$ Trapping Mechanisms Comparison 132

Figure 5.35: Analysis 1, Linear Dimensionless Predictive Model Fit .133

Figure 5.36: Analysis 2, Nonlinear Dimensionless Predictive Model Fit 135

Figure 5.37: Analysis 2, Nonlinear Dimensionless Predictive Model, Absolute Percent Error between Simulated and Predicted Results .135

Figure 5.38: Analysis 3, Linear Dimensionless Predictive Model Fit (Independent of Bulk Volume of the Aquifer) .136 
Figure 5.39: Analysis 4, Nonlinear Dimensionless Predictive Model Fit (Independent of Pore Volume of Aquifer).

Figure 5.40: Analysis 3, Linear Dimensionless Predictive Model, Absolute Percent Error between Simulated and Predicted Results 137

Figure 5.41: Analysis 4, Nonlinear Dimensionless Predictive Model, Absolute Percent Error between Simulated and Predicted Results .138

Figure B.1: Porosity (\%) Distribution 153

Figure B.2: Permeability (mD) Distribution 153

Figure B.3: Horizontal to Vertical Permeability Ratio Distribution 153

Figure B.4: Reference Depth (m) Distribution 153

Figure B.5: Pressure Gradient (psi/ft) Distribution 153

Figure B.6: Geothermal Gradient $\left({ }^{\circ} \mathrm{C} / \mathrm{km}\right)$ Distribution 153

Figure B.7: Salinity (weight fraction) Distribution .154

Figure B.8: Irreducible Water Saturation (fraction) Distribution .154

Figure B.9: Gas Relative Permeability End Point Distribution .154

Figure B.10: Corey Water Coefficient Distribution .154

Figure B.11: Corey Gas Coefficient Distribution .154

Figure B.12: Kozeny-Carman Coefficient Distribution .154

Figure B.13: Diffusion Coefficient ( $\left.\mathrm{ft}^{2} / \mathrm{day}\right)$ Distribution .155

Figure B.14: Forward Reaction Rate (1/day) Distribution .155

Figure B.15: Backward Reaction Rate (1/day) Distribution .155 
Figure B.16: Formation Dip (degree) Distribution

Figure C.1: Porosity vs. Permeability 156

Figure C.2: Porosity vs. Horizontal to Vertical Permeability Ratio. 156

Figure C.3: Porosity vs. Reference Depth 156

Figure C.4: Porosity vs. Pressure Gradient. 156

Figure C.5: Porosity vs. Geothermal Gradient 156

Figure C.6: Porosity vs. Salinity 156

Figure C.7: Porosity vs. Irreducible Water Saturation 157

Figure C.8: Porosity vs. Gas Relative Permeability End Point 157

Figure C.9: Porosity vs. Corey Water Exponent 157

Figure C.10: Porosity vs. Corey Gas Exponent 157

Figure C.11: Porosity vs. Kozeny-Carman Coefficient 157

Figure C.12: Porosity vs. Diffusion Coefficient 157

Figure C.13: Porosity vs. Forward Reaction Rate 158

Figure C.14: Porosity vs. Backward Reaction Rate 158

Figure C.15: Porosity vs. Formation Dip 158

Figure C.16: Permeability vs. Horizontal to Vertical Permeability Ratio ......158

Figure C.17: Permeability vs. Reference Depth 158

Figure C.18: Permeability vs. Pressure Gradient 158

Figure C.19: Permeability vs. Geothermal Gradient 159 
Figure C.20: Permeability vs. Salinity .159

Figure C.21: Permeability vs. Irreducible Water Saturation .159

Figure C.22: Permeability vs. Gas Relative Permeability End Point 159

Figure C.23: Permeability vs. Corey Water Exponent 159

Figure C.24: Permeability vs. Corey Gas Exponent 159

Figure C.25: Permeability vs. Kozeny-Carman Coefficient 160

Figure C.26: Permeability vs. Diffusion Coefficient .160

Figure C.27: Permeability vs. Forward Reaction Rate .160

Figure C.28: Permeability vs. Backward Reaction Rate 160

Figure C.29: Permeability vs. Formation Dip 160

Figure C.30: Horizontal to Vertical Permeability Ratio vs. Reference Depth 160

Figure C.31: Horizontal to Vertical Permeability Ratio vs. Pressure Gradient 161

Figure C.32: Horizontal to Vertical Permeability Ratio vs. Geothermal Gradient 161

Figure C.33: Horizontal to Vertical Permeability Ratio vs. Salinity ..... 161

Figure C.34: Horizontal to Vertical Permeability Ratio vs. Irreducible Water Saturation 161

Figure C.35: Horizontal to Vertical Permeability Ratio vs. Gas Relative Permeability End Point. 161 
Figure C.36: Horizontal to Vertical Permeability Ratio vs. Corey Water Exponent 161

Figure C.37: Horizontal to Vertical Permeability Ratio vs. Corey Gas Exponent 162

Figure C.38: Horizontal to Vertical Permeability Ratio vs. Kozeny-Carman Coefficient 162

Figure C.39: Horizontal to Vertical Permeability Ratio vs. Diffusion Coefficient 162

Figure C.40: Horizontal to Vertical Permeability Ratio vs. Forward Reaction Rate 162

Figure C.41: Horizontal to Vertical Permeability Ratio vs. Backward Reaction Rate 162

Figure C.42: Horizontal to Vertical Permeability Ratio vs. Formation Dip ...162

Figure C.43: Reference Depth vs. Pressure Gradient 163

Figure C.44: Reference Depth vs. Geothermal Gradient 163

Figure C.45: Reference Depth vs. Salinity 163

Figure C.46: Reference Depth vs. Irreducible Water Saturation 163

Figure C.47: Reference Depth vs. Gas Relative Permeability End Point....163

Figure C.48: Reference Depth vs. Corey Water Exponent 163

Figure C.49: Reference Depth vs. Corey Gas Exponent 164

Figure C.50: Reference Depth vs. Kozeny-Carman Coefficient. 164

Figure C.51: Reference Depth vs. Diffusion Coefficient .164 
Figure C.52: Reference Depth vs. Forward Reaction Rate

Figure C.53: Reference Depth vs. Backward Reaction Rate .164

Figure C.54: Reference Depth vs. Formation Dip 164

Figure C.55: Pressure Gradient vs. Geothermal Gradient 165

Figure C.56: Pressure Gradient vs. Salinity 165

Figure C.57: Pressure Gradient vs. Irreducible Water Saturation 165

Figure C.58: Pressure Gradient vs. Gas Relative Permeability End Point..165

Figure C.59: Pressure Gradient vs. Corey Water Exponent 165

Figure C.60: Pressure Gradient vs. Corey Gas Exponent 165

Figure C.61: Pressure Gradient vs. Kozeny-Carman Coefficient. 166

Figure C.62: Pressure Gradient vs. Diffusion Coefficient 166

Figure C.63: Pressure Gradient vs. Forward Reaction Rate 166

Figure C.64: Pressure Gradient vs. Backward Reaction Rate 166

Figure C.65: Pressure Gradient vs. Formation Dip 166

Figure C.66: Geothermal Gradient vs. Salinity 166

Figure C.67: Geothermal Gradient vs. Irreducible Water Saturation 167

Figure C.68: Geothermal Gradient vs. Gas Relative Permeability End Point 167

Figure C.69: Geothermal Gradient vs. Corey Water Exponent 167

Figure C.70: Geothermal Gradient vs. Corey Gas Exponent 167 
Figure C.71: Geothermal Gradient vs. Kozeny-Carman Coefficient 167

Figure C.72: Geothermal Gradient vs. Diffusion Coefficient 167

Figure C.73: Geothermal Gradient vs. Forward Reaction Rate .168

Figure C.74: Geothermal Gradient vs. Backward Reaction Rate. .168

Figure C.75: Geothermal Gradient vs. Formation Dip 168

Figure C.76: Salinity vs. Irreducible Water Saturation 168

Figure C.77: Salinity vs. Gas Relative Permeability End Point 168

Figure C.78: Salinity vs. Corey Water Exponent 168

Figure C.79: Salinity vs. Corey Gas Exponent 169

Figure C.80: Salinity vs. Kozeny-Carman Coefficient 169

Figure C.81: Salinity vs. Diffusion Coefficient 169

Figure C.82: Salinity vs. Forward Reaction Rate 169

Figure C.83: Salinity vs. Backward Reaction Rate 169

Figure C.84: Salinity vs. Formation Dip. 169

Figure C.85: Irreducible Water Saturation vs. Gas Relative Permeability End Point. 170

Figure C.86: Irreducible Water Saturation vs. Corey Water Exponent..... .170

Figure C.87: Irreducible Water Saturation vs. Corey Gas Exponent. 170

Figure C.88: Irreducible Water Saturation vs. Kozeny-Carman Coefficient 170 Figure C.89: Irreducible Water Saturation vs. Diffusion Coefficient 170 
Figure C.90: Irreducible Water Saturation vs. Forward Reaction Rate

Figure C.91: Irreducible Water Saturation vs. Backward Reaction Rate.....171

Figure C.92: Irreducible Water Saturation vs. Formation Dip. .171

Figure C.93: Gas Relative Permeability End Point vs. Corey Water Exponent 171

Figure C.94: Gas Relative Permeability End Point vs. Corey Gas Exponent 171

Figure C.95: Gas Relative Permeability End Point vs. Kozeny-Carman Coefficient 171

Figure C.96: Gas Relative Permeability End Point vs. Diffusion Coefficient 171

Figure C.97: Gas Relative Permeability End Point vs. Forward Reaction Rate 172

Figure C.98: Gas Relative Permeability End Point vs. Backward Reaction Rate .172

Figure C.99: Gas Relative Permeability End Point vs. Formation Dip .172

Figure C.100: Corey Water Exponent vs. Corey Gas Exponent .172

Figure C.101: Corey Water Exponent vs. Kozeny-Carman Coefficient.......172

Figure C.102: Corey Water Exponent vs. Diffusion Coefficient. 172

Figure C.103: Corey Water Exponent vs. Forward Reaction Rate. 173

Figure C.104: Corey Water Exponent vs. Backward Reaction Rate 173

Figure C.105: Corey Water Exponent vs. Formation Dip .173 
Figure C.106: Corey Gas Exponent vs. Kozeny-Carman Coefficient.

Figure C.107: Corey Gas Exponent vs. Diffusion Coefficient

Figure C.108: Corey Gas Exponent vs. Forward Reaction Rate

Figure C.109: Corey Gas Exponent vs. Backward Reaction Rate

Figure C.110: Corey Gas Exponent vs. Formation Dip 174

Figure C.111: Kozeny-Carman Coefficient vs. Diffusion Coefficient 174

Figure C.112: Kozeny-Carman Coefficient vs. Forward Reaction Rate 174

Figure C.113: Kozeny-Carman Coefficient vs. Backward Reaction Rate ...174

Figure C.114: Kozeny-Carman Coefficient vs. Formation Dip 174

Figure C.115: Diffusion Coefficient vs. Forward Reaction Rate 175

Figure C.116: Diffusion Coefficient vs. Backward Reaction Rate 175

Figure C.117: Diffusion Coefficient vs. Formation Dip 175

Figure C.118: Forward Reaction Rate vs. Backward Reaction Rate 175

Figure C.119: Forward Reaction Rate vs. Formation Dip 175

Figure C.120: Backward Reaction Rate vs. Formation Dip .175 


\section{LIST OF TABLES}

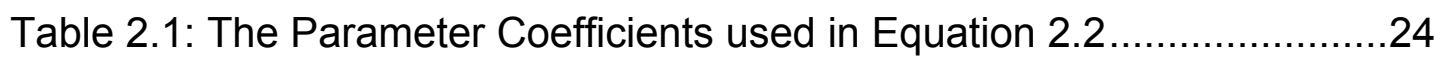

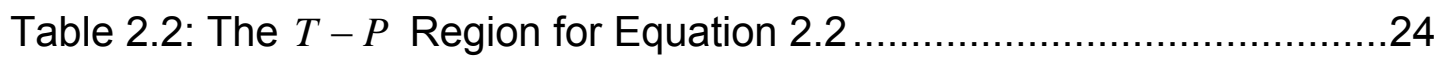

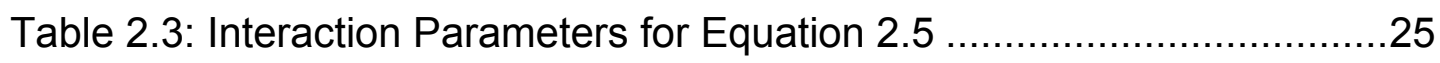

Table 2.4: An Example of Latin Hypercube Sampling...........................40

Table 4.1: Permeability Data Found From Literature .............................62

Table 4.2: Vertical to Horizontal Permeability Ratio Found From Literature .62

Table 4.3: Depth Data Found From Literature ....................................63

Table 4.4: Pressure Gradient Data Found From Literature........................64

Table 4.5: Geothermal Gradient Data Found From Literature ...................64

Table 4.6: Salinity Data Found From Literature ...................................65

Table 4.7: Relative Permeability Characteristics...................................66

Table 4.8: Irreducible Water Saturation and Gas Relative Permeability End Points ........................................................................... 66

Table 4.9: Diffusion Coefficient of $\mathrm{CO}_{2}$ in Water ...................................67

Table 4.10: Input Variables Used in the Study .................................69

Table 4.11: Design Case Number vs. Design Discrepancy ......................70

Table 4.12: Discrepancy Change with Design ..................................... 71 
Table 4.13: Constants $A$ and $B$ for Equation 4.6 for different rock types ....79

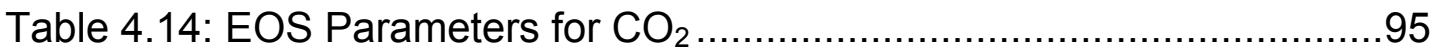

Table 5.1: Case 1, Statistical Analysis of Linear Predictive Model...............99

Table 5.2: Case 1, Linear Predictive Model Variables and Coefficients........99

Table 5.3: Case2 and Case 3, Statistical Analysis of Linear Predictive Models 103

Table 5.4: Case 2 and Case 3, Linear Predictive Model Variables and Coefficients 104

Table 5.5: Case1 and Case 2, Statistical Analysis of Reduced Form of Linear Predictive Models 124

Table 5.6: Case 1 and Case 2, Reduced Form of Linear Predictive Model Variables and Coefficients 124

Table 5.7: Injected Moles of $\mathrm{CO}_{2}$ and Trapping Mechanisms, Statistical Analysis of Linear Predictive Models 131

Table 5.8: Injected Moles of $\mathrm{CO}_{2}$ and Trapping Mechanisms, Linear Predictive Model Variables and Coefficients 131

Table 5.9: Analysis 1 and Analysis 2, Dimensionless Predictive Model Variables and Coefficients 134

Table 5.10: Analysis 3 and Analysis 4, Statistical Analysis of Dimensionless Predictive Models 138

Table 5.11: Analysis 3 and Analysis 4, Dimensionless Predictive Model Variables and Coefficients 139

Table A1: Correlation Coefficient of Simulation Input Variables 152 


\section{NOMENCLATURE}

\section{Abbreviations}

$\begin{array}{ll}\text { AIM } & \text { Adaptive-Implicit Method } \\ \text { CT } & \text { Computerized Tomography } \\ \text { DOE } & \text { Design of Experiment } \\ \text { EGR } & \text { Enhanced Gas Recovery } \\ \text { EIA } & \text { Energy Information Administration } \\ \text { EOR } & \text { Enhanced Oil Recovery } \\ \text { GtC } & \text { Giga ton carbon } \\ \text { IMPES } & \text { Implicit Pressure and Explicit Saturation } \\ \text { IPCC } & \text { Intergovernmental Panel on Climate Change } \\ \text { IRONEX } & \text { Iron Fertilization Experiment } \\ \text { Mt } & \text { Mega ton } \\ \text { P } & \text { Photosynthesis } \\ \text { Pg } & \text { Peta gram } \\ \text { ppm } & \text { parts per million } \\ \text { R } & \text { Respiration } \\ \text { SACS } & \text { Saline Aquifer CO }{ }_{2} \text { Storage } \\ \text { SRES } & \text { Special Report on Emission Scenarios } \\ \text { UCSCS } & \text { Ultimate CO }{ }_{2} \text { Sequestration Capacity in Solution }\end{array}$

\section{Greek Symbols}

$\beta \quad$ Coefficient of variables in metamodel

$\rho \quad$ Correlation coefficient of two matrices

$\rho \quad$ Density $\left[\mathrm{M} / \mathrm{L}^{3}\right]$

$\Delta \quad$ Difference 


$\begin{array}{ll}\varepsilon & \text { Error term of metamodel } \\ \varphi & \text { Fugacity coefficient } \\ \mu & \text { Poisson's ratio } \\ \phi & \text { Porosity }\left[\mathrm{L}^{3} / \mathrm{L}^{3}\right] \\ \Phi & \text { Potential }\left[\mathrm{M} / \mathrm{LT}^{2}\right] \\ \lambda_{j k} & \text { Relative mobility of phase } j \text { at layer } k\left[\mathrm{~L}^{3} \mathrm{~T} / \mathrm{M}\right] \\ \lambda & \text { Second-order interaction parameters of solubility model } \\ \lambda & \text { Thermal conductivity [ML/T } \Theta \text { ] } \\ \kappa & \text { Thermal conductivity }\left[\mathrm{ML} / \mathrm{T}^{3} \Theta\right] \\ \alpha & \text { Thermal expansion }[1 / \Theta] \\ \zeta & \text { Third-order interaction parameters of solubility model } \\ \mu & \text { Viscosity [M/LT] }\end{array}$

\section{Latin Symbols}

A Empirical constants of thermal conductivity equation

$A_{1} \quad$ Empirical Kozey-Carman constant

avisc(i) Viscosity temperature dependence correlation coefficient for $i^{\text {th }}$ component $\left[\mathrm{L}^{2}\right]$

$B \quad$ Empirical constants of thermal conductivity equation

bvisc(i) Viscosity temperature dependence correlation coefficient for $i^{\text {th }}$ component $[\Theta]$

c Compressibility [ $\left[\mathrm{LT}^{2} / \mathrm{M}\right]$

c Concentration $\left[\mathrm{Mmole} / \mathrm{L}^{3}\right]$

c Kozeny-Carman coefficient

$C^{k} \quad$ K-dimensional unit cube

CC Geometric factor

CMM Molecular weight [M/Mmole]

cond $_{\infty} \quad$ Infinite condition number 


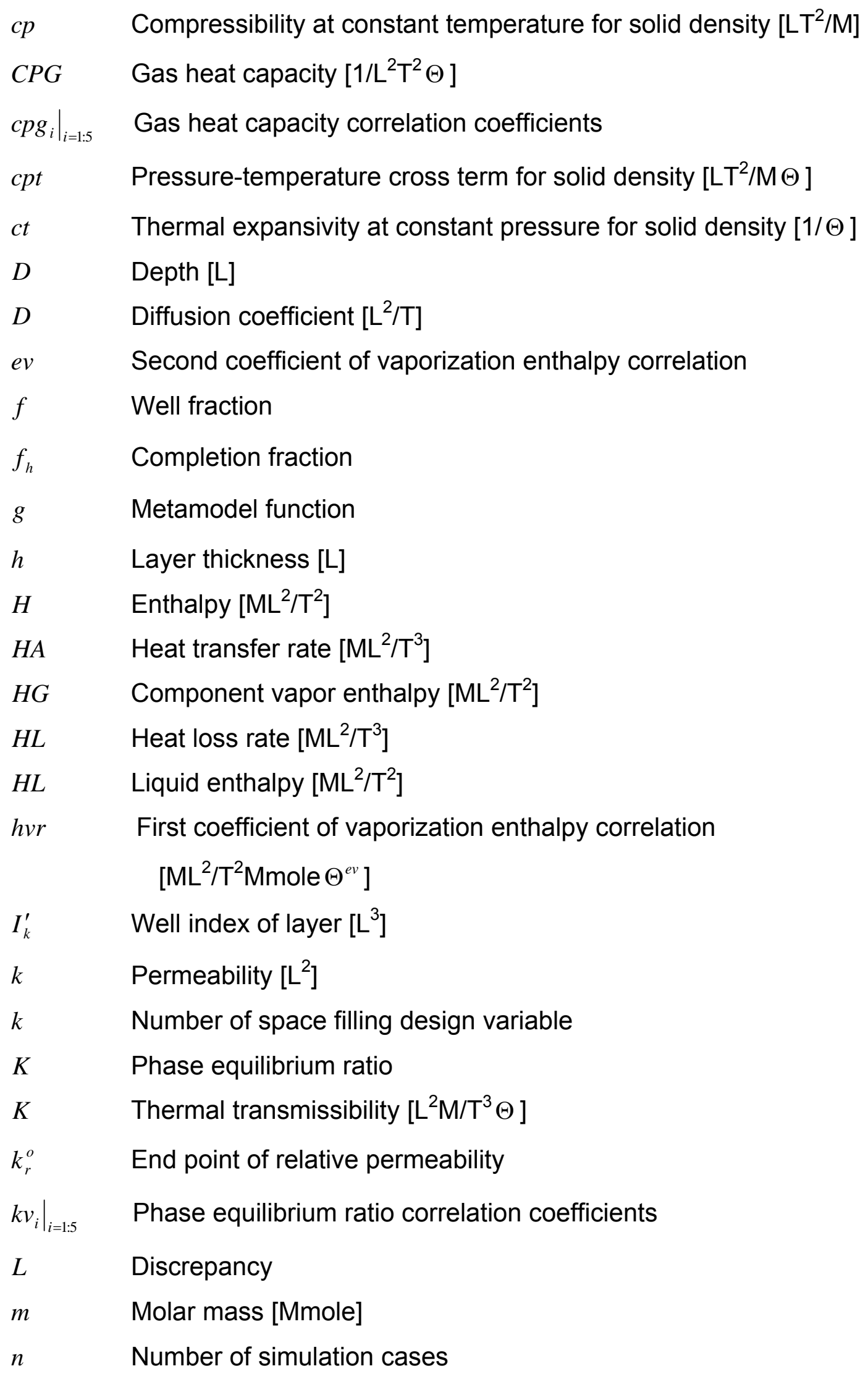




\begin{tabular}{|c|c|}
\hline$n_{b}$ & Number of active grid blocks \\
\hline$n_{w}$ & Number of open wells \\
\hline Neq & Total number of equations \\
\hline$P$ & Pressure $\left[M / L^{2}\right]$ \\
\hline$q a q$ & Volumetric flow rate for thermal aquifer $\left[\mathrm{L}^{3} / \mathrm{T}\right]$ \\
\hline$r$ & Volumetric rate of reaction $\left[\mathrm{Mmole} / \mathrm{TL}^{3}\right]$ \\
\hline$r_{e}$ & Effective block radius [L] \\
\hline$r_{w}$ & Wellbore radius [L] \\
\hline$R$ & Universal gas constant $\left[\mathrm{ML}^{2} / \mathrm{T}^{2} \mathrm{Mmole} \Theta\right]$ \\
\hline$R_{i}$ & Residual form of conversion equation for $i^{\text {th }}$ component \\
\hline$r r f$ & Reaction frequency factor $[1 / T]$ \\
\hline$s$ & Reactant stoichiometric coefficient \\
\hline$s$ & Skin \\
\hline$s^{\prime}$ & Product stoichiometric coefficient \\
\hline$S$ & Over-burden stress $\left[\mathrm{M} / \mathrm{LT}^{2}\right]$ \\
\hline$S$ & Salinity $[M / M]$ \\
\hline$S$ & Saturation $\left[L^{3} / L^{3}\right]$ \\
\hline$S$ & Surface area per unit bulk volume $\left[\mathrm{L}^{2} / \mathrm{L}^{3}\right]$ \\
\hline$T$ & Temperature $[\Theta]$ \\
\hline$T$ & Transmissibility $\left[\mathrm{L}^{3}\right]$ \\
\hline$U$ & Internal energy $\left[\mathrm{ML}^{2} / \mathrm{T}^{2}\right]$ \\
\hline$v$ & Volumetric flow rate $\left[\mathrm{L}^{3} / \mathrm{T}\right]$ \\
\hline$V$ & Volume $\left[\mathrm{L}^{3}\right]$ \\
\hline$V(i)$ & Partial molar volume of component $i\left[\mathrm{~L}^{3} / \mathrm{Mmole}\right]$ \\
\hline$w$ & Water mole fraction \\
\hline$x$ & Oil mole fraction \\
\hline$x$ & Variable in metamodel \\
\hline$X$ & Mass fraction \\
\hline$y$ & Gas mole fraction \\
\hline
\end{tabular}




$\begin{array}{ll}y & \text { Mole fraction } \\ Z & \text { Gas compressibility factor }\end{array}$

\section{Subscripts}

$\begin{array}{ll}b & \text { Brine } \\ c & \text { Critical } \\ C D & \text { Conduction } \\ C V & \text { Convection } \\ f & \text { Fluid } \\ g & \text { Gas phase } \\ g r & \text { Residual gas } \\ h & \text { Horizontal } \\ k & \text { Reaction } \\ n g & \text { Corey gas coefficient } \\ n w & \text { Corey water coefficient } \\ o & \text { Oil phase } \\ r & \text { Reference } \\ r & \text { Relative } \\ r & \text { Rock } \\ s & \text { Solid or absorbed component } \\ v & \text { Vertical } \\ v & \text { Void } \\ w & \text { Water phase } \\ w & \text { Wellbore } \\ w i & \text { Flowing wellbore } \\ & \text { Irreducible water } \\ & \\ & \end{array}$




\section{CHAPTER 1}

\section{INTRODUCTION}

When compared to other greenhouse gasses such as methane $\left(\mathrm{CH}_{4}\right)$ and nitrous oxide, carbon dioxide $\left(\mathrm{CO}_{2}\right)$ is the most abundant greenhouse gas in the atmosphere. It is responsible for about $64 \%$ of the greenhouse effect [1]. According to IPCC (2007), global atmospheric concentration of $\mathrm{CO}_{2}$ has increased from a pre- industrial value of about 280 ppm to 379 ppm in 2005. The annual $\mathrm{CO}_{2}$ concentration growth rate was larger during the last 10 years (1995-2005 average: 1.9 ppm per year), than it has been since the beginning of continuous direct atmospheric measurements (1960-2005 average: $1.4 \mathrm{ppm}$ per year) although there is a year-to-year variability in growth rates [2].

The main reason for the increase in atmospheric concentration of $\mathrm{CO}_{2}$ since the pre-industrial period is increase in fossil fuel use and land-use change. Annual fossil fuel $\mathrm{CO}_{2}$ emissions increased from an average of 6.4 [6.0 to 6.8] GtC (23.5 [22.0 to 25.0] $\mathrm{GtCO}_{2}$ ) per year in 1990s to 7.2 [6.9 to 7.5] GtC (26.4 [25.3 to 27.5] $\mathrm{GtCO}_{2}$ ) per year in 2000-2005 (2004 and 2005 data are interim estimates). Estimated annual $\mathrm{CO}_{2}$ emission associated with land-use change is 1.6 [0.5 to 2.7] $\mathrm{GtC}$ (5.9 [1.8 to 9.9] $\left.\mathrm{GtCO}_{2}\right)$ over the 1990 s [2].

Increase in $\mathrm{CO}_{2}$ emission to the atmosphere is most likely cause of global climate change of the past 50 years. Record of past global surface temperature shows that the 100-year linear trend (1906 to 2005) of $0.74{ }^{\circ} \mathrm{C}$ [0.56 ${ }^{\circ} \mathrm{C}$ to $0.92^{\circ} \mathrm{C}$ ] is larger than the corresponding trend for 1901 to 2000 of 
$0.6^{\circ} \mathrm{C}\left[0.4^{\circ} \mathrm{C}\right.$ to $\left.0.8^{\circ} \mathrm{C}\right]$ and the linear trend over the last 50 years $\left(0.13^{\circ} \mathrm{C}\right.$ $\left[0.10^{\circ} \mathrm{C}\right.$ to $\left.0.16^{\circ} \mathrm{C}\right]$ per decade) is nearly twice that for the last 100 years [2].

Further warming and global climate change will most likely be observed if greenhouse gas emissions continue at or above current rate. To predict the future changes in climate (2090-2099), different SRES (Special Report on Emission Scenarios) scenarios prepared. According to SRES, even if concentrations are kept constant, global average surface air temperature change will be $0.6{ }^{\circ} \mathrm{C}$ (likely range is $0.3^{\circ} \mathrm{C}$ to $0.9^{\circ} \mathrm{C}$ ). Among these scenarios, the best estimate for low scenario is $1.8^{\circ} \mathrm{C}$ (likely range $1.1^{\circ} \mathrm{C}$ to $2.9^{\circ} \mathrm{C}$ ), and best estimate for the high scenario $4.0^{\circ} \mathrm{C}$ (likely range is $2.4^{\circ} \mathrm{C}$ to $\left.6.4^{\circ} \mathrm{C}\right)[2]$.

There are two ways to mitigate the $\mathrm{CO}_{2}$ emission, namely, source oriented options and $\mathrm{CO}_{2}$ sinks [3]. The first option aims to reduce $\mathrm{CO}_{2}$ emission by energy conversion. Several examples are using energy more efficiently to reduce fossil fuel combustion or using low-carbon and carbon-free fuels and technologies such as nuclear power and renewable sources such as solar energy, wind power, and biomass fuels. Nevertheless, oil, natural gas and coal provide about $75 \%$ of the world's energy and they are likely to provide major world energy at least next century due to its availability, competitive cost, ease of transport and storage and large resources [4-5]. The second option is to capture the $\mathrm{CO}_{2}$ for either utilization or sequestration into oceans or geological media such as depleted gas and oil reservoirs, coal seams and deep saline aquifers. Of all alternatives, $\mathrm{CO}_{2}$ sequestration in deep saline aquifers is one of the most promising ways to mitigate the greenhouse gas effect since they are found in almost all sedimentary basins and provide very large storage capacity (1000 and 10000 billions tones of $\mathrm{CO}_{2}$ [6]) and technology to inject $\mathrm{CO}_{2}$ into deep saline aquifers is already available [3].

$\mathrm{CO}_{2}$ storage project (SACS), the first commercial application of $\mathrm{CO}_{2}$ storage in deep saline aquifer in the world, shows the feasibility of $\mathrm{CO}_{2}$ sequestration 
into deep saline aquifers. $\mathrm{CO}_{2}$ obtained from natural gas produced from Sleipner Field, North Sea, was injected into Utsira sandstone formation from 1996 to 2004 with a rate of $1 \mathrm{Mt} \mathrm{CO}_{2}$ per year at a depth $1000 \mathrm{~m}$ without any significant operational problems [7]. Furthermore, to determine reliability of the sequestration process and the fate of the injected $\mathrm{CO}_{2}$ and to assess the $\mathrm{CO}_{2}$ sequestration impact on environment, 1600 tons of $\mathrm{CO}_{2}$ was injected at a depth of $1500 \mathrm{~m}$ into high permeability Frio sandstone from October 4 to 14,2004 . The other main aim of this study was to reveal the conceptual model and develop experience for future large-scale $\mathrm{CO}_{2}$ injection experiment [8].

When $\mathrm{CO}_{2}$ is injected into deep saline aquifers, it starts to rise due to the density difference between formation water and $\mathrm{CO}_{2}$ until it reaches an impermeable seal which prevents the $\mathrm{CO}_{2}$ migration towards surface (hydrodynamic trapping). Some part of the injected $\mathrm{CO}_{2}$ dissolves into formation water (solubility trapping) and forms a weak carbonic acid which reacts with divalent cations and precipitate as carbonate minerals (mineral trapping) [9]. $\mathrm{CO}_{2}$ sequestration in saline aquifers involves complex multiphase flow processes as well as geomechanical, and geochemical processes, such as advection and diffusion, convective mixing, phase appearance/disappearance, dissolution and precipitation of minerals, and other chemical reactions [10].

Numerical simulation of $\mathrm{CO}_{2}$ sequestration started with van der Meer's work of in a circular anticlinal stratigraphic trap with non-reactive transport modeling in 1990s [11]. After that the solubility of the $\mathrm{CO}_{2}$ in water and empirical relative permeability relationship between liquid and gas phases were included, when Holt et al studied the $\mathrm{CO}_{2}$ sequestration into aquifers and oil reservoirs with ECLIPSE 100, a black oil simulator [12]. Law and Bachu studied the $\mathrm{CO}_{2}$ sequestration into a sedimentary basin for 30 years by using STARS to model multidimensional, multicomponent flow and phase partitioning between separate and dissolved phase of $\mathrm{CO}_{2}$ [13]. Many 
simulations have been made to show the feasibility of the $\mathrm{CO}_{2}$ sequestration and to demonstrate the fate of the injected $\mathrm{CO}_{2}$.

Deep saline aquifers are rarely target of the exploration, and the data related to them generally is obtained from regional geology based on surface mapping, few stratigraphic wells and large-scale seismic surveys. As a result, deep saline aquifer data uncertainty is much larger than that of better known areas of hydrocarbon and mining exploration. Numerical simulation, in fact, plays an important role to evaluate the feasibility and reliability of $\mathrm{CO}_{2}$ sequestration and to explore possible scenarios and uncertainty analysis [14].

In this study, all variables that affect the $\mathrm{CO}_{2}$ storage capacity of the deep saline carbonate aquifers are found from published literature data. Possible scenarios are simulated to create a database which then is used to find a predictive model to estimate the storage capacity of the deep saline carbonate aquifers. Next, $\mathrm{CO}_{2}$ trapping mechanisms are investigated to determine the most effective $\mathrm{CO}_{2}$ storage mechanism. Finally, sensitivity analyses are conducted to find out the most important parameters that affect the storage capacity of the deep saline aquifers. 


\section{CHAPTER 2}

\section{LITERATURE REVIEW}

\section{1. $\mathrm{CO}_{2}$ Mitigation Alternatives}

$\mathrm{CO}_{2}$ concentration in the atmosphere is continuously increasing since the world energy demand is increasing due to global population and economic growth (see Figure 2.1) [15].

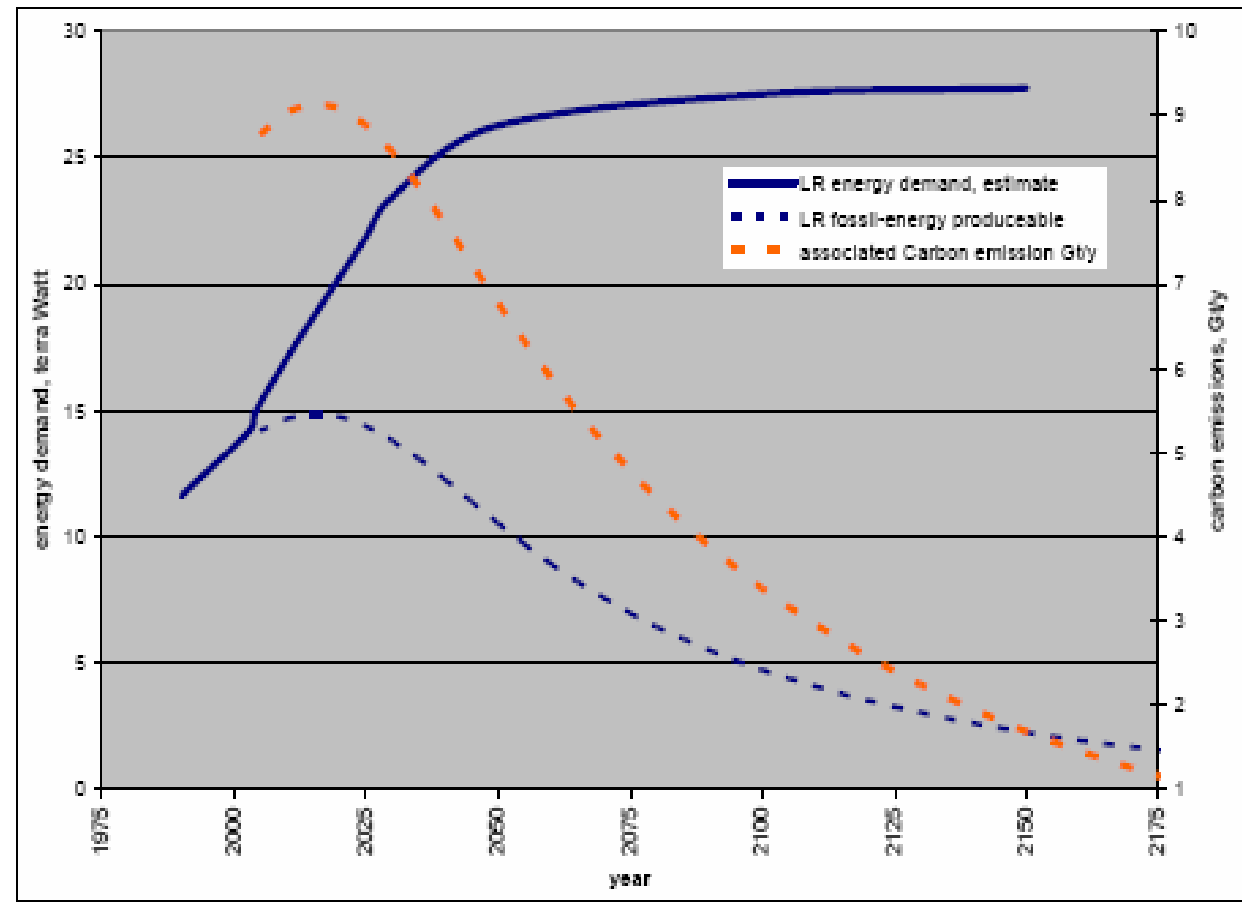

Figure 2.1: Long Range Fossil Energy Supply and Associated Carbon Emission [15] 
According to EIA (2007), fossil fuels supply the $86 \%$ of the world energy demand and this dependence is expected to continue in the near future. For this reason, sequestration of $\mathrm{CO}_{2}$ plays an important role to decrease the $\mathrm{CO}_{2}$ concentration in the atmosphere [15].

$\mathrm{CO}_{2}$ can be sequestrated into terrestrial ecosystems, oceans, and geologic formations such as active or depleted oil and gas reservoirs, deep unmineable coal formations and aqueous formations.

\subsubsection{Terrestrial Ecosystem}

The aim of developing enhanced $\mathrm{CO}_{2}$ sequestration in the biosphere is to create a rapid gain in withdrawal of $\mathrm{CO}_{2}$ from the atmosphere over the next 50 years by either enhancing the net removal of $\mathrm{CO}_{2}$ from the atmosphere or preventing the $\mathrm{CO}_{2}$ net emission from terrestrial ecosystem into the atmosphere in order to allow time for implementation of other technological advances that will help mitigate $\mathrm{CO}_{2}$ emission [16].

Wisniewski et al. identifies the opportunities to sequester and converse terrestrial carbon as decreasing deforestation and maintaining existing carbon pools, establishing additional areas of forest to foster carbon sequestration, increasing the productivity of existing forests and carbon sequestration, employing agroforestry as a land-use practice to conserve and sequester carbon, managing soil systems, agronomic and desert crop as carbon sink, and offsetting fossil fuel combustion with biomass or biomassderived fuels [17].

The total amount of carbon stored in terrestrial ecosystem is approximately $2000 \mathrm{GtC}$ and net removal of $\mathrm{CO}_{2}$ from the atmosphere is estimated as $2 \mathrm{GtC}$ annually; however, this estimation is uncertain since it is based on the difference between photosynthesis $(P)$ and respiration $(R)$ difference which can be calculated from annual change in atmospheric $\mathrm{CO}_{2}$ and accounting 
for oceanic carbon dynamics. Unfortunately, this information cannot be used to understand how biosphere will regulate the atmospheric $\mathrm{CO}_{2}$ since environmental variables such as temperature, moisture, nutrient availability determine the $P: R$ ratio and environmental variables are different from ecosystem to ecosystem. Furthermore, the other factor making the estimate difficult is that biogeochemical dynamics that control the flow of carbon among plants, soils and the atmosphere are poorly understood [16].

In addition to these uncertainties, carbon sequestration in terrestrial ecosystem is continuously changing since human response to climatic change and environmental issues, population growth, economic development, and technological changes gives rise to changes in patterns of the land use, settlement, and resource management, which makes the understanding of global carbon cycle incomplete $[16,17]$. Even with these uncertainties, the potential of the carbon sequestration in the terrestrial ecosystem is one of the promising ways to mitigate $\mathrm{CO}_{2}$ effect; therefore, further research is needed to understand the response and feedbacks of the terrestrial biosphere [17].

\subsubsection{Oceans}

Oceans are considered as the largest sinks for $\mathrm{CO}_{2}$ sequestration. In sea, $\mathrm{CO}_{2}$ is sequestrated naturally by photosynthetic fixation by the facilities of the ocean organisms and remineralization process. Every year these activities sequester the one third of the anthropogenic $\mathrm{CO}_{2}$ emission [16]. Brewer et al. state that ocean takes up about 10 billion tons per year of $\mathrm{CO}_{2}$ by gas exchange with the atmosphere and if no active sequestration methods are employed, about $85 \%$ of the anthropogenic $\mathrm{CO}_{2}$ presently in the atmosphere will eventually finds its way into the oceans in hundreds of years [18]. Besides, additional $\mathrm{CO}_{2}$ can be sequestered into oceans by two methods: 
direct injection of relatively pure $\mathrm{CO}_{2}$ stream or enhancement of $\mathrm{CO}_{2}$ uptake capacity of oceans by fertilization process such as iron fertilization.

$\mathrm{CO}_{2}$ directly injected into oceans can be sequestrated by dissolution into water column. Injection of $\mathrm{CO}_{2}$ at depths between $500-1500 \mathrm{~m}$ is advantageous since compression and pipeline costs are lower compared with greater depths; however, the impact of the reduced $\mathrm{pH}$ on midwater organisms remains unknown yet. The other question about the midwater $\mathrm{CO}_{2}$ release is that determination of depth of release and $\mathrm{CO}_{2}$ dissolution rate, which determine the length of exchange time with the atmosphere. Peltzer et al. conducted an experiment to determine the fate of the midwater $\mathrm{CO}_{2}$ release. Small amounts of liquid $\mathrm{CO}_{2}$ were released at $800 \mathrm{~m}$ depth and ambient temperature and observed over a one hour period. It is found that the mean rise rate which was initially $1 \mathrm{~cm}$ diameter rose to $12.4 \mathrm{~cm} / \mathrm{sec}$ and $90 \%$ of the mass loss occurred within 30 minutes and $200 \mathrm{~m}$ of the release point [19].

$\mathrm{CO}_{2}$ can also be disposed into the oceans as a plume at depths greater than $3000 \mathrm{~m}$ since $\mathrm{CO}_{2}$ density is greater than water density, which cause the $\mathrm{CO}_{2}$ sinks greater depth and even form hydrates [16]. Brewer et al. conducted an experiment by releasing $\mathrm{CO}_{2}$ at a depth of $3650 \mathrm{~m}$ and observed that conversion of the liquid $\mathrm{CO}_{2}$ to hydrate and volume of the $\mathrm{CO}_{2}$ was larger than the volume of $\mathrm{CO}_{2}$ released due to the hydrate formation [20]. Since the ocean is not saturated with $\mathrm{CO}_{2}, \mathrm{CO}_{2}$ released into ocean eventually dissolves and the rate of hydrate dissolution is low, which limits the local $\mathrm{pH}$ reduction and increase the length of exchange time [18].

However, physical and chemical interactions between seawater and $\mathrm{CO}_{2}$ and interaction between $\mathrm{CO}_{2}$ rich seawater and surrounding water should be studied in more detail in order to understand the impact of the $\mathrm{CO}_{2}$ sequestration on the ocean ecosystem; therefore, the $\mathrm{CO}_{2}$ impact on ecology need to be studied with long-term simulation before injection. Also, $\mathrm{CO}_{2}$ 
hydrate formation kinetics has not been fully understood yet to take advantages of sequestration of $\mathrm{CO}_{2}$ with hydrate formation.

$50 \mathrm{Pg}$ Carbon is sequestrated in the deep oceans annually with the natural process of carbon fixation by phytoplankton via the biological pump involving gravitational setting, remineralization and burial of biogenic debris. These processes can be accelerated by fertilization of the oceans with micronutrients (such as iron) and macronutrients (such as nitrogen and phosphorus). Two unenclosed transient iron tests (IRONEX I and II) were conducted in the equatorial Pacific in 1993 and 1995 in order to test the hypothesis that a lack of iron limits the phytoplankton grow. In IRONEX II, $500 \mathrm{~kg}$ iron was added to $72 \mathrm{~km}^{2}$ patch of surface water. Significant increase in photosynthesis and chlorophyll concentrations and decrease in partial pressure of $\mathrm{CO}_{2}$ were observed. Nevertheless, the long term effect of the iron fertilization cannot be predicted from these tests; therefore, sustained fertilization effect on ecosystem is not known yet. For this reason, long-term ecological monitoring is essential after the fertilization which is impractical to implement [16].

Besides environmental effect, the $\mathrm{CO}_{2}$ sequestration into oceans is currently impractical due to the location and depth of injection. The cost of the transportation of $\mathrm{CO}_{2}$ to injection location is prohibitive. As injection depth increase, the sequestration will be more effective. This requires more technology which increases the cost as well [3].

\subsubsection{Geological Media}

Geological media is the most attractive possible large capacity $\mathrm{CO}_{2}$ sink since most power plants are close to the geological media. In addition, two advantages make $\mathrm{CO}_{2}$ sequestration in geological media favorable: general public acceptance and mature technology developed already by the energy 
industry for hydrocarbon exploration and production. The volumes available for sequestration, the long term integrity of the storage, liability and the cost associated with the transport and injection of $\mathrm{CO}_{2}$ are still uncertain [3].

\subsubsection{Oil and Gas Reservoirs}

$\mathrm{CO}_{2}$ sequestration into oil and gas reservoirs has already been in use for many reasons. First of all, structural or stratigraphic traps causing the oil and gas accumulates beneath them and prevent escaping to the surface are well developed. Therefore, injected $\mathrm{CO}_{2}$ remains in the reservoir unless pathways to the surface or adjacent formations are created by overpressuring the reservoir or by fracturing out of the reservoir at well or by leak around well. Secondly, during the exploration and development stage, not only the geologic structure and physical characteristics of reservoirs but also properties of the fluid in the reservoir are well understood. Finally, $\mathrm{CO}_{2}$ behavior and trapping of $\mathrm{CO}_{2}$ can easily be predicted by using sophisticated computer models developed in oil industry [16].

$\mathrm{CO}_{2}$ is injected into the oil reservoir in order to increase the oil production by decreasing the viscosity of the residual oil and causing oil to swell, which leads to oil flow more steadily. The concept of $\mathrm{CO}_{2}$ injection for oil recovery was developed as early as 1916; however, the first $\mathrm{CO}_{2}$ injection was applied in the Ritchie field in 1964. The first bigger $\mathrm{CO}_{2}$ project, SACROC Unit in Scurry County in the Permian Basin, started to inject $\mathrm{CO}_{2}$ as an immiscible secondary recovery mechanism. After this project, $\mathrm{CO}_{2}$ floods have been used successfully throughout several areas in the US, especially in the Permian Basin. Today, there are about $78 \mathrm{CO}_{2}$ floods project operations worldwide, 67 in US, 2 in Canada, 2 in Turkey, 5 in Trinidad and 1 in Brazil [21]. 
Currently, 20000 tons per day of $\mathrm{CO}_{2}$ are injected to oil fields for EOR purpose [22]. Some of the $\mathrm{CO}_{2}$ injected into oil reservoirs is produced while significant fraction remains there. Produced $\mathrm{CO}_{2}$ is separated and injected back into the reservoirs. According to screening criteria proposed for selecting reservoirs for $\mathrm{CO}_{2}$ injection with the purpose of either increase in production of oil or long term storage of $\mathrm{CO}_{2}$, upwards of $80 \%$ of oil reservoirs worldwide might be suitable for $\mathrm{CO}_{2}$ injection based upon oil recovery criteria alone. Furthermore, $\mathrm{CO}_{2}$ sequestration widely applicable for both sandstone and carbonate formations with variety of permeabilities and thickness; the only restrictions for $\mathrm{CO}_{2}$ sequestration in oil reservoirs are the availability of $\mathrm{CO}_{2}$ and the pipeline cost to carry $\mathrm{CO}_{2}$ to oil producing regions [23].

In the same way, $\mathrm{CO}_{2}$ may be injected to depleted but still active gas reservoirs to increase the gas production by providing pressure support; however, pilot tests augmented with laboratory and modeling studies are needed. Small scale $\mathrm{CO}_{2}$ injection of about 30000 tones/year was started in mid 2004 into K12B gas field situated offshore the Netherlands by Gaz de France [24]. This first test lasted from May to December 2004 and proved that $\mathrm{CO}_{2}$ injection into depleted gas reservoir is feasible and safe. After that, second test was started in January 2005 in order to examine the reservoir response by monitoring the gas injection and production rates, the pressure and temperatures at various locations. During this test period, $\mathrm{CO}_{2}$ breakthrough in the well was not observed and no clear evidence was detected for improvement in gas production performance due to short period of test time; however, simulation results for this test showed that increase in gas production would be slow and gradual and continuous injection was needed to increase the EGR potential of $\mathrm{CO}_{2}$ injection [25].

Although $\mathrm{CO}_{2}$ have been used for many oil and gas reservoirs, in the longterm volume of $\mathrm{CO}_{2}$ sequestration in oil and gas reservoirs is not comparatively large compared with the global emission of $\mathrm{CO}_{2}$ to the 
atmosphere [16]. Moreover, the location of the oil and gas reservoirs are not usually near a primary source of $\mathrm{CO}_{2}$ emission, which may make $\mathrm{CO}_{2}$ sequestration into oil and gas reservoirs unsuitable places for $\mathrm{CO}_{2}$ sequestration.

\subsubsection{Coal Beds}

Coal bed methane reservoirs are dual porosity reservoirs consisting of primary (matrix) and secondary (fracture) storage system containing high volume of methane especially in matrix [26]. Unlike oil and gas reservoirs, methane in coal beds retains by adsorption rather than by trapping beneath an impermeable overlying cap rock. $\mathrm{CO}_{2}$ can be sequestered into coal beds, which increases the methane production since affinity of coal to $\mathrm{CO}_{2}$ is twice that of methane [3]. Enhancing the coal bed methane production by sequestrating the $\mathrm{CO}_{2}$ is first tested at San Juan Basin in North America. In San Juan Basin (New Mexico and Colorado), $75 \%$ of the in place methane is expected to be produced by injecting the 3 million scf/day $\mathrm{CO}_{2}$ through four injection wells [16].

Methane production from coal seems is made by pumping off large volume of formation water, which cause pressure reduction and desorption of methane (primary recovery method). Nearly, $20 \%$ to $60 \%$ of original gas in place is produced with primary recovery method and large amount of gas, for example $10 \mathrm{Tcf}$ of natural gas in San Juan basin is believed to be left in the coal seams [27].

Coal seam reservoir characteristics are really important for successful $\mathrm{CO}_{2}$ sequestration and methane production. Favorable coal seem reservoirs are laterally continuous, thick, minimally faulted and folded, vertically isolated from surrounding strata with at least moderate permeable (1 to $5 \mathrm{mD}$ ). Also the reservoir depth has greater impact on $\mathrm{CO}_{2}$ sequestration process since 
shallow reservoirs tend to be low in reservoir pressure and, therefore, low in gas content. On the other hand, the reservoirs in greater depth generally have low permeability [27].

Ultimate estimated worldwide enhanced methane recovery from favorable coal beds is $68 \mathrm{Tcf}$ in expense to 7.1 million tones of $\mathrm{CO}_{2}$ [27]. Although $\mathrm{CO}_{2}$ can be sequestrated into coal-bed reservoirs, some shortcomings make $\mathrm{CO}_{2}$ sequestration into coal seams unfavorable. Coal beds stratigraphy, structure, porosity and permeability are site specific, which brings necessity of individually characterization of coal beds [16] and most coal seams have low permeability due to their complex geological settings [3].

\subsubsection{Deep Saline Aquifers}

Since water in the deep saline aquifers is not suitable for industrial and agricultural use, and human consumption, they are used for hazardous and non-hazardous liquid waste [3].

Although brine formations have the largest capacity (1000 and 10000 billions tones of $\left.\mathrm{CO}_{2}[6]\right)$ and the most common reservoirs are in the subsurface, there is little practical experience with $\mathrm{CO}_{2}$ in brine formations and $\mathrm{CO}_{2}$ sequestration in aquifers has been discussed in the technical literature since the early 1990s [16].

According to Carbon Sequestration and Research and Development report, the main issues for $\mathrm{CO}_{2}$ sequestration in deep saline aquifers are [16]:

$>$ The disposal rate of $\mathrm{CO}_{2}$

$>$ The availability storage rate of $\mathrm{CO}_{2}$ (ultimate $\mathrm{CO}_{2}$ inventory)

$>$ The presence of cap rock of low permeability, and potential $\mathrm{CO}_{2}$ leakage through imperfect confinement

$>$ Identification and characterization of suitable aquifer formations and cap rock structures 
Uncertainty due to incomplete knowledge of subsurface conditions and process

Corrosion resistance of materials to be used in injection wells and associated facilities

\subsubsection{1. $\mathrm{CO}_{2}$ Storage Projects}

Although $\mathrm{CO}_{2}$ sequestration into deep saline aquifers is a new concept, two important projects show the feasibility of the safely sequestration of these formations. Important information is obtained from these projects by monitoring the real behavior of the immiscible $\mathrm{CO}_{2}$ behavior in the formations. In addition, the storage capacity of the formations and long-term fate of $\mathrm{CO}_{2}$ can be predicted with the help of simulations.

\subsection{The Sleipner Field and SACS Project}

Gas produced from Sleipner field has content of $9 \% \mathrm{CO}_{2}$. To comply with the sales of gas specification, $\mathrm{CO}_{2}$ has to be removed. Since this represent a large volume of $\mathrm{CO}_{2}$, it was decided to inject $\mathrm{CO}_{2}$ into Utsira Formation, a large saline aquifer located between the gas reservoir and the sea floor (see Figure 2.2), instead of releasing it into the atmosphere [8].

The Utsira Formation lies 700 to $1000 \mathrm{~m}$ below the sea level and extends for more than $400 \mathrm{~km}$ from north to south and 50 to $100 \mathrm{~km}$ east to west. This formation consists of uncemented fine-grained, with medium and occasional course grains with a local thickness of $200 \mathrm{~m}$. Porosity estimation of the formation ranges from $27 \%$ to $31 \%$ based on core microscopy analysis and $35 \%$ to $42.5 \%$ based on laboratory core experiments [7]. 


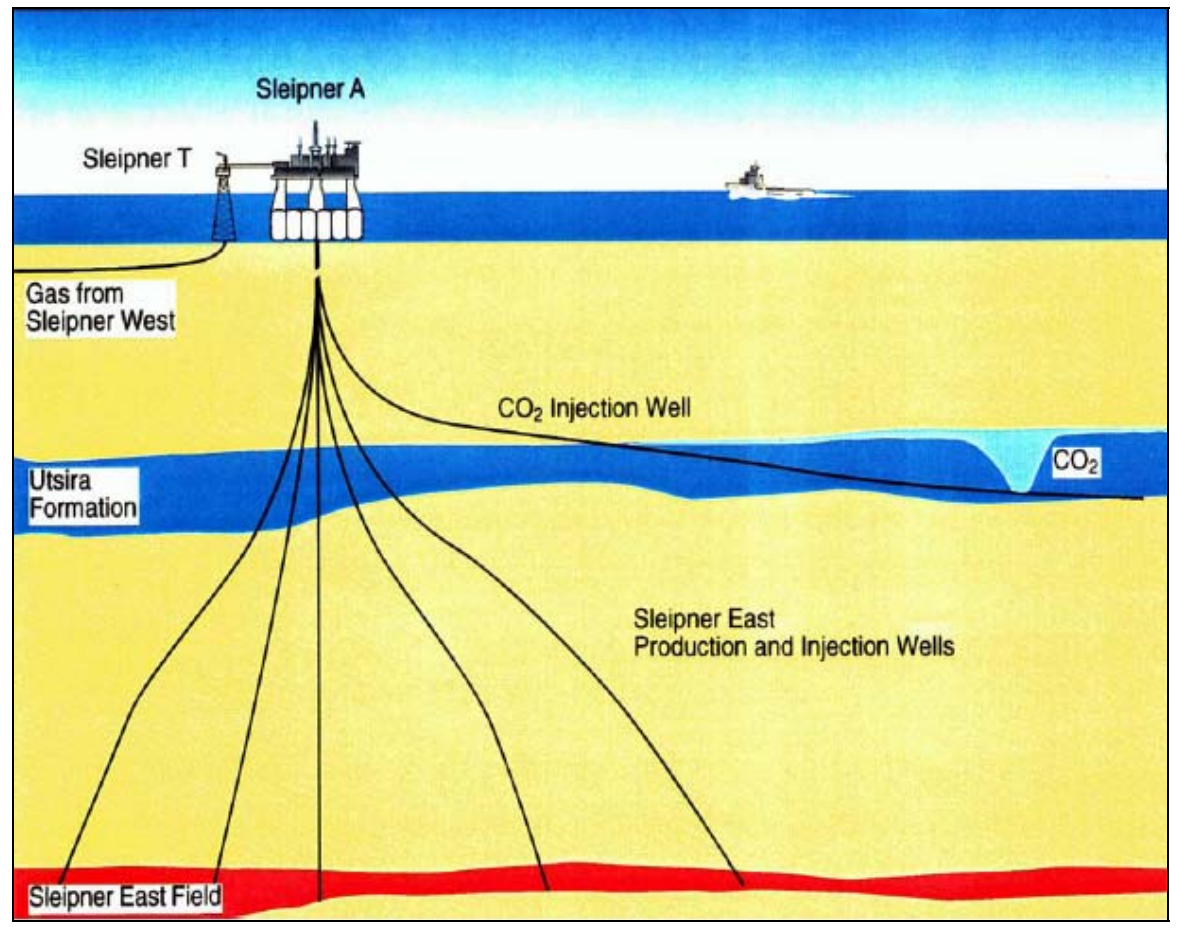

Figure 2.2: The Sleipner Gas Field and $\mathrm{CO}_{2}$ Injection [7]

$1 \mathrm{Mt} \mathrm{CO}_{2}$ per year has been injecting into Utsira Formation since October 1996 and a separate project called the saline aquifer $\mathrm{CO}_{2}$ storage (SACS) project was established in 1998 in order to collect relevant information about the injection of $\mathrm{CO}_{2}$ into Utsira formation and similar underground structures around the North Sea so that other organizations can take the advantages of the SACS findings to undertake new projects of this type [7].

In this project, $\mathrm{CO}_{2}$ injected into Utsira Formation was monitored with conventional time lapse seismic data in order to understand behavior of the $\mathrm{CO}_{2}$ in the underground saline aquifer. Figure 2.3 shows that injected $\mathrm{CO}_{2}$ which was supercritical phase in the formation pressure and temperature moved up due to buoyancy effect from injection points and accumulated under the overlying cap rock. Thin shale layers caused the $\mathrm{CO}_{2}$ to migrate laterally for several hundred meters, which enhanced the $\mathrm{CO}_{2}$ solubility by increasing the contact surface [7]. 


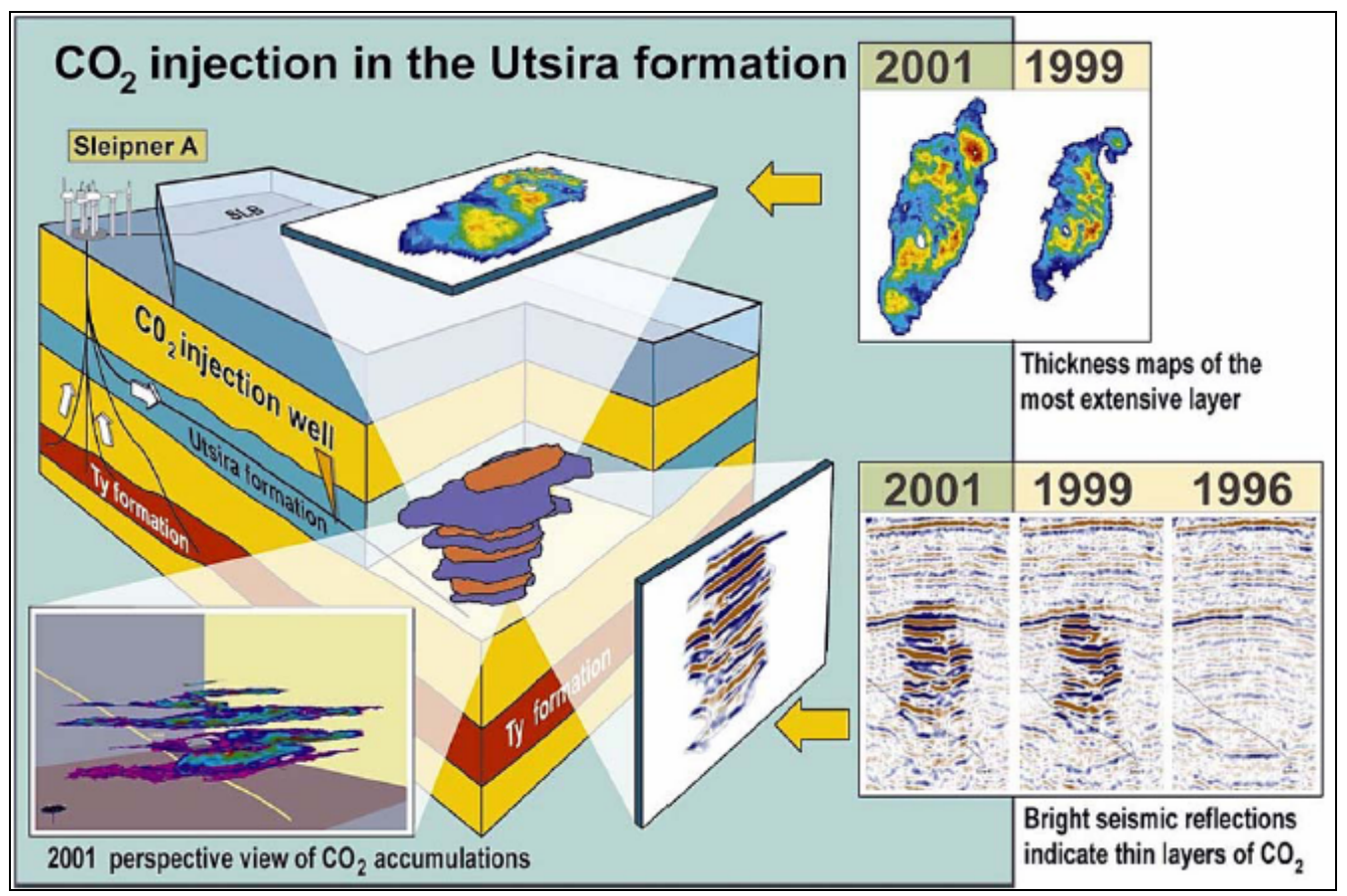

Figure 2.3: Repeated Seismic Surveys and Position of Injected $\mathrm{CO}_{2}[7]$

Hellevang et al. modeled the volume of the Utsira Formation $\left(3000 \times 3000 \times 250 \mathrm{~m}^{3}\right)$ meshed into $9 \times 9 \times 24$ grids by using ATHENA, a thermal 3D-reactive-transport numerical code. Post injection period (980 years) followed by 20 years of injection period and they found similar $\mathrm{CO}_{2}$ migration trend. The aim of their study was to illustrate the interaction between $\mathrm{CO}_{2}$ and solid mineral framework in order to understand the long-term geological storage of injected $\mathrm{CO}_{2}$ potential of this reservoir. They found that mineral reactions do not significantly influence the $\mathrm{CO}_{2}$ amount stored in the reservoir and do not change the macroscopic flow variables such as porosity and permeability; however, mineral reactions may influence the water chemistry and reactivity of the water with respect to solid mineral frameworks [28]. 


\subsection{Frio Brine Pilot}

Frio Formation, in the area of Houston, Texas, USA, was chosen to develop a suitable site and conduct initial experiments. The setting advantages are listed below [29].

Large volumes of $\mathrm{CO}_{2}$ released from nearby power generation and industrial sources,

$>$ Numerous high-injectivity sandstones served as injection targets, and numerous thick shales served as seals,

$>$ Available abundant geologic and geotechnical data,

$>$ Well developed infrastructure, including many inactive wells and easy and low-cost access to needed support for field operations.

In addition to setting advantages, the part of the Frio Formation between 1000 and $3000 \mathrm{~m}$ below the surface has storage capacity between $208 \times 10^{9}$ and $358 \times 10^{9}$ metric tons of $\mathrm{CO}_{2}$ when storage efficiency is taken between 1 to 6 percent [30].

From October 4 to $14,2004,1600$ tons of $\mathrm{CO}_{2}$ was injected at $1500 \mathrm{~m}$ below surface into high permeable (2.3 Darcy) brine-bearing sandstone of the Frio Formation with the following goals [8].

Demonstrate that $\mathrm{CO}_{2}$ can be injected into a brine formation without adverse health, safety, or environmental effects,

Determine the subsurface distribution of injected $\mathrm{CO}_{2}$ using diverse monitoring technologies,

Demonstrate validity of conceptual and numerical models,

Develop experience necessary for success of large-scale $\mathrm{CO}_{2}$ injection experiments.

This project showed that public and environmental concerns were moderate, practical, and proportional to minimal risks taken by the project and included issues such as traffic and potential of risks to water resources. Diverse suite 
technologies were used in the injection zone and in the near surface environment to measure and monitor $\mathrm{CO}_{2}$ plume (see Figure 2.4) [8].

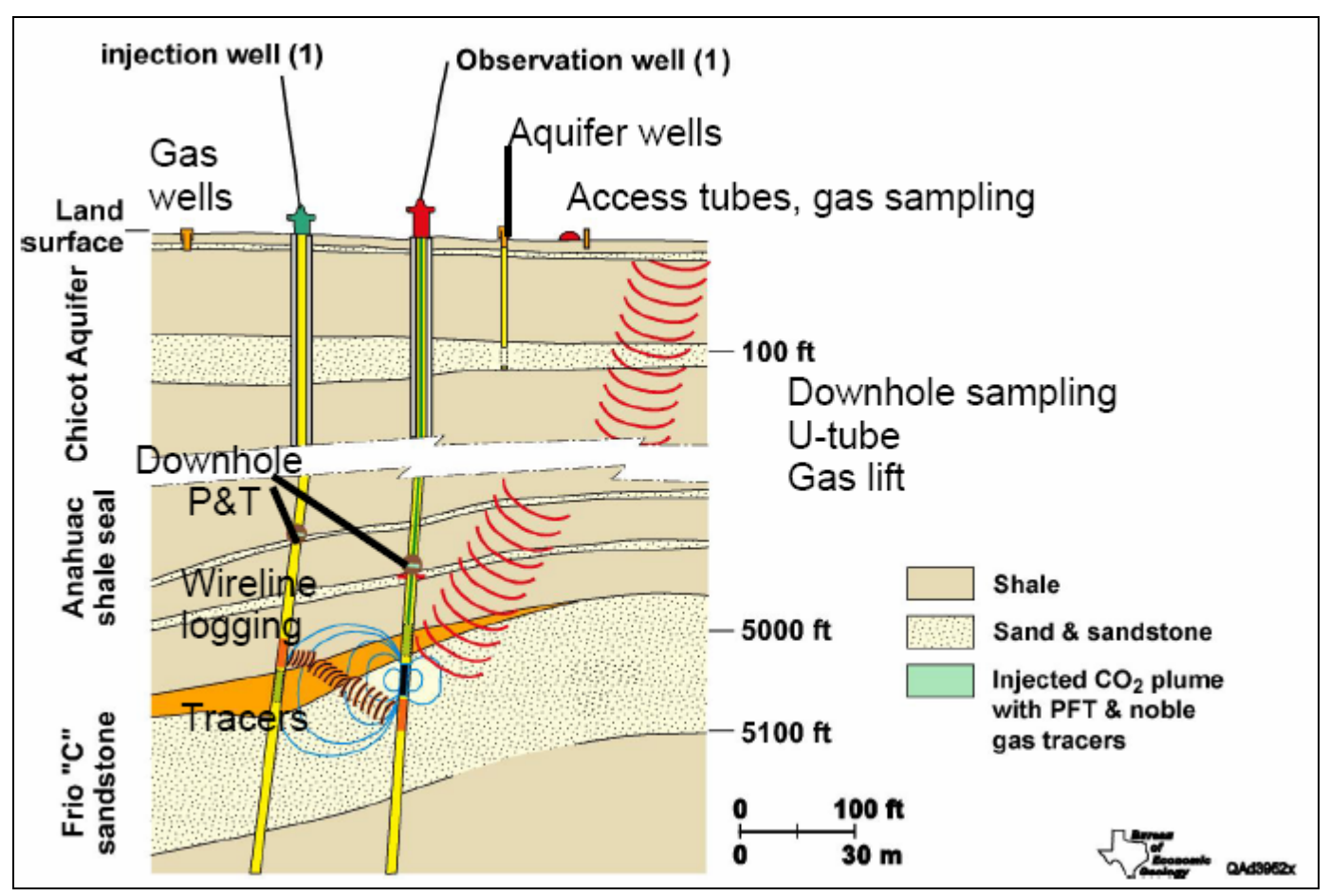

Figure 2.4: Overview of Monitoring Strategy at the Frio Brine Storage Experiment [8]

Measurements indicated that $\mathrm{CO}_{2}$ saturation increased to $100 \%$ pore space near the injection zone and $80 \%$ pore space near the observation well [8].

Hovorka et al. modeled the part of the Frio Formation which extends $1 \mathrm{~km}^{2}$ and is thickness of $100 \mathrm{~m}$ by using TOUGH2. The model had 10 layers, sequence of alternating sands and shale, thickness of which varied 4 to $15 \mathrm{~m}$ and each layer included 400 grid blocks with lateral dimensions of $50 \mathrm{~m} . \mathrm{CO}_{2}$ was injected at a constant rate of 750000 tons per year in order to examine the $\mathrm{CO}_{2}$ saturation during the injection time. The simulation results showed that preferential flows exist through higher permeability zones and buoyancy flow of the immiscible $\mathrm{CO}_{2}$ are apparent [30]. 


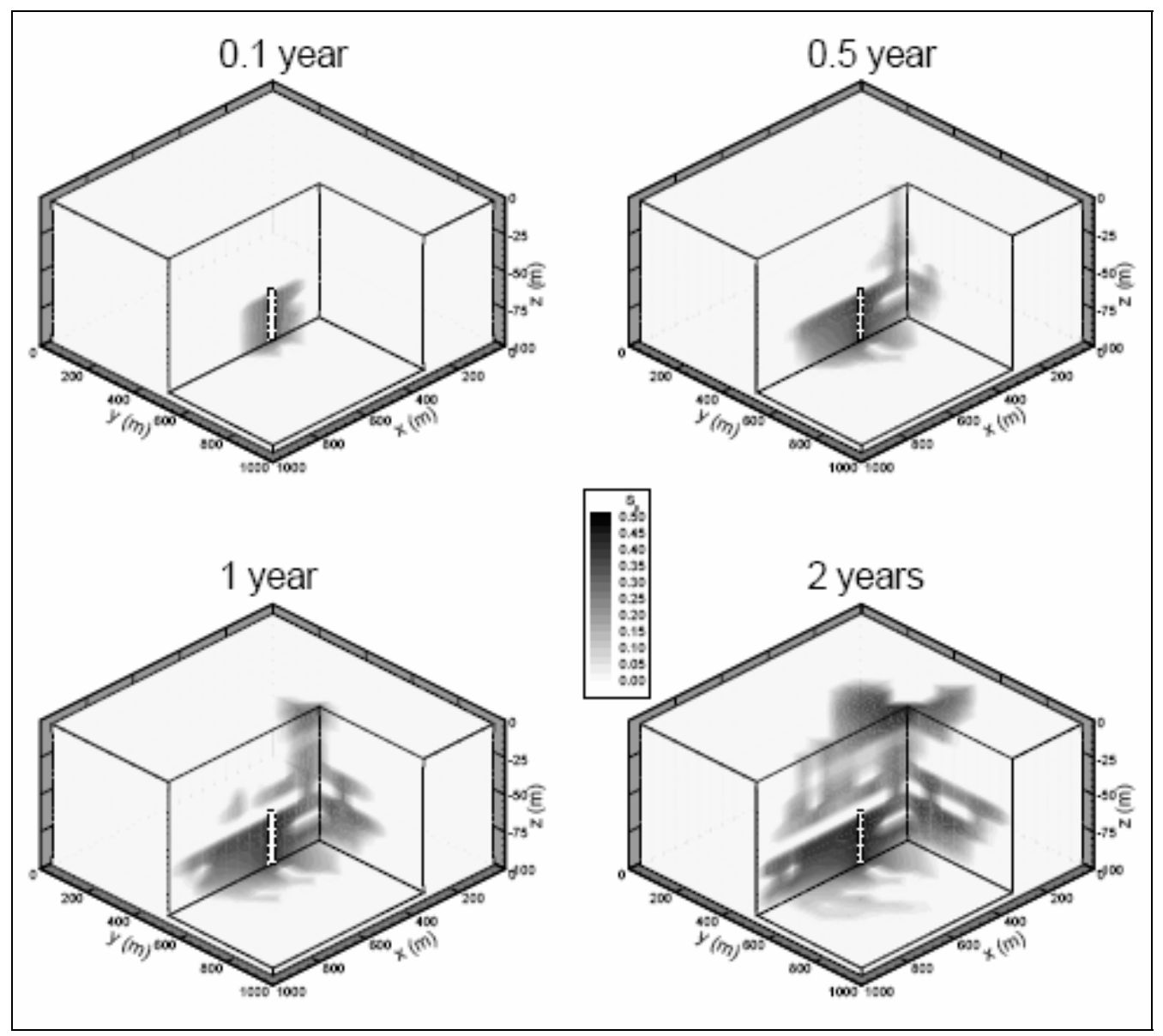

Figure 2.5: Modeled $\mathrm{CO}_{2}$ Distribution After 0.1, 0.5, 1.0 and 2.0 Years of Injection [30]

\subsubsection{2. $\mathrm{CO}_{2}$ Trapping Mechanism}

$\mathrm{CO}_{2}$ can be sequestrated through three main mechanisms, namely, hydrodynamic trapping, solubility trapping and mineralization.

\subsection{Hydrodynamic Trapping}

Most of the injected $\mathrm{CO}_{2}$ is stored by this mechanism. Supercritical $\mathrm{CO}_{2}$ can form a plume whose size and extent to which it comes in contact with brine is controlled by relative permeability of supercritical $\mathrm{CO}_{2}$ and brine, gravity, and heterogeneity of permeability field. Storage of $\mathrm{CO}_{2}$ could be occurred in two 
topological forms within the formation. $\mathrm{CO}_{2}$ can form a large continuous plume which moves while more $\mathrm{CO}_{2}$ is injected. Also, $\mathrm{CO}_{2}$ can form a randomly distributed trapped stagnant cluster, which may form in water-wet systems after $\mathrm{CO}_{2}$ is terminated due to the displacement mechanism. In this form, the brine residing in the corners displaces the gas in the center of a pore or throat. The brine starts to swell, causing arc menisci when the relevant capillary pressure decreases. The $\mathrm{CO}_{2}$ trapped with hydrodynamic way finally may shrink and eventually disappear due to the dissolution of $\mathrm{CO}_{2}$ into the brine [31].

\subsection{Solubility Trapping}

$\mathrm{CO}_{2}$ concentration in water increases due to the dissolution of $\mathrm{CO}_{2}$, which depends on salinity of the brine, pressure, temperature, and geochemical reactions of dissolved $\mathrm{CO}_{2}$ with primary minerals of the host rock that may dissolve into the aqueous phase. Also viscosity of the $\mathrm{CO}_{2}$ and brine, permeability, and compressibility of rock and matrix affect the solubility by affecting the pressure. Other factors determining the $\mathrm{CO}_{2}$ solubility into brine are contact area between the $\mathrm{CO}_{2}$ and brine, which strongly depends on hydrodynamic trapping variables stated above, well location and injection pattern [31].

\subsection{Mineral Trapping}

Homogenous and heterogeneous chemical reactions occur between $\mathrm{CO}_{2}$ and minerals of formations dissolved in the liquid phase and secondary low soluble minerals are formed and precipitate. This mechanism is important in large time scales since rate of these reactions are very slow. $\mathrm{CO}_{2}$ sequestration by mineral trapping is directly related to rock type, sedimentary structure, mineralogy and diffusion. Dissolution and precipitation of minerals 
may change the porosity of the field which in turn affects the flow of the field [31].

\subsection{Physical Properties of the Supercritical $\mathrm{CO}_{2}$}

Critical point of a pure substance is the end point of the gas/liquid temperature diagram beyond which no distinction can be made between gas and liquid phase. For $\mathrm{CO}_{2}$ this point is characterized by a critical pressure $\left(P_{c}\right)$ of 73.86 bar and a critical temperature $\left(T_{c}\right)$ of $31.1^{\circ} \mathrm{C}$ (see Figure 2.6). $\mathrm{CO}_{2}$ at supercritical state has both gas properties such as low viscosity (typically around $10^{-4}$ to $10^{-3} \mathrm{cp}$ ) and liquid properties such as high density [32]. Calculation of physical properties of pure $\mathrm{CO}_{2}$ is given in section 2.3.

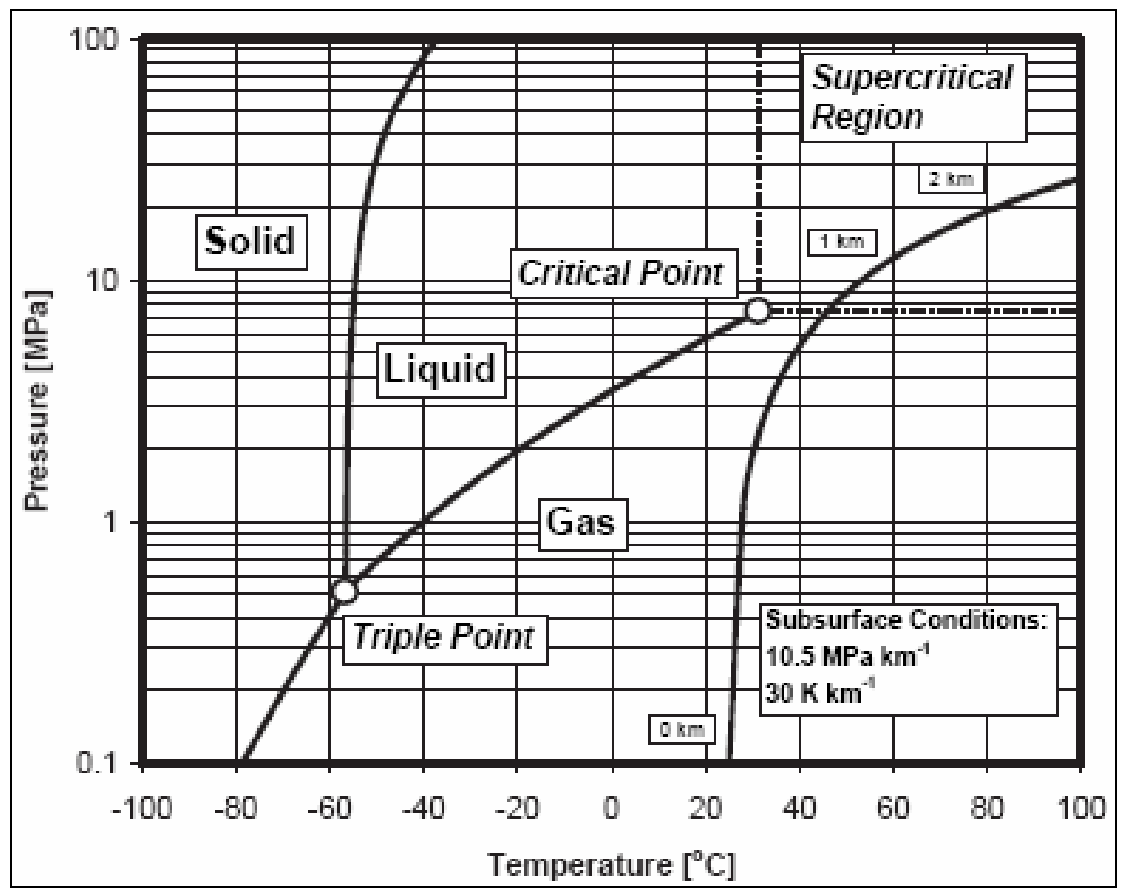

Figure 2.6: Phase Diagram for Pure $\mathrm{CO}_{2}[31]$ 
Water and $\mathrm{CO}_{2}$ are two immiscible fluids under the reservoir conditions; therefore, $\mathrm{CO}_{2}$-rich fluid will flood on the top of the water-rich fluid. However, dissolution of $\mathrm{CO}_{2}$ into the water and water dissolution into $\mathrm{CO}_{2}$ take place at the $\mathrm{CO}_{2}$-water contact. The properties of these mixtures can be modeled using an Equation of State.

Hangx summarized the effect of temperature, pressure, and salinity on the solubility of the $\mathrm{CO}_{2}$ as [33];

$>$ At constant pressure and salinity, the solubility of $\mathrm{CO}_{2}$ decreases until $\sim 100{ }^{\circ} \mathrm{C}$, after that the solubility of $\mathrm{CO}_{2}$ increases.

At constant temperature and salinity, the solubility of $\mathrm{CO}_{2}$ increases with increasing pressure. The effect of pressure on $\mathrm{CO}_{2}$ solubility diminishes with increasing pressure; therefore, at lower pressures the solubility of $\mathrm{CO}_{2}$ increases more rapidly than at higher pressures.

$>$ Increase in salt in the solution decreases the solubility of $\mathrm{CO}_{2}$. The magnitude of this effect depends on the salt composition. For example, monovalent salt solutions such as $\mathrm{NaCl}$ and $\mathrm{KCl}$ lessen the solubility of $\mathrm{CO}_{2}$ more than divalent salt solutions such as $\mathrm{CaCl}_{2}$ and $\mathrm{MgCl}_{2}$.

Duan and Sun $(2003 ; 2005)$ derived a theoretical model to calculate the $\mathrm{CO}_{2}$ solubility in pure water and aqueous solution containing $\mathrm{Na}^{+}, \mathrm{Cl}^{-}, \mathrm{K}^{+}, \mathrm{Mg}^{2+}$, $\mathrm{Ca}^{2+}$ and $\mathrm{SO}_{4}{ }^{2-}$, which is valid for temperatures 0 to $260^{\circ} \mathrm{C}$, pressures from 0 to 2000 bars, ionic strength up to $4.5 \mathrm{M}$ [33]. The model is defined as,

$$
\begin{aligned}
& \ln m_{\mathrm{CO}_{2}}=\ln y_{\mathrm{CO}_{2}} \varphi_{\mathrm{CO}_{2}} P-\frac{\mu_{\mathrm{CO}}^{l(0)}}{R T}+2 \lambda_{\mathrm{CO}_{2}-\mathrm{Na}}\left(m_{\mathrm{Na}}+m_{K}+2 m_{\mathrm{Ca}}+2 m_{\mathrm{Mg}}\right) \\
& -\zeta_{\mathrm{CO}_{2}-\mathrm{Na} a \mathrm{Cl}} m_{\mathrm{Cl}}\left(m_{\mathrm{Na}}+m_{\mathrm{K}}+m_{\mathrm{Mg}}+m_{\mathrm{Ca}}\right)+0.07 m_{\mathrm{SO}_{4}}
\end{aligned}
$$

where $\varphi_{\mathrm{CO}_{2}}$ is the fugacity coefficient of $\mathrm{CO}_{2}$ and it is defined as 
$\varphi_{\mathrm{CO}_{2}}=b_{1}+\left[b_{2}+b_{3} T+b_{4} / T+b_{5} /(T-150)\right] P+\left[b_{6}+b_{7} T+b_{8} / T\right] P^{2}$

$+\left[b_{9}+b_{10} T+b_{11} / T\right] \ln P+\left[b_{12}+b_{13} T\right] / P+b_{14} / T+b_{15} T^{2}$

where $b_{i}$ and $y_{\mathrm{CO}_{2}}$ are fitted parameters given in Table 2.1 and the mole fraction of the $\mathrm{CO}_{2}$ in the vapor phase calculated from Equation 2.3, respectively.

$y_{\mathrm{CO}_{2}}=\left(P-P_{\mathrm{H}_{2} \mathrm{O}}\right) / P$

The vapor pressure of water can be calculated by the following equation assuming the vapor pressure of water does not differ from the pure water saturation pressure.

$P_{\mathrm{H}_{2} \mathrm{O}}=\left(\frac{P_{c, \mathrm{H}_{2} \mathrm{O}} T}{T_{c, \mathrm{H}_{2} \mathrm{O}}}\right)\left[\begin{array}{l}1-38.640844(-t)^{1.9}+5.8948420 t+59.876516 t^{2} \\ +26.654627 t^{3}+10.637097 t^{4}\end{array}\right]$

where $t=\left(T-T_{c}\right) / T_{c}$

$\lambda, \zeta$ and $\mu_{\mathrm{CO}_{2}}^{l(0)} / R T$ are second-order and third-order interaction parameters, and standard chemical potential. $R$ is universal gas constant. All three parameters depend on pressure and temperature given by the following equation, where $\operatorname{par}(T, P)$ represents the $\lambda, \zeta$ and $\mu_{\mathrm{CO}_{2}}^{l(0)} / R T$.

$$
\begin{aligned}
& \operatorname{par}(T, P)=c_{1}+c_{2} T+c_{3} / T+c_{4} T^{2}+c_{5} /(630-T)+c_{6} P+c_{7} P \ln T \\
& +c_{8} P / T+c_{9} P /(630-T)+c_{10} P^{2} /(630-T)^{2}+c_{11} T \ln P
\end{aligned}
$$

The $T-P$ regions are given in the Table 2.2 . 
Table 2.1: The Parameter Coefficients used in Equation 2.2

\begin{tabular}{|c|c|c|c|c|c|c|}
\hline T P Range & $\mathbf{1}$ & $\mathbf{2}$ & $\mathbf{3}$ & $\mathbf{4}$ & $\mathbf{5}$ & $\mathbf{6}$ \\
\hline$b_{1}$ & 1.0 & $-7.17349 \mathrm{E}-1$ & $-6.51290 \mathrm{E}-2$ & 5.03840 & -16.06315 & $-1.56935 \mathrm{E}-1$ \\
\hline$b_{2}$ & $4.75868 \mathrm{E}-3$ & $1.59854 \mathrm{E}-4$ & $-2.14300 \mathrm{E}-4$ & $-4.42577 \mathrm{E}-3$ & $-2.70580 \mathrm{E}-3$ & $4.46214 \mathrm{E}-4$ \\
\hline$b_{3}$ & $-3.35700 \mathrm{E}-6$ & $-4.92865 \mathrm{E}-7$ & $-1.14449 \mathrm{E}-6$ & & & $-9.10806 \mathrm{E}-7$ \\
\hline$b_{4}$ & 0.0 & & & 1.95723 & $1.41192 \mathrm{E}-1$ & \\
\hline$b_{5}$ & -1.31794 & & & & & \\
\hline$b_{6}$ & $-3.83891 \mathrm{E}-6$ & $-2.78553 \mathrm{E}-7$ & $-1.15581 \mathrm{E}-7$ & $2.42234 \mathrm{E}-6$ & $8.11330 \mathrm{E}-7$ & $1.06474 \mathrm{E}-7$ \\
\hline$b_{7}$ & & $1.18770 \mathrm{E}-9$ & $1.19524 \mathrm{E}-9$ & & & $2.42734 \mathrm{E}-10$ \\
\hline$b_{8}$ & $2.28151 \mathrm{E}-3$ & & & $-9.37961 \mathrm{E}-4$ & $-1.14531 \mathrm{E}-4$ & \\
\hline$b_{9}$ & & & & -1.50260 & 2.38957 & $3.58743 \mathrm{E}-1$ \\
\hline$b_{10}$ & & & & $3.02722 \mathrm{E}-3$ & $5.05275 \mathrm{E}-4$ & $6.33197 \mathrm{E}-5$ \\
\hline$b_{11}$ & & & & -31.37734 & -17.76346 & -249.89661 \\
\hline$b_{12}$ & & -96.53951 & -221.34306 & -12.84706 & 985.92232 & \\
\hline$b_{13}$ & & $4.47749 \mathrm{E}-1$ & & & & \\
\hline$b_{14}$ & & 101.81078 & 71.82039 & & & 888.76800 \\
\hline$b_{15}$ & & $5.37839 \mathrm{E}-6$ & $6.60892 \mathrm{E}-6$ & $-1.50566 \mathrm{E}-5$ & $-5.49653 \mathrm{E}-7$ & $-6.63480 \mathrm{E}-7$ \\
\hline
\end{tabular}

Table 2.2: The $T-P$ Region for Equation 2.2

\begin{tabular}{|c|c|}
\hline Region & $T-P$ Interval \\
\hline & $273 K<T<573 K, P<P_{1}\left(\right.$ when $T<305 K, P_{1}=P_{\text {sat }, \mathrm{CO}_{2}} ;$ when \\
1 & $305 K<405 K, P_{1}=75+(T-305) \times 1.25 ;$ \\
& when $\left.T>405 K, P_{1}=200 \mathrm{bar}\right)$ \\
\hline 2 & $273 K<T<340 K, P_{1}<P<1000$ bar \\
\hline 3 & $273 K<T<340 K, P>1000$ bar \\
\hline 4 & $340 K<T<435 K, P_{1}<P<1000$ bar \\
\hline 5 & $340 K<T<435 K, P>1000$ bar \\
\hline 6 & $T>435 K, P>P_{1}$ \\
\hline
\end{tabular}


Table 2.3: Interaction Parameters for Equation 2.5

\begin{tabular}{|l|c|c|c|}
\hline & $\mu_{\mathrm{CO}_{2}}^{l(0)} / R T$ & $\lambda_{\mathrm{CO}_{2} \mathrm{Na}}$ & $\zeta_{\mathrm{CO}_{2}-\mathrm{Na}-\mathrm{Cl}}$ \\
\hline$C_{1}$ & 28.9447706 & -0.411370585 & $3.6389723 \mathrm{E}-4$ \\
\hline$C_{2}$ & -0.0354581768 & $6.07632013 \mathrm{E}-4$ & $-1.98298980 \mathrm{E}-5$ \\
\hline$C_{3}$ & -4770.67077 & 97.5347708 & \\
\hline$C_{4}$ & $1.02782768 \mathrm{E}-5$ & & \\
\hline$C_{5}$ & 33.8126098 & & \\
\hline$C_{6}$ & $9.04037140 \mathrm{E}-3$ & & \\
\hline$c_{7}$ & $-1.14934031 \mathrm{E}-3$ & & \\
\hline$C_{8}$ & -0.30745726 & -0.0237622469 & $2.12220830 \mathrm{E}-3$ \\
\hline$C_{9}$ & -0.0907301486 & 0.0170656236 & $-5.24873303 \mathrm{E}-3$ \\
\hline$C_{10}$ & $9.32713393 \mathrm{E}-4$ & & \\
\hline$C_{11}$ & & $1.41335834 \mathrm{E}-5$ & \\
\hline
\end{tabular}

Figure 2.7, 2.8 and 2.9 give the $\mathrm{CO}_{2}$ solubility as a function of salinity, pressure and temperature respectively and compare the calculated $\mathrm{CO}_{2}$ solubility with the observed data. 


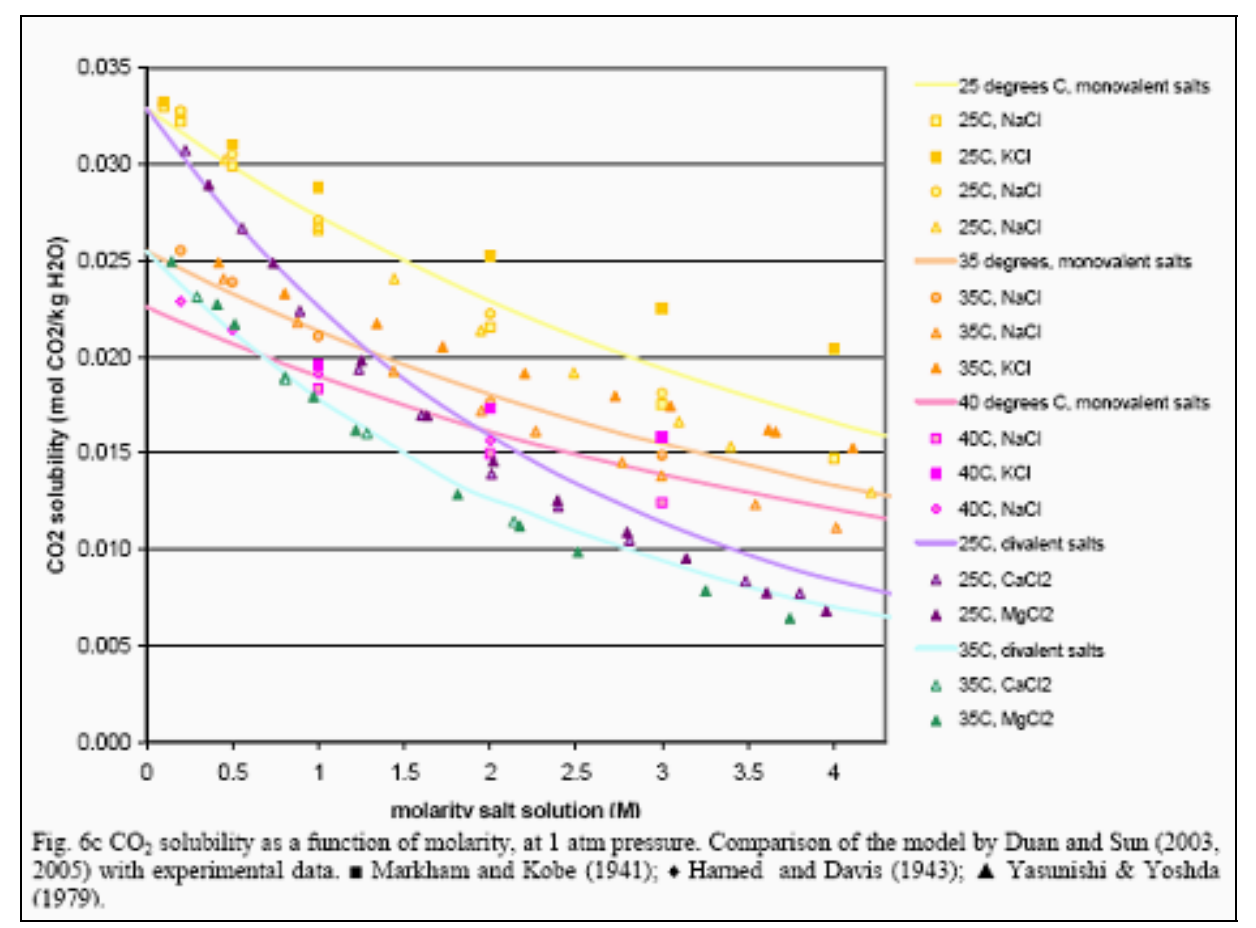

Figure 2.7: $\mathrm{CO}_{2}$ Solubility as a Function of Molarity [33]

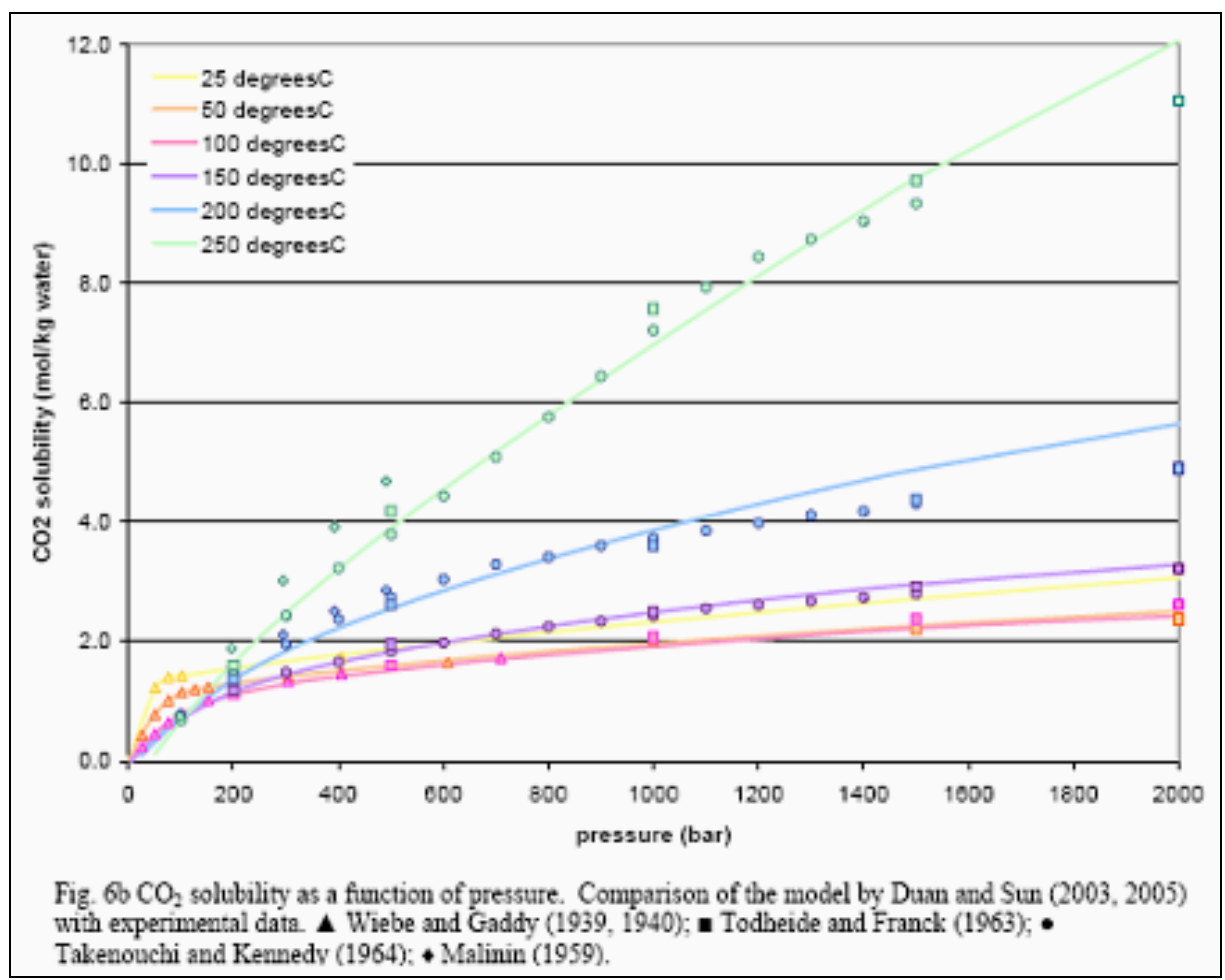

Figure 2.8: $\mathrm{CO}_{2}$ Solubility as a Function of Pressure [33] 


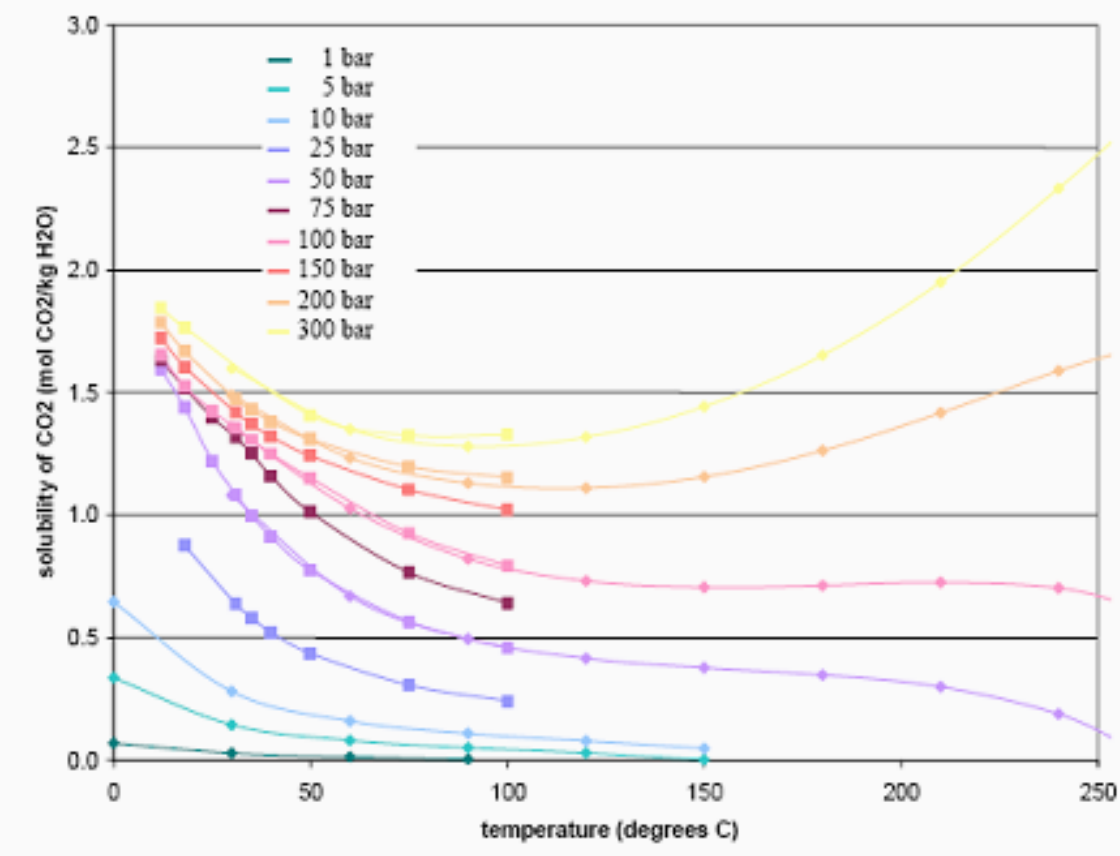

Fig. $6 \mathrm{a} \mathrm{CO}$ solubility as a function of temperature. $\bullet$ Duan and Sun $(2003)$; - Wiebe \& Gaddy (1939, 1940 ).

Figure 2.9: $\mathrm{CO}_{2}$ Solubility as a Function of Temperature [33]

\subsection{Dissolved $\mathrm{CO}_{2}$ Chemistry}

When $\mathrm{CO}_{2}$ dissolves in water, it generates a weak carbonic acid, $\mathrm{H}_{2} \mathrm{CO}_{3}$ which dissociates into $\mathrm{HCO}_{3}^{-}$and $\mathrm{CO}_{3}^{2-}$. Reaction steps are given by Equations 2.6 and 2.9.

$$
\begin{aligned}
& \mathrm{CO}_{2}(g) \Leftrightarrow \mathrm{CO}_{2}(a q) \\
& \mathrm{CO}_{2}(a q)+\mathrm{H}_{2} \mathrm{O} \Leftrightarrow \mathrm{H}_{2} \mathrm{CO}_{3}(a q) \\
& \mathrm{H}_{2} \mathrm{CO}_{3}(a q) \Leftrightarrow \mathrm{H}^{+}+\mathrm{HCO}_{3}^{-} \\
& \mathrm{HCO}_{3}^{-} \Leftrightarrow \mathrm{H}^{+}+\mathrm{CO}_{3}^{2-}
\end{aligned}
$$


Dissolution of the $\mathrm{CO}_{2}$ depends on the $\mathrm{pH}$. Figure 2.10 shows the $\mathrm{CO}_{2}(a q), \mathrm{HCO}_{3}^{-}$and $\mathrm{CO}_{3}^{2-}$ concentration change with $\mathrm{pH}$ in $1 \mathrm{~m} \mathrm{NaCl}$ solution at $60^{\circ} \mathrm{C} . \mathrm{CO}_{2}(a q)$ is dominant for the lower $\mathrm{pH}$, then $\mathrm{HCO}_{3}^{-}$and $\mathrm{CO}_{3}^{2-}$ become dominant for intermediate and high $\mathrm{pH}$, respectively [32].

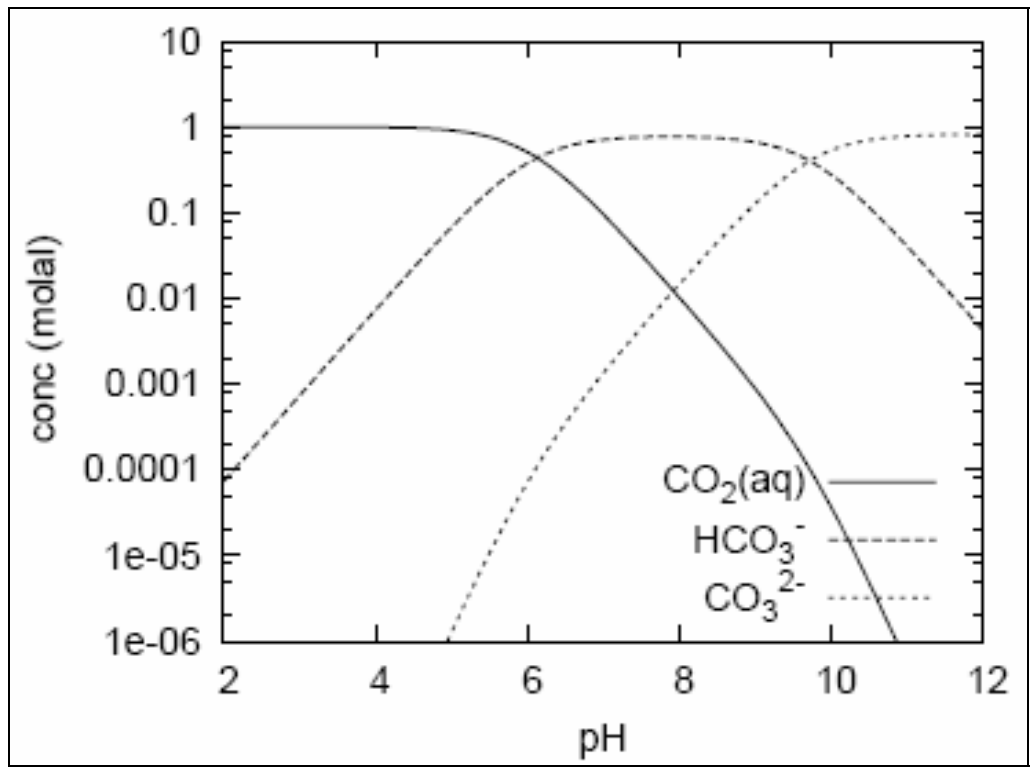

Figure 2.10: Dissolution of $\mathrm{CO}_{2}$ as a function of $\mathrm{pH}$ [32]

The host rock minerals may create a buffering effect and $\mathrm{pH}$ of the system increase, which leads to increase in concentration of $\mathrm{HCO}_{3}^{-}$and $\mathrm{CO}_{3}^{2-}$, and a total dissolved $\mathrm{CO}_{2}$ concentration much larger than the concentration of the $\mathrm{CO}_{2}(a q)$ [32].

\subsection{Reactivity of the Dissolved $\mathrm{CO}_{2}$}

When $\mathrm{CO}_{2}$ is dissolved in the water, it can react with minerals dissolved in the water. Lagneau et al. classified minerals reacting with $\mathrm{CO}_{2}$ into two main classes [32]. The first class of minerals leads to mineral trapping when they 
react with $\mathrm{CO}_{2}$. These minerals contain calcium, magnesium, iron and other divalent ions, which can lead to the formation of carbonates. A general reaction for this class of minerals can be written as;

Silicates $+m \mathrm{CO}_{2}+n \mathrm{H}_{2} \mathrm{O} \Leftrightarrow$ Carbonates + Feldspar + Kaolinite + Quartz

Feldspar can also react with $\mathrm{CO}_{2}$ to form dawsonite and quartz;

$\mathrm{K}-$ feldspar $+\mathrm{CO}_{2}(a q)+\mathrm{Na}^{+} \Leftrightarrow$ Dawsonite +3 Quartz $+\mathrm{K}^{+}$

The second class of minerals is carbonated minerals, which cannot lead to mineral trapping since they already contain carbonate ions. These minerals are more soluble in acidic water; therefore the acidic water due to $\mathrm{CO}_{2}$ dissolution dissolves these minerals. Although these minerals are secondary source of terms of carbonate, they can efficiently buffer the pore water $\mathrm{pH}$ at intermediate levels. As a result, total dissolved $\mathrm{CO}_{2}$ concentration increases. A general equation of reaction involving second class of minerals can be written as,

Carbonates $+\mathrm{CO}_{2}+\mathrm{H}_{2} \mathrm{O} \Leftrightarrow$ Cations $+2 \mathrm{HCO}_{3}^{-}$

Thibeau et al. studied specific mineralization pathways and their individual $\mathrm{CO}_{2}$ mineralization potential. The most three important pathways are calcium pathway, magnesium pathway and iron pathway [34].

At the calcium pathway, non-carbonate, calcium-rich mineral, Anorhite, dissolution provides calcium to the formation water while secondary minerals such as Kaolinite precipitate using the ions resulting from the Anorhite dissolution and Calcite precipitation.

$$
\begin{aligned}
& \text { Anorthite }+8 \mathrm{H}^{+} \Leftrightarrow 4 \mathrm{H}_{2} \mathrm{O}+\mathrm{Ca}^{2+}+2 \mathrm{Al}^{3+}+2 \mathrm{SiO}_{2}(a q) \\
& \text { Kaolinite }+6 \mathrm{H}^{+} \Leftrightarrow 5 \mathrm{H}_{2} \mathrm{O}+2 \mathrm{Al}^{3+}+2 \mathrm{SiO}_{2}(a q)
\end{aligned}
$$


These two equations with calcite dissolution reaction combined into,

Anorthite $+2 \mathrm{H}_{2} \mathrm{O}+\mathrm{CO}_{2}(a q) \Leftrightarrow$ Calcite + Kaolinite

The importance of this pathway is that $\mathrm{CO}_{2}$ mineralization balance the $\mathrm{pH}$ decrease since no $\mathrm{H}^{+}$forms in this pathway.

At the magnesium pathway, Illite dissolution (Eqn.16) provides the magnesium mineral and Dolomite precipitate with the presence of calcium results from Calcite dissolution (Eqn.17).

Illite $+8 \mathrm{H}^{+} \Leftrightarrow 5 \mathrm{H}_{2} \mathrm{O}+0.6 \mathrm{~K}^{+}+0.25 \mathrm{Mg}^{2+}+2.3 \mathrm{Al}^{3+}+3.5 \mathrm{SiO}_{2}(a q)$

4Illite + Calcite $+\mathrm{CO}_{2}(a q)+4 \mathrm{H}_{2} \mathrm{O}+2.4 \mathrm{H}^{+} \Leftrightarrow$

Dolomite $+2.4 K^{+}+4.8$ Chalcedony +4.6 Kaolinite

At the iron pathway, an iron-rich mineral Annite dissolves (Eqn.18) and iron ions combine with bicarbonate and precipitates as Siderite (Eqn.19).

$$
\begin{aligned}
& \text { Annite }+10 \mathrm{H}^{+} \Leftrightarrow 6 \mathrm{H}_{2} \mathrm{O}+3 \mathrm{Fe}^{2+}+\mathrm{K}^{+}+\mathrm{Al}^{3+}+3 \mathrm{SiO}_{2}(a q) \\
& \text { Annite }+3 \mathrm{CO}_{2}(a q)+\mathrm{H}^{+} \Leftrightarrow \\
& \quad \mathrm{K}^{+}+0.5 \mathrm{H}_{2} \mathrm{O}+3 \text { Siderite }+2 \text { Chalcedony }+0.5 \text { Kaolinite }
\end{aligned}
$$

Simulations made for these three pathways showed that the less efficient path way is the magnesium pathway in terms of $\mathrm{CO}_{2}$ mineralization due to small magnesium content of Illite [34].

\subsection{Previous Works Related to the Deep Saline Aquifers}

Nghiem et al. conducted three studies with GEM-GHG, a fully coupled geochemical compositional Equation-of-State (EOS) compositional simulator. The first simulation showed the validity of the geochemistry module in the compositional simulator GEM-GHG by comparing the result of the simulation 
with the result of the geochemistry software The Geochemist's Workbench $\circledast$ (GWB). After showing the validity of the simulator, two-dimensional and three-dimensional simulations were made to illustrate the effect of gravity and mineral trapping on $\mathrm{CO}_{2}$ sequestration in an aquifer. They observed that most of the injected $\mathrm{CO}_{2}(\mathrm{~g})$ dissolved after 150 years and substantial calcite and dolomite precipitated in the region of high $\mathrm{CO}_{2}$ dissolution. They found that brine density increased due to the dissolution of the $\mathrm{CO}_{2}$ and started to migrate downwards [35].

Doughty showed the importance of the hysteresis with two problems, leakage of $\mathrm{CO}_{2}$ from storage formation to the ground surface and examination of the heterogeneity within the storage formation by using TOUGH2. For each problem, three cases were considered, hysteric model and two non-hysteric models. The first non-hysteric model had large residual water saturation and small residual gas saturation, whereas the other one had small residual water saturation and large residual gas saturation. In his study, it was pointed that using hysteric model to correctly capture the behavior of the $\mathrm{CO}_{2}$ plume especially during post injection period was important since none of the nonhysteric models adequately predicted the $\mathrm{CO}_{2}$ plume behavior [36] .

Hurter et al. discussed the mutual solubility of the $\mathrm{CO}_{2}$ and brine, dry-out and salting-out problems and showed the importance of these problems by conducting two set of studies. In the first set of simulations, they identified the dry-out impact on well injectivity assuming reservoir filled with pure water by injecting pure $\mathrm{CO}_{2}$ and water saturated $\mathrm{CO}_{2}$. It is found that injectivity increased in the case of pure $\mathrm{CO}_{2}$ injection since water vaporized into $\mathrm{CO}_{2}$ caused an increase in permeability. In the second set of simulations made to examine the salting-out problem for low salinity and high salinity brine; precipitation had small effect on injection for low salinity brine [14]. 
Ennis-King et al. carried out numerical simulations of $\mathrm{CO}_{2}$ sequestration in the Petrel Sub-Basin, North West Australia with the TOUGH2 code. They studied the grid block size effect and made sensitivity analysis to make the end point relative permeability effects on dissolution rates clear. They found that dissolution of $\mathrm{CO}_{2}$ was overestimated during injection and underestimated for long time scales for coarser grid model. Irreducible water saturation, Swr was the most sensitive parameter during the injection phase and as residual water saturated with $\mathrm{CO}_{2}$; therefore, the greater $\mathrm{Swr}$ caused more dissolution [37].

Izgeç et al. examined the porosity and permeability change of the heterogeneous core taken from carbonate aquifer by using computerized tomography (CT) and used these results to make sensitivity analysis for forward (dissolution) and backward (precipitation) chemical reaction rates, Kozeny-Carman coefficient, blockage effect of particles, adsorption rate of $\mathrm{CO}_{2}$ and initial concentration of species by using CMG-STARS. They found that the trend of rock properties change is case sensitive since change of rock properties strongly depends on distribution of pores, brine composition and thermodynamic conditions. Also, they observed hydrodynamic and solubility trapping leads to more $\mathrm{CO}_{2}$ sequestration than mineral trapping and adsorption $[38,39]$.

Ozah et al. made numerical simulations using a compositional reservoir simulator GEM to understand the flow and long-term storage potential of pure $\mathrm{CO}_{2}$ and $\mathrm{CO}_{2}-\mathrm{H}_{2} \mathrm{~S}$ mixtures in deep saline aquifers. They also made a sensitivity analysis of mean permeability, dip angle, vertical to horizontal permeability ratio $\left(k_{v} / k_{h}\right)$ and injection intervals. Injection of $\mathrm{CO}_{2}-\mathrm{H}_{2} \mathrm{~S}$ mixture led to increase in residual gas saturation, while free gas saturation decreased. They found that injectivity and storage capacity increased with increase in mean permeability and gas dissolved into brine increased with dip angle increase and $k_{v} / k_{h}$ decrease due to long distance migration of gas. 
Risk of gas reaching the top of the formation increased with the increase in injection intervals. They also observed that porosity and permeability change due to the mineralization was small since mineralization of $\mathrm{CO}_{2}$ did not significantly contributed to the storage of $\mathrm{CO}_{2}$; however, mineralization lessened the free gas saturation in the long-term [40].

Mo et al. studied the impact of the $\mathrm{CO}_{2}$ injection rate, reservoir layering, capillary pressure and residual $\mathrm{CO}_{2}$ saturation on $\mathrm{CO}_{2}$ distribution in deep saline aquifers by using a commercial black-oil reservoir simulator by setting the $\mathrm{CO}_{2}$ solubility in water zero in order to reduce the number of adjustable parameters. They found that $\mathrm{CO}_{2}$ injection rate and effective vertical permeability strongly affect the position and quantity of $\mathrm{CO}_{2}$ in each grid block and sweep efficiency of the $\mathrm{CO}_{2}$. Increase in sweep efficiency and $\mathrm{CO}_{2}$-water capillary pressure resulted in more residual trapped gas. They also showed that the amount of trapped gas can be estimated from average $\mathrm{CO}_{2}$ saturation if the sweep efficiency is good [41].

Kumar et al. conducted a $\mathrm{CO}_{2}$ sequestration simulation in a deep saline aquifer by using GEM in order to better understand and quantify estimates of the most important $\mathrm{CO}_{2}$ storage mechanism. They found that effect of residual gas on $\mathrm{CO}_{2}$ storage could be very large, even more effective than dissolution of $\mathrm{CO}_{2}$ and mineralization. They also carried out sensitivity study of temperature, mean permeability, salinity, vertical to horizontal permeability ratio $\left(k_{v} / k_{h}\right)$, irreducible gas saturation and dip angle. They showed that aquifer dip and $k_{v} / k_{h}$ had significant effect on gas migration pathway, which in turn affected the dissolution of $\mathrm{CO}_{2}$ in brine and mineralization. $\mathrm{CO}_{2}$ dissolution and mineralization increased with increase in dip angle and decrease in $k_{v} / k_{h} . \mathrm{CO}_{2}$ dissolution also increased with decrease in residual gas saturation since $\mathrm{CO}_{2}$ is more mobile. Increase in mean permeability increased the injectivity leading more dissolution. They observed that the dissolution of $\mathrm{CO}_{2}$ increased with increase in temperature as opposed to 
most reported observations. The main reason of increase in dissolution is that decrease in $\mathrm{CO}_{2}$ viscosity, which cause increase in contact area, which in turn increases the solubility of $\mathrm{CO}_{2}[42]$.

Saripalli et al. developed a semi-analytical model to simulate the deep well injection of $\mathrm{CO}_{2}$ assuming uniform formation properties, constant injection rate and instantaneous $\mathrm{CO}_{2}$ dissolution. Equations were developed for the radial injection of an immiscible $\mathrm{CO}_{2}$ phase into confined formations, its axisymmetric flow around the injector and eventual buoyancy driven transport with simultaneous dissolution. They investigated the effect of pertinent fluid, reservoir and operational characteristics on the deep well injection of $\mathrm{CO}_{2}$, bubble growth and dissolution. The results of this model showed that injected $\mathrm{CO}_{2}$ grows as a bubble radially outward and eventually dissolved in the formation water while it floats the top due to the buoyancy and settles near the top confining layer [43].

Bachu et al. proposed an empirical formula to calculate the capacity of the deep saline aquifers given in Eqn. 2.20 assuming the pore volume completely filled with water. The Ultimate $\mathrm{CO}_{2}$ Sequestration Capacity in Solution (UCSCS) of an aquifer is the difference between the ultimate capacity and current carbon content in solution.

$U C S C S=\iiint \phi\left(\rho_{S} X_{S}^{C O_{2}}-\rho_{0} X_{0}^{C O_{2}}\right) d x d y d z$

where $\phi$ is porosity, $\rho$ is the density of the formation water, $X^{\mathrm{CO}_{2}}$ is the carbon content in mass fraction and subscript 0 and $S$ represent current carbon content and at saturation respectively. The mass fraction of $\mathrm{CO}_{2}$ at saturation, $X^{\mathrm{CO}_{2}}$ is function of the salinity, temperature and pressure and determined in-situ conditions [44]. 


\subsection{Design of Experiment}

The (statistical) design of experiment (DOE) is defined as an efficient procedure for planning the experiments so that the data obtained from experiment can be analyzed to yield valid and objective conclusion [45].

Experimental design can be efficiently used for complex simulation model with a high-dimensional input space characterized by complex response surface. To efficiently analyze the output of the simulations, the experimental design should have the following desirable characteristics [46].

Approximate orthogonality of the input variables

Space-filling, that is, the collection of experimental cases should be a representative subset of the points in the hypercube of explanatory variables

$>$ Ability to examine many variables (20 or more) effectively

$>$ Flexibility in analyzing and estimating as many effects, interactions, and threshold as possible

$>$ Ease in generating the design

Ability to gracefully handle premature experiment termination

\subsubsection{Experiment Design Characteristics}

The two most important characteristics of experimental design are orthogonality and space-filling property. Orthogonality of the design matrix can be measured either the maximum pairwise correlation or condition number and the space-filling property of the design matrix can be evaluated either Euclidean maximum minimum ( $\mathrm{Mm}$ ) distance between design points or the modified $M L_{2}$ discrepancy from uniform design theory. 


\subsubsection{Orthogonality}

Orthogonality is used to estimate whether there is a correlation between design input variables. The correlation between two vectors $\mathbf{v}=\left[v_{1}, v_{2}, \ldots ., v_{n}\right]^{T}$ and $\mathbf{w}=\left[w_{1}, w_{2}, \ldots ., w_{n}\right]^{T}$ can be defined as $\rho$ given in Eqn.2.21.

$$
\rho=\frac{\sum_{i=1}^{n}\left[\left(v_{i}-\bar{v}\right)\left(w_{i}-\bar{w}\right)\right]}{\sqrt{\sum_{i=1}^{n}\left(v_{i}-\bar{v}\right)^{2} \sum_{i=1}^{n}\left(w_{i}-\bar{w}\right)^{2}}}
$$

If the correlation, $\rho$ between two vectors is zero, then they are orthogonal. Orthogonality of the design matrix $(\mathbf{X})$ can also be evaluated by condition number of $\left(\mathbf{X X}^{T}\right)$. An orthogonal design matrix has a condition number of 1 , while non-orthogonal matrix has a condition number greater than 1 . Condition number can be defined in terms of infinity norm by

$\operatorname{cond}_{\infty}(\phi)=\|\phi\|_{\infty}\left\|\phi^{-1}\right\|_{\infty}$

where $\phi$ is correlation matrix of the design matrix.

\subsubsection{Space-Filling Property}

The points of design matrix having good space filling property are distributed throughout entire experimental design region. Two methods can be used to define space filling property of the design matrix, namely, $M L_{2}$ discrepancy and Euclidean maximum minimum $(\mathrm{Mm})$ distance.

Define a distance list $\mathbf{d}=\left(d_{1}, d_{2}, \cdots, d_{[n(n-1)] / 2}\right)$, where the elements of $\mathbf{d}$ are the Euclidean inter-site distance of the $\mathrm{n}^{\text {th }}$ point in the design matrix, ordered from smallest to largest. The Euclidean $(\mathrm{Mm})$ distance is defined as the 
minimum distance in the $\mathbf{d}$ matrix, which corresponds to $d_{1}$. The larger the Euclidean $(\mathrm{Mm})$ distance, the better space filling design since each point is separated from each other to cover all design range, which is particularly important when the response surface is not predicted.

The second method to evaluate the space-filling property of the design is the calculation of the discrepancy. Fang and Wang gave the definition of discrepancy as follows [47]. Define $k$-dimensional unit cube $C^{k}$ and $P=\left\{x_{j}, j=1, \ldots, n\right\}$ be a subset of points on $C^{k}$ and $v([0, \gamma])=\gamma_{1} \gamma_{2} \ldots \gamma_{k}$ the volume of a rectangle $[0, \gamma]$. For any $\gamma \in C^{k}$, let $N(\gamma, P)$ be the number of points satisfying $x_{j} \leq \gamma$. Then the discrepancy is

$$
L_{\infty}=\sup _{\gamma \in C^{k}}\left|\frac{N(\gamma, P)}{n}-v(|0, \gamma|)\right|
$$

The equation compares the proportion of points within the rectangular subspaces to the volume of the rectangles. Discrepancy, which is the supremum of the absolute difference over all nested rectangles anchored at the origin, indicates the how good the space filling is. The minimum theoretical value is zero, indicating a better space filling property. The larger discrepancy value means there is too many or too few design points in the design region.

The Eqn. 2.23 is difficult to compute and it is only used to evaluate the space filling property of the design with maximum two variables and 10 runs. Fang et al. proposed modified $L_{2}$ discrepancy $\left(M L_{2}\right)$ given in Eqn.2.24 as an approximation of $L_{\infty}$ [48]. Eqn.2.24 is simple to calculate compared with Eqn.2.23 and also it is valid for more than two variables and more than 10 runs.

$$
M L_{2}=\left(\frac{3}{4}\right)^{k}-\frac{2^{1-k}}{n} \sum_{d=1}^{n} \prod_{i=1}^{k}\left(3-x_{d i}^{2}\right)+\frac{1}{n^{2}} \sum_{d=1}^{n} \sum_{j=1}^{n} \prod_{i=1}^{k}\left[2-\left(\max \left(x_{d i}, x_{j i}\right)\right]\right.
$$




\subsubsection{Space-Filling Design}

For deterministic modeling systems such as computer simulation involving many variables with complicated interrelationship, space filling design can be used to find simpler empirical model in order to adequately predict the behavior of the system. To decrease the difference between the values obtained empirical model and value obtained from simulation, design points are chosen such that points are spread out as far from each other as possible or points are spaced out evenly [49]

There are three common space filling designs, namely, Sphere Packing, Latin Hypercube and Uniform. Sphere Packing Space Filling Design is used to maximize the minimum distance between design points with nearest points by spreading the points equally as much as possible inside design range. In the Latin Hypercube Space Filling Design, each variable divided into many levels from lower bound to upper bound of the variable. Design points are chosen such that minimum distance between the points is maximized while even spacing between factor levels is maintained. In Uniform Space Filling Design, design points are separated such that the integrated difference between the design points and the uniform distribution is minimized.

Figure 2.11 taken from the JMP DOE Guide compares the Space Packing, Latin Hypercube and Uniform space filling designs for two variables with 8 point, range of which from 0 to 1 .The minimum distance between the points and their closest neighbor point and discrepancy are given for each design. While Sphere Packing design is the best with respect to minimum distance, it is the worst design with respect to discrepancy. Just the opposite, although Uniform Design is the best design with respect to discrepancy, it is the worst design with respect to minimum distance. Latin Hypercube Design is the optimum one; both minimum distance and discrepancy are taken into account. 


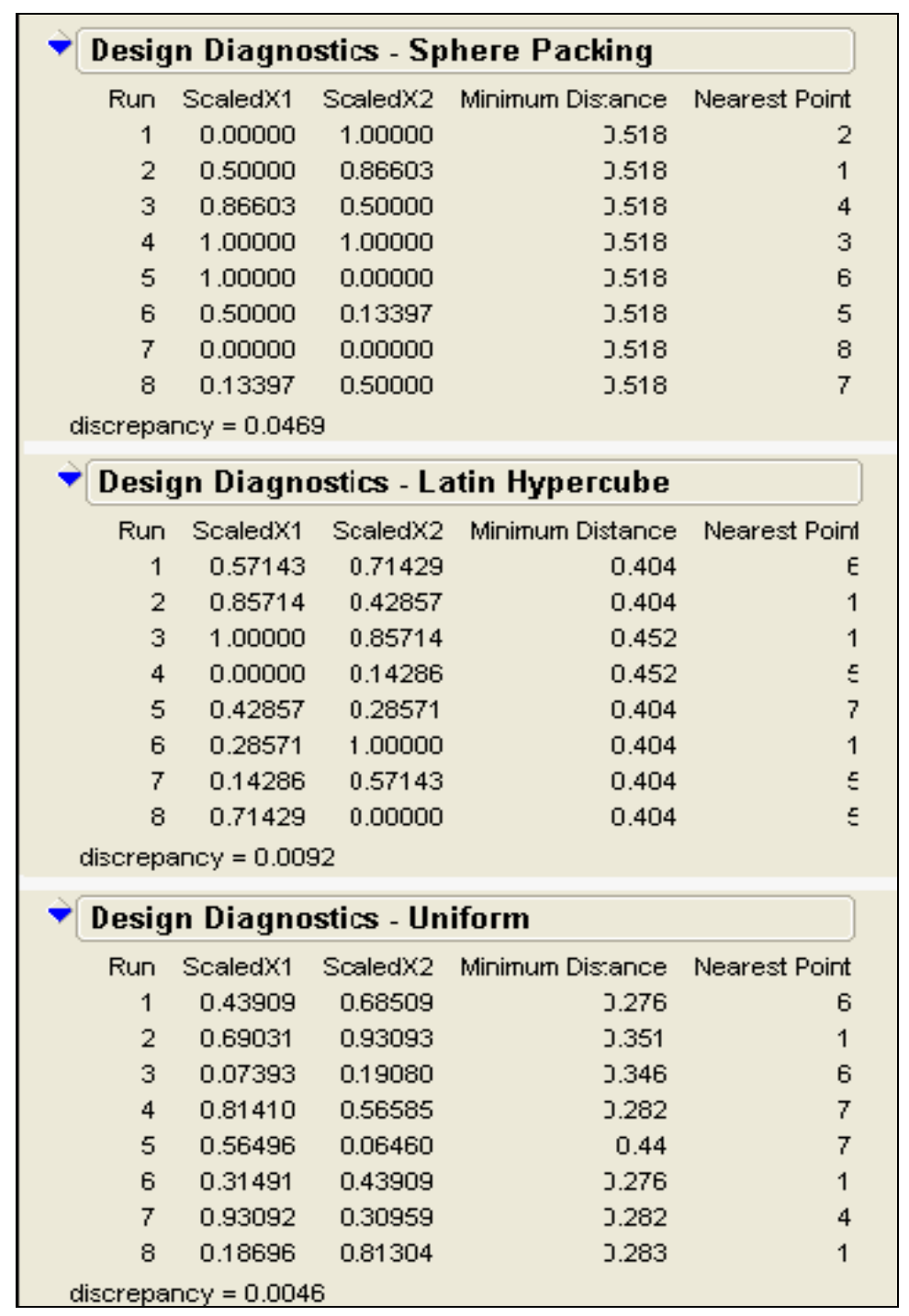

Figure 2.11: Comparison of Diagnostic for Three Eight-Run Space Filling Design From Output of JMP [49]

\subsubsection{Latin Hypercube Sampling}

Input variables of design matrix are considered as random variables with known distribution functions. According to McKay et al. (1979), for each input variable, $x_{k}$, "all portions of its distribution [are] represented by input values" by dividing its range into " $n$ strata of equal marginal probability $1 / n$, and [sampling] once from [within] each strata."[50]. To prepare $n$ cases, $n$ 
sampled input variables are chosen with $n$ ! possible permutation being equally likely.

To clarify the Latin sampling, assume that there are 3 variables with uniform distribution function, the range of which is 0 to 1.10 simulation cases are prepared, then, each variable interval is divided into 10 equal probable intervals $[0,0.1),[0.1,0.2),[0.2,0.3),[0.3,0.4),[0.4,0.5),[0.5,0.6),[0.6,0.7)$, $[0.7,0.8),[0.8,0.9)$ and $[0.9,1]$. For each input variable, the order in which the 10 sampled values appear in the design matrix is randomly determined, with all 10 ! possible being equally likely [46]. Table 2.4 gives the Latin Hypercube sampling for each variable for 10 simulation cases.

Table 2.4: An Example of Latin Hypercube Sampling

\begin{tabular}{|c|c|c|c|}
\hline Run & Variable 1 & Variable 2 & Variable 3 \\
\hline 1 & 0.63 & 0.53 & 0.90 \\
\hline 2 & 0.42 & 0.48 & 0.04 \\
\hline 3 & 0.89 & 0.19 & 0.89 \\
\hline 4 & 0.08 & 0.77 & 0.27 \\
\hline 5 & 0.23 & 0.30 & 0.59 \\
\hline 6 & 0.98 & 0.01 & 0.32 \\
\hline 7 & 0.15 & 0.22 & 0.61 \\
\hline 8 & 0.33 & 0.68 & 0.12 \\
\hline 9 & 0.58 & 0.93 & 0.48 \\
\hline 10 & 0.71 & 0.87 & 0.74 \\
\hline
\end{tabular}

\subsubsection{Latin Hypercube Design}

Tang (1993) defined the Latin Hypercube Design as design obtained by Latin hypercube sampling [51]. From the definition $n \times k$ Latin hypercube design consists of $k$ permutation of the vector $\{1,2, \ldots, n\}^{T}$. As a result, the input values are predetermined and there is no sampling within strata. Each of the $k$ columns contains $1,2, \ldots, n$ randomly assigned, without replacement, to one of the $k$ variables to create the Latin hypercube design. 
Latin Hypercube Design has many advantages over other designs. First of all, Latin Hypercube Design is simple to construct since it is composed of combination of several permutation of $1,2, \ldots, n$. Secondly, the number of variables and run size are not limited. Thirdly, this design achieves the maximum uniformity in each univariate margin since it has $n$ distinct levels of its variables.

However, Latin Hypercube Design does not guarantee any property for two or higher dimensional margins; therefore, the user has to find the right permutation so that design has desirable properties. The simplest strategy to find the desirable design is to use a random Latin Hypercube in which the permutations are selected randomly so that there are no possible systematic patterns in the resulting design.

\subsubsection{Model Construction}

Sacks et al. states the three important objectives of the computer experiments as [52]

Predicting the response at untried inputs

$>$ Optimizing a function of the input variables

$>$ Tuning the computer code to physical data

Consider that the simulation model containing $k$ input variable generates a vector of output response denoted as $y$. Let $i^{\text {th }}$ variable be denoted as $x_{i}$ and let $y_{i}$ be an individual output response obtained from simulation. A metamodel, simple model when compared with the simulation model, is found to describe the relationship between input variables $\left(x_{1}, x_{2}, \ldots, x_{k}\right)$ and the output measure $\left(y_{i}\right)$. A metamodel can be defined with a function $g$ by [46], 
$y=g\left(x_{1}, x_{2}, \ldots, x_{k}\right)+\varepsilon$

where $\varepsilon$ is an error term. A good metamodel is one where $g$ makes parsimonious use of variable and the error tem $(\varepsilon)$ is small. One of the simplest metamodels is one in which $g$ is linear combination of the input variables.

$g=\beta_{0}+\sum_{i=1}^{k} \beta_{i} x_{i}$

To estimate the $(k+1)$ coefficients and error term, the number of run, $n$ must satisfy the following condition.

$n>k+1$

As stated in the section 2.2.1.1, if the correlation between any two columns representing the input variables $x_{i}$ and $x_{j}$ are zero, input variables are orthogonal and the coefficient of the regression $\beta_{i}$ and $\beta_{j}$ are uncorrelated.

Unfortunately, for many simulations, a linear metamodel may not sufficiently characterize the simulation response due to the quadratic and bilinear interaction effects of simulation input variables. In this situation, the metamodel can be defined as,

$g=\beta_{0}+\sum_{i=1}^{k} \beta_{i} x_{i}+\sum_{j=1}^{k} \beta_{j} x_{j}^{2}+\sum_{i=1}^{k} \sum_{j>i} \beta_{i, j} x_{i} x_{j}$

In this case, the number of simulation runs, $n$ should satisfy the following criteria to estimate the coefficients and error term.

$n>\left[k+k+\left(\begin{array}{l}k \\ 2\end{array}\right)+1\right]$ 


\subsection{STARS}

STARS is a three-phase multi-component thermal and steam additive simulator. Figure 2.12 shows how the STARS works. STARS uses the data set created initially by the user and each simulator run creates 3 output files, namely, a text output file, an SR2 index file (IRF) and a SR2 main file (MRF). If a restart run is desired, STARS uses several existing input files, Data Set, Index-In and Main-Results-In, and generates new output ones [53].

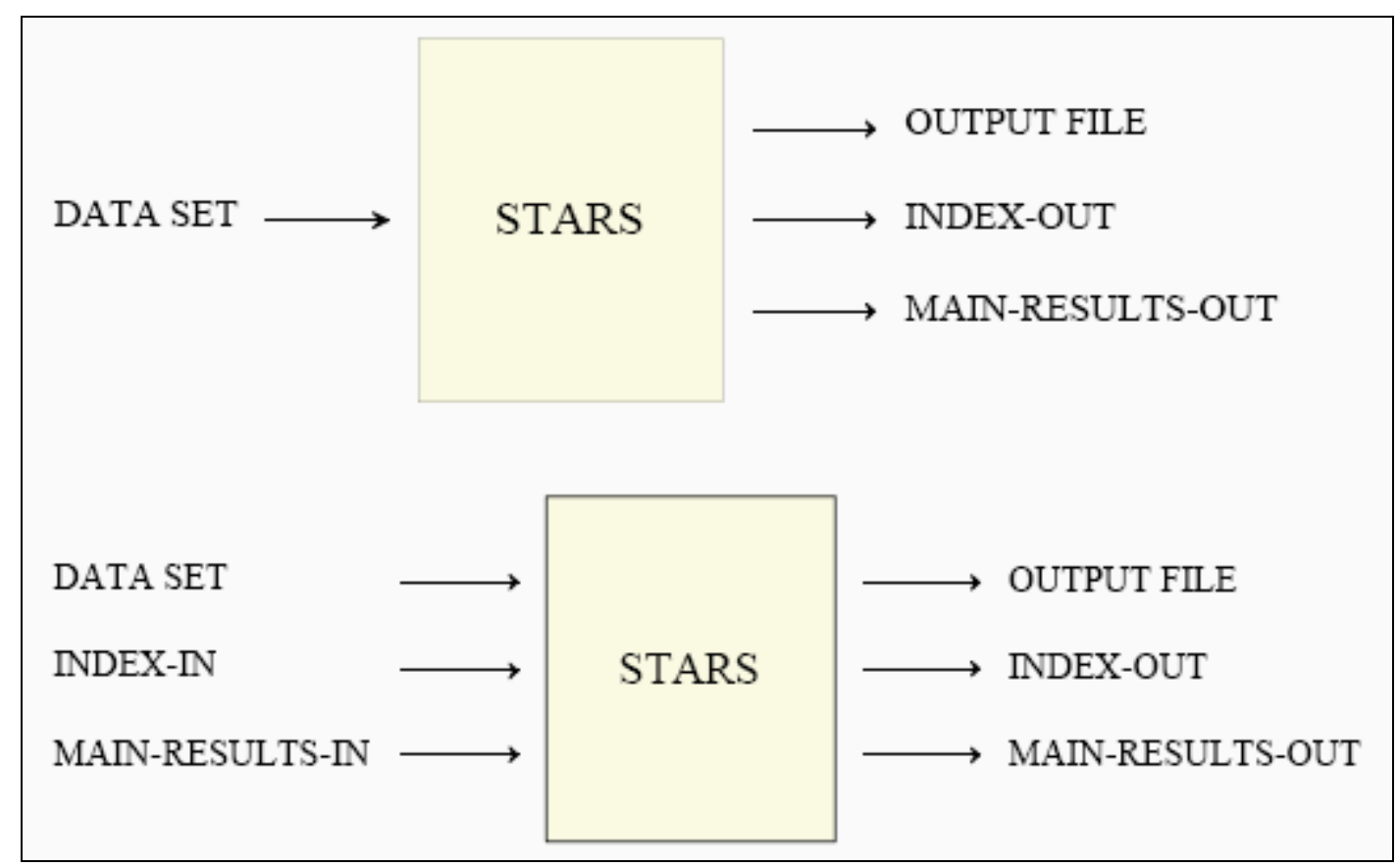

Figure 2.12: Operation Mechanism of STARS [53]

There are nine data groups in the keyword input system [53]

$>$ Input/Output Control: Define parameters that control the input and output activities of the simulator such as filenames, units, titles, choices and frequency of writing to both the output and SR2 file, and restart control. 
Reservoir Description: Contain data describing the basic reservoir definition and the simulation grids used to represent the reservoir. This data group consists of five subgroups: Simulation Grid and Grid Refinement Options, Choice of Natural Fracture Reservoir Options, Well Discretization Option, Basic Reservoir Rock Properties and Sector Options.

Other Reservoir Properties: Describe rock compressibility, reservoir rock thermal properties and overburden heat loss.

Component Properties: Indicate number of each type of component and gives basic properties of the fluids and solids such as viscosity, density and enthalpy. In this section, reactions and reaction properties should be specified for each solid component.

Rock-Fluid Data: Define relative permeability curves of the fluids in the reservoir, capillary pressure, and component adsorption, diffusion, and dispersion properties.

$>$ Initial Conditions: Specify the initial pressure and temperature of the reservoir, fluid saturations, and solid concentrations of each grid block.

Numerical Methods Control: Define parameters that control the simulator numerical activities such as time stepping, iterative solution of non-linear flow equations, and the solution of resulting system of linear equations.

Geomechanical Model: Define material behavior and contain two options namely, plastic and nonlinear elastic deformation model and single-well boundary unloading model.

$>$ Well and Recurrent Data: Control the well data and time dependent variables such as flow rates. 


\subsubsection{Conservation Equations}

For any conserved quantity $\varphi$, an inventory rate equation can be written as;

$\left(\begin{array}{l}\text { Rate of } \\ \text { input of } \varphi\end{array}\right)-\left(\begin{array}{l}\text { Rate of } \\ \text { output of } \varphi\end{array}\right)+\left(\begin{array}{l}\text { Rate of } \\ \text { additive of } \varphi\end{array}\right)=\left(\begin{array}{l}\text { Rate of } \\ \text { accumulation of } \varphi\end{array}\right)$

Additive term is the source and sink term represent the injection and production respectively.

Total volume $(V)$ of the system is defined as the sum of the volume of rock matrix $(r)$, solid and adsorbed component $(s)$, water phase $(w)$, gas phase $(g)$ and oil phase $(o)$.

$V=V_{r}+V_{s}+V_{w}+V_{o}+V_{g}$

Fluid volume $\left(V_{f}\right)$ is,

$V_{f}=V_{w}+V_{o}+V_{g}$

Void volume $\left(V_{v}\right)$ is,

$V_{v}=V-V_{r}=V_{f}+V_{s}$

Then void porosity $\left(\phi_{v}\right)$ is defined as,

$\phi_{v}=V_{v} / V$

Fluid porosity $\left(\phi_{f}\right)$ is defined as,

$\phi_{f}=V_{f} / V=\left(V_{v}-V_{s}\right) / V=\left(V_{v} / V\right)\left(1-V_{s} / V_{v}\right)$

or

$\phi_{f}=\phi_{v}\left(1-\sum c_{s i} / \rho_{s i}\right)$ 
where $c_{s i}$ and $\rho_{s i}$ concentration and density of the solid and adsorbed component.

Saturations are defined as,

$S_{w}=V_{w} / V_{f}=V_{w} / \phi_{f} V$

$S_{o}=V_{o} / V_{f}=V_{o} / \phi_{f} V$

$S_{g}=V_{g} / V_{f}=V_{g} / \phi_{f} V$

$S_{w}+S_{o}+S_{g}=1$

Accumulation term for the flowing and adsorbed component $i\left(A d_{i}\right)$ can be written as,

$V \frac{\partial}{\partial t}\left[\phi_{f}\left(\rho_{w} S_{w} w_{i}+\rho_{o} S_{o} x_{i}+\rho_{g} S_{g} y_{i}\right)+\phi_{v} A d_{i}\right]$

Accumulation term for solid component $i$ is,

$V \frac{\partial}{\partial t}\left[\phi_{v} c_{i}\right]$

Accumulation term for energy is,

$V \frac{\partial}{\partial t}\left[\phi_{f}\left(\rho_{w} S_{w} U_{w}+\rho_{o} S_{o} U_{o}+\rho_{g} S_{g} U_{g}\right)+\phi_{v} c_{s} U_{s}+\left(1-\phi_{v}\right) U_{r}\right]$

$U$ represents the internal energy which is function of temperature and phase composition.

Flow terms of flowing component is,

$\rho_{w} v_{w} w_{i}+\rho_{o} v_{o} x_{i}+\rho_{g} v_{g} y_{i}+\phi \rho_{w} D_{w i} \Delta w_{i}+\phi \rho_{g} D_{g i} \Delta y_{i}+\phi \rho_{o} D_{o i} \Delta x_{i}$

where $D$ is the dispersibilities of the component due to the concentration difference and $v$ is the volumetric flow rate. 
Flow term of energy is,

$\rho_{w} v_{w} H_{w}+\rho_{o} v_{o} H_{o}+\rho_{g} v_{g} H_{g}+K \Delta T$

Where $H$ and $K$ are enthalpy and thermal transmissibility at the interface, respectively.

The volumetric flow rate is,

$v_{j}=T\left(\frac{k_{r j}}{\mu_{j} r_{j}}\right) \Delta \Phi_{j}$

where $T$ and $\Phi$ represent the transmissibility and potential of grid block, respectively.

Then the flow term becomes,

$$
\begin{aligned}
& T_{w} \rho_{w} w_{i} \Delta \Phi_{w}+T_{o} \rho_{o} x_{i} \Delta \Phi_{o}+T_{g} \rho_{g} y_{i} \Delta \Phi_{g} \\
& \quad+\phi D_{w i} \rho_{w} \Delta w_{i}+\phi D_{o i} \rho_{o} \Delta x_{i}+\phi D_{g i} \rho_{g} \Delta y_{i}
\end{aligned}
$$

And flow term of energy becomes,

$T_{w} \rho_{w} H_{w} \Delta \Phi_{w}+T_{o} \rho_{o} H_{o} \Delta \Phi_{o}+T_{g} \rho_{g} H_{g} \Delta \Phi_{g}+K \Delta T$

Well Source/Sink Terms for flowing component is,

$$
\rho_{w} q_{w k} w_{i}+\rho_{o} q_{o k} X_{i}+\rho_{g} q_{g k} y_{i}
$$

Well source/sink term for energy is,

$$
\rho_{w} q_{w k} H_{w}+\rho_{o} q_{o k} H_{o}+\rho_{g} q_{g k} H_{g}
$$

The Reaction source/sink term for component $i$ in $k$ reaction is,

$$
V \sum_{k=1}^{n_{r}}\left(s_{k i}^{\prime}-s_{k i}\right) r_{k}
$$


Reaction sink/source term for energy is,

$V \sum_{k=1}^{n_{r}} H_{r k} r_{k}$

where $s^{\prime}, s, r$ and $H$ are product and reactant stoichiometric coefficients, volumetric rate of reaction and reaction enthalpy, respectively.

Heat loss source/sink term for energy is,

$\sum_{k=1}^{n_{r}} H L_{k}+H L_{v}+H L_{c}$

$H L_{k}, H L_{v}$, and $H L_{c}$ are the rate of heat transfer from the adjacent region to the region of interest through the surface $k$, and the rate of heat transfer from a convective and a constant heat model, respectively.

The thermal aquifer sink/source term for water component is,

$\sum_{k=1}^{n_{f}} \rho_{w} q a q_{w k}$

The thermal aquifer sink/source term for the energy is,

$\sum_{k=1}^{n_{f}}\left(H A_{C V}-H A_{C D}\right)_{k}$

$H A_{C V}, H A_{C D}$ and $q a q_{w}$ are the rate of heat transfer by convection and conduction, and volumetric flow rate through a block face. 
The conservation equation of flowing and adsorbed component is defined as,

The rate of accumulation of flowing and adsorbed component

$=$ The rate of flowing term due to potential difference

+ The rate of $\sin k$ / sourceterm of reaction

+ The rate of flowing term due to dispersibility

+ The rate of $\sin k /$ sourceterm of aquifer

+ The rate of $\sin k /$ sourcceterm of well

The Eqn. 2.56 can be stated as;

$V \frac{\partial}{\partial t}\left[\phi_{f}\left(\rho_{w} S_{w} w_{i}+\rho_{o} S_{o} x_{i}+\rho_{g} S_{g} y_{i}\right)+\phi_{v} A d_{i}\right]$

$=\sum_{k=1}^{n_{f}}\left[T_{w} \rho_{w} w_{i} \Delta \Phi_{w}+T_{o} \rho_{o} x_{i} \Delta \Phi_{o}+T_{g} \rho_{g} y_{i} \Delta \Phi_{g}\right]+V \sum_{k=1}^{n_{f}}\left(s_{k i}^{\prime}-s_{k i}\right)$

$+\sum_{k=1}^{n_{f}}\left[\phi D_{w i} \rho_{w} \Delta w_{i}+\phi D_{o i} \rho_{o} \Delta x_{i}+\phi D_{g i} \rho_{g} \Delta y_{i}\right]$

$+\delta_{i w} \sum_{k=1}^{n_{f}} \rho_{w} q a q_{w k}+\sum_{k=1}^{n_{f}} \rho_{w} q_{w k} w_{i}+\rho_{o} q_{o k} x_{i}+\rho_{g} q_{g k} y_{i}$

The conservation equation of solid component $i$ can be written as,

Accumulation term of solid component $i=$

The reaction $\sin k$ / sourceterm for component $i$

The Eqn. 2.58 can be stated as;

$V \frac{\partial}{\partial t}\left[\phi_{v} c_{i}\right]=V \sum_{k=1}^{n_{f}}\left(s_{k i}^{\prime}-s_{k i}\right) r_{k}$ 
The conservation equation of energy is defined as,

The rate of accumulation of energy

$=$ The rate of flow of energy due to potential difference

+ The rate of flow of energy due to thermal conductivity at the int erface

+ The rate of $\sin k /$ sourcceterm of energy from well

+ The rate of $\sin k$ / sourceterm of energy dueto reaction

+ The rate of $\sin k$ / sourceterm of energy heat loss to adjacent region

+ The rate of $\sin k$ / sourceterm of energy from thermal aquifer

The Eqn. 2.60 can be stated as;

$$
\begin{aligned}
& V \frac{\partial}{\partial t}\left[\phi_{f}\left(\rho_{w} S_{w} U_{w}+\rho_{o} S_{o} U_{o}+\rho_{g} S_{g} U_{g}\right)+\phi_{v} c_{s} U_{s}+\left(1-\phi_{v}\right) U_{r}\right] \\
& =\sum_{k=1}^{n_{f}}\left[T_{w} \rho_{w} H_{w} \Delta \Phi_{w}+T_{o} \rho_{o} H_{o} \Delta \Phi_{o}+T_{g} \rho_{g} H_{g} \Delta \Phi_{g}\right] \\
& +\sum_{k=1}^{n_{f}} K \Delta T+\sum_{k=1}^{n_{f}} \rho_{w} q_{w k} H_{w}+\rho_{o} q_{o k} H_{o}+\rho_{g} q_{g k} H_{g} \\
& +V \sum_{k=1}^{n_{r}} H_{r k} r_{r k}+V \sum_{k=1}^{n_{r}} H L_{o}+H L_{v}+H L_{c}+\sum_{k=1}^{n_{f}}\left(H A_{C V}+H A_{C D}\right)_{k}
\end{aligned}
$$

\subsubsection{Solution of Basic Equations}

For each grid block the following equations are solved simultaneously.

$>$ All component conservation equations

$>$ Energy conservation equation

Phase constrain equation (optional) given in Eqn. 2.62.

$$
\sum_{i=1}^{n_{c}} y_{i}=1 \text { or } S_{w}+S_{o}+S_{g}=1
$$

If the system is isothermal, the energy and phase constrain equations are not solved. Nonlinear equations are solved with Newton Method. Linear system of equations obtained from application of Newton Method is solved with Gauss Elimination or LU Decomposition Methods. 
Algebraic works can be reduced with Adaptive-Implicit Reduction. This method is used to create smaller Jacobian matrix. Furthermore, in some situations further elimination of unknowns can be achieved with red-black ordering scheme (a generalized D4 numbering system).

\subsubsection{Newton's Method}

Eqn. 2.30 is written as residual form, $R_{i}$ and the equation is solved when $R_{i}=0$. $R_{i}=\left(\begin{array}{l}\text { Rate of } \\ \text { input of } \varphi\end{array}\right)-\left(\begin{array}{l}\text { Rate of } \\ \text { output of } \varphi\end{array}\right)+\left(\begin{array}{l}\text { Rate of } \\ \text { additive of } \varphi\end{array}\right)-\left(\begin{array}{l}\text { Rate of } \\ \text { accumulation of } \varphi\end{array}\right)$

If there are $n_{b}$ active grid blocks and $n_{w}$ open wells, then total number of equations, Neq will be given in Eqn. 2.64.

$$
N e q=n_{b} \times n_{e q}+n_{w}
$$

There are also Neq primary variables. Define $\mathbf{X}$ represent the variable matrix. In general, each residual $R_{i}$ depends on $X_{i}$ and $\mathbf{R}$ can be stated as

$$
\mathbf{R}=\mathbf{R}(\mathbf{X})
$$

Where $\mathbf{R}$ and $\mathbf{X}$ are Neq-length vector.

$$
\begin{aligned}
& \mathbf{X}^{k+1}=\mathbf{X}^{k}-\left[\mathbf{J}^{k}\right]^{-1} \mathbf{R} \\
& \text { or } \mathbf{J}^{k}\left(\mathbf{X}^{k+1}-\mathbf{X}^{k}\right)=-\mathbf{R}^{k}
\end{aligned}
$$

where $\mathbf{J}=d \mathbf{R} / d \mathbf{X}$ is the Jacobian matrix of derivatives and $k$ is the Newton iteration number. The initial $\mathbf{X}^{0}$ is usually $\mathbf{X}^{N}$, the solution to the previous timestep. The iterative solution converges when both $\left(\mathbf{X}^{k+1}-\mathbf{X}^{k}\right)$ and $\mathbf{R}$ are 
sufficiently small. When the convergence is achieved, the solution at the current time is $\mathbf{X}^{N+1}=\mathbf{X}^{k+1}$.

\subsubsection{Gauss Elimination Method}

Gauss elimination is the oldest and most popular direct solution method involving two distinct stages. The first stage is the elimination stage, in which unknowns are systematically from the rows of matrix equation. Upper triangular matrix is formed at the end of the elimination stage. The second stage is the back substitution stage, in which the unknowns are determined by substituting known quantities into the upper triangular matrix formed in the first stage [54].

In the elimination stage, the first equation is divided by the coefficient of the first unknown term, then the first unknown is eliminated from succeeding equations. This elimination is repeated $n$ times. At the end of the elimination stage, the last equation of the resulting system has only the last unknown remaining. The last equation is solved explicitly for the last unknown, then, the back substitution stage is used to solve for the remaining unknowns successively.

Mathematically, the following expressions give the Gauss elimination procedure for the $\mathbf{A X}=\mathbf{D}$.

$$
\left[\begin{array}{cccc}
a_{11} & a_{12} & \cdots & a_{1 n} \\
a_{21} & a_{22} & \cdots & a_{2 n} \\
\vdots & \vdots & \vdots & \vdots \\
a_{n 1} & a_{n 2} & \cdots & a_{n n}
\end{array}\right]\left[\begin{array}{c}
x_{1} \\
x_{2} \\
\vdots \\
x_{n}
\end{array}\right]=\left[\begin{array}{c}
d_{1} \\
d_{2} \\
\vdots \\
d_{n}
\end{array}\right]
$$


For $i=1,2, \ldots, n$ define the initial matrixes as $d_{i}^{(0)}=d_{i}$ and $a_{i, j}^{(0)}=a_{i, j}$.

Elimination Stage;

for $i=1,2, \ldots, n$

$d_{i}^{(i)}=\frac{d_{i}^{(i-1)}}{a_{i, i}^{(i-1)}}$

for $j=i+1, i+2, \ldots, n$

$a_{i, j}^{(i)}=\frac{a_{i, j}^{(i-1)}}{a_{i, i}^{(i-1)}}$

$a_{i, i}=1.0$

for $k=i+1, i+2, \ldots, n$

$d_{k}^{(i)}=d_{k}^{(i-1)}-d_{i}^{(i)} a_{k, i}^{(i-1)}$

for $j=i+1, i+2, \ldots, n$

$a_{k, j}^{(i)}=a_{k, j}^{(i-1)}-a_{i, j}^{(i)} a_{k, i}^{(i-1)}$

$a_{k, i}^{(i)}=0$

Back substitution Stage

for $i=n-1, n-2, \ldots, 1$

$x_{n}=d_{n}^{(n)}$

$x_{i}=d_{i}^{(n)}-\sum_{j=i+1}^{n} a_{i, j}^{(n)} x_{j}$ 


\subsubsection{LU Decomposition}

LU decomposition of matrix $\mathbf{A}$ is product of two matrixes $\mathbf{L}$ and $\mathbf{U}$, where $\mathbf{L}$ and $\mathbf{U}$ represent the lower triangular and upper triangular matrix given in Eqn. 2.77 [55].

$$
\mathbf{A}=\mathbf{L} \cdot \mathbf{D}
$$

For the case of a $4 \times 4$ matrix $\mathbf{A}$, LU decomposition is given below.

$$
\left[\begin{array}{cccc}
\alpha_{11} & 0 & 0 & 0 \\
\alpha_{21} & \alpha_{22} & 0 & 0 \\
\alpha_{31} & \alpha_{32} & \alpha_{33} & 0 \\
\alpha_{41} & \alpha_{42} & \alpha_{43} & \alpha_{44}
\end{array}\right]\left[\begin{array}{cccc}
\beta_{11} & \beta_{12} & \beta_{13} & \beta_{14} \\
\beta_{21} & \beta_{22} & \beta_{23} & 0 \\
\beta_{31} & \beta_{32} & 0 & 0 \\
\beta_{41} & 0 & 0 & 0
\end{array}\right]=\left[\begin{array}{llll}
a_{11} & a_{12} & a_{13} & a_{14} \\
a_{21} & a_{22} & a_{23} & a_{24} \\
a_{31} & a_{32} & a_{33} & a_{34} \\
a_{41} & a_{42} & a_{43} & a_{44}
\end{array}\right]
$$

Such decomposition can be used to solve a linear equation

$$
\mathbf{A} \cdot \mathbf{X}=(\mathbf{L} \cdot \mathbf{U}) \cdot \mathbf{X}=\mathbf{L} \cdot(\mathbf{U} \cdot \mathbf{X})=\mathbf{B}
$$

by first solved for the vector $\mathbf{Y}$ such that

$$
\mathbf{L} \cdot \mathbf{Y}=\mathbf{B}
$$

and then solved

$$
\mathbf{U} \cdot \mathbf{X}=\mathbf{Y}
$$

The LU Decomposition algorithm can be given as;

$$
\begin{aligned}
& \alpha_{i 1} \beta_{1 j}+\ldots=a_{i j} \\
& i<j: \alpha_{i 1} \beta_{1 j}+\alpha_{i 2} \beta_{2 j}+\ldots+\alpha_{i i} \beta_{i j}=a_{i j} \\
& i=j: \alpha_{i 1} \beta_{1 j}+\alpha_{i 2} \beta_{2 j}+\cdots+\alpha_{i i} \beta_{j j}=a_{i j} \\
& i>j: \alpha_{i 1} \beta_{1 j}+\alpha_{i 2} \beta_{2 j}+\cdots+\alpha_{i j} \beta_{j j}=a_{i j}
\end{aligned}
$$


There are $N^{2}$ equations and $N^{2}+N$ unknowns $\alpha$ 's and $\beta$ 's. Since the number of unknowns are greater than number of equation $N$ of the unknowns are specified arbitrarily as,

$\alpha_{i i} \equiv 1 \quad i=1, \ldots, N$

For $i=1,2, \ldots, j$, the Eqn. 2.83, Eqn. 2.84, and Eqn. 2.85 are used and Eqn. 2.87 is used to calculate $\beta_{i j}$

$\beta_{i j}=a_{i j}-\sum_{k=1}^{i-1} \alpha_{i k} \beta_{k j}$

For $i=j+1, j+2, \ldots, N$, the Eqn. 2.85 is used and Eqn. 2.88 is used to calculate $\alpha_{i j}$

$\alpha_{i j}=\frac{1}{\beta_{j j}}\left(\alpha_{i j}-\sum_{k=1}^{j-1} \alpha_{i k} \beta_{k j}\right)$

\subsubsection{Adaptive Implicit Method (AIM) and Implicit Pressure Explicit Saturation (IMPES)}

When the variables such as pressure, saturation and temperature change suddenly, then fully implicit method is used; otherwise, IMPES is used [53].

The objective of the IMPES method is to obtain a single pressure equation for each grid block by combining all flow equation in order to eliminate the unknown saturation. In this method, capillary pressures and transmissibilities are evaluated explicitly at the old iteration level, $k$, then the set of pressure equations written for each block is solved. IMPES method should be used when saturation changes slowly from one timestep to the next due to the explicit treatment of saturations. 


\subsubsection{Red Black Ordering (D-4)}

In red-black ordering method, grids are ordered in the form of diagonal in order to increase the efficiency of the direct-solution procedure by increasing the convergence. Figure 2.13 and Figure 2.14 show the red-black ordering for $6 \times 4$ grids and the resulting matrix in which the fill blocks show the nonzero elements, respectively. The resulting matrix is obtained by loading the data of the shaded grids first and then loading the others so that adjacent grids are not loaded successively. The advantages of this ordering method is that the number of steps is reduced to half during elimination stage since after the elimination of lower left part of the matrix elements by using the upper left part creates the lower right diagonal matrix. Figure 2.15 shows the resulting matrix after the elimination stage where shaded squares show the non-zero elements and shaded circle shows the non-zero elements obtained after the elimination stage [54].

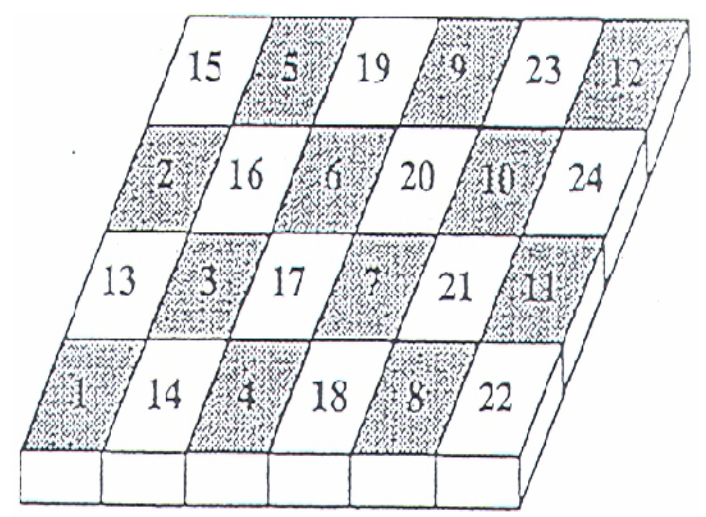

Figure 2.13: Red-Black Ordering [54] 


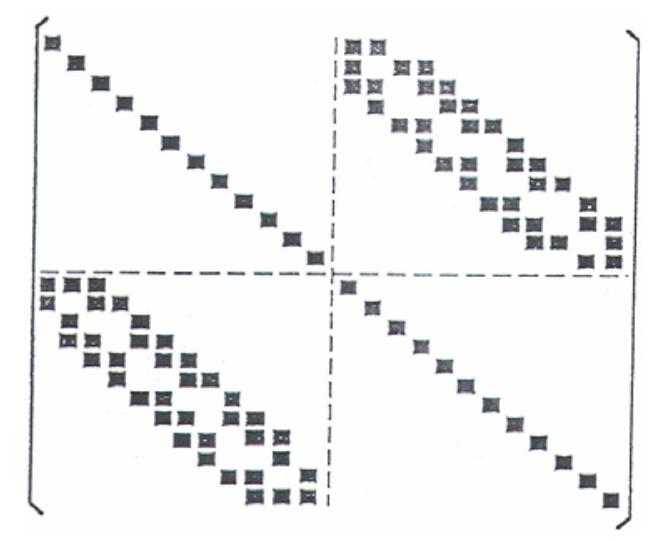

Figure 2.14: Red-Black Ordering Resulting Matrix [54]

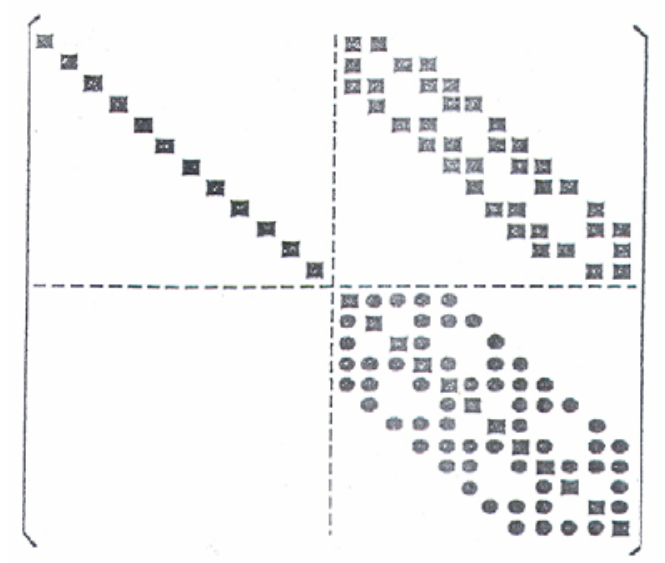

Figure 2.15: Resulting Matrix after Elimination Stage [54]

The lower right diagonal matrix is reduced system of equations and it can be solved any either direct or iterative methods. After that the remaining unknowns can be determined from back substitution. 


\section{CHAPTER 3}

\section{STATEMENT OF THE PROBLEM}

$\mathrm{CO}_{2}$ concentration in the atmosphere has rapidly increased since industrial revolution, which negatively affects the world climate. In order to reduce the $\mathrm{CO}_{2}$ greenhouse effect, many $\mathrm{CO}_{2}$ mitigation alternatives are considered, one of which is the $\mathrm{CO}_{2}$ sequestration in deep saline aquifers. Deep saline aquifers properties are not known much since they are rarely target of exploration. $\mathrm{CO}_{2}$ sequestration in deep saline aquifers has been studied since 1990s. Most of these studies are case studies conducted for sandstones to understand the $\mathrm{CO}_{2}$ migration and distribution of $\mathrm{CO}_{2}$ in the aquifer. Other studies are conducted to understand effects of the variables on gas storage capacity; however the sensitivity parameters are limited. Therefore, the main focus of this study is deep saline carbonate aquifers and their $\mathrm{CO}_{2}$ storage capacities.

In this study, all variables that affect the storage capacity of the deep saline carbonate aquifers will be determined and their range will be found from the published literature in order to create a predictive model to estimate the storage capacity in such aquifers. To create a predictive model, the optimum design of experiment method will be chosen so that simulation cases will cover the whole space created by variables. Also, the quality of the design will be evaluated by looking into important characteristics of the design. Numerical simulation cases will be conducted for a hypothetical closed aquifer. A linear predictive model will be constructed with least square method by using simulation results. Then, sensitivity analysis of the 
predictive model will be conducted to understand the effect of each parameter on the storage capacity. The numbers of moles of $\mathrm{CO}_{2}$ dissolved in the formation water, remaining as a free gas and reacting with $\mathrm{Ca}^{2+}$ will be calculated to construct the predictive model for each trapping mechanisms. By comparing the number of moles of $\mathrm{CO}_{2}$ trapped with each mechanism, the most effective trapping mechanism will be determined and this result will be compared with the sensitivity analysis results. Grid dimensions will be increased to 2 and 3 times and simulation cases will be repeated in order to find dimensionless predictive model with the same method. 


\section{CHAPTER 4}

\section{METHODOLOGY}

Methodology is divided into four parts. First part illustrates the selection of variables used in the Latin Hypercube Space Filling Design. In the second part, the most important properties, orthogonality and space filling property, will be evaluated. In the third part, preparation of the simulation cases will be explained step by step. Finally, in the last part, the dimensionless model constructed for this study will be discussed.

\subsection{Input Variable}

In this part, how the range of variables used in this study is determined and explained by giving the reference literature.

\subsubsection{Porosity}

Porosity range observed in carbonate aquifers is determined using pore volume compressibility data. According to literature data (Figure 4.1), porosity range can be defined from $1 \%$ to $25 \%$ for limestone formations [63]. 


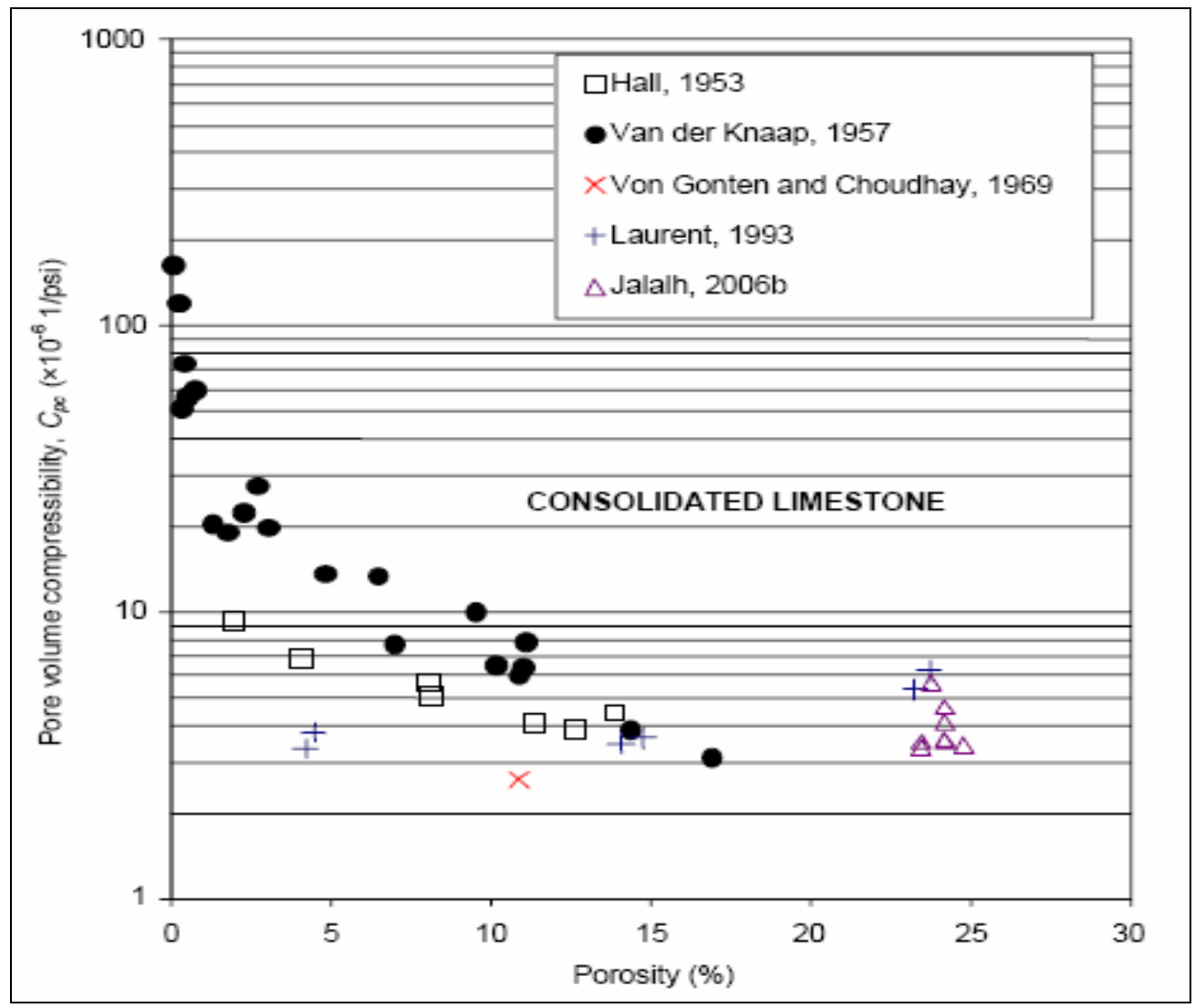

Figure 4.1: Porosity versus Pore Volume Compressibility from the Literature [63]

\subsubsection{Permeability}

Permeability limits are determined from the case studies and sensitivity analyses. Table 4.1 shows the permeability data found from the literature. The lowest permeability is $0.2 \mathrm{mD}$ and highest value is $2000 \mathrm{mD}$. For practical purpose, permeability range is chosen as $1 \mathrm{mD}$ to $2000 \mathrm{mD}$. 
Table 4.1: Permeability Data Found From Literature

\begin{tabular}{|l|c|}
\hline \multicolumn{1}{|c|}{ Permeability } & Reference \\
\hline 1 Darcy & 3 \\
\hline $200 \mathrm{mD}$ (horizontal) - 66 mD (vertical) & 14 \\
\hline 2 Darcy & 34 \\
\hline $100 \mathrm{mD}, 2000 \mathrm{mD}$ & 35 \\
\hline $200 \mathrm{mD}$ & 36 \\
\hline $16 \mathrm{mD}, 60 \mathrm{mD}, 120 \mathrm{mD}$ & 37 \\
\hline $2.9-1020 \mathrm{mD}$ & 38 \\
\hline $10,100,1000 \mathrm{mD}$ & 40 \\
\hline $20-2000 \mathrm{mD}$ (good formations) & 41 \\
\hline $0.2-20 \mathrm{mD}$ (bad formations) & 41 \\
\hline $30.6 \mathrm{mD}, 38.4 \mathrm{mD}$ & 56 \\
\hline $1-15 \mathrm{mD}$ & 57 \\
\hline
\end{tabular}

\subsubsection{Ratio of Vertical Permeability to Horizontal Permeability}

Permeability in $\mathrm{x}, \mathrm{y}$ and $\mathrm{z}$ directions are not equal since permeability changes with direction. Usually, areal permeability values, $k_{x}$ and $k_{y}$ are assumed to be equal and vertical permeability is smaller than the areal permeability due to the confining pressure in the vertical direction caused by formations above aquifer. The ratios of vertical permeability to horizontal permeability are given in Table 4.2.

Table 4.2: Vertical to Horizontal Permeability Ratio Found From Literature

\begin{tabular}{|l|c|}
\hline \multicolumn{1}{|c|}{$k_{v} / k_{h}$} & Reference \\
\hline $0.01,0.03,0.07$ & 37 \\
\hline 1 & 35 \\
\hline 0.5 & 36 \\
\hline $0,0.001,0.1,1.0$ & 40 \\
\hline $0.1,1$ & 68 \\
\hline
\end{tabular}


According to literature survey, the minimum $k_{v} / k_{h}$ ratio is zero corresponding to no vertical communication in formation but it is not feasible. Therefore the minimum value is taken as 0.001 and maximum value is 1 assuming homogenous formation, in which vertical permeability equals to horizontal permeability.

\subsubsection{Depth of Aquifer}

For temperatures and pressures greater than $31.1^{\circ} \mathrm{C}$ and $7.38 \mathrm{MPa}, \mathrm{CO}_{2}$ is in supercritical state in which $\mathrm{CO}_{2}$ has both gas and liquid properties such as low viscosities and high densities. $\mathrm{CO}_{2}$ injection in supercritical state is more feasible than gaseous injection since a larger volume of $\mathrm{CO}_{2}$ can be stored due to its high density in supercritical state. For depths larger than $800 \mathrm{~m}$, the aquifer pressure and temperature enables $\mathrm{CO}_{2}$ storage in supercritical state. Table 4.3 gives the depth of the deep saline aquifers found from literature. Most of the aquifers are located 1000 to $2000 \mathrm{~m}$. The optimum range for simulations can be taken as $1000 \mathrm{~m}$ to $3400 \mathrm{~m}$.

Table 4.3: Depth Data Found From Literature

\begin{tabular}{|l|c|}
\hline \multicolumn{1}{|c|}{ Depth } & Reference \\
\hline $1000 \mathrm{~m}$ & 7 \\
\hline $1500 \mathrm{~m}$ & 8 \\
\hline $730 \mathrm{~m}$ (Reservoir top) & 14 \\
\hline $1000 \mathrm{~m}$ (injection depth) & 28 \\
\hline $900,1200 \mathrm{~m}$ (Reservoir tops) & 35 \\
\hline $1000 \mathrm{~m}$ & 36 \\
\hline $5300 \mathrm{ft}$ (1616 m) & 40 \\
\hline $800 \mathrm{~m}$ (Reservoir top) & 41 \\
\hline $1000 \mathrm{~m}$ (injection depth) & 57 \\
\hline $1626 \mathrm{~m}$ & 58 \\
\hline $1000-3400 \mathrm{~m}$ & 59 \\
\hline $800-1000 \mathrm{~m}$ & 60 \\
\hline $1100 \mathrm{~m}$ (Reservoir top) & 68 \\
\hline
\end{tabular}




\subsubsection{Pressure Gradient}

Pressure gradients are searched instead of pressure. If the pressure is directly used, abnormal or subnormal pressure aquifers could be simulated. For example, high pressures may be assigned to aquifers at shallow depths or low pressures may be given to aquifers at high depths. Table 4.4 gives the pressure gradient found from the literature. Even though the minimum pressure gradient is $0.427 \mathrm{psi} / \mathrm{ft}$, the minimum pressure gradient is taken 0.44 since the fresh water pressure gradient is $0.433 \mathrm{psi} / \mathrm{ft}$ and maximum pressure gradient is chosen as $0.49 \mathrm{psi} / \mathrm{ft}$.

Table 4.4: Pressure Gradient Data Found From Literature

\begin{tabular}{|c|c|}
\hline Pressure Gradient (psi/ft) & Reference \\
\hline 0.435 & 35 \\
\hline 0.448 & 35 \\
\hline 0.442 & 36 \\
\hline 0.442 & 37 \\
\hline 0.427 & 40 \\
\hline 0.464 & 61 \\
\hline 0.442 & 68 \\
\hline
\end{tabular}

\subsubsection{Geothermal Gradient}

Similar to pressure gradient, temperature gradient is used to calculate the temperature of the aquifers.

Table 4.5: Geothermal Gradient Data Found From Literature

\begin{tabular}{|c|c|}
\hline Geothermal Gradient & Reference \\
\hline $29^{\circ} \mathrm{C} / \mathrm{km}$ & 37 \\
\hline $30^{\circ} \mathrm{C} / \mathrm{km}$ & 36 \\
\hline $30^{\circ} \mathrm{C} / \mathrm{km}$ & 60 \\
\hline $35^{\circ} \mathrm{C} / \mathrm{km}$ & 61 \\
\hline
\end{tabular}


The minimum and maximum temperature gradients are chosen as 29 and 35 ${ }^{\circ} \mathrm{C} / \mathrm{km}$ (Table 4.5).

\subsubsection{Salinity}

Table 4.6 gives the salinity of several deep saline aquifers found from the literature. The largest interval is 20000 ppm to 340000 ppm given in Reference 6.

Table 4.6: Salinity Data Found From Literature

\begin{tabular}{|l|c|}
\hline Salinity & Reference \\
\hline $250 \mathrm{~g} / \mathrm{l}$ & 14 \\
\hline $30 \mathrm{~g} / \mathrm{l}$ & 34 \\
\hline $100000 \mathrm{ppm}$ & 36 \\
\hline $32000 \mathrm{ppm}$ & 37 \\
\hline $100000 \mathrm{ppm}$ & 40 \\
\hline $3.0 \mathrm{wt} \%$ & 41 \\
\hline $200-400 \mathrm{mg} / \mathrm{l}$ & 56 \\
\hline $278000-320000 \mathrm{mg} / \mathrm{kg}$ & 57 \\
\hline $27096 \mathrm{ppm}$ & 58 \\
\hline $20000-340000 \mathrm{ppm}$ & 59 \\
\hline
\end{tabular}

The unit ppm means the part per million in weights, milligram per kilogram. Salinities are entered as weight percent and 20000 ppm and 340000 ppm are 0.02 to 0.34 in weight percent, respectively. However; to use the internal water viscosity table of the STARS, the range is chosen as 0 to 0.26 .

\subsubsection{Relative Permeability}

Relative permeability is calculated using the Corey power law relative permeability method assuming the $\mathrm{CO}_{2}$-water drainage curves. To calculate the gas-water relative permeability curves, the end points of the water and 
gas relative permeability curves, and Corey water and Corey gas exponents, and irreducible water saturation are needed. Table 4.7 gives gas relative permeability end points, irreducible water saturations, and the Corey exponents of water and gas obtained from laboratory experiments [59]. Table 4.8 also gives the irreducible water saturations and gas relative end points obtained from literature.

Table 4.7: Relative Permeability Characteristics [59]

\begin{tabular}{|l|l|c|c|c|c|}
\hline Rock Sample & Formation & Krg (end point) & Swirr & Corey Water & Corey Gas \\
\hline Cardium \#1 & Sandstone & 0.526 & 0.197 & 1.3 & 1.7 \\
\hline Cardium \#2 & Sandstone & 0.129 & 0.425 & 1.2 & 1.3 \\
\hline Viking \#1 & Sandstone & 0.3319 & 0.558 & 2.9 & 3.2 \\
\hline Viking \#2 & Sandstone & 0.2638 & 0.423 & 1.7 & 2.8 \\
\hline Ellerslie & Sandstone & 0.1156 & 0.659 & 2.1 & 2.2 \\
\hline Wabamun \#1 & Carbonate & 0.5289 & 0.595 & 1.4 & 5.6 \\
\hline Wabamun \#2 & Carbonate & 0.1883 & 0.569 & 1.4 & 2.1 \\
\hline Nisku \#1 & Carbonate & 0.1768 & 0.33 & 2.8 & 1.1 \\
\hline Nisku \#2 & Carbonate & 0.0999 & 0.492 & 2.7 & 4.6 \\
\hline Cooking Lake & Carbonate & 0.0685 & 0.476 & 1.4 & 5.6 \\
\hline Basal Cambrian & Carbonate & 0.5446 & 0.294 & 1.8 & 5.0 \\
\hline
\end{tabular}

Table 4.8: Irreducible Water Saturation and Gas Relative Permeability End Points

\begin{tabular}{|l|l|c|}
\hline \multicolumn{1}{|c|}{ Swirr } & \multicolumn{1}{|c|}{ krg (end point) } & Reference \\
\hline $0.628,0.276,0.194,0.161,0.145,0.137$ & $0.13,0.52,0.62,0.68,0.70,0.71$ & 40 \\
\hline $0.379,0.271,0.197$ & $0.2978,0.4557,0.5260$ & 58 \\
\hline $0.1,0.2,0.3$ & $0.11,0.20,0.30$ & 60 \\
\hline
\end{tabular}

According to STARS software, water relative permeability end point has to be 1 since the formation is aquifer. The range of Corey exponents of water and gas are taken as 1 to 6 considering Corey exponents for both sandstone and carbonate formations due to insufficient data. 0.1 to 0.5 and 0.1 to 1 are chosen for irreducible water saturation and gas relative permeability end point, respectively. 


\subsubsection{Kozeny-Carman Coefficient}

Kozeny-Carman Coefficient describes the relationship between porosity and permeability. It determines the permeability change due to porosity change resulted from chemical precipitation and dissolution reactions. The range of Kozeny-Carman coefficient is 0 to 12 . However; the range is chosen as 0 to 10 due to STARS limitation.

\subsubsection{0. $\mathrm{CO}_{2}-$ Water Diffusion Coefficient}

The range of diffusion coefficient of $\mathrm{CO}_{2}$ in water $\left(D_{\mathrm{CO} 2}\right)$ is taken large since there is little data of $\mathrm{CO}_{2}$ diffusion in water at high pressures and temperatures.

Table 4.9: Diffusion Coefficient of $\mathrm{CO}_{2}$ in Water [62]

\begin{tabular}{|c|c|c|}
\hline Water Temperature $\odot$ & $\mathbf{C O}_{2}$ Pressure (bar) & $\mathbf{D}_{\mathbf{C O 2}}\left(\mathbf{m}^{2} / \mathbf{s}\right)$ \\
\hline 40 & 30 & $7.20 \mathrm{E}-10$ \\
\hline 40 & 40 & $4.70 \mathrm{E}-10$ \\
\hline 40 & 50 & $1.10 \mathrm{E}-09$ \\
\hline 40 & 60 & $1.50 \mathrm{E}-09$ \\
\hline 40 & 70 & $1.70 \mathrm{E}-09$ \\
\hline 40 & 80 & $1.80 \mathrm{E}-09$ \\
\hline 40 & 90 & $1.30 \mathrm{E}-09$ \\
\hline 20 & 1 & $1.85 \mathrm{E}-09$ \\
\hline 13 & $294-392$ & $1.30 \mathrm{E}-09$ \\
\hline
\end{tabular}

Table 4.9 gives the diffusion coefficients obtained from literature. There is no trend between diffusion coefficient of $\mathrm{CO}_{2}$ in water and pressure. The lowest diffusion coefficient is assumed to be zero assuming no diffusion and the maximum diffusion coefficient is $0.005 \mathrm{ft}^{2} /$ day $\left(5.34 \mathrm{E}-09 \mathrm{~m}^{2} / \mathrm{s}\right)$. 


\subsubsection{Reaction Rates}

There is no published literature data for the reaction rates; therefore, trial and error procedure is used to determine the forward and backward reaction rate ranges. The interval of 0 to $4001 /$ day is chosen for the reaction rates.

\subsubsection{Formation Dip}

Most of the studies are related to horizontal formations having dip 0. Ozah et al. [40] studied the effect of the dip on storage potential. They assumed that deep angle is 0,1 and 5 . As it can be seen from these data, formations can have very low dip angle, so dip angle interval is chosen as 0 to 6.

\subsection{Latin Hypercube Space Filling Design}

Table 4.10 gives the input variables and their range used in simulation runs. There are 16 variables used in this study. To cover whole range of each variable, three values should be taken in order to define trend of a variable properly. These are lower limit, upper limit and middle value. To consider all possibilities, factorial design method should be used where the number of cases is equal to $3^{16}$. To decrease the number of the cases, two values are chosen for each variable, lower limit and upper limit. In this situation, the number of cases is $2^{16}$.

In order to define each variable interval sufficiently and decrease the number of cases, Design of Experiment method is used. Since the main aim is to cover whole space created by the variables, the Space Filling Design is used and to obtain maximum uniformity Latin Hypercube Sampling Method is chosen. 
Table 4.10: Input Variables Used in the Study

\begin{tabular}{|l|c|c|}
\hline Variable & Lower Limit & Upper Limit \\
\hline Porosity $(\%)$ & 1 & 25 \\
\hline Permeability (mD) & 1 & 2000 \\
\hline $\mathrm{k}_{\text {vertical }} / \mathrm{k}_{\text {horizontal }}$ & 0.001 & 1 \\
\hline Depth $(\mathrm{m})$ & 1000 & 3400 \\
\hline Pressure Gradient ( psi/ft) & 0.44 & 0.49 \\
\hline Geothermal Gradient $\left({ }^{\circ} \mathrm{C} / \mathrm{km}\right)$ & 29 & 35 \\
\hline Salinity (weight fraction) & 0 & 0.26 \\
\hline Swirr (fraction) & 0.1 & 0.5 \\
\hline krg (end point) & 0.1 & 1 \\
\hline Corey Water Exponent & 1 & 6 \\
\hline Corey Gas Exponent & 1 & 6 \\
\hline Kozeny-Carman Coefficient & 0 & 10 \\
\hline Diffusion Coefficient (ft ${ }^{2} /$ day) & 0 & 0.005 \\
\hline Forward Reaction Rate (1/day) & 0 & 400 \\
\hline Backward Reaction Rate (1/day) & 0 & 400 \\
\hline Formation Dip (degree) & 0 & 6 \\
\hline
\end{tabular}

Space Filling Design and Latin Hypercube Sampling Methods are discussed in the theory part. This design is prepared with JMP software. In this method, variables are entered as continuous variables and according to Latin Hypercube Sampling, variable ranges are divided into number of cases. In each interval a random number is chosen so that each interval probability is equal to one over the case number.

For the space filling design, variables should be orthogonal; however, some variables in the simulation depend on others. For example, pressure and temperature depend on depth, and vertical permeability is related to the permeability of the formation. To eliminate this dependency in the design, pressure gradient and temperature gradient, rather than pressure and temperature, are used so that abnormal situations like high pressures at low depths and low pressures at high depths are prevented. Also, the ratio of vertical permeability to horizontal permeability is entered instead of vertical permeability. 
Using Eqn. 2.27 and 16 variables, 17 cases are enough to determine the unknowns of the linear predictive model if the design is orthogonal. Two important characteristics of space filling design should be checked. The first characteristic is space filling property from discrepancy and the second characteristic is orthogonality from the correlation coefficient.

For space filling property of the design, cases are prepared and discrepancy and Euclidean maximum minimum distance are checked. Discrepancy shows the integrated difference between the design points and the uniform distribution. If the discrepancy is 0 , perfect space filling property is obtained. If the discrepancy is close to 1 , then there are too few or too many data in the variable space. Table 4.11 shows the design case number and the corresponding design discrepancy values.

As can be seen from the Table 4.11, as the number of cases increases, the discrepancy decreases, which means the space filling property is getting better. The number of cases is chosen as 100 in order to minimize the number of simulations.

Table 4.11: Design Case Number vs. Design Discrepancy

\begin{tabular}{|c|c|}
\hline Case Number & Discrepancy \\
\hline 20 & 1.2392 \\
\hline 30 & 0.7479 \\
\hline 40 & 0.5423 \\
\hline 50 & 0.4220 \\
\hline 60 & 0.3351 \\
\hline 70 & 0.2796 \\
\hline 80 & 0.2563 \\
\hline 90 & 0.2162 \\
\hline 100 & 0.1941 \\
\hline 110 & 0.1727 \\
\hline 120 & 0.1541 \\
\hline 130 & 0.1441 \\
\hline 140 & 0.1317 \\
\hline 150 & 0.1222 \\
\hline
\end{tabular}


JMP software normalizes the variables between 0 and 1 , and normalized range is divided into number of cases intervals. The design points are chosen randomly in each interval and then points are converted back to their original range. Discrepancy changes with each design due to random selection of design points. For this reason, 8 designs are prepared to find the best design. Table 4.12 shows the design trial number and the corresponding discrepancy number. The sixth design which results in the smallest discrepancy is chosen for this study.

Table 4.12: Discrepancy Change with Design

\begin{tabular}{|c|c|}
\hline Trial Number & Discrepancy \\
\hline 1 & 0.1941 \\
\hline 2 & 0.1916 \\
\hline 3 & 0.1928 \\
\hline 4 & 0.1914 \\
\hline 5 & 0.1925 \\
\hline 6 & 0.1868 \\
\hline 7 & 0.1900 \\
\hline 8 & 0.1962 \\
\hline
\end{tabular}

One of the most important properties of the Latin Hypercube Design is that it mimics the uniform distribution of variables. Figure 4.2 gives the distribution of porosity and its quantiles as an example. The horizontal axis gives the data range and number of count is stated at the above of the each bar. The other distributions of variables are given in Appendix B.

Figure 4.3 shows the distribution of the correlation coefficients between the variables. The minimum and maximum correlation coefficients are -0.1375 between salinity and geothermal gradient and 0.1825 between irreducible water saturation and pressure gradient, respectively. All correlation coefficients between variables (Appendix $A$ ) are close to 0 , which means that each variable is independent of the others. This shows that the design is nearly orthogonal. 


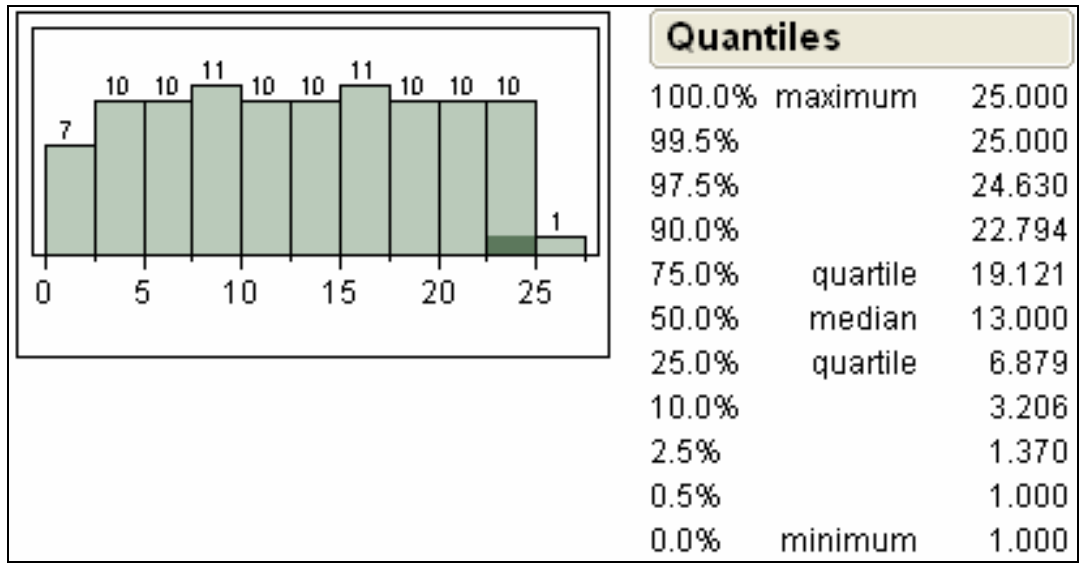

Figure 4.2: Porosity (\%) Design Data Distribution

The space filling property is also checked with the projected distribution of the variables. Figure 4.4 gives the projected distribution of porosity and permeability as an example. Other projected distributions are given in Appendix C.

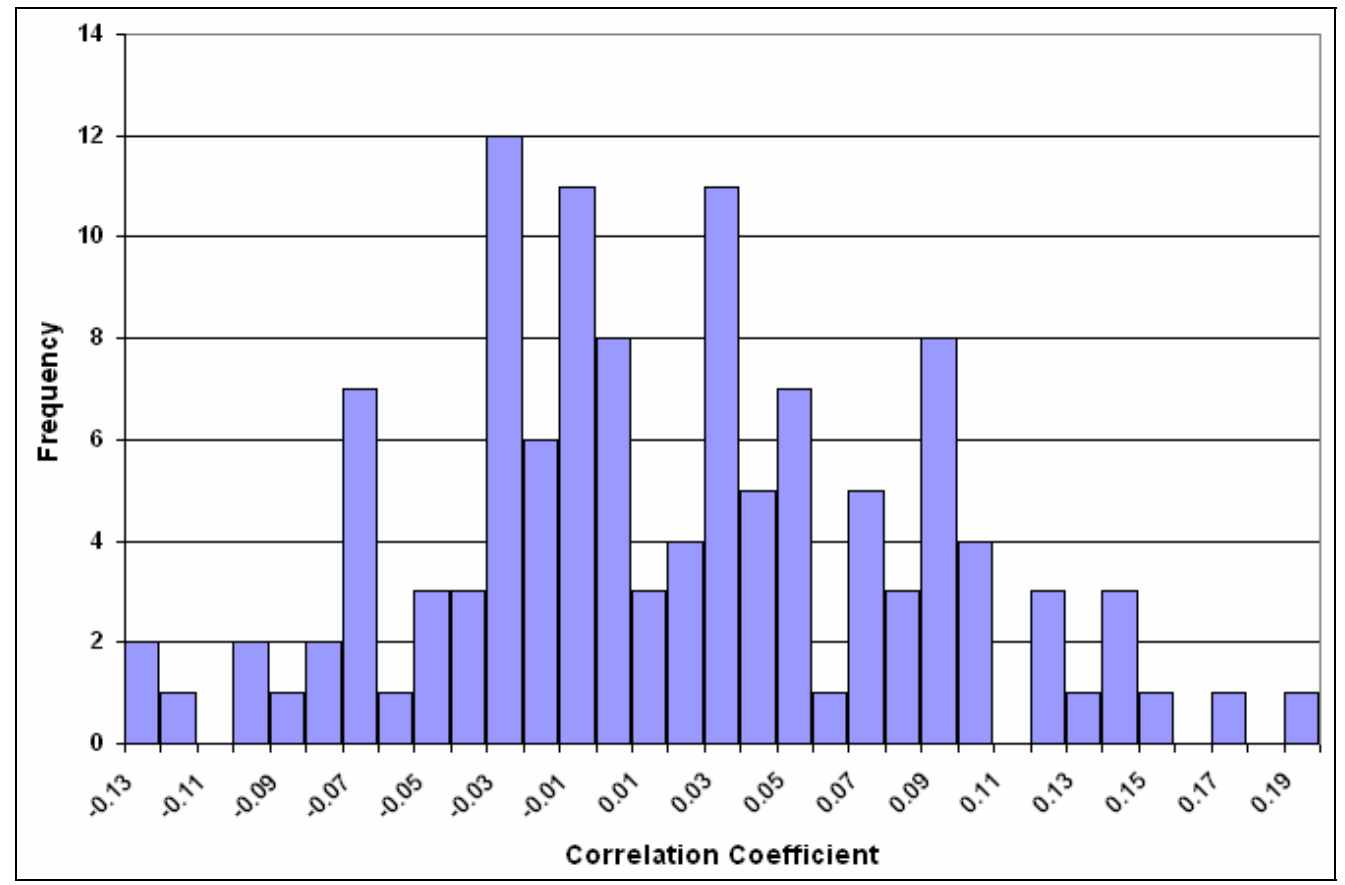

Figure 4.3: Correlation Coefficient Distribution 


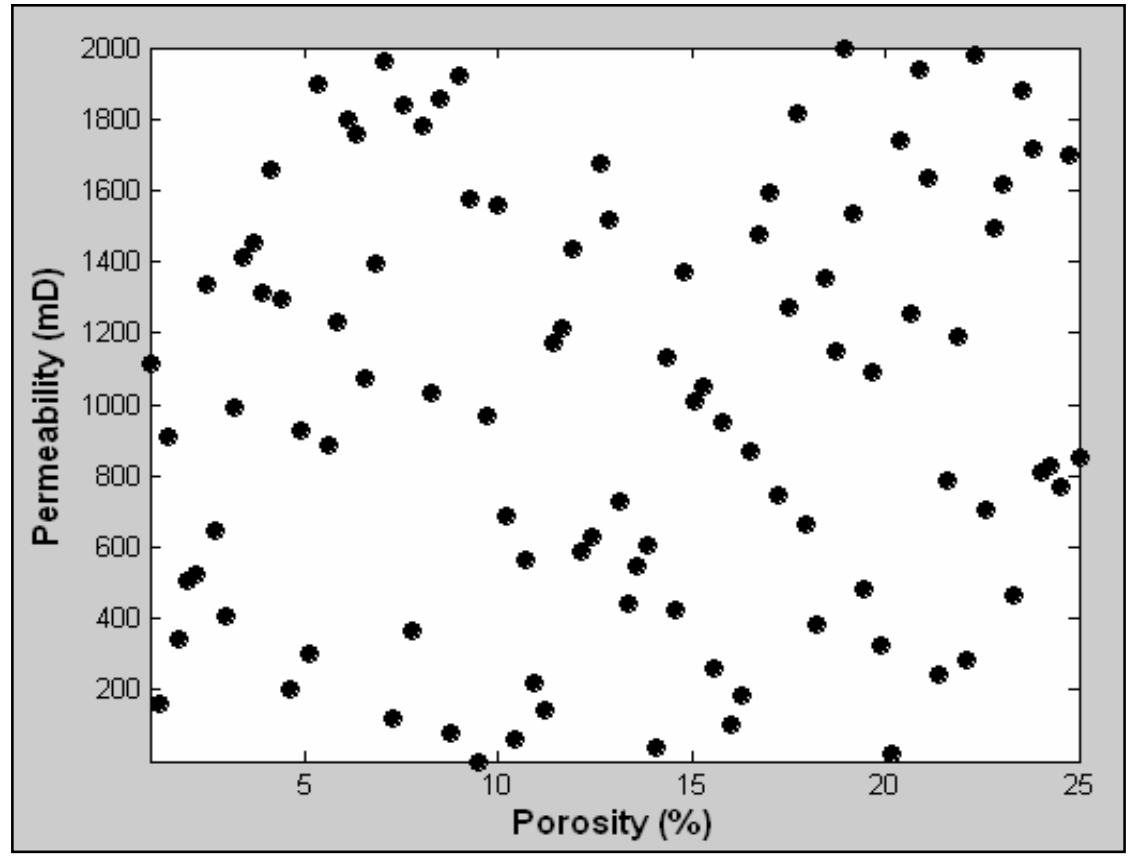

Figure 4.4: Porosity vs. Permeability Projected Distribution

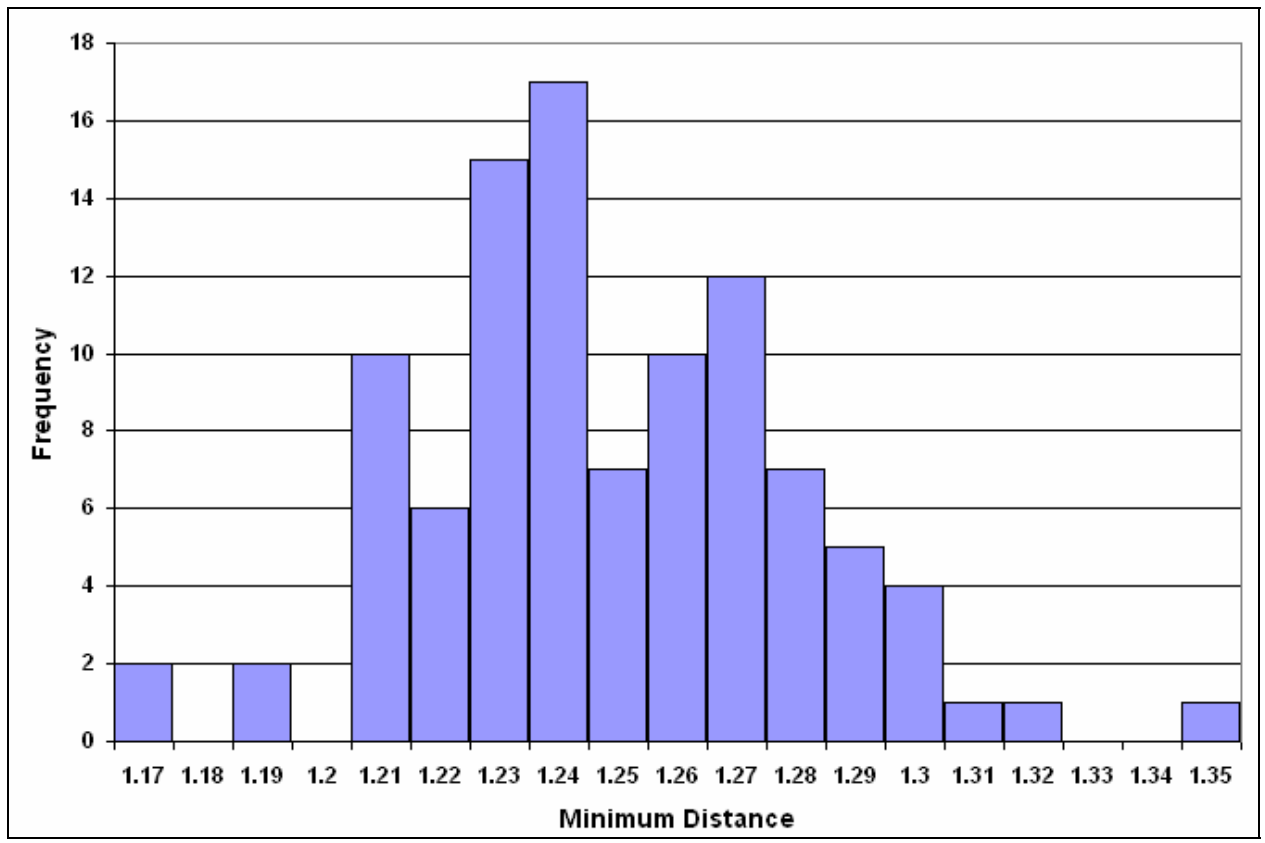

Figure 4.5: Euclidean Maximum Minimum Distance Distribution 
Figure 4.5 shows the distribution of the Euclidean maximum minimum distance of the normalized design points. These distances change between 1.168 and 1.342. The design can be said to be good since the distance between points are close.

100 cases guarantee that the space filling property in the case of some simulation stop due to the convergence problem of matrix solution or other reason.

\subsection{Simulation Model}

\subsubsection{Input-Output Control}

At the start of the file data, the project name is defined with *TITLE keywords. There are three units in the program, SI, Field and Lab unit systems. For this study, Field unit is selected for the input and output data.

The maximum number of error messages before the simulation terminates is chosen as 20. To determine whether the input data is within the expected range or not, ${ }^{*}$ RANGECHECK *ON keyword is used.

The frequency of the writing to the out print file is adjusted with *WPRN keyword and it is specified in the recurrent data section using the ${ }^{*} \mathrm{TIME}$ keyword. Information written to the output file and Simulation Results File are controlled with *OUTPRN and ${ }^{*}$ OUTSRF keywords. All grid properties are written to these files with ${ }^{*} \mathrm{GRID}{ }^{*} \mathrm{ALL}$ keywords. Grid arrays are written to the output file in standard order with *PRNTORIEN 11 keyword so that the data in the output file can be easily copied for other file if needed. 


\subsubsection{Aquifer Description}

There are two types of gridding in the STARS, namely rectangular Cartesian grid and radial-angular grid. In this study rectangular Cartesian grid is chosen with *GRID *CART option. Since CMG STARS license is educational, the grid number is limited and it should be less than 10000 . That is why hypothetical aquifers created during this study contain 9522 grids, 23 grids in $x$ and $y$ direction and 18 grids in $z$ direction. The grid dimensions are $250 \mathrm{ft}$ in $x$ and $y$ direction and $50 \mathrm{ft}$ in $z$ direction except outer grids. Their dimensions are $50 \mathrm{ft}$ in all direction. These grids are used to create closed boundary by assigning their transmissibilities and porosities to 0 .

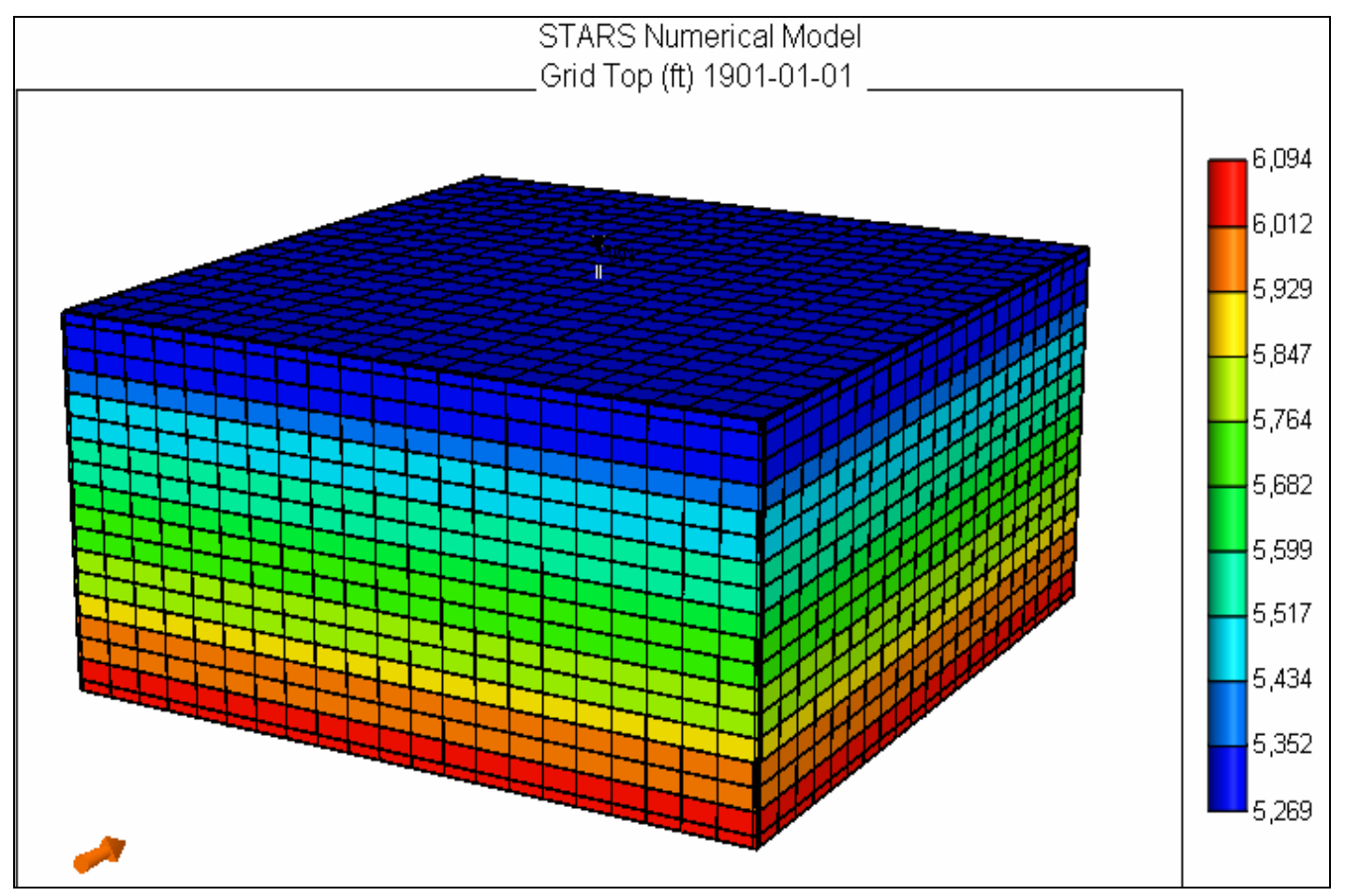

Figure 4.6: Reservoir Appearance 
Aquifer layers are ordered in increasing order starting from the top of the reservoir by pointing the $\mathrm{K}$ direction down with *KDIR *DOWN keywords.

The aquifer is assumed to be inclined in the $x$ direction only. The depth of the aquifer is defined with ${ }^{*}$ DEPTH ${ }^{*}$ TOP option since the aquifer is inclined. Reference grid block should be given to define aquifer top. For this aquifer, the reference grid block is the first grid block (index of 1, 1, and 1). The aquifer is homogenous and porosity and permeability of the grid blocks are constant. The anisotropy exists only horizontal and vertical directions; therefore, permeability in $\mathrm{x}$ and $\mathrm{y}$ directions are equal or greater than the one in $\mathrm{z}$ direction.

Transmissibility multiplier is chosen as default (1) for inner grid blocks and in order to prevent flow outer grid blocks, the transmissibility multiplier in all direction for these grid blocks is chosen as zero. Also, porosities are taken as zero for these blocks in order to prevent diffusion.

\subsubsection{Other Aquifer Properties}

Only one rock type, carbonate, is chosen for this study. The effective formation compressibility of the pore space is calculated from the modified Horne's model formula (Eqn. 4.1) proposed by Motulsky and Christpoulos (2003, as cited in Jalalh, A. A. in 2006) for limestone as a function of porosity. Figure 4.7 shows the comparison of the published limestone pore volume compressibility data with modified Horne curve [63].

$$
C_{p c-\text { mod-limestone }}=\exp \left(3.9952-33.933 \phi+98.04 \phi^{2}\right) \times 10^{-6} \quad 1 / p s i
$$




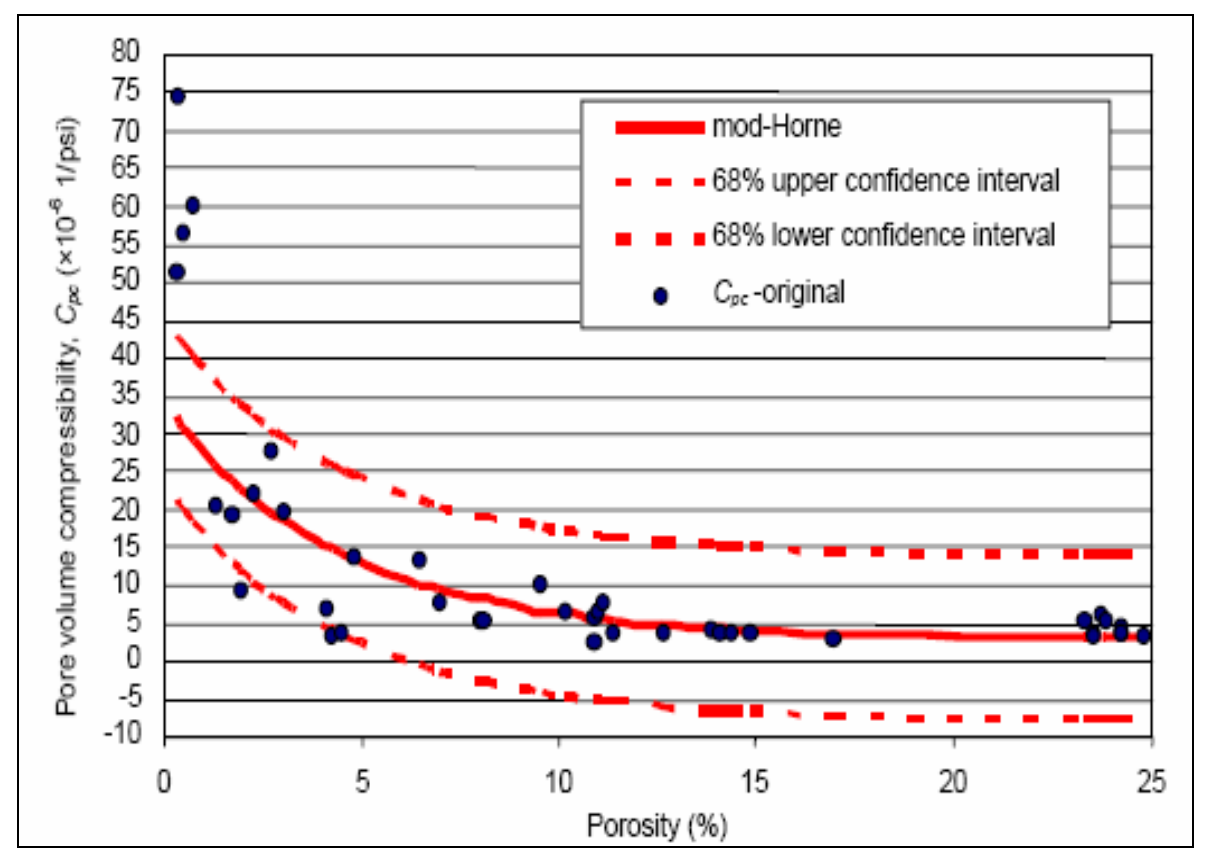

Figure 4.7: Pore Volume Compressibility from the Literature and Mod-Horne Curve [63]

Permeability and porosity relation can be defined with Kozeny correlation [64] given in Eqn. 4.2.

$$
k=A_{1} \frac{\phi^{3}}{S^{2}}
$$

where $S$ and $A_{1}$ are the surface area per unit bulk volume and an empirical constant known as Kozeny constant. This equation can also be written as;

$k=A_{1} \frac{\phi^{3}}{\left(1-\phi^{2}\right)^{2} S_{o}^{2}}$

where $S_{o}$ is the surface area per unit volume of solid material. In this study, initial porosity and permeability are taken as independent; however, the change in permeability with porosity change due to dissolution and precipitation is expressed with Kozeny-Carman type formula given in Eqn. 4.4 . 
$k(\phi)=k_{o}\left(\frac{\phi}{\phi_{o}}\right)^{c}\left(\frac{1-\phi_{o}}{1-\phi}\right)^{2}$

$k_{0}$ and $\phi_{0}$ are the initial permeability and porosity entered the program, while $k$ and $\phi$ are the permeability and porosity at the specific time step. $c$ is the Kozeny-Carman coefficient.

The thermal expansion coefficient, $\alpha$ defined by Eqn. 4.5 is used to express the volume change of formation due to a temperature change. The thermal expansion of calcite is $0.00000381 /{ }^{\circ} \mathrm{C}(0.000002111 / \mathrm{F})$ [65].

$\alpha=\frac{1}{V}\left(\frac{\partial V}{\partial T}\right)_{P}$

The density of the limestone changes between 167 to $171 \mathrm{lb} / \mathrm{ft}^{3}$ and it is taken as $170 \mathrm{lb} / \mathrm{ft}^{3}$ for the volumetric heat capacity calculation. Volumetric heat capacity is equal to density times specific heat capacity of the aquifer $(0.2$ $\mathrm{Btu} / \mathrm{lbm}-\mathrm{F})$. The volumetric heat capacity of the aquifer is equal to $34 \mathrm{Btu} / \mathrm{ft}^{3}-\mathrm{F}$ [66].

Heat losses to the outer grid blocks at the aquifer top and bottom are defined with *HLOSSPROP *OVERBUR/*UNDERBURN keywords. Default volumetric heat capacity and thermal conductivity of the formation adjacent to the aquifer are taken as $35 \mathrm{Btu} / \mathrm{ft}^{3}-\mathrm{F}$ and $24 \mathrm{Btu} / \mathrm{ft}-$ day- $\mathrm{F}$, respectively.

The thermal conductivity $(\lambda)$ of the aquifer rock is calculated as a function of temperature with the Equation proposed by Zoth \& Hänel (1998) [67].

$$
\lambda(T)=A+\frac{B}{350+T}
$$

where $\lambda$ is given in $\mathrm{W} / \mathrm{m}-\mathrm{K}, T$ in ${ }^{\circ} \mathrm{C}$, and the empirical constants, $A$ and $B$, obtained from a least square methods for different rocks are given in Table 4.13 . 
Table 4.13: Constants $A$ and $B$ for Equation 4.6 for different rock types [67]

\begin{tabular}{|l|l|l|l|}
\hline Rock Type & T $\odot$ & A & B \\
\hline Rock salt & $-20-40$ & -2.11 & 2960 \\
\hline Limestone & $0-500$ & 0.13 & 1073 \\
\hline Metamorphic rocks & $0-1200$ & 0.75 & 705 \\
\hline Acid rocks & $0-1400$ & 0.64 & 807 \\
\hline Basic rocks & $50-1100$ & 1.18 & 474 \\
\hline Ultra-basic-rocks & $20-1400$ & 0.73 & 1293 \\
\hline All rock type (except salt) & $0-800$ & 0.7 & 770 \\
\hline
\end{tabular}

The temperature range of limestone given in Table 4.13 is suitable for this study. The thermal conductivity of the aquifer rock at reference temperature, $25^{\circ} \mathrm{C}$, is $2.9913 \mathrm{~W} / \mathrm{m}-\mathrm{K}(41.4807 \mathrm{Btu} / \mathrm{ft}-$ day- $\mathrm{F})$. Thermal conductivity of the water and $\mathrm{CO}_{2}$ are $0.6 \mathrm{~W} / \mathrm{m}-\mathrm{K}(8.3202 \mathrm{Btu} / \mathrm{ft}-$ day-F) [67] and $0.08 \mathrm{~W} / \mathrm{m}-\mathrm{K}$ (8.3202 Btu/ft-day-F) [66], respectively.

Volume-weighted phase mixing thermal conductivity is calculated with Eqn.4.7.

$\kappa_{\text {mix }}=\phi_{f}\left(\kappa_{w} S_{w}+\kappa_{o} S_{o}+\kappa_{g} S_{g}\right)+\left(1-\phi_{v}\right) \kappa_{r}+\left(\phi_{v}-\phi_{f}\right) \kappa_{s}$

$\kappa_{w}, \kappa_{o}, \kappa_{g}, \kappa_{r}, \kappa_{s}$ are thermal conductivity of water, oil, gas, rock, and solid, respectively. $\phi_{f}$ and $\phi_{v}$ are fluid porosity and void porosity, respectively.

\subsubsection{Component Properties}

The formation is assumed to be composed of carbonate only and in the aquifer, there are 5 components, namely, water, $\mathrm{CO}_{2}, \mathrm{CaCO}_{3}, \mathrm{Ca}\left(\mathrm{HCO}_{3}\right)_{2}$ and $\mathrm{NaCl}$. These components are entered to the software with ${ }^{*} \mathrm{MODEL}$ keyword in appropriate order. $\mathrm{CO}_{2}$ is defined as gas although it is in super 
critical state and $\mathrm{CaCO}_{3}, \mathrm{Ca}\left(\mathrm{HCO}_{3}\right)_{2}$ and $\mathrm{NaCl}$ are defined as solid dissolved in aqueous phase (water).

In compositional models, the phase equilibrium is specified via phase equilibrium ratios, $K$-value. $K$ value is function of gas phase pressure, $P$ and temperature, $T$ given in Eqn. 4.8.

$K=(k v 1 / P+k v 2 P+k v 3) \exp (k v 4 /(T-k v 5))$

$k v 1, k v 2, k v 3, k v 4$ and $k v 5$ are coefficients of the gas-liquid $K$ value and specified as,

$K_{i}^{g w}=\frac{y_{i}}{w_{i}} \quad K_{i}^{g o}=\frac{y_{i}}{x_{i}} \quad K_{i}^{o w}=\frac{x_{i}}{w_{i}}$

where $y, w$ and $x$ are the mole fractions of gas, water and oil fraction, respectively.

In this study, only $K_{i}^{g w}$ is defined since there is no oil in the reservoir and to use internal water $K$ values, all coefficients are assigned 0.

For all components, molecular weight is entered. For water and $\mathrm{CO}_{2}$ critical temperature $\left(T_{c}\right)$ and critical pressure $\left(P_{c}\right)$ are entered for gas compressibility factor, $Z$ and vaporization enthalpy calculation. $Z$ factor is calculated with Redlich-Kwong EOS with zero interaction coefficient given below.

$Z^{3}-Z^{2}+\left(A-B^{2}-B\right) Z-A B=0$

where $A=0.427480\left(P / P_{c}\right)\left(T / T_{c}\right)^{2.5}$

$$
B=0.086640\left(P / P_{c}\right)\left(T_{c} / T\right)
$$

Reference pressure at which densities are entered and reference temperature for temperature dependent properties calculations are chosen 
as 14.7 psia and $25^{\circ} \mathrm{C}$. Surface temperature and pressure are determined as $20{ }^{\circ} \mathrm{C}$ and 14.7 psia.

Gas heat capacity correlation coefficients, cpg1, cpg2, cpg3 and cpg 4 , and first coefficient of vaporization enthalpy correlation, $h v r$, are entered for the water and $\mathrm{CO}_{2}$ and second coefficient of vaporization enthalpy correlation (ev), the program default value, 0.38 is used. Gas heat capacity and vaporization enthalpy are calculated with the Eqn. 4.13 -4.14, respectively.

$C P G(T)=c p g 1+\operatorname{cpg} 2 \times T+\operatorname{cpg} 3 \times T^{2}+\operatorname{cpg} 4 \times T^{3}$

$\operatorname{HVAP}(T)=h v r\left(T_{c}-T\right)^{e v}$

The component vapor enthalpy at any specified temperature, $H G(T)$, is the integral of $C P G(T)$ from reference temperature, $T_{r}$ to $T$. Liquid enthalpy, $H L(T)$ is calculated with Eqn. 4.15.

$H L(T)=H G(T)-H V A P(T)$

Solid densities are entered at reference pressure, $P_{r}$, and reference temperature, $\mathrm{T}_{r}$, for $\mathrm{CaCO}_{3}, \mathrm{Ca}\left(\mathrm{HCO}_{3}\right)_{2}$ and $\mathrm{NaCl}$ as 169.24, 132.02 and $136 \mathrm{lb} / \mathrm{ft}^{3}$, respectively. Solid density of component $k$ is calculated at specific pressure, $P$ and temperature, $T$ with Eqn. 4.16.

$\rho_{s k}(T, P)=\rho_{k 0} \exp \left[c p\left(P-P_{r}\right)-c t\left(T-T_{r}\right)+\operatorname{cpt}\left(P-P_{r}\right)\left(T-T_{r}\right)\right]$

where $c p, c t$ and $c p t$ are compressibility at constant temperature, thermal expansivity at constant pressure and pressure-temperature cross term for density. These factors are taken 0 , corresponding to constant solid densities. Mass density of the of the formation water is calculated by the Eqn. 4.17 4.18 presented by Batzle and Wang (1992) which is valid for temperatures between 20 and $30{ }^{\circ} \mathrm{C}$, pressures between 5 and $100 \mathrm{MPa}$ and salinities up to $320000 \mathrm{mg} / \mathrm{l}[44]$. 


$$
\begin{aligned}
& \rho_{w}=1+1 \times 10^{-6}\left(\begin{array}{l}
-80 T-3.3 T^{2}+0.00175 T^{3}+489 P-2 P T+0.016 T^{2} P \\
-1.3 \times 10^{-5} T^{3} P-0.333 P^{2}-0.002 T P^{2}
\end{array}\right) \\
& \rho_{b}=\rho_{w}+S\left\{-0.668+0.44 S+1 \times 10^{-6}\left(\begin{array}{l}
300 P-2400 P S \\
+T(80-3 T-3300 S-13 P+47 P S)
\end{array}\right)\right\}
\end{aligned}
$$

where $T$ is temperature in ${ }^{\circ} \mathrm{C}, P$ is pressure in $\mathrm{MPa}, S$ is salinity in mass fraction $\left(\mathrm{ppm} / 10^{6}\right)$ and $\rho_{w}$ and $\rho_{b}$ are fresh water and brine density values, respectively, in $\mathrm{g} / \mathrm{cm}^{3}$.

STARS calculates the pure component density of water, $\rho_{w i}$ from Eqn. 4.19 as a function of $P$ and $T$.

$$
\rho_{w i}(P, T)=\rho_{w i}^{0} \exp \left[a\left(P-P_{r}\right)-b\left(T-T_{r}\right)-\frac{1}{2} c\left(T^{2}-T_{r}^{2}\right)\right]
$$

where $a$ is compressibility, $b+c T$ is the thermal expansion coefficient as a function of temperature and $\rho_{w i}^{0}$ is the density of the water at reference pressure, $P_{r}$ and reference temperature, $T_{r}$.

The linear mixing rule (Eqn. 4.20) is used to calculate the liquid densities when $\mathrm{CO}_{2}$ dissolves in liquid.

$$
V=\sum V(i) \times X(i)
$$

where $V, V(i)$ and $X(i)$ are molar volume of phase (inverse of phase mole density), partial molar volume of component $i$ in the phase and mole fraction of component $i$ in the phase, respectively. 
Gas phase density is calculated implicitly with Eqn. 4.21 after the calculation of the compressibility of gas, $Z$ from Redlich-Kwong EOS with zero interaction coefficients.

$\rho_{g}=P / R T Z$

For gas viscosity calculation, composition-independent internal gas viscosity correlation (Eqn. 4.22) is used.

$\mu_{g}=(0.00864 c p)(1.574+0.0044 T)$

Liquid viscosity, viso can be calculated with the correlation (Eqn. 4.23) and avisc and bvisc are taken from the CMG help manual.

$\operatorname{viso}(i)=\operatorname{avisc}(i) \exp [\operatorname{bvisc}(i) / T]$

For water, the coefficients of avisc and bvisc are taken as 0 in order to use internal water viscosity option derived from the SPE monograph "Pressure Buildup and Flow Tests in Wells" by C.S. Matthews and D.G. Russell (1967) [53].

To define the equilibrium, two reactions are entered.

$\mathrm{CO}_{2}+\mathrm{H}_{2} \mathrm{O}+\mathrm{CaCO}_{3} \Rightarrow \mathrm{Ca}\left(\mathrm{HCO}_{3}\right)_{2}$

$\mathrm{Ca}\left(\mathrm{HCO}_{3}\right)_{2} \Rightarrow \mathrm{CO}_{2}+\mathrm{H}_{2} \mathrm{O}+\mathrm{CaCO}_{3}$

Each reaction stoichiometric coefficient of reacting components (sto1) and produced components (sto2) and reaction frequency factor $\left(r_{r k}\right)$ are entered with *STOREAC, *STOPROD and *FREQFAC, respectively. The STARS checks the mass balance using the entered molecular weight (CMM) and stoichiometric coefficients of the reacting and produced components (Eqn. 4.26).

$\sum C M M(i) \operatorname{sto1}(i)=\sum C M M(i) \operatorname{sto} 2(i)$ 
Also, for each reaction, the reaction enthalpy and activation energy $\left(E_{a k}\right)$ are taken as 0 . Phase of the components in the reaction are defined with *RPHASE keyword entering 1 for water phase, $\mathrm{H}_{2} \mathrm{O}, 3$ for gas phase, $\mathrm{CO}_{2}$ and 4 for solid phases, $\mathrm{CaCO}_{3}, \mathrm{Ca}\left(\mathrm{HCO}_{3}\right)_{2}$ and $\mathrm{NaCl}$. Concentration dependency of the reaction is defined with *RORDER keyword, 0 is entered for the component not affecting the reaction rate, $\mathrm{CaCO}_{3}$, and 1 is entered for the component affecting the reaction rate, $\mathrm{H}_{2} \mathrm{O}, \mathrm{CO}_{2}, \mathrm{Ca}\left(\mathrm{HCO}_{3}\right)_{2}$ and $\mathrm{NaCl}$. *O2CONC keyword is entered to indicate that mole density of the gas component is used in the reaction rate expression; therefore, the unit of the constant part of the reaction rate expression $\left(r_{r k}\right)$ is $1 /$ day. Reaction rate, $r k$, is given in Eqn. 4.27.

$r k=r_{r k} \exp \left(\frac{-E_{a k}}{R T}\right) \prod_{i=1}^{n c} C_{i}$

where $C_{i}$ is the solid concentration of the reacting component can be defined as multiplication of void porosity $\left(\phi_{v}\right)$ by concentration of component $i\left(c_{i}\right)$.

\subsubsection{Rock-Fluid Data}

Rock-fluid data is entered in this part of the program, start with *ROCK FLUID keyword. Only one rock type is defined for the aquifer, limestone. Default wettability option, "WATWET, is used, which means water phase is next to the rock and other phases are located in the middle of the pore space if exist. In this study, the formation is aquifer; therefore, only formation water exists in the pore spaces. *STONE2 keyword is entered so that three-phase relative permeability curves are calculated according to Stone's second model. In this model, the water and gas relative permeabilities are assumed to be functions only of their own saturations and oil permeabilities are 
calculated by using the two phase relative permeabilities, water-oil and gasoil, from the Eqn. 4.28 given below.

$k_{r o}=\left(k_{r o(w)}+k_{r o(w i)} k_{r w(o)}\right)\left(k_{r o(g)}+k_{r o(w i)} k_{r g(o)}\right)-k_{r o(w i)}\left(k_{r w(o)}+k_{r g(o)}\right)$

where $k_{r o(w i)}$ is the oil relative permeability measured at irreducible water saturation with no gas present, $k_{r o(w)}$ and $k_{r o(g)}$ are the oil relative permabilities calculated at $S_{o}=1-S_{w}$ and $S_{o}=1-S_{g}-S_{w i}$, respectively. $k_{r w(o)}$ and $k_{r g(o)}$ are water and gas relative permeabilities at two phase water-oil and oil-gas systems [53].

In this study, there is no oil in the formation and two phase relative permeability curves are calculated with Corey power law model as a function of normalized saturation, $S$. The power law permeability and normalized saturation are given by the following Equations.

$S=\frac{\left(S_{w}-S_{w i}\right)}{\left(1-S_{g r}-S_{w i}\right)}$

$k_{r w}(S)=k_{r w}^{o} S^{n w}$

$k_{r g}(S)=k_{r g}^{o}(1-S)^{n g}$

where $k_{r w}^{o}$ and $k_{r g}^{o}$ are the end points of the relative permeability curves and $n w$ and $n g$ are the Corey water and Corey gas coefficients. Figure 4.8 shows the water and gas relative permeability curves for irreducible saturation, gas end point relative permeability, Corey water and Corey gas coefficients are $0.148,0.309,2.111$ and 3.626 , respectively. 


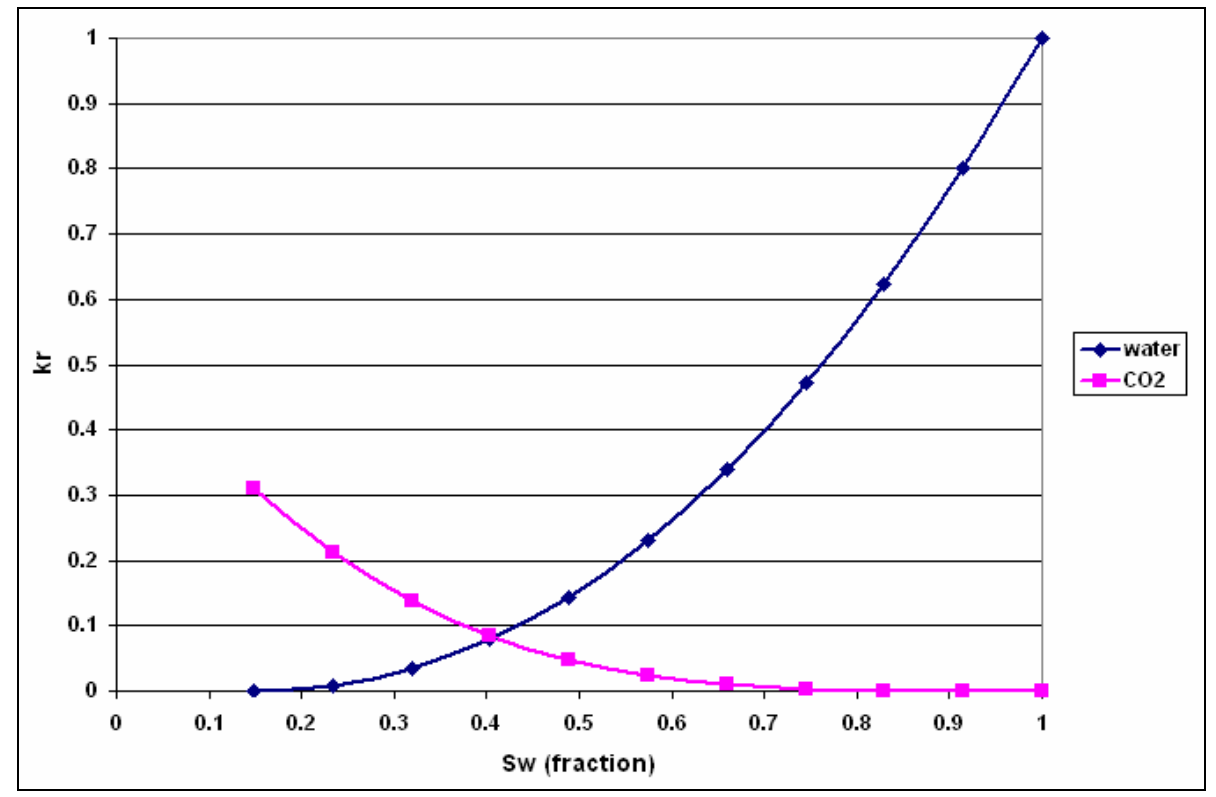

Figure 4.8: Relative Permeability Curves

The water-oil and oil-gas relative permeabilities have finite values but oil permeabilities are given as zero except at the residual water and gas saturation in order to prevent error " $k_{r o}>0$ when $S_{o}=0$ ".

Diffusion of $\mathrm{CO}_{2}$ in $\mathrm{x}, \mathrm{y}$ and $\mathrm{z}$ directions are assumed to be same since the formation is homogenous. Diffusion of water in $\mathrm{CO}_{2}$ is neglected.

\subsubsection{Initial Conditions}

This part defines the initial condition of the aquifer and starts with *INITIAL keyword. The reference depth is determined as the sum of the reference block top given for aquifer location and half of the aquifer thickness (800 ft). Aquifer pressure and temperature are calculated at the reference depth for given pressure and temperature gradient. "VERTICAL *DEPTH_AVE keyword is used to perform pressure distribution with depth and initial reservoir temperature is taken as constant. 
There are 3 solid components, $\mathrm{CaCO}_{3}, \mathrm{Ca}\left(\mathrm{HCO}_{3}\right)_{2}$ and $\mathrm{NaCl}$. The concentrations of these solid components are defined in lb-mole per aquifer pore volume $\mathrm{ft}^{3}$. Figure 4.9 gives the solubility of the $\mathrm{CaCO}_{3}$ in $\mathrm{CO}_{2}$-free water at different temperatures. The $\mathrm{CaCO}_{3}$ comes from the dissolution of the limestone and $\mathrm{CaCO}_{3}$ solubility is very low compared with $\mathrm{NaCl}$. The temperature of the aquifer change from 36 to $120{ }^{\circ} \mathrm{C}$ and at this range solubility of the $\mathrm{CaCO}_{3}$ nearly remains unchanged [69], for this reason, the concentration of the $\mathrm{CaCO}_{3}$ is taken as a constant.

The concentration of the $\mathrm{Ca}\left(\mathrm{HCO}_{3}\right)_{2}$ is taken as 0 since there is no $\mathrm{CO}_{2}$ at the initial condition. The solubility of the $\mathrm{NaCl}$ in $100 \mathrm{~g}$ water [70] is given in Figure 4.10.

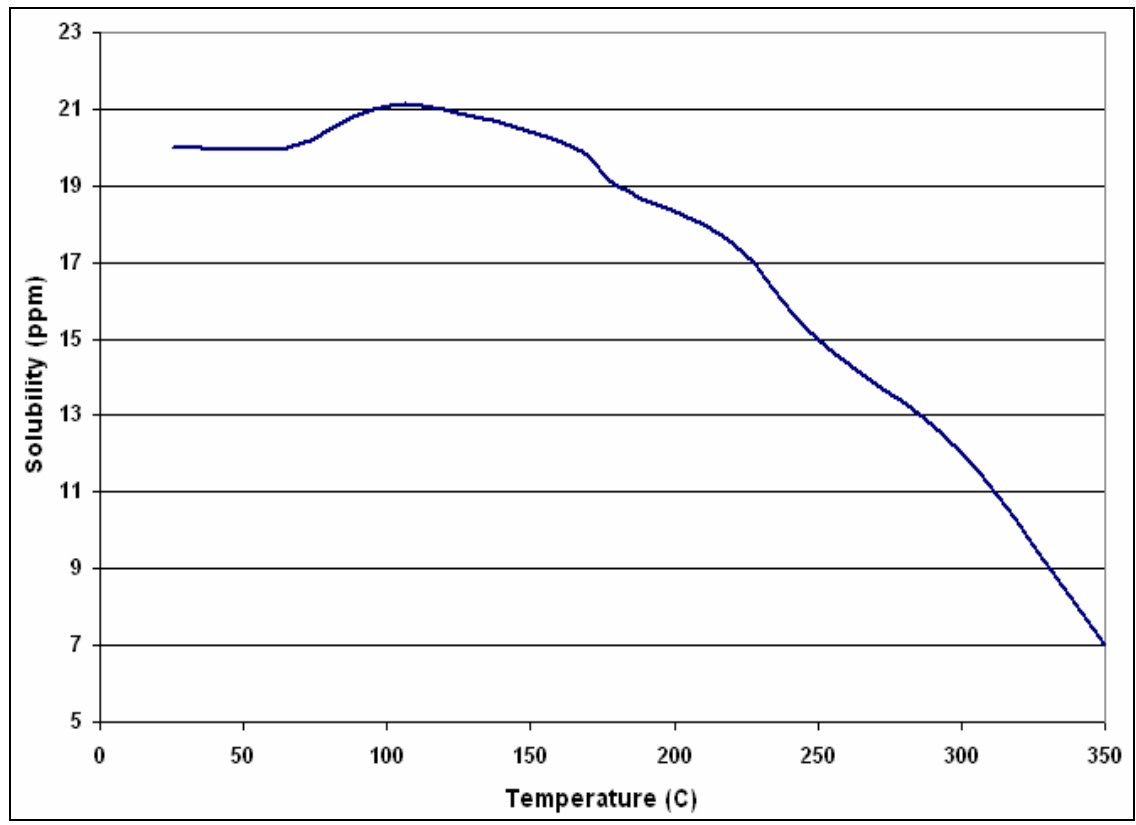

Figure 4.9: Solubility of $\mathrm{CaCO}_{3}$ with temperature [69] 


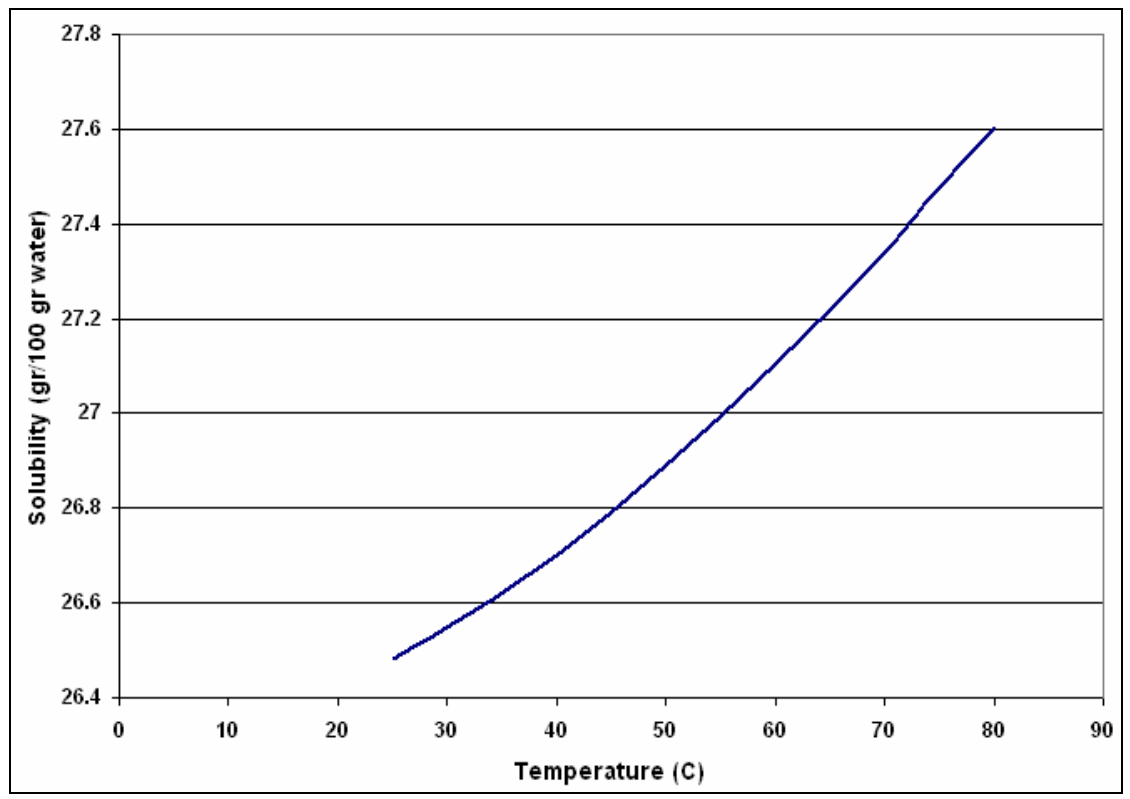

Figure 4.10: Solubility of $\mathrm{NaCl}$ with temperature [70]

The solubility of $\mathrm{NaCl}$ increases slowly as temperature increases. The salinity range is taken as 0 to 0.26 in weight percent. Solubility of the $\mathrm{NaCl}$ is more than the salinity range, for this reason the concentration of $\mathrm{NaCl}$ only depends on its availability in the formation.

To determine the concentration of $\mathrm{NaCl}$, the mass of the solution is taken as $1 \mathrm{gr}$ and then weight of the $\mathrm{NaCl}$ is taken to be equal to weight fraction of the $\mathrm{NaCl}$. Formation water weight is equal to one minus weight of $\mathrm{NaCl}$. The number of moles of $\mathrm{NaCl}$ is calculated by dividing the weight of the $\mathrm{NaCl}$ to its molecular weight, $58.4428 \mathrm{lb} / \mathrm{lb}$-mole. Formation water density is calculated using its temperature, pressure and salinity with Eqn. 4.17 and Eqn. 4.18. Volume of the formation water is calculated by dividing the weight of the water to its density. 


\subsubsection{Numerical Control}

This part of the program starts with *NUMERICAL keyword. All keywords in this part are optional since each keyword affects the way the simulation runs. These keywords are used in order to accelerate the simulation convergence in order to decrease the simulation time. Maximum timestep number is chosen as 10000 so that simulation due to any convergence problem is stopped to determine the problem. Maximum and minimum timestep sizes are entered as 60 and 360 days; however, minimum timestep size is even decreased to 5 days in some simulations due to convergence problems. For the first time interval, the software is used the timesteps given in the well \& recurrent part, after that the software automatically calculates appropriate timestep size between minimum and maximum timestep interval.

Temperature of the $\mathrm{CO}_{2}$ injected into formation is same as the aquifer temperature; therefore, block temperature is assumed to be not changing during the simulations. For these situations, isothermal run is defined with the *TFORM *ZT *ISOTHERMAL keywords so that the energy equations are not solved and simulation run time decreases significantly.

When convergence at a certain timestep size fails, the timestep size is reduced and calculations are repeated. To control the timestep cuts, maximum number of cuts is entered with *NCUTS keyword. For this study, maximum number of cuts before the run aborted is chosen as 20 .

\subsubsection{Well and Recurrent Data}

The well and recurrent data part starts with * RUN keyword. This part contains information about well and well related data, and other time dependent information. Reference time is given with *TIME keyword as 0 day instead of specifying year, month and day of the reference time. Size of the timestep following the reference time should be given between the first and second 
timestep by the user. In this study, the reference time is entered as 140 days with *DTWELL.

Only one injection vertical well located at the center of the aquifer is defined. The location of the grid blocks containing the injection well in $x$ and $y$ direction is 12,12 . Total mobility of the grid blocks containing this well is calculated implicitly, whereas the rate is calculated using the total mobility of the grid blocks with the Eqn. 4.32 given below.

$q_{j k}=I_{k}^{\prime} \lambda_{j k}\left(P_{w / k}-P_{k}\right)$

where $I_{k}^{\prime}$ is the well index of layer $k, \lambda_{j k}$ relative mobility of phase $j$ at layer $k$ and $P_{w f k}$ flowing wellbore pressure and $P_{k}$ grid block pressure of layer $k$.

The well index is given Eqn. 4.33.

$I_{k}^{\prime}=\frac{2 \pi h k f_{h} f}{\ln \left(r_{e} / r_{w}\right)+s}$

$r_{e}=C C \sqrt{\frac{\Delta x^{2}+\Delta y^{2}}{f \pi}}$

$I_{k}^{\prime}$ depends on layer thickness $(h)$, absolute permeability around wellbore $(k)$, completion fraction $\left(f_{h}\right)$, well fraction $(f)$, wellbore radius $\left(r_{w}\right)$, effective block radius $\left(r_{e}\right)$ and skin factor $(s) . \Delta x$ and $\Delta y$, and CC are grid block dimensions in $\mathrm{x}$ and $\mathrm{y}$ directions and geometric factor, respectively.

Well bore radius and skin are 0.375 and 0 . Geometric factor and well fraction are 0.249 and 1 since the well is located center of the interior grid block.

Injected fluid is pure $\mathrm{CO}_{2}$; therefore, the mole fraction of the injected gas phase is entered as $1 . \mathrm{CO}_{2}$ injection temperature and pressure are chosen to be equal to the aquifer temperature and 1.2 times reservoir pressure so that the injected $\mathrm{CO}_{2}$ is in supercritical condition. 
Two operating constraints and one monitoring constraint are chosen for each simulation run. First operating constraint is maximum gas injection rate in order to prevent the sudden increase in bottom hole pressure due to high injection rate. Maximum injection rate is also the initial injection rate which is set to $1 \mathrm{MMscf} / \mathrm{day}$. Second one is the maximum bottomhole pressure in order to avoid fracturing. It is set to 0.9 times of the fracture pressure. Figure 4.11 shows the fracture pressure estimation from different methods for the Gulf Coast [71]. The minimum estimation is obtained from the Hubbert and Willis method and to be in safe pressure limits, this method is used in this study.

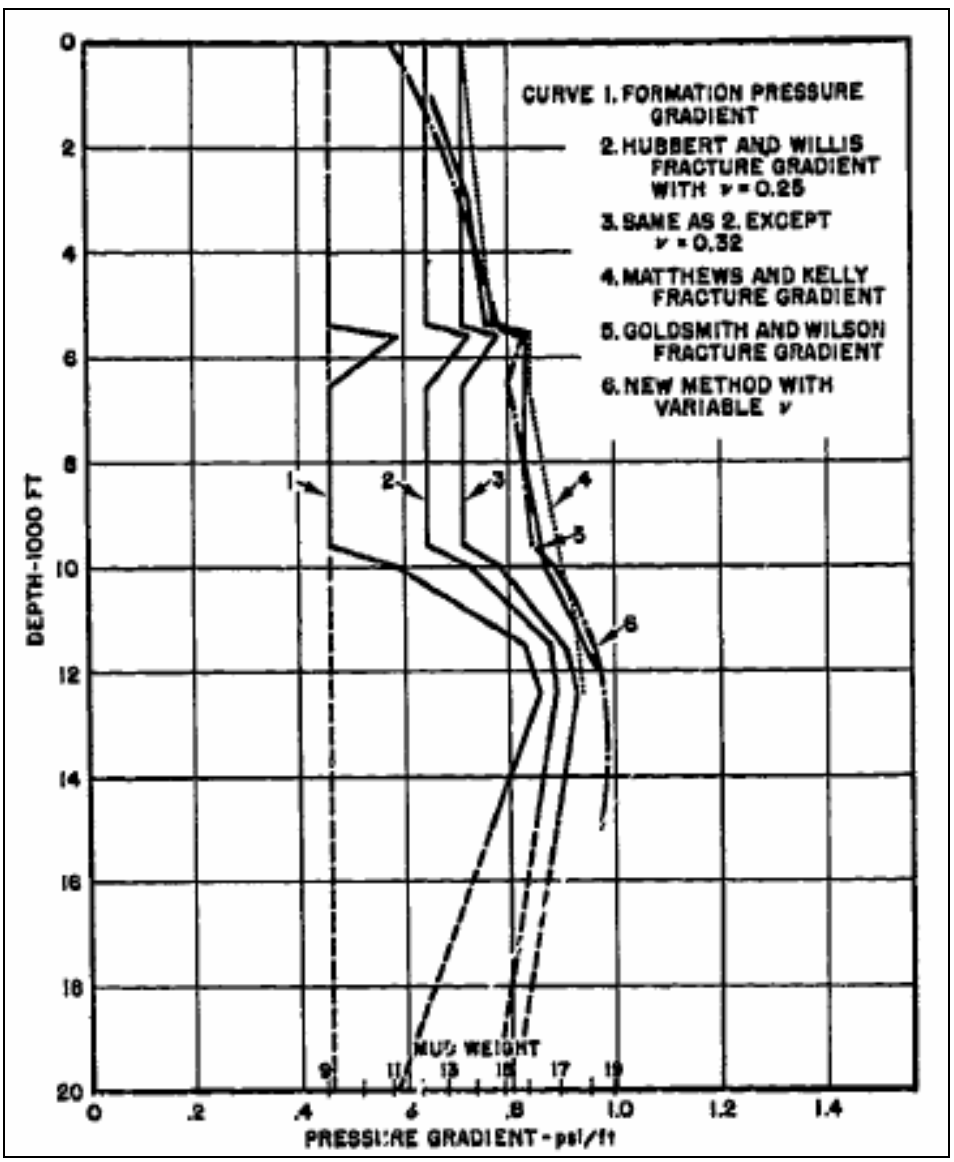

Figure 4.11: Formation and Fracture Pressure Gradient [71] 
Hubbert and Willis method [72] relies on the following equation proposed by Eaton [71] to estimate the fracture pressure gradient.

$$
\frac{P_{w}}{D}=\left(\frac{S}{D}-\frac{P}{D}\right)\left(\frac{\mu}{1-\mu}\right)+\frac{P}{D}
$$

where $D, P_{w}, P, S$ and $\mu$ are depth (ft), wellbore pressure (psi), formation pressure (psi), over-burden stress (psi) and Poisson's ratio respectively. Taking over-burden stress gradient as $1 \mathrm{psi} / \mathrm{ft}$ and Poisson's ratio as 0.25 , the Eqn. 4.35 is simplified to,

$$
\frac{P_{w}}{D}=\frac{1}{3}\left(1+\frac{P}{D}\right)
$$

Monitoring constraint is the minimum injection rate, 100 scuft/day. This constraint is chosen in order to prevent the injection rate decrease to even 1 scf/day.

Bottom half part of the well is perforated; the location of the perforation in $\mathrm{x}, \mathrm{y}$ and $z$ directions is 12,12 , and 10:17. The selection of the perforation location is made according to safety condition. Since $\mathrm{CO}_{2}$ density is lower than formation water density in aquifer pressure and temperature, which causes $\mathrm{CO}_{2}$ move up until it reaches the impermeable layer, cap rock. $\mathrm{CO}_{2}$ can escape through the cap rock due to the capillary effect and diffusion or react with cap rock. For this reason, to increase the arrival time of $\mathrm{CO}_{2}$ to cap rock, bottom part of the injection well is perforated.

The injected gas amount, pressure, grid block saturations and other properties are written the output files for every year. Total simulation times are chosen as 300,500 and 600 years for the aquifers with grid dimensions $250 \mathrm{ft}, 500 \mathrm{ft}$ and $750 \mathrm{ft}$ in $\mathrm{x}$ and $\mathrm{y}$ direction, respectively. 


\subsection{Predictive Models and Sensitivity Analysis}

After the simulation runs, a predictive linear model is constructed for deep saline carbonate aquifers using Eqn. 2. 25. The error term, $\varepsilon$ is assumed to be zero since the storage capacity of the deep Saline carbonate aquifers are obtained from simulations instead of experiment. Conducting experiments could produce different but closer results; however, simulations always give the same result provided that input variables entered to simulation remain same.

Model is constructed by using simulation input parameters instead of design input variables. The model is defined by the equation, $f(\vec{x}, \vec{a})$ where $\vec{x}$ and $\vec{a}$ are variable matrix representing the input parameters and coefficient matrix, respectively. The model can be written as,

$$
f(\vec{x}, \vec{a})=a_{o}+a_{1} x_{1}+a_{2} x_{2}+\cdots+a_{n} x_{n}
$$

where $n$ is the number of input parameters. The unknown coefficients are found such that the sum of the squared deviations between the values obtained from simulations and the values calculated from equation of $f(\vec{x}, \vec{a})$ is minimized. SAS' JMP software is used for predictive model construction and predictive model sensitivity analysis.

Injected $\mathrm{CO}_{2}$ trapping mechanisms are determined from the 300 years of simulation runs. Mineralized $\mathrm{CO}_{2}$ is determined from the concentration of the $\mathrm{Ca}\left(\mathrm{HCO}_{3}\right)_{2}$ since the initial concentration of $\mathrm{Ca}\left(\mathrm{HCO}_{3}\right)_{2}$ is 0 ; and free gas is calculated from Equation of State. Gas compressibility factor is calculated by the equation of state (EOS) proposed by Zhenhao Duan et al (1992). This EOS is valid for temperatures and pressures from 0 to $1000^{\circ} \mathrm{C}$ and 0 to 8000 bars [73].

$$
Z=\frac{P V}{R T}=\frac{P_{r} V_{r}}{T_{r}}=1+\frac{B}{V_{r}}+\frac{C}{V_{r}^{2}}+\frac{D}{V_{r}^{4}}+\frac{E}{V_{r}^{5}}+\frac{F}{V_{r}^{2}}\left(\beta+\frac{\gamma}{V_{r}^{2}}\right) \exp \left(-\frac{\gamma}{V_{r}^{2}}\right)
$$


where

$$
\begin{aligned}
& B=a_{1}+\frac{a_{2}}{T_{r}^{2}}+\frac{a_{3}}{T_{r}^{3}} \\
& C=a_{4}+\frac{a_{5}}{T_{r}^{2}}+\frac{a_{6}}{T_{r}^{3}} \\
& D=a_{10}+\frac{a_{11}}{T_{r}^{2}}+\frac{a_{12}}{T_{r}^{3}} \\
& F=\frac{\alpha}{T_{r}^{3}} \\
& P_{r}=\frac{P}{P_{c}} \\
& T_{r}=\frac{T}{T_{c}} \\
& V_{r}=\frac{V}{V_{c}} \\
& P_{c}
\end{aligned}
$$

$P_{c}, T_{c}$ and $R$ are critical pressure in psia, critical temperature in ${ }^{\circ} \mathrm{R}$ and universal gas constant which is 10.73 psia cuft / (lbmole $\left.{ }^{\circ} \mathrm{R}\right)$, respectively. The coefficients are given in Table 4.14. The $z$ factor is calculated with an iterative method by using Matlab (The $\mathrm{m}$ file for this calculation is given in Appendix D). In this iterative method, firstly, an initial value of $z$ is assumed and $V$ is calculated, and then by using calculated $V, z$ is recalculated. If the difference between assumed $z$ and calculated $z$ is bigger than the specified tolerance $(0.00001$ is chosen for this study), the next $z$ assumption is taken 
as the calculated one and the same procedure is repeated until the difference between $z$ assumed and $z$ calculated is less than tolerance.

After calculation of the number of moles of free, mineralized and dissolved $\mathrm{CO}_{2}$, predictive model is found for each trapping mechanism by using least square method and trapping mechanisms are compared to find the most effective trapping mechanism. Finally, simulation runs are repeated for $x$ and y grid dimensions of $500 \mathrm{ft}$ and $750 \mathrm{ft}$ in order to find new predictive model which is independent of grid dimensions with the same method.

Table 4.14: EOS Parameters for $\mathrm{CO}_{2}$

\begin{tabular}{|l|l|}
\hline$a_{1}$ & $8.99288497 \mathrm{E}-02$ \\
\hline$a_{2}$ & $-4.94783127 \mathrm{E}-01$ \\
\hline$a_{3}$ & $4.77922245 \mathrm{E}-02$ \\
\hline$a_{4}$ & $1.03808883 \mathrm{E}-02$ \\
\hline$a_{5}$ & $-2.82516861 \mathrm{E}-02$ \\
\hline$a_{6}$ & $9.49887563 \mathrm{E}-02$ \\
\hline$a_{7}$ & $5.20600880 \mathrm{E}-04$ \\
\hline$a_{8}$ & $-2.93540971 \mathrm{E}-04$ \\
\hline$a_{9}$ & $-1.77265112 \mathrm{E}-03$ \\
\hline$a_{10}$ & $-2.51101973 \mathrm{E}-05$ \\
\hline$a_{11}$ & $8.93353441 \mathrm{E}-05$ \\
\hline$a_{12}$ & $7.88998563 \mathrm{E}-05$ \\
\hline$\alpha$ & $-1.66727022 \mathrm{E}-02$ \\
\hline$\beta$ & $1.39800000 \mathrm{E}+00$ \\
\hline$\gamma$ & $2.96000000 \mathrm{E}-02$ \\
\hline
\end{tabular}




\section{CHAPTER 5}

\section{RESULTS AND DISCUSSIONS}

\subsection{Predictive Model Construction for $\mathrm{CO}_{2}$ Sequestration in Deep Saline Carbonate Aquifers}

To develop a predictive model for $\mathrm{CO}_{2}$ sequestration in deep saline carbonate aquifers, the variables which affect the $\mathrm{CO}_{2}$ storage capacity of the aquifers are determined from the published literature data. These variables are the rock properties; porosity, permeability and vertical permeability; area, thickness, formation dip and depth of the aquifer, reservoir conditions; temperature and pressure, reservoir fluid properties; relative permeability characteristics of the formation water and $\mathrm{CO}_{2}$ and salinity of formation water, forward and backward reaction rates and Kozeny-Carman coefficient which determines the permeability change with porosity due to the reaction, and diffusion coefficient of $\mathrm{CO}_{2}$ in water.

Space filling design is chosen for this study to cover whole space created by the variables and two important characteristics of this design are checked to determine quality of the space filling design, orthogonality and space filling property. To construct this design, JMP software is used and the number of cases is determined by increasing the number of cases until sufficient discrepancy is obtained. Point selection in the design is made using Latin Hypercube Sampling in which the interval of the variables in the design are divided into number of cases and one point is selected randomly in each interval so that maximum uniformity is obtained and the probability of each 
interval selection equals. The best number of cases is found to be 100 from discrepancy analysis. As the points are selected randomly from each interval, a different design is obtained at each JMP run. For this reason, 8 Latin Hypercube Space Filling designs are prepared and the best one having minimum discrepancy is chosen. The orthogonality of the design is also checked by correlation coefficient of the variables. All correlation coefficients should be close to 0 , which means that each variable is independent of other variables.

The hypothetical aquifer created for this study is $5250 \mathrm{ft}$ long, $5250 \mathrm{ft}$ wide and $800 \mathrm{ft}$ thick. There is only one injection well at the center of the aquifer and lower half of the well is perforated in order to increase the time at which $\mathrm{CO}_{2}$ reaches the top of the aquifer. When $\mathrm{CO}_{2}$ is injected into formation, it is trapped by three trapping mechanisms, namely, hydrodynamic trapping, solubility trapping and mineralization. These three trapping mechanisms occur simultaneously and to define all trapping mechanisms as correctly as possible, CMG STARS software is chosen for simulation runs. After input variable selection and design point construction, simulation cases are prepared with the help of STARS' help manual and simulation runs are conducted.

Three constraints are chosen for each simulation case. The first one is the initial injection rate, $1 \mathrm{MMscf} / \mathrm{day}$. The initial injection rate is chosen as a constraint in order to prevent the high flow rates and sudden increase in bottom hole pressure. Second one is the maximum bottom hole pressure in order to avoiding fracturing which is 0.9 times of fracture pressure calculated from Hubbert and Willies method. Final constraint is the final injection rate, $100 \mathrm{scf} /$ day. If final injection rate was not specified as constraint, injection rate could even decrease to $1 \mathrm{scf} /$ day. 
In addition to the cumulative $\mathrm{CO}_{2}$ injected in the aquifer, saturation of water and $\mathrm{CO}_{2}$, concentration of all solid components and pressure are exported for each grid blocks in order to find $\mathrm{CO}_{2}$ amount for each trapping mechanism.

By using the JMP software, a predictive model for $\mathrm{CO}_{2}$ sequestration in deep saline aquifers is constructed with least squares method in which sum of the squared deviation between the $\mathrm{CO}_{2}$ storage capacity of the aquifer obtained from simulation and $\mathrm{CO}_{2}$ storage capacity of the aquifer obtained from equation is minimized. In the first case, two analyses are performed to determine which input variables, design variables or simulation variables, should be used in the predictive model. In the first analysis, the predictive model is constructed with the variables used in the space filling design preparation and in the second analysis; the design is constructed with the variables used in the simulation. Figure 5.1 and Figure 5.2 show the fit of the $\mathrm{CO}_{2}$ storage capacity of the aquifer obtained from simulation (actual) with $\mathrm{CO}_{2}$ storage capacity obtained from linear predictive model (predicted). In these figures, solid and dashed red lines show the $45^{\circ}$ line used to see how values obtained from predictive model coincides with values obtained from simulation and confidence intervals, respectively. Table 5.1 compares the statistical results of the fit for these two analyses.

The linear predictive model, $f(\vec{x}, \vec{a})$ can be represented by the following equation where $\vec{x}$ and $\vec{a}$ are variable matrix and coefficient matrix, respectively. Table 5.2 gives the coefficients and variables of the linear predictive models constructed for these two analyses.

$$
f(\vec{x}, \vec{a})=a_{o}+a_{1} x_{1}+a_{2} x_{2}+\cdots+a_{n} x_{n}=a_{0}+\sum_{i=1}^{16} a_{i} x_{i}
$$


Table 5.1: Case 1, Statistical Analysis of Linear Predictive Model

\begin{tabular}{|l|c|c|}
\cline { 2 - 3 } \multicolumn{1}{c|}{} & Analysis 1 & Analysis 2 \\
\hline RSquare & 0.799993 & 0.805334 \\
\hline RSquare Adj & 0.759992 & 0.766401 \\
\hline Root Mean Square Error & $1.25 \mathrm{E}+09$ & $1.23 \mathrm{E}+09$ \\
\hline Mean of Response & $8.75 \mathrm{E}+09$ & $8.75 \mathrm{E}+09$ \\
\hline Observations & 97 & 97 \\
\hline
\end{tabular}

Table 5.2: Case 1, Linear Predictive Model Variables and Coefficients

\begin{tabular}{|l|l|r|r|}
\hline \multirow{2}{*}{$i$} & \multicolumn{1}{|c|}{ Variable $\left(x_{i}\right)$} & \multicolumn{1}{c|}{ Analysis 1 } & \multicolumn{1}{c|}{ Analysis 2 } \\
\cline { 3 - 4 } & & \multicolumn{1}{c|}{ Coefficient $\left(a_{i}\right)$} & \multicolumn{1}{c|}{ Coefficient $\left(a_{i}\right)$} \\
\hline 1 & Constant & 14026842191.312 & 2779509132.807 \\
\hline 2 & Porosity & -90644704.869 & -90463725.926 \\
\hline 3 & Permeability & 62947.466 & 249634.104 \\
\hline 4 & Vertical Permeability & -504334706.392 & -371774.215 \\
\hline 5 & Reference Depth & 2949599.294 & 2596928.234 \\
\hline 6 & Pressure & -20624202729.275 & -3256097.538 \\
\hline 7 & Temperature & -44954322.851 & -11051530.100 \\
\hline 8 & Salinity & -2093844856.983 & -2151029996.092 \\
\hline 9 & Swirr & 1545847518.636 & 1535190740.556 \\
\hline 10 & Krg (end point) & -1173519033.865 & -1136515031.330 \\
\hline 11 & Corey Water Exponent & -39936256.889 & -51861394.754 \\
\hline 12 & Corey Gas Exponent & 137138344.126 & 139175656.065 \\
\hline 13 & Kozeny-Carman Coefficient & 43940655.559 & 45702982.882 \\
\hline 14 & Diffusion Coefficient & -18166811591.984 & -20937783801.066 \\
\hline 15 & Forward Reaction Rate & 1421261.115 & 1528201.819 \\
\hline 16 & Backward Reaction Rate & -514951.252 & -559511.925 \\
\hline 17 & Formation Dip & 128817056.684 & 134735957.862 \\
\hline
\end{tabular}




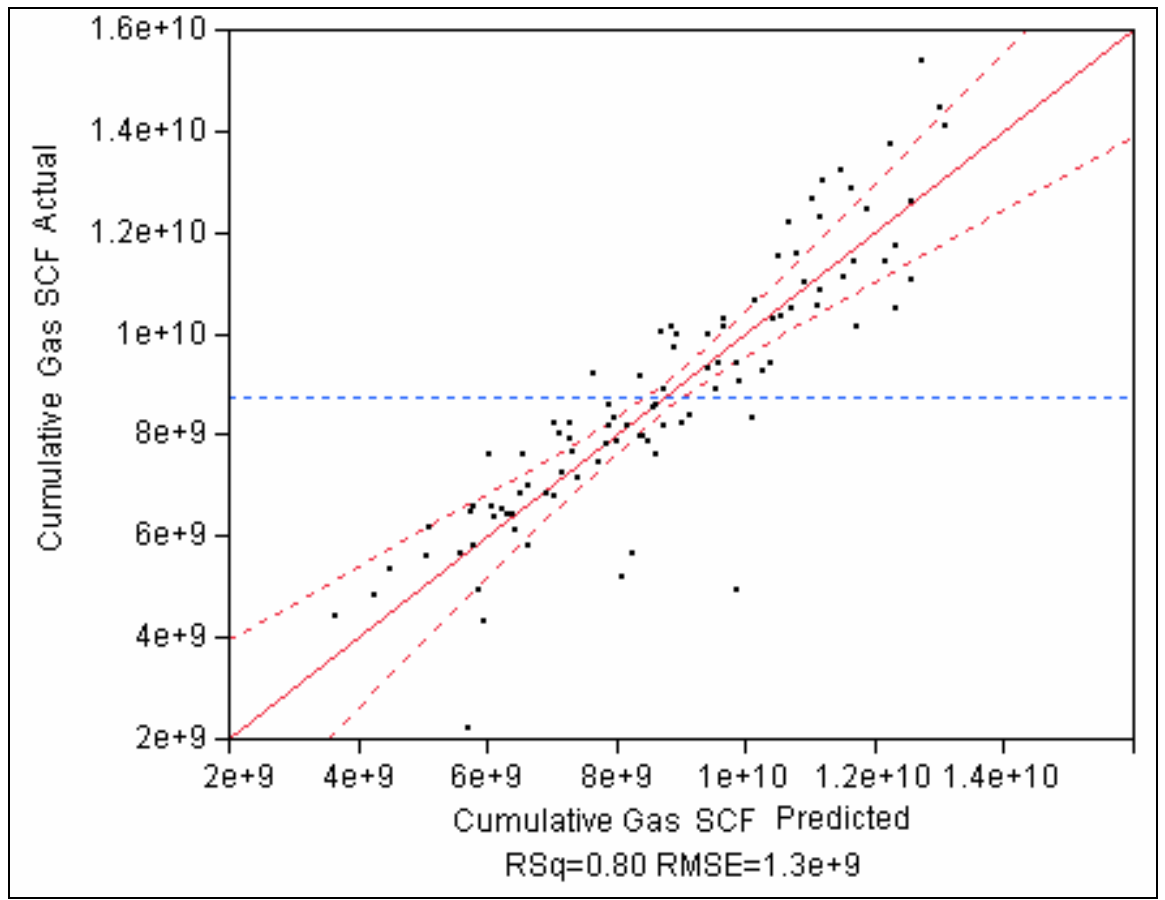

Figure 5.1: Case 1, Analysis 1, Linear Predictive Model Fit (Function of Design Input Variables)

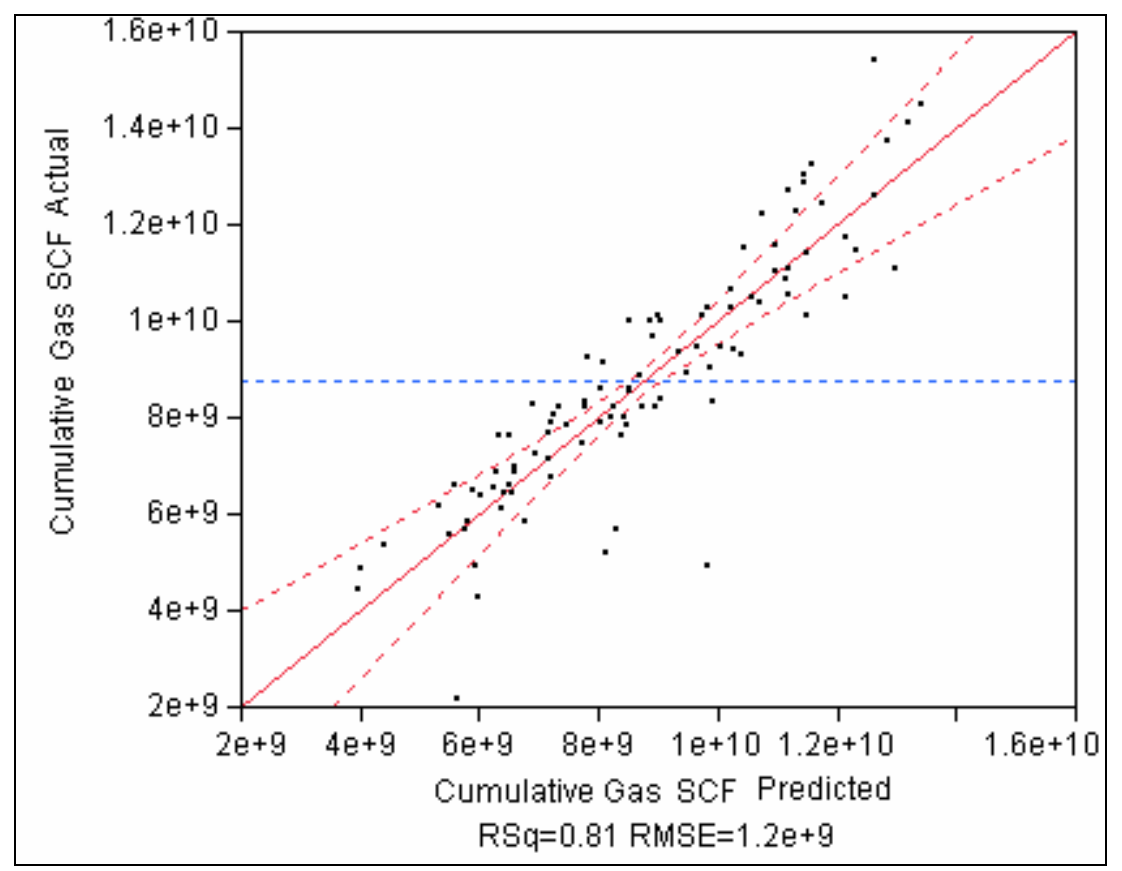

Figure 5.2: Case 1, Analysis 2, Linear Predictive Model Fit (Function of Simulation Input Variables) 
100 cases are prepared for this study; however it can be seen from Table 5.1 that there are 97 cases in these analysis since 3 simulation runs are terminated due to the convergence problems. The correlation coefficient is large and sum of the root mean square error is small for Analysis 2, which shows the construction of linear predictive model to estimate the $\mathrm{CO}_{2}$ storage capacity of the deep saline aquifers is more representative.

Also, to determine the goodness of the fit, the error between the $\mathrm{CO}_{2}$ storage capacity of the aquifer obtained from simulations and linear predictive model should be compared. Figure 5.3 and Figure 5.4 give the absolute percent error between calculated and simulated $\mathrm{CO}_{2}$ storage capacity for these analyses. As it can be seen from these figures, most of the absolute errors are less than $20 \%$.

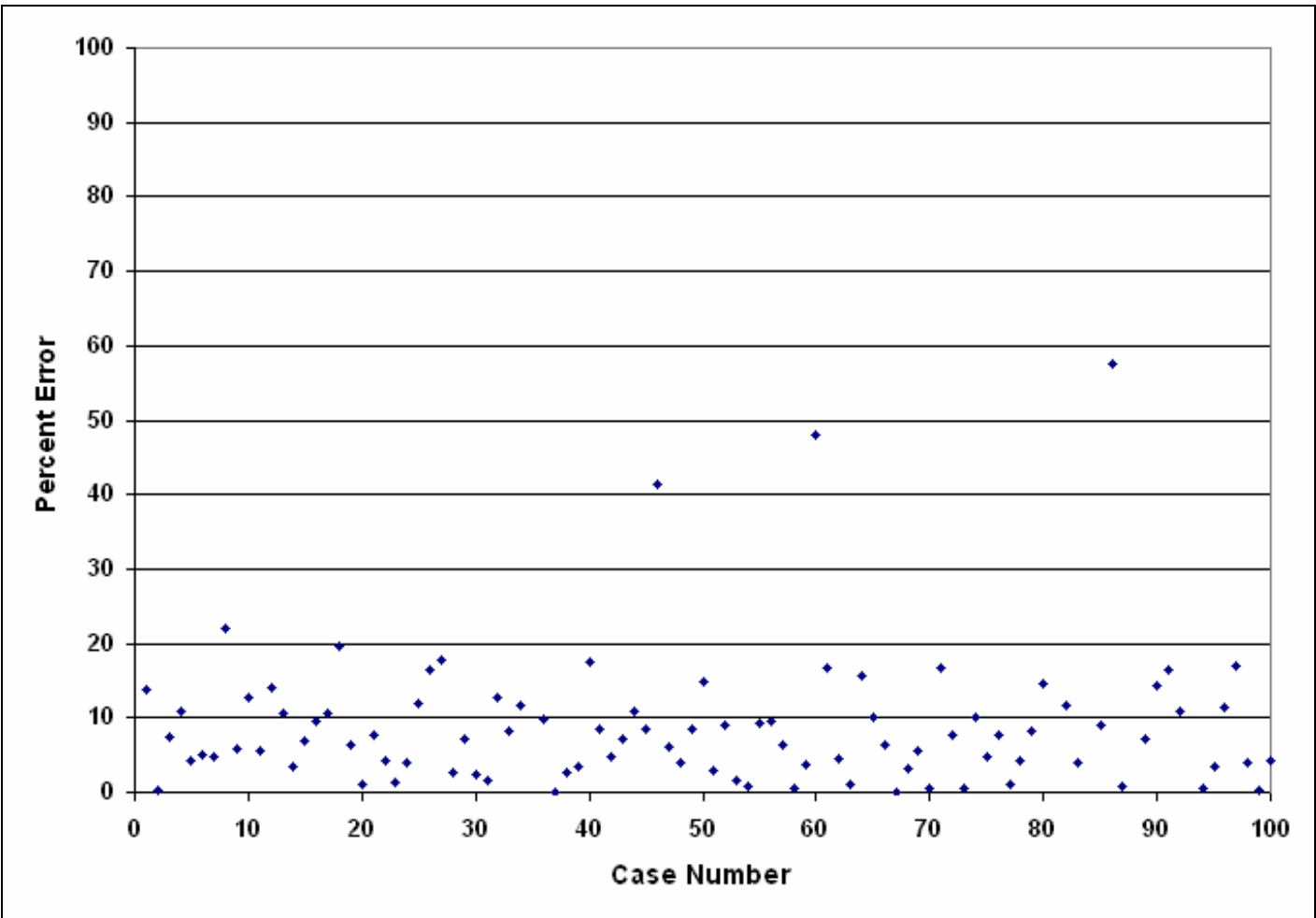

Figure 5.3: Case 1, Analysis 1, Absolute Percent Error between Simulated and Predicted Results 


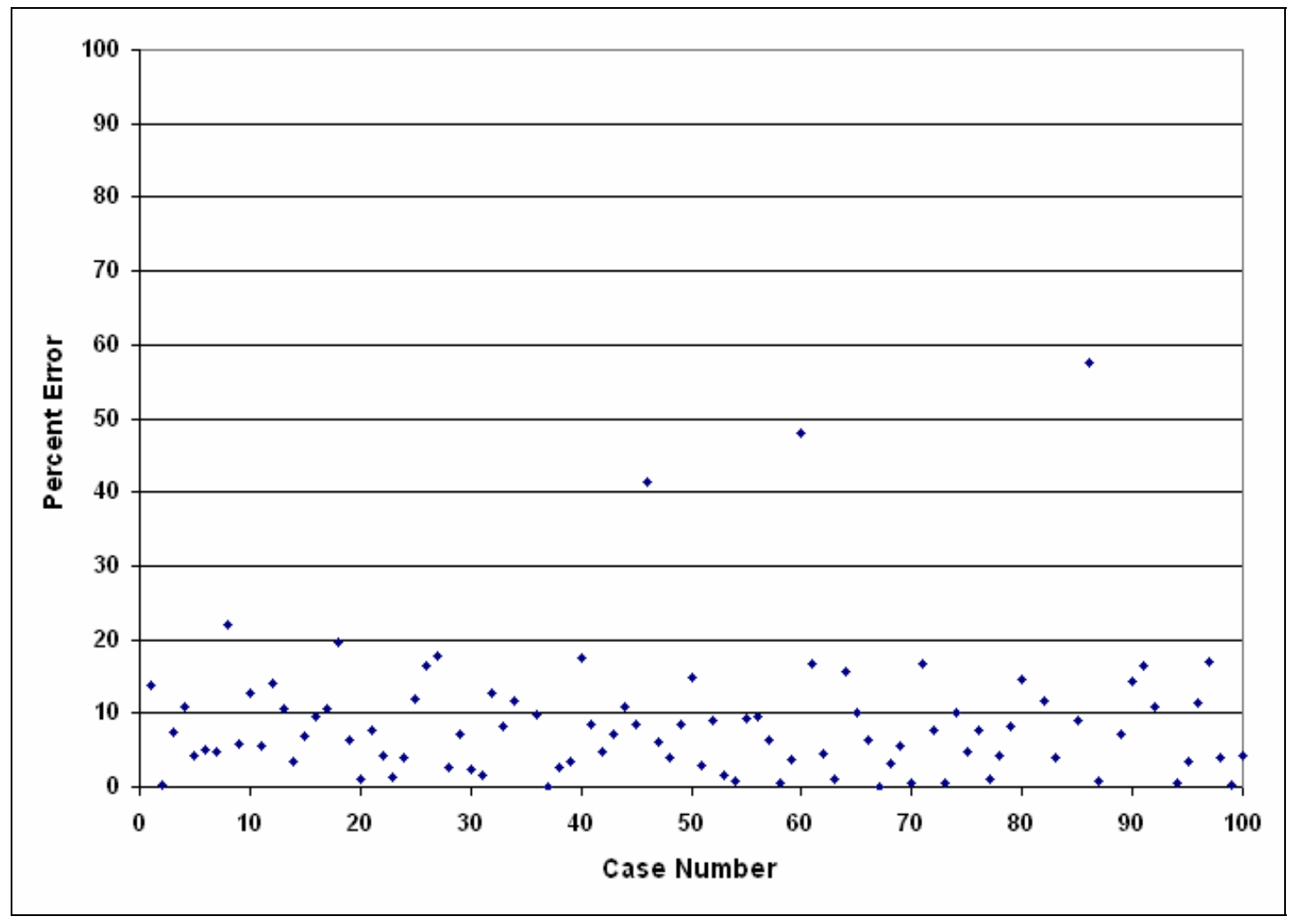

Figure 5.4: Case 1, Analysis 2, Absolute Percent Error between Simulated and Predicted Results

After determination of the linear predictive model and predictive model input variables, the grid dimensions are increased from $250 \mathrm{ft}$ to $500 \mathrm{ft}$ and $750 \mathrm{ft}$ and all simulations are repeated to find a predictive model for greater deep saline aquifers to estimate the $\mathrm{CO}_{2}$ storage capacity of them. Figure 5.5 and 5.6 give the fit of the $\mathrm{CO}_{2}$ storage capacity obtained from simulations and $\mathrm{CO}_{2}$ storage capacity obtained from linear predictive models for Case 2 and Case 3.

Table 5.3 gives the statistical analysis of the predictive model for Case 2 and Case 3. As it can be seen from the summary of fit models in Table 5.3, as the grid dimensions increase, correlation coefficient of fit decreases due to diffusion problem. When $\mathrm{CO}_{2}$ is injected into formation, software assumes that it completely fills the whole grid block and comes into equilibrium 
instantaneously; for this reason, as the grid dimensions increase, $\mathrm{CO}_{2}$ diffuses more. Figure 5.7 and Figure 5.8 give the absolute percent error of $\mathrm{CO}_{2}$ storage capacity between simulated and predicted values.

With the same manner, the linear predictive model is defined as the sum of the linear combination of variable given in Eqn. 5.1 and Table 5.4 shows the variable used to construct the linear predictive model and corresponding coefficients for Case 2 and Case 3.

Table 5.3: Case2 and Case 3, Statistical Analysis of Linear Predictive Models

\begin{tabular}{|l|c|c|}
\cline { 2 - 3 } \multicolumn{1}{c|}{} & Analysis Case 2 & Analysis Case 3 \\
\hline RSquare & 0.793514 & 0.780739 \\
\hline Rsquare Adj & 0.752217 & 0.736887 \\
\hline Root Mean Square Error & $5.23 \mathrm{E}+09$ & $1.32 \mathrm{E}+10$ \\
\hline Mean of Response & $3.62 \mathrm{E}+10$ & $8.58 \mathrm{E}+10$ \\
\hline Observations & 97 & 97 \\
\hline
\end{tabular}


Table 5.4: Case 2 and Case 3, Linear Predictive Model Variables and Coefficients

\begin{tabular}{|r|l|r|r|}
\hline \multirow{2}{*}{$i$} & \multicolumn{1}{|c|}{ Variable $\left(x_{i}\right)$} & \multicolumn{1}{c|}{ Case 2 } & \multicolumn{1}{c|}{ Case 3 } \\
\cline { 3 - 4 } & & \multicolumn{1}{c|}{ Coefficient $\left(a_{i}\right)$} & \multicolumn{1}{c|}{ Coefficient $\left(a_{i}\right)$} \\
\hline 1 & Constant & 12046267977.563 & 24805348167.552 \\
\hline 2 & Porosity & -414802704.605 & -975063093.904 \\
\hline 3 & Permeability & -947169.705 & 1366640.790 \\
\hline 4 & Vertical Permeability & 9777774.539 & -2954450.980 \\
\hline 5 & Reference Depth & -11147061.391 & -25428321.801 \\
\hline 6 & Pressure & -60685417.794 & -182575326.401 \\
\hline 7 & Temperature & -6943259416.789 & -12983981824.091 \\
\hline 8 & Salinity & 5568076935.533 & 13166997770.033 \\
\hline 9 & Swirr & -4320623101.382 & -8795990204.116 \\
\hline 10 & krg (end point) & -327956671.493 & -711926521.995 \\
\hline 11 & Corey Water Exponent & 600819357.544 & 1681442420.064 \\
\hline 12 & Corey Gas Exponent & 208392743.928 & 606264040.230 \\
\hline 13 & Kozeny-Carman Coefficient & -38215808870.313 & -262322134117.590 \\
\hline 14 & Diffusion Coefficient & 7235398.950 & 21082222.054 \\
\hline 15 & Forward Reaction Rate & -2904431.109 & -13402001.929 \\
\hline 16 & Backward Reaction Rate & 1023815062.781 & 3681544687.144 \\
\hline 17 & Formation Dip & &
\end{tabular}

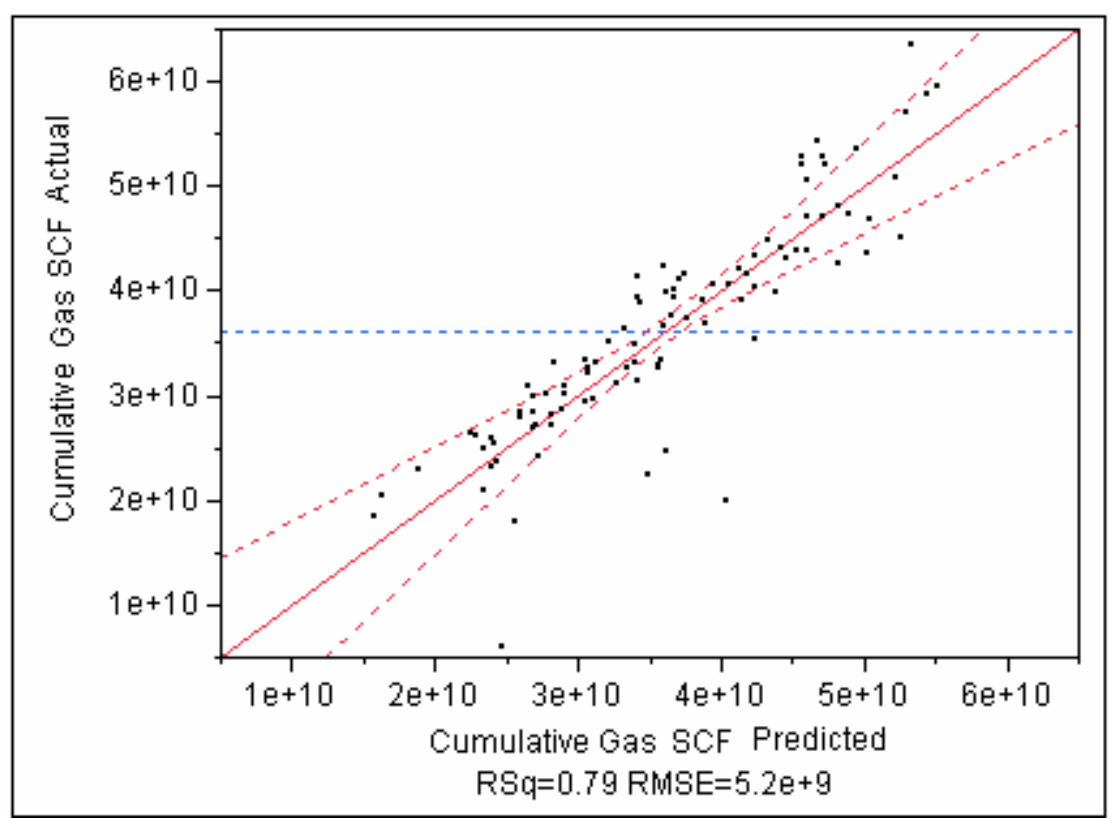

Figure 5.5: Case 2, Linear Predictive Model Fit 


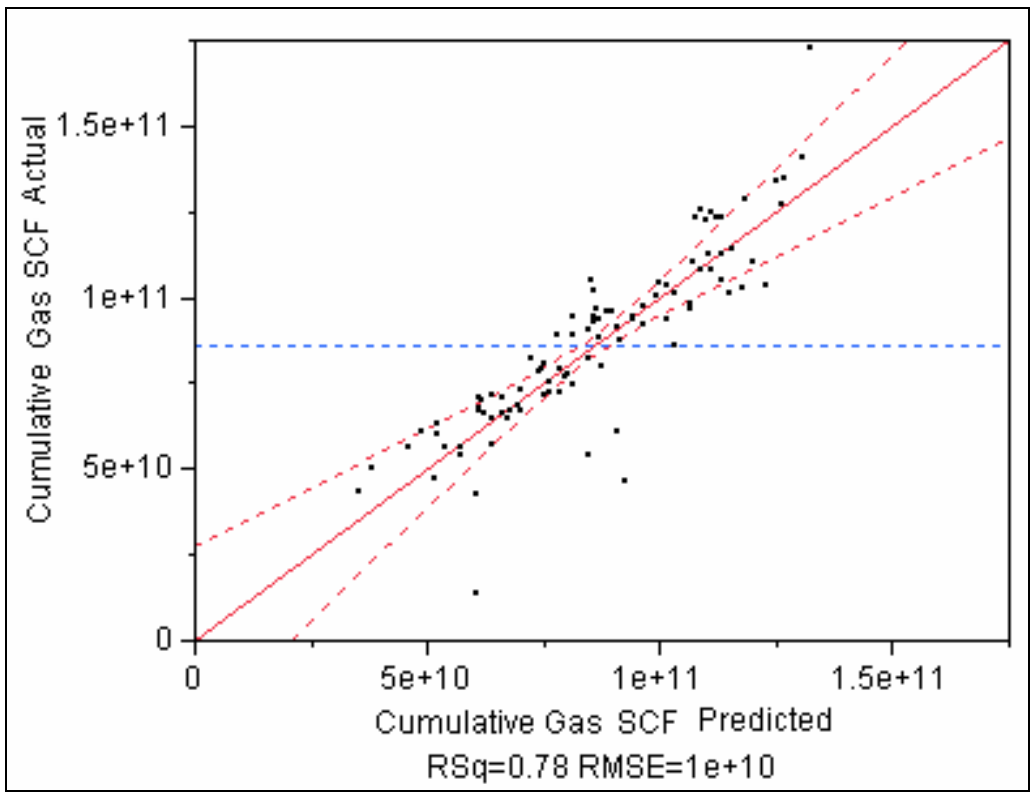

Figure 5.6: Case 3, Linear Predictive Model Fit

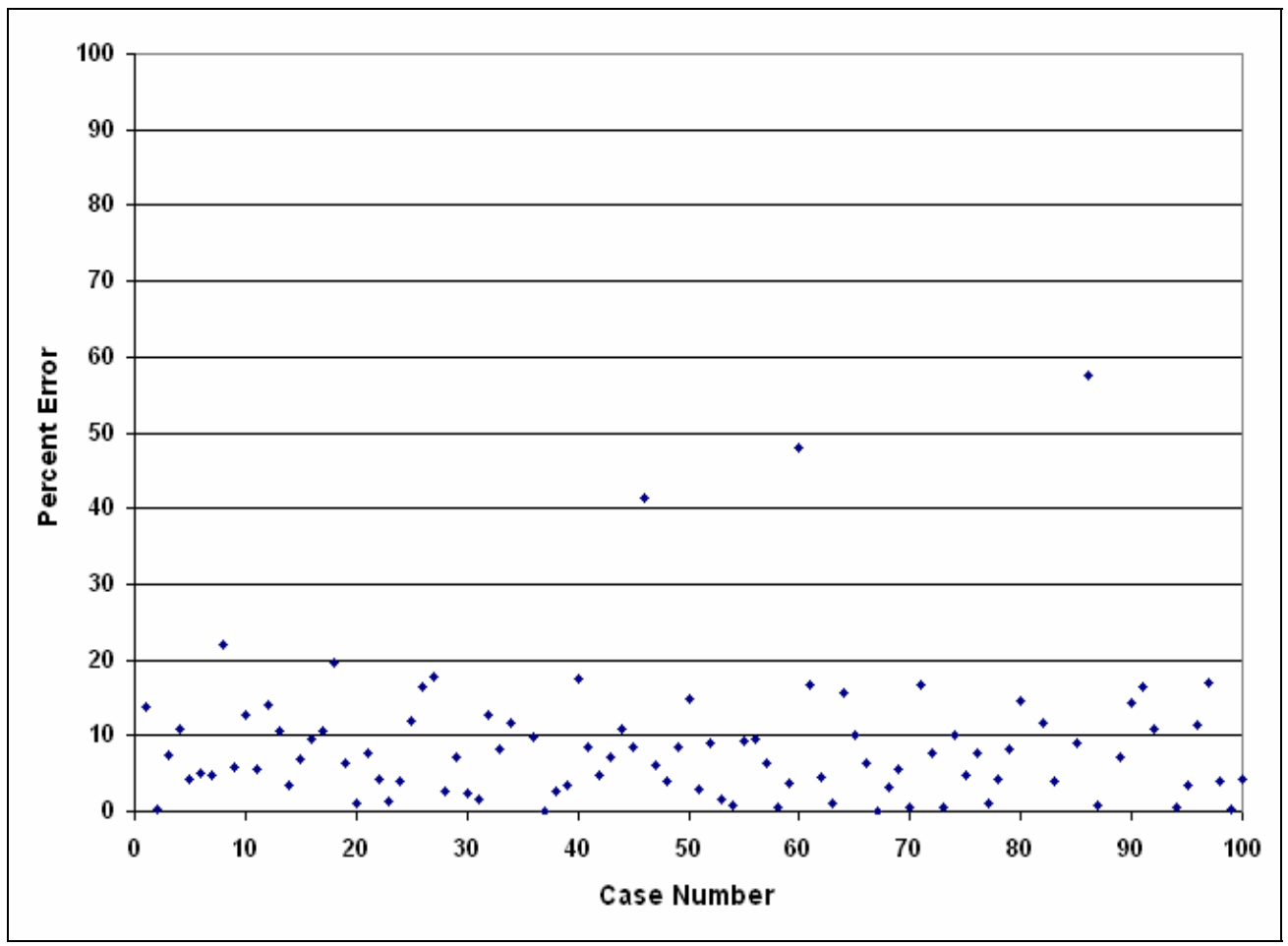

Figure 5.7: Case 2, Absolute Percent Error between Simulated and Predicted Results 


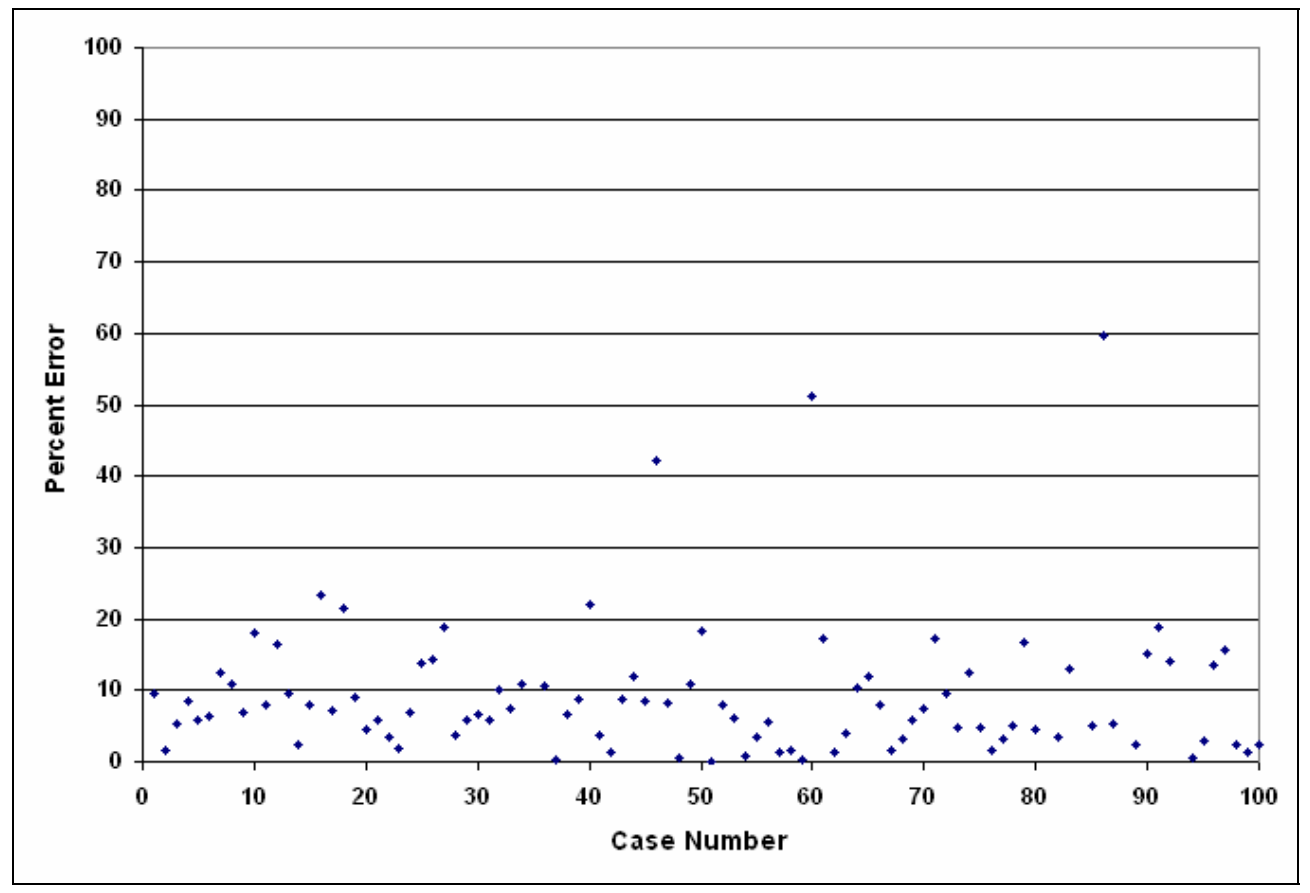

Figure 5.8: Case 3, Absolute Percent Error between Simulated and Predicted Results

\subsection{Sensitivity Analysis of the Predictive Model Constructed for $\mathrm{CO}_{2}$ Sequestration in Deep Saline Carbonate Aquifers}

After the predictive model construction for three different grid dimensions, $250 \mathrm{ft}(76 \mathrm{~m}), 500 \mathrm{ft}(152 \mathrm{~m})$ and $750 \mathrm{ft}(228 \mathrm{~m})$, a sensitivity analysis is carried out in order to understand how each variable affects the $\mathrm{CO}_{2}$ storage capacity of the deep saline carbonate aquifer and which variables are much more effective. Figure 5.9 gives the Pareto Chart of the first case. On the left side of the figure, the input variables used in the linear predictive model are listed according to importance order. On the right side of the figure, the Pareto plot shows the effect of the each variable on $\mathrm{CO}_{2}$ storage capacity as percent weight bars and cumulative weight line. As can be seen from the Pareto chart, the most important variables affecting the $\mathrm{CO}_{2}$ storage capacity of the aquifer are reference depth and porosity of the aquifer. 


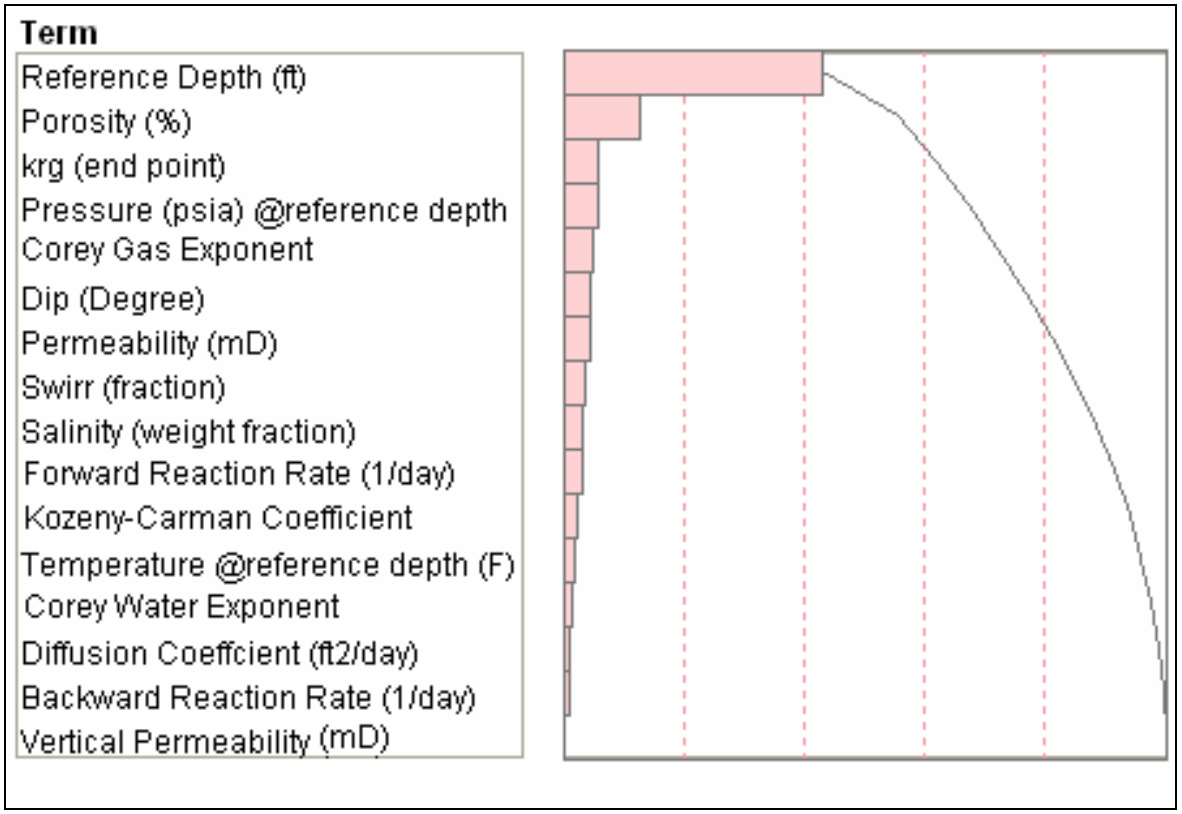

Figure 5.9: Case1, Analysis 2, Pareto Plot

To show the importance of each variable, a reference case is chosen and sensitivity analysis is made. In this sensitivity analysis, red values show the variables at reference case and corresponding $\mathrm{CO}_{2}$ storage capacity of the aquifer. Each variable's effect on $\mathrm{CO}_{2}$ storage capacity of the aquifer is explained below.

\subsubsection{Reference Depth of the Aquifer}

Figure 5.10 shows the $\mathrm{CO}_{2}$ storage capacity sensitivity of the reference depth of the aquifer. Vertical axis gives the change of the $\mathrm{CO}_{2}$ storage capacity of the aquifer and horizontal axis gives the reference depth of formation. The red values on these axes are the reference case depth and the $\mathrm{CO}_{2}$ storage value valid whole sensitivity analysis. 


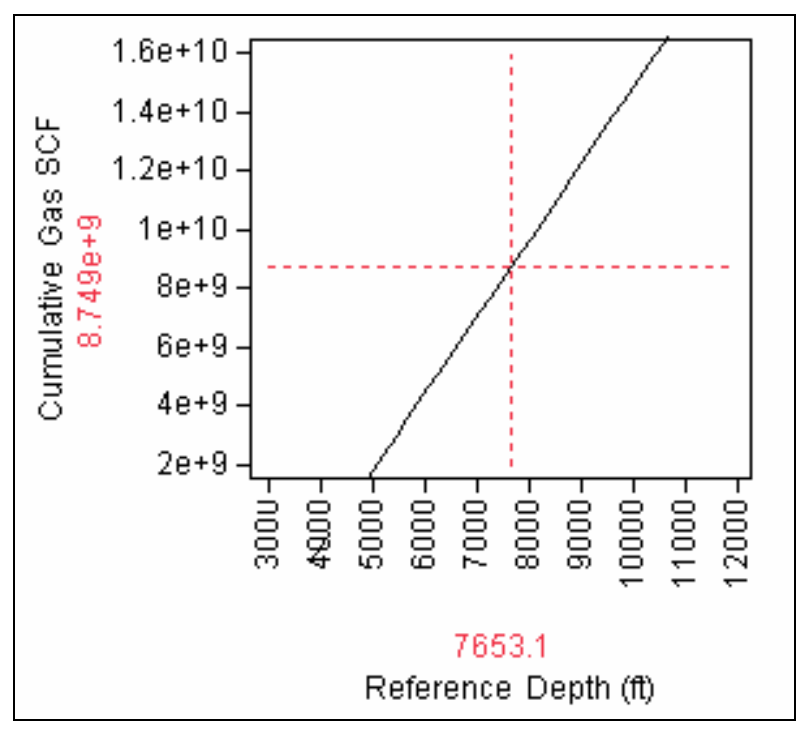

Figure 5.10: Aquifer Reference Depth Sensitivity Analysis

$\mathrm{CO}_{2}$ storage capacity of the aquifer increases with reference depth of the formation since the difference between fracture pressure and formation pressure increases with depth. Fracture pressure gradient is calculated with Eqn. 5.2. $D, P_{w}$ and $P$ are depth (ft), fracture pressure (psi), formation pressure (psi), respectively. 0.9 times this pressure is used as constraint for the maximum allowable bottom hole pressure in the simulation runs.

As it can be seen from this equation, the difference between formation pressure and fracture pressure increases as depth increase. Also, as the maximum bottom hole pressure increases, the injection rate and injection time increase.

$$
\frac{P_{w}}{D}=\frac{1}{3}\left(1+\frac{P}{D}\right)
$$




\subsubsection{Aquifer Pressure @ Reference Depth}

In the Latin Hypercube Space Filling Design created for this study, the pressure gradient range is entered to the design instead of aquifer pressure range; therefore, formation depth determines the aquifer pressure. As the pressure gradient increase, the pressure of the aquifer at specified depth increases, which cause to difference between fracture pressure and formation pressure decrease (Eqn. 5.2); for this reason, $\mathrm{CO}_{2}$ storage capacity of the aquifer decrease with increasing pressure at reference depth (Figure 5.11).

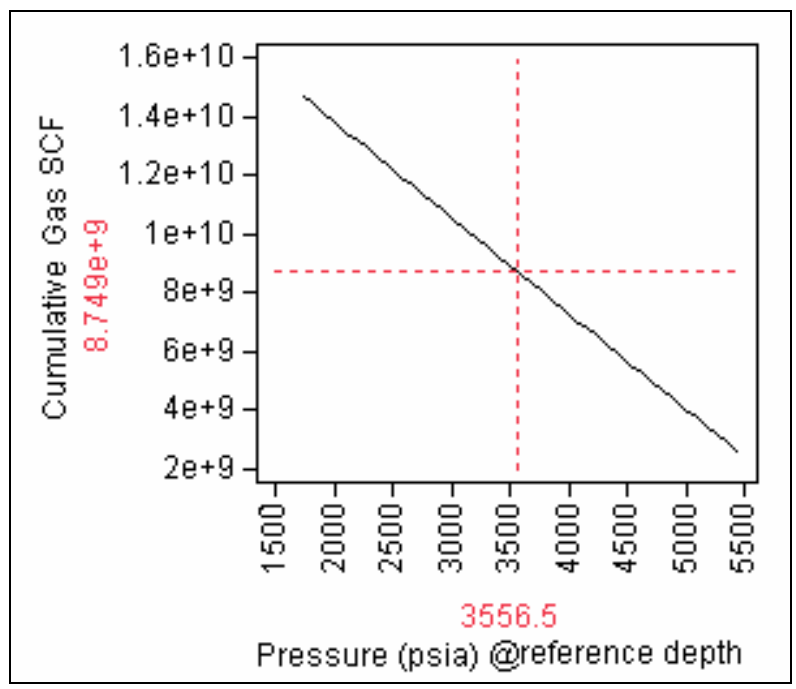

Figure 5.11: Aquifer Pressure Sensitivity Analysis

\subsubsection{Porosity of the Aquifer}

The $\mathrm{CO}_{2}$ storage capacity of the aquifer is expected to increase with porosity since porosity is directly proportional to the storage capacity of the aquifer; however, opposite trend is observed. $\mathrm{CO}_{2}$ storage capacity of the aquifer decreases with porosity due to fixed aquifer boundaries (Figure 5.12). 


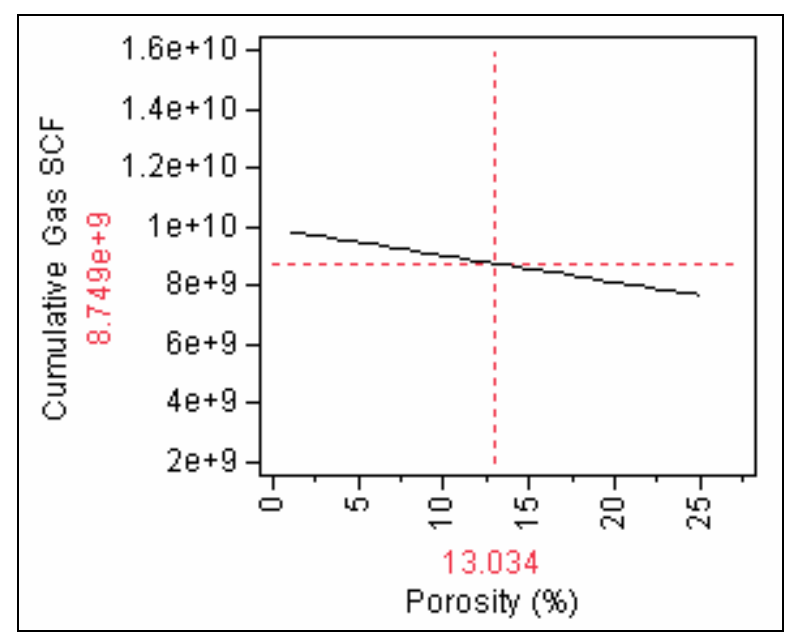

Figure 5.12: Aquifer Porosity Sensitivity Analysis

A confined aquifer has closed boundaries, which means that there is no flux in and out of the reservoir due to increase in pressure of the aquifer. For this reason, pore volume compressibility has much more effect than porosity on $\mathrm{CO}_{2}$ storage capacity. Pore volume compressibility decreases with increasing porosity.

\subsubsection{Aquifer Temperature and Formation Water Salinity}

Figure 5.13 and Figure 5.14 show the $\mathrm{CO}_{2}$ storage capacity sensitivity to temperature of the aquifer and salinity of the formation water. As it can be seen from these figures, increase in temperature of the aquifer and salinity of the formation water lead to a decrease in $\mathrm{CO}_{2}$ storage capacity of the aquifer since the solubility of $\mathrm{CO}_{2}$ decreases as temperature and salinity increase. 


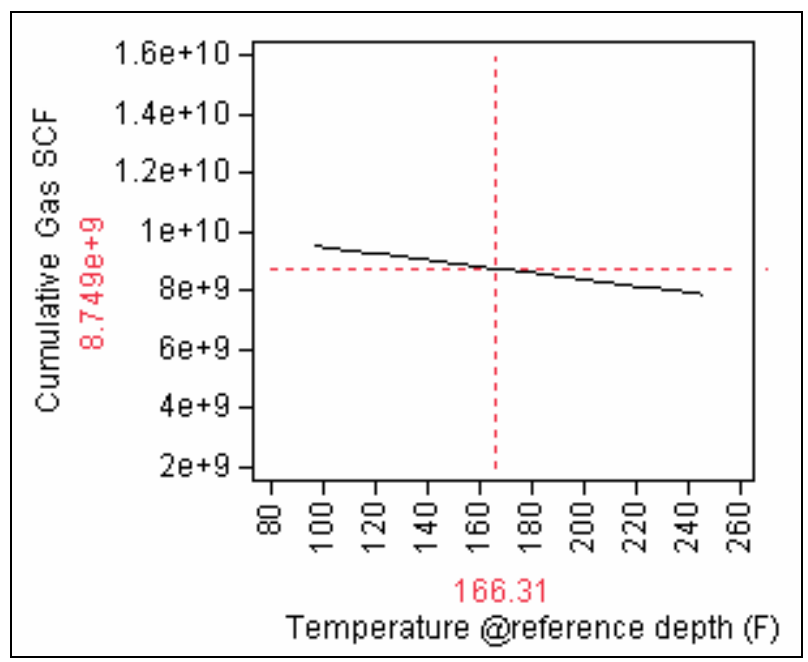

Figure 5.13: Aquifer Temperature Sensitivity Analysis

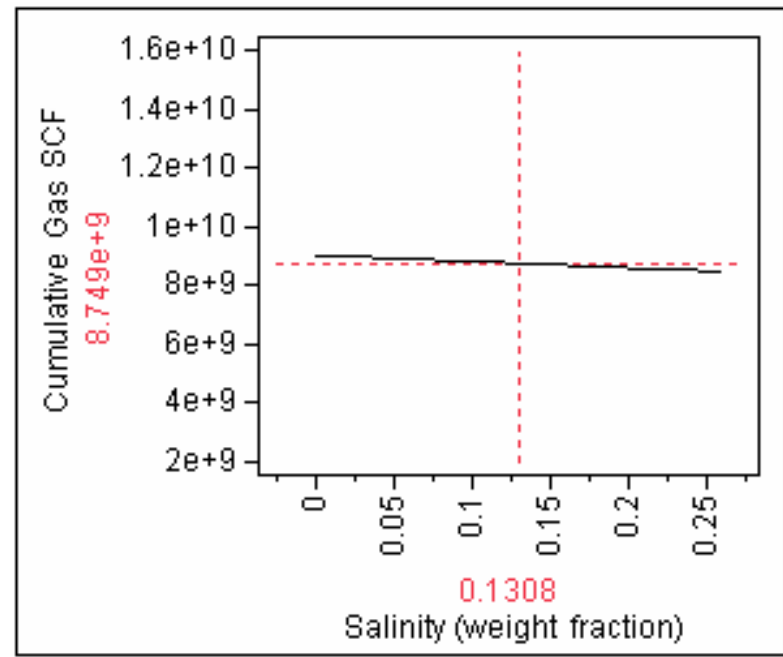

Figure 5.14: Formation Water Salinity Sensitivity Analysis

\subsubsection{Irreducible Water Saturation}

Figure 5.15 shows the $\mathrm{CO}_{2}$ storage capacity change with irreducible water saturation $\left(S_{\text {wirr }}\right) \cdot \mathrm{CO}_{2}$ storage capacity of the aquifer increases with increasing $S_{\text {wirr }}$ since the amount of $\mathrm{CO}_{2}$ dissolved in the formation water 
increases. This also decreases the aquifer pressure increase which enhances the $\mathrm{CO}_{2}$ storage.

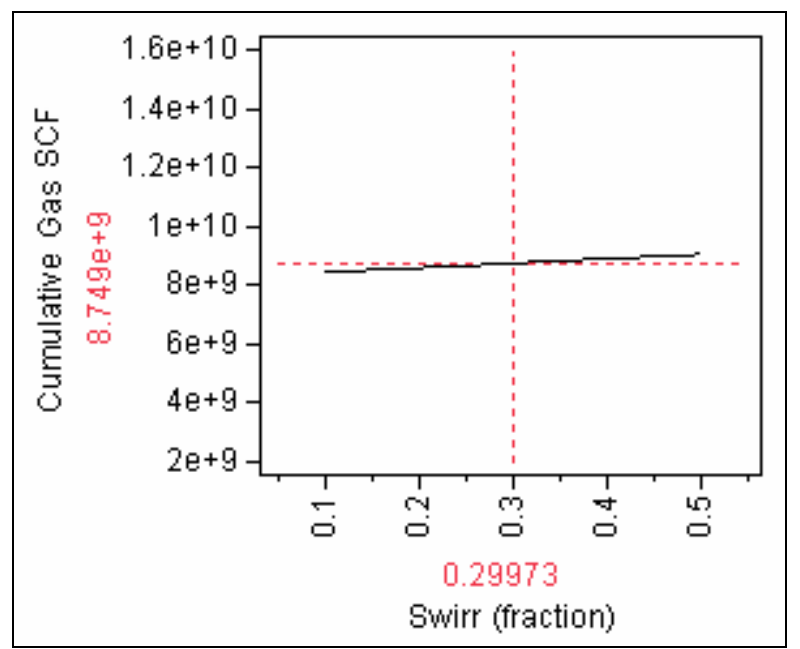

Figure 5.15: Irreducible Water Saturation Sensitivity Analysis

\subsubsection{Horizontal Permeability of the Aquifer}

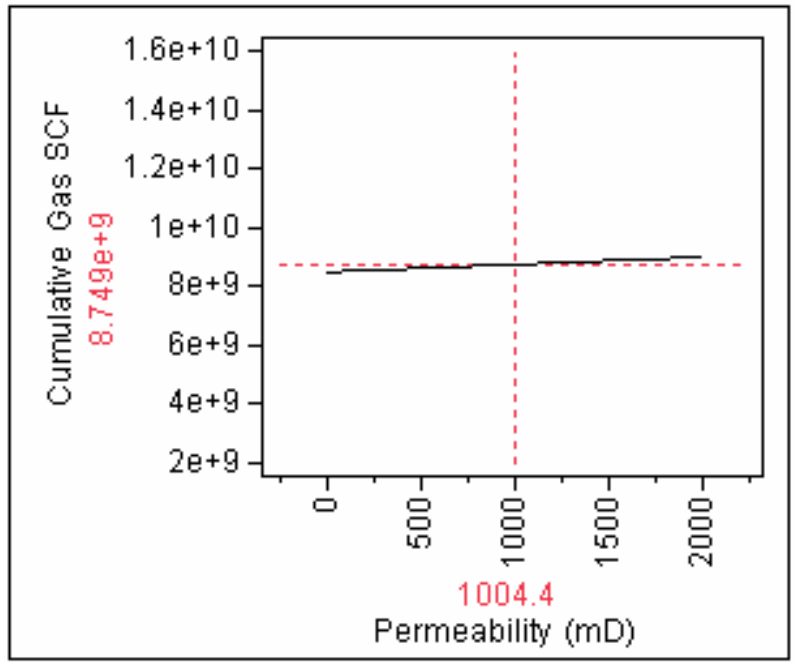

Figure 5.16: Aquifer Permeability Sensitivity Analysis 
Permeability in $\mathrm{x}$ and $\mathrm{y}$ directions are taken equal and this permeability represents the horizontal permeability of the aquifer. As horizontal permeability increases $\mathrm{CO}_{2}$ reaches aquifers boundaries faster, causing more contact with formation water and an increase in dissolution of $\mathrm{CO}_{2}$ is expected. Increase in solubility of $\mathrm{CO}_{2}$ leads to increase in $\mathrm{CO}_{2}$ storage capacity (Figure 5.16).

\subsubsection{Vertical Permeability and Dip of the Aquifer}

When $\mathrm{CO}_{2}$ is injected into the formation, it moves up due to the density difference between $\mathrm{CO}_{2}$ and formation water until it reaches an impermeable seal. Increase in formation dip (Figure 5.17) and decrease in vertical permeability of the formation (Figure 5.18) cause $\mathrm{CO}_{2}$ move laterally, which cause an increase in contact area and dissolution of $\mathrm{CO}_{2}$. Increase in $\mathrm{CO}_{2}$ dissolution enhances the $\mathrm{CO}_{2}$ storage capacity of the aquifer.

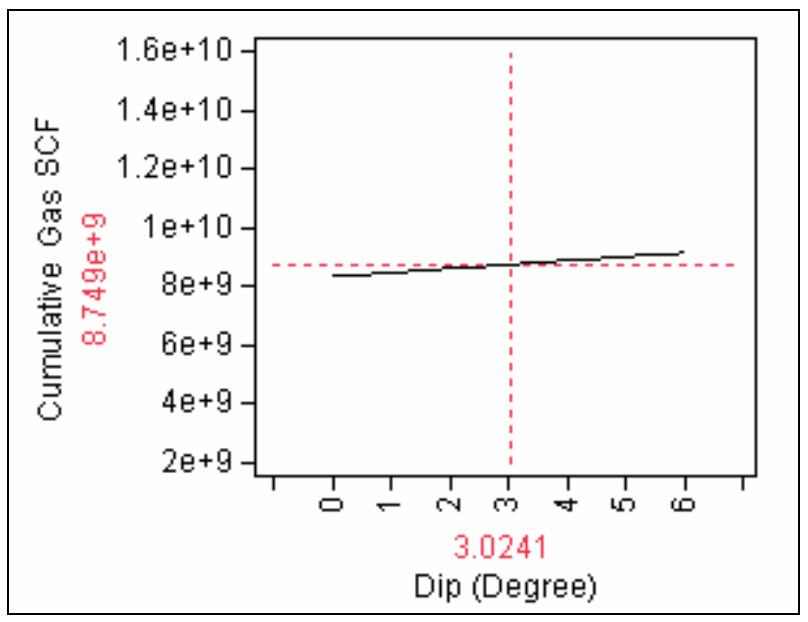

Figure 5.17: Aquifer Dip Sensitivity Analysis 


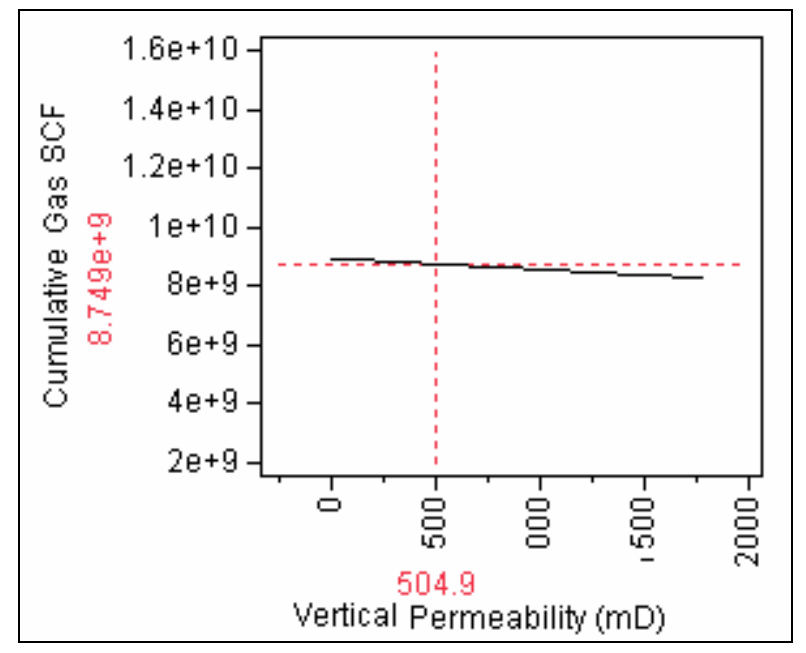

Figure 5.18: Aquifer Vertical Permeability Sensitivity Analysis

\subsubsection{Gas Relative Permeability End Point, Corey Water and Corey Gas Exponents}

Since the mobility of gas is more than mobility of water, gas is more mobile than formation water in the aquifer, causing gas to bypass water. Decrease in relative permeability of $\mathrm{CO}_{2}$ and increase in relative permeability of formation water prevent $\mathrm{CO}_{2}$ bypass and increase the gas water contact time, which enhance the solubility of $\mathrm{CO}_{2}$ and $\mathrm{CO}_{2}$ storage capacity of the aquifer.

Increase in Corey exponent causes to relative permeability decrease; therefore increase in Corey Gas Exponent (Figure 5.19) and decrease in $\mathrm{CO}_{2}$ relative permeability end point (Figure 5.20) lead to $\mathrm{CO}_{2}$ storage capacity increase, while decrease in Corey Water Exponent (Figure 5.21) causes $\mathrm{CO}_{2}$ storage capacity increase. 


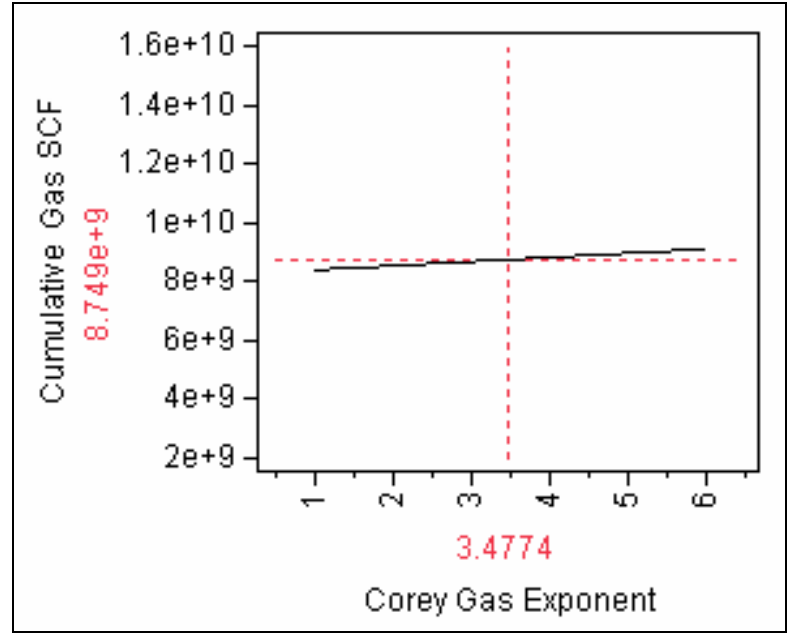

Figure 5.19: Corey Gas Exponent Sensitivity Analysis

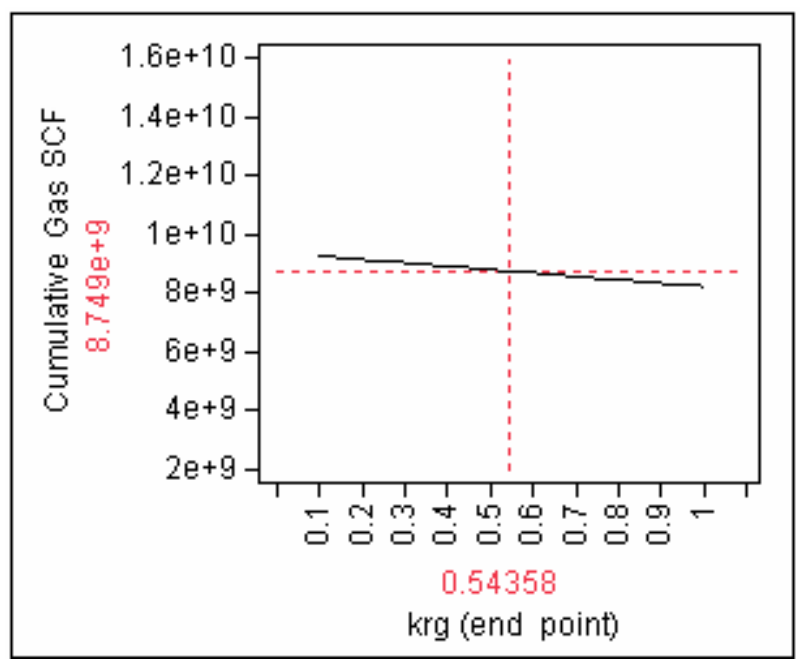

Figure 5.20: Gas Relative Permeability End Point Sensitivity Analysis 


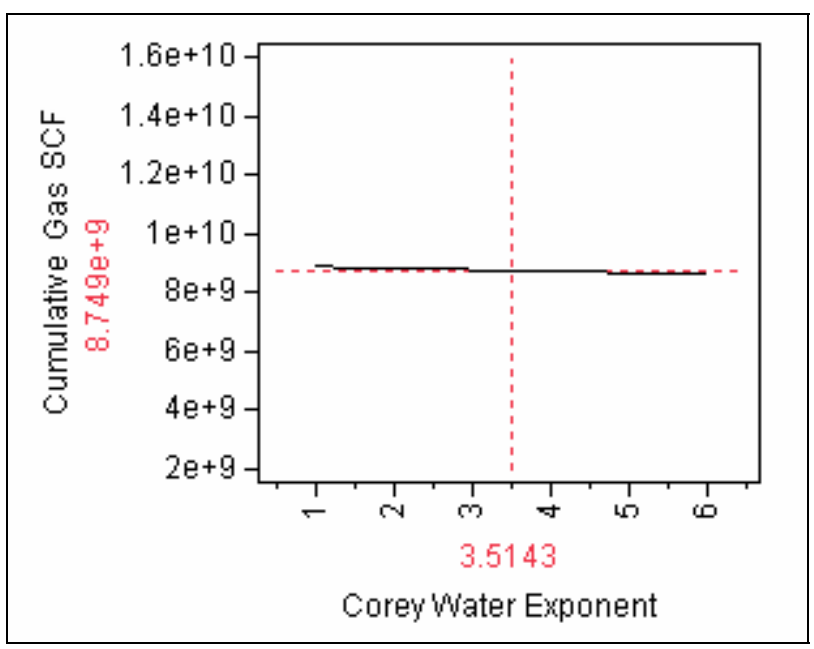

Figure 5.21: Corey Water Exponent Sensitivity Analysis

\subsubsection{Diffusion Coefficient of $\mathrm{CO}_{2}$ in Water}

Diffusion coefficient of $\mathrm{CO}_{2}$ in water slightly affects the $\mathrm{CO}_{2}$ storage capacity of the aquifer (Figure 5.22). As diffusion coefficient of $\mathrm{CO}_{2}$ increases, $\mathrm{CO}_{2}$ storage capacity of the aquifer decreases although the contact area of $\mathrm{CO}_{2}$ and water increase. The main reason for decrease in $\mathrm{CO}_{2}$ storage capacity of the aquifer can be explained with decrease in the solubility of $\mathrm{CO}_{2}$ due to the decrease in partial pressure of $\mathrm{CO}_{2}$. 


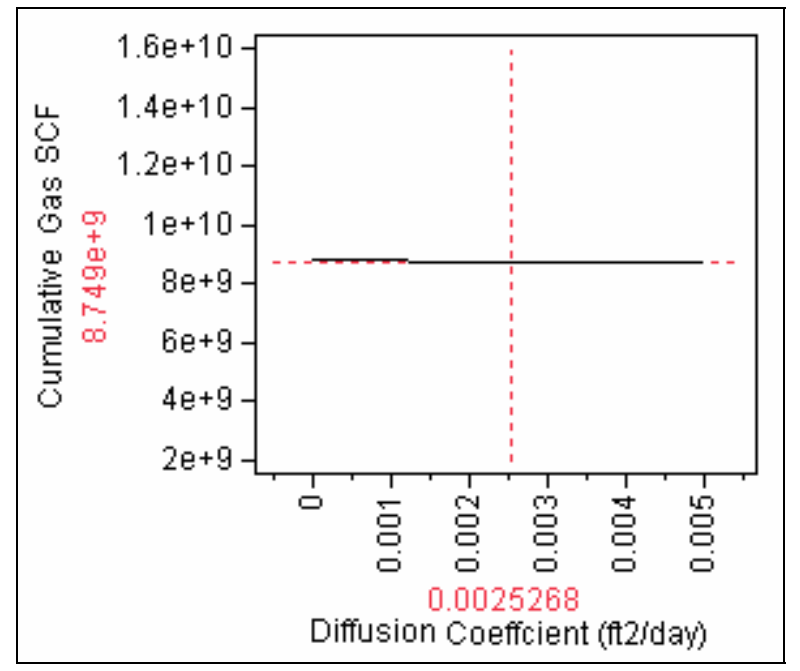

Figure 5.22: Diffusion Coefficient of $\mathrm{CO}_{2}$ Sensitivity Analysis

\subsubsection{Forward and Backward Reaction Rates}

Figure 5.23 and Figure 5.24 show the $\mathrm{CO}_{2}$ storage capacity change with forward reaction rate and backward reaction rate, respectively. Reactions depend on both reaction rate constants entered as simulation inputs and $\mathrm{CO}_{2}$ concentration of the aquifer.

Reaction rates are one of the less insensitive variables for $\mathrm{CO}_{2}$ storage capacity of the aquifer. In carbonate aquifers, $\mathrm{CO}_{2}$ dissolution decreases $\mathrm{pH}$. As it is stated in the theory part, $\mathrm{CO}_{2}(a q)$ is dominant for the lower $\mathrm{pH}$ while $\mathrm{HCO}_{3}^{-}$and $\mathrm{CO}_{3}^{2-}$ become dominant for intermediate and high $\mathrm{pH}$, respectively. For this reason, $\mathrm{CO}_{2}$ dissolution is more effective than mineralization. Increase in forward reaction rate slightly increase the gas storage capacity of the aquifer; decrease in backward reaction rate almost insensitive for the $\mathrm{CO}_{2}$ storage capacity of the aquifer. 


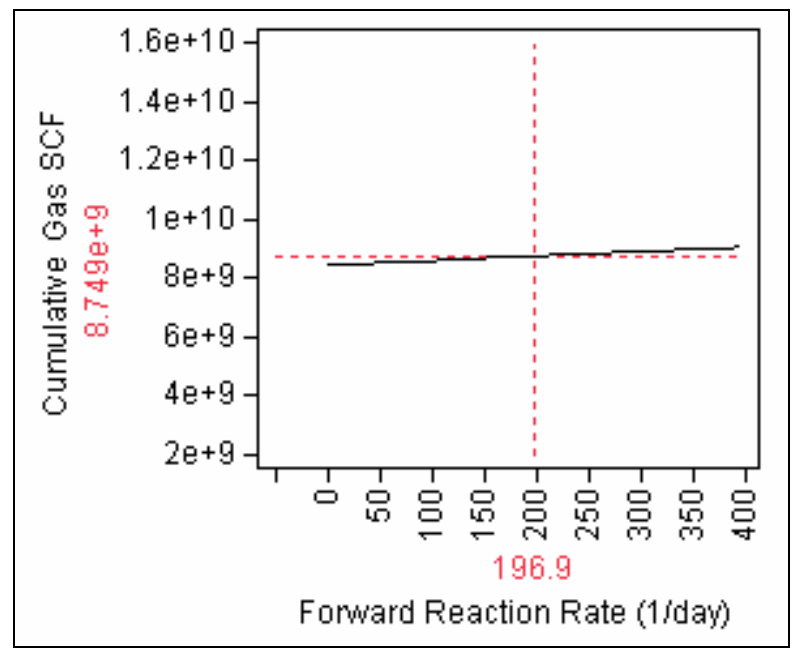

Figure 5.23: Forward Reaction Rate Sensitivity Analysis

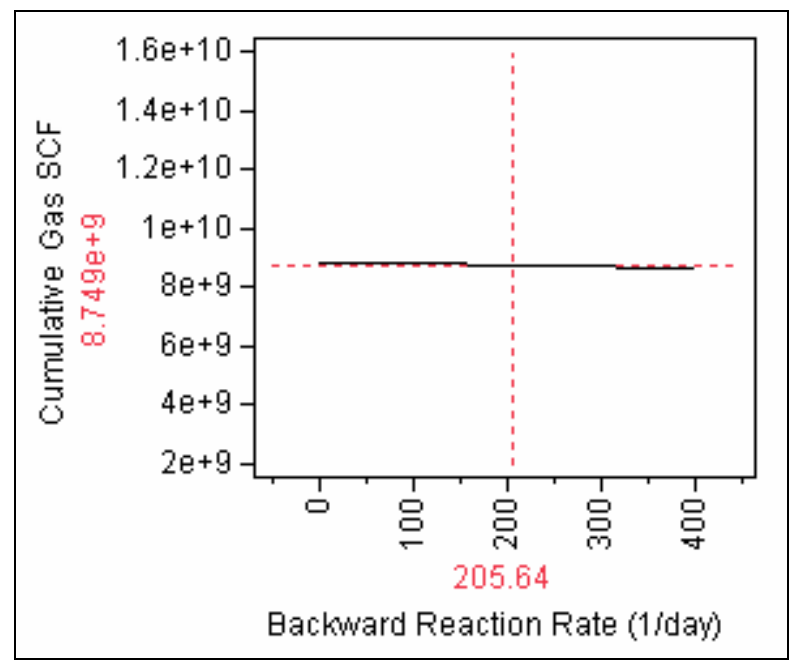

Figure 5.24: Backward Reaction Rate Sensitivity Analysis

\subsubsection{Kozeny-Carman Coefficient}

The permeability changes as porosity changes due to the dissolution and precipitation of $\mathrm{CaCO}_{3}$. The permeability change can be quantified with Kozeny-Carman Equation (Eqn. 4.4). Kozeny-Carman Coefficient effect is said to be time dependent since the porosity change results from the reactions is time dependent due to the $\mathrm{CO}_{2}$ concentration change. Also, its 
effect depends on forward and backward reaction frequencies. According to Eqn. 4.4, if the backward reaction frequency is more than that of the forward reaction, increase in Kozeny-Carman Coefficient causes an increase the $\mathrm{CO}_{2}$ storage capacity of the aquifer since the porosity ratio becomes more than 1 . On the other hand, if the forward reaction frequency is more than that of the backward reaction, increase in Kozeny-Carman Coefficient causes a decrease in $\mathrm{CO}_{2}$ storage capacity of the aquifer since the porosity ratio becomes less than 1 . During $\mathrm{CO}_{2}$ injection, $\mathrm{CO}_{2}$ moves up due to the buoyancy and remains under the impermeable layer. Therefore, forward reaction frequency is larger at the upper part of the aquifer due to more $\mathrm{CO}_{2}$ concentration while backward reaction frequency is larger at the lower part of the aquifer. For this reason, the $\mathrm{CO}_{2}$ storage capacity increases with increase in Kozeny-Carman Coefficient (Figure 5.25). However, the sensitivity of the Kozeny-Carman Coefficient is less than compared to other variables such as formation depth and temperature since reaction rates frequencies are less in carbonate formations.

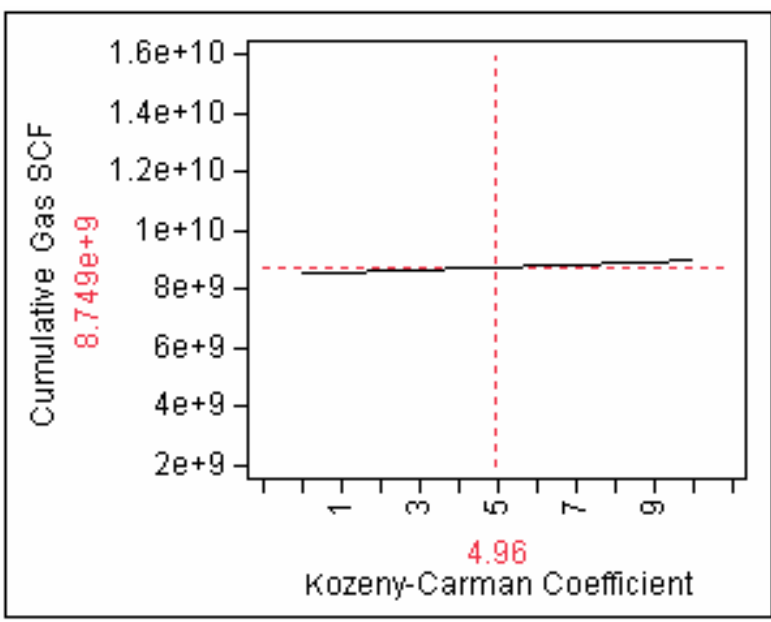

Figure 5.25: Kozeny-Carman Coefficient Sensitivity Analysis 


\subsubsection{Overall Discussion of Sensitivity Analysis}

In this section, results from the sensitivity analysis of this study are discussed using the results of sensitivity analyses found from the published literature.

Although reference depth has an indirect effect on $\mathrm{CO}_{2}$ storage capacity of the aquifer, it seems to be the most sensitive variable in this study. Reference depth determines the temperature and pressure of the aquifer. Increase in reference depth causes an increase in pressure and temperature of the formation. Increase in pressure then leads to more $\mathrm{CO}_{2}$ dissolve into formation water. Therefore; increase in $\mathrm{CO}_{2}$ storage capacity of the aquifer is expected with increase in formation pressure. However; the storage capacity of the aquifer decreases since the difference between the fracture pressure and formation pressure decrease. Kumar et al. [42] conducted a sensitivity analysis to reveal the effect of temperature on aquifer storage capacity. They found that increase in temperature of the aquifer enhances the $\mathrm{CO}_{2}$ dissolution. The reason of increase in solubility of $\mathrm{CO}_{2}$ is that increase in temperature causes a decrease in $\mathrm{CO}_{2}$ viscosity which increases mobility of $\mathrm{CO}_{2}$ and increase in contact area between $\mathrm{CO}_{2}$ and formation water. However; in this study, $\mathrm{CO}_{2}$ storage capacity is found to decrease due to decrease in $\mathrm{CO}_{2}$ dissolution in formation water. The main reason of this difference is the aquifer boundary conditions. Kumar et al. used a generic aquifer and they created constant pressure boundaries by using the production wells along all boundaries. On the other hand, the generic aquifer used in this study has closed boundaries. $\mathrm{CO}_{2}$ movement is free in the Kumar et al. study due to the constant pressure boundary while $\mathrm{CO}_{2}$ movement is restricted with closed aquifer boundaries in this study. Therefore, temperature effect on solubility is more dominant than that on $\mathrm{CO}_{2}$ viscosity.

Similarly, $\mathrm{CO}_{2}$ storage capacity of the aquifer is found to decrease with an increase in porosity due to the closed boundaries of the aquifer. 
Unfortunately, no sensitivity analysis is found related to the porosity effect on storage capacity from the literature since sensitivity analyses are conducted for specific generic or actual formations with constant pressure boundaries.

Ozah et al. [40] and Kumar et al. [42] studied the mean horizontal permeability effect on $\mathrm{CO}_{2}$ storage capacity of the aquifer. They found that mean permeability increase leads to an increase in $\mathrm{CO}_{2}$ storage capacity of the aquifer due to the increase in gas migration which results in increase in solubility of $\mathrm{CO}_{2}$ in formation water. Results found in this study are in accord with the finding of Ozah et al. and Kumar et al.

Ozah et al. [40] and Kumar et al. [42] also conducted sensitivity analyses to reveal the horizontal to vertical permeability ratio, $k_{v} / k_{h}$, and formation dip. They found that increase in formation dip and decrease in $k_{v} / k_{h}$ change the $\mathrm{CO}_{2}$ migration pattern from vertical to lateral, causing an increase in $\mathrm{CO}_{2}$ migration pathway. This migration extension increases the solubility of $\mathrm{CO}_{2}$ in formation water by increasing the contact area. This study also shows that $\mathrm{CO}_{2}$ storage capacity decreases with increase in permeability ratio and decrease in dip.

Kumar et al. [42] also studied the effect of salinity and they found that increase in salinity decreases the $\mathrm{CO}_{2}$ dissolution into formation water which is consistent with findings presented in this study [30]. This decrease of $\mathrm{CO}_{2}$ dissolution into formation water leads to a decrease in $\mathrm{CO}_{2}$ storage capacity of the aquifer.

Increase in irreducible water saturation leads to increase in $\mathrm{CO}_{2}$ storage capacity which is consistent with the study conducted by Ennis-King et al. They found that increase in residual water saturation enhances the solubility of $\mathrm{CO}_{2}$ since residual water saturation is saturated with $\mathrm{CO}_{2}[37,60]$. Dissolution of $\mathrm{CO}_{2}$ also decreases the pressure increase since the dissolved $\mathrm{CO}_{2}$ occupies less volume compared to free gas in the pores. 
Effect of Corey water and gas exponents and gas relative permeability end point were not studied in the past literature. Since these variables affect the $\mathrm{CO}_{2}$ and water movement in the aquifer, their effects can be compared with other variables affecting the $\mathrm{CO}_{2}$ and water movements. Increase in Corey gas exponent and decrease in gas relative end points decrease the movement of $\mathrm{CO}_{2}$, and decrease in Corey water exponent causes an increase in water movement. These changes decrease the bypass of $\mathrm{CO}_{2}$ and increase the contact time and contact area, which in turn increase the $\mathrm{CO}_{2}$ dissolution and $\mathrm{CO}_{2}$ storage capacity of the aquifer.

In this study, it is found that forward and backward reaction rates are less sensitive when compared to other parameters. This result is consistent with the study conducted by Zerai et al. [57] who conducted a simulation to understand the equilibrium modeling of $\mathrm{CO}_{2}$-brine-mineral reactions for sandstone and carbonate deep saline aquifers in eastern Ohio, USA. They found that change of total minerals in carbonate formation remains nearly constant since $\mathrm{CO}_{2}$ injected into a carbonate formation increases the acidity and dissolves carbonate minerals but not react with formation. They found that $\mathrm{CO}_{2}$ sequestration mechanism in carbonate host rocks are solubility and hydrodynamic trapping. They also found that increase in temperature decreases the mineralization due to an decrease in $\mathrm{CO}_{2}$ solubility. As Kozeny-Carman coefficient describes the change in permeability due to change in porosity related to the precipitation and dissolution of host rock, Kozeny-Carman coefficient can be considered to have a negligible effect on CO2 sequestration in deep saline carbonate aquifers.

Decrease in $\mathrm{CO}_{2}$ storage capacity with increase in diffusion coefficient due to the decrease in partial pressure of the $\mathrm{CO}_{2}$ is an important finding of this study. This result is consistent with the study conducted by Camper et al. [74] where they discussed the relationship between diffusion and solubility of the gases based on temperature effect. They measured the solubility of gases such as $\mathrm{CO}_{2}$, ethane and propane in room-temperature ionic liquids. By 
using these measurements, they modeled the gas diffusion as a function of temperature, gas viscosity and molecular radius of gases. They found that diffusion of gasses increases with decrease in molecular radius, increase in temperature and decrease in viscosity. Also increase in temperature enhances the diffusion since this also causes to decrease in viscosity of gases. After that they calculated the Henry's constant of gases and showed that Henry's constant is inversely proportional to the temperature. As temperature increases, Henry's constant decreases, which decreases the solubility of gases since higher partial pressure of gases is needed for dissolution. It can be simply stated that diffusion is inversely related to the solubility of $\mathrm{CO}_{2}$ due to the opposite effect of parameters affecting the diffusion and solubility of $\mathrm{CO}_{2}$.

\subsubsection{Reduced Form of the Predictive Model}

The predictive models for specified aquifers are constructed by using 16 different simulation input variables. It can be seen from the Figure 5.3, 5.4, 5.7 and 5.8, absolute percent error of the values obtained from simulations and predictive models are usually less than $\% 20$.

In most of the reservoir engineering applications, it is impossible to find a value all of the variables used in the predictive model. For this reason, the predictive model is reduced to a form containing only most sensitive variables. The sensitivity of the variables is given in decreasing order in the Pareto plot given in Figure 5.9. According to this plot, the most sensitive variables are reference depth, porosity, gas relative permeability end point, pressure at the reference depth, gas Corey coefficient, dip of the formation and finally the absolute permeability of the aquifer.

For reduced form of the predictive model, Analysis 2 of the Case 1 is used and most sensitive variables are considered. In the first and second cases of 
the reduced form, the most sensitive 6 and 7 variables are taken into account, respectively. Figure 5.26 and Figure 5.27 show the fit of the reduced predictive models with 6 and 7 variables, respectively. Table 5.5 and Table 5.6 give the statistical analysis of this 2 reduced form and predictive models coefficients, respectively.

To evaluate the goodness of the fit of the reduced form of the predictive models, the error between the value obtained from the simulation and the value obtained from the predictive model is calculated for these two cases. Figure 5.28 and Figure 5.29 give the absolute percent error of these two fits.

From the statistical analysis of the models, the correlation coefficients decrease as the number of variables decrease. However, the decrease is acceptable since most of the absolute percent errors are less than $20 \%$.

Table 5.5: Case1 and Case 2, Statistical Analysis of Reduced Form of Linear Predictive Models

\begin{tabular}{|l|r|l|}
\cline { 2 - 3 } \multicolumn{1}{c|}{} & \multicolumn{1}{c|}{ Case 1 } & Case 2 \\
\hline RSquare & 0.785744 & 0.785879 \\
\hline RSquare Adj & 0.77146 & 0.769038 \\
\hline Root Mean Square Error & $1.22 \mathrm{E}+09$ & $1.23 \mathrm{E}+09$ \\
\hline Mean of Response & $8.75 \mathrm{E}+09$ & $8.75 \mathrm{E}+09$ \\
\hline Observations & 97 & 97 \\
\hline
\end{tabular}

Table 5.6: Case 1 and Case 2, Reduced Form of Linear Predictive Model Variables and Coefficients

\begin{tabular}{|r|l|r|r|}
\hline \multirow{2}{*}{$i$} & \multicolumn{1}{|c|}{ Variable $\left(x_{i}\right)$} & Case 1 (6 variables) & Case 2 (7 variables) \\
\cline { 3 - 4 } & & Coefficient $\left(a_{i}\right)$ & Coefficient $\left(a_{i}\right)$ \\
\hline 1 & Constant & 2776471119.405 & 2745406464.278 \\
\hline 2 & Reference Depth & 2169583.091 & 2164112.238 \\
\hline 3 & Porosity & -88132132.421 & -88420422.534 \\
\hline 4 & krg (end point) & -1139007131.536 & -1143461766.086 \\
\hline 5 & Pressure & -2759010.800 & -2749099.256 \\
\hline 6 & Corey Gas Exponent & 152184033.775 & 150134369.100 \\
\hline 7 & Formation Dip & 138896132.634 & 138789312.334 \\
\hline 8 & Permeability & - & 51090.039 \\
\hline
\end{tabular}




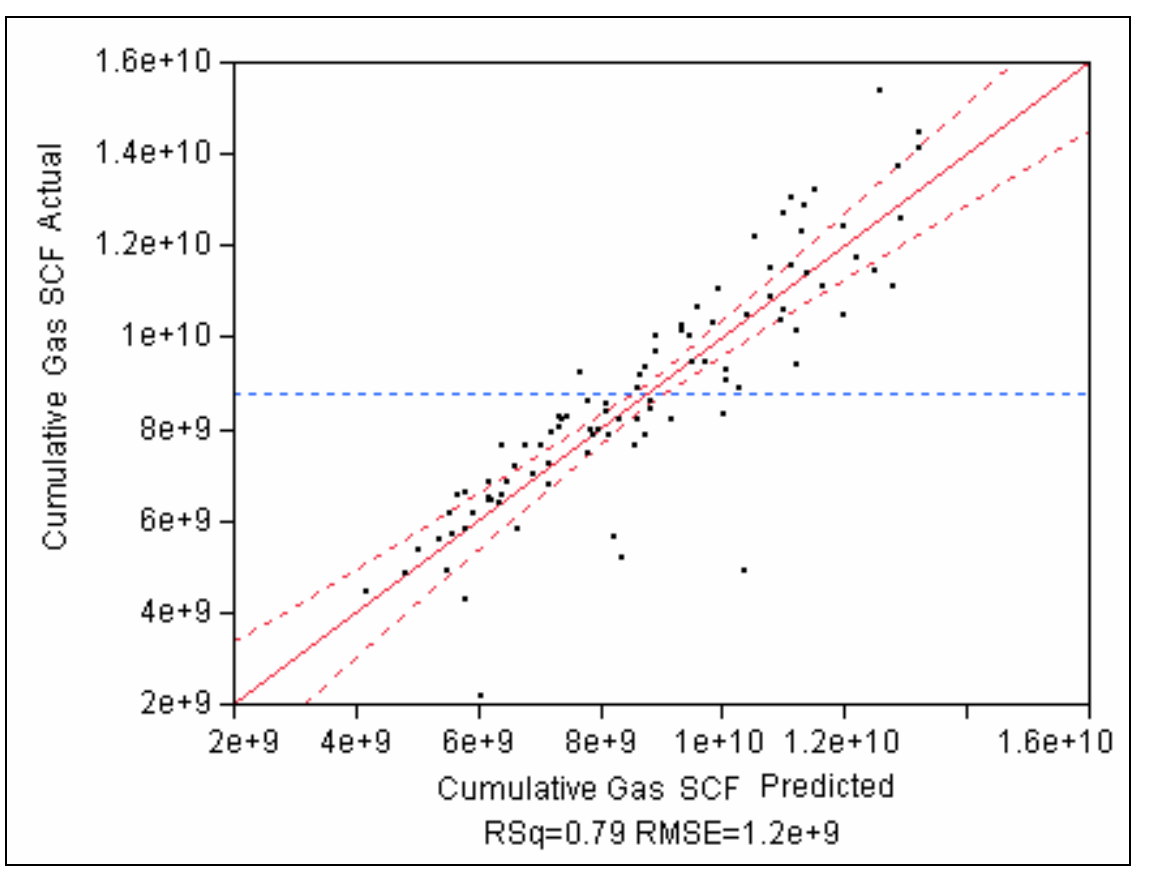

Figure 5.26: Reduced Form, Case 1, Linear Predictive Model Fit

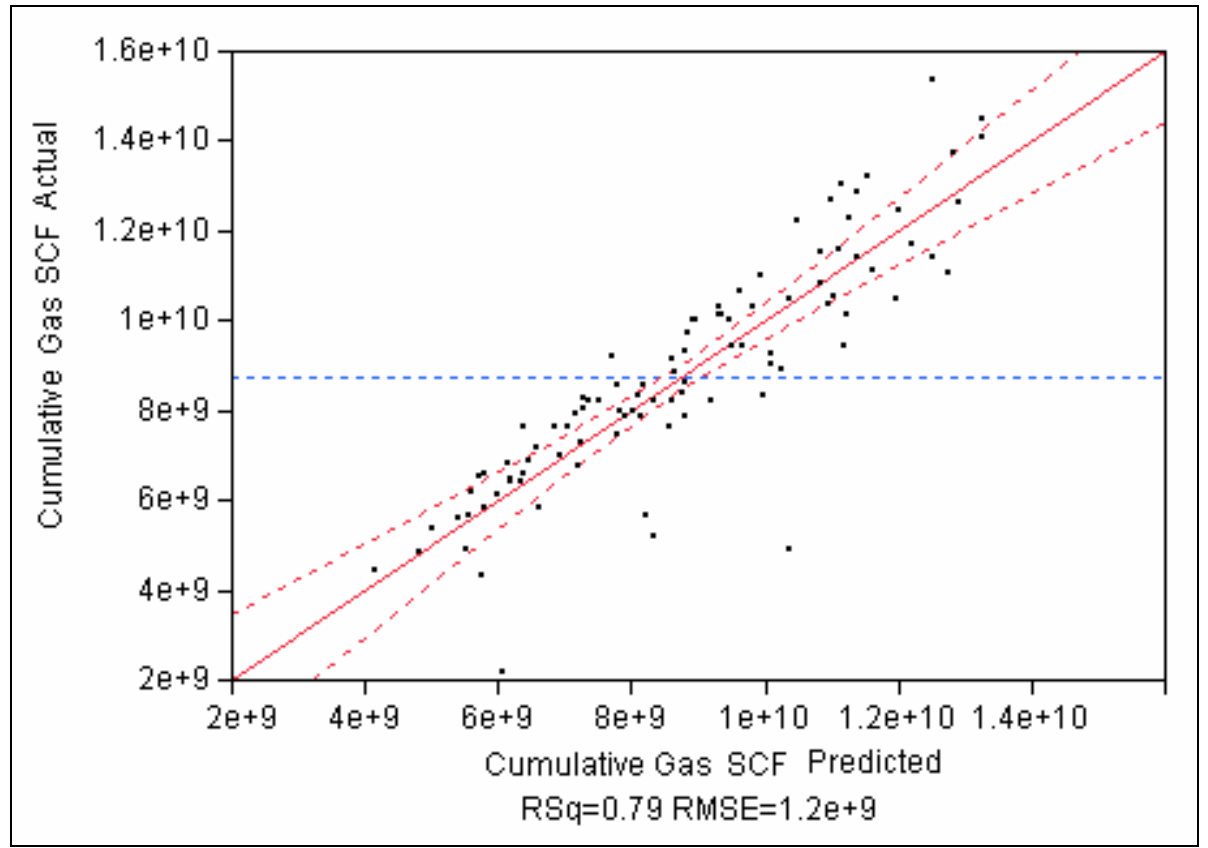

Figure 5.27: Reduced Form, Case 2, Linear Predictive Model Fit 


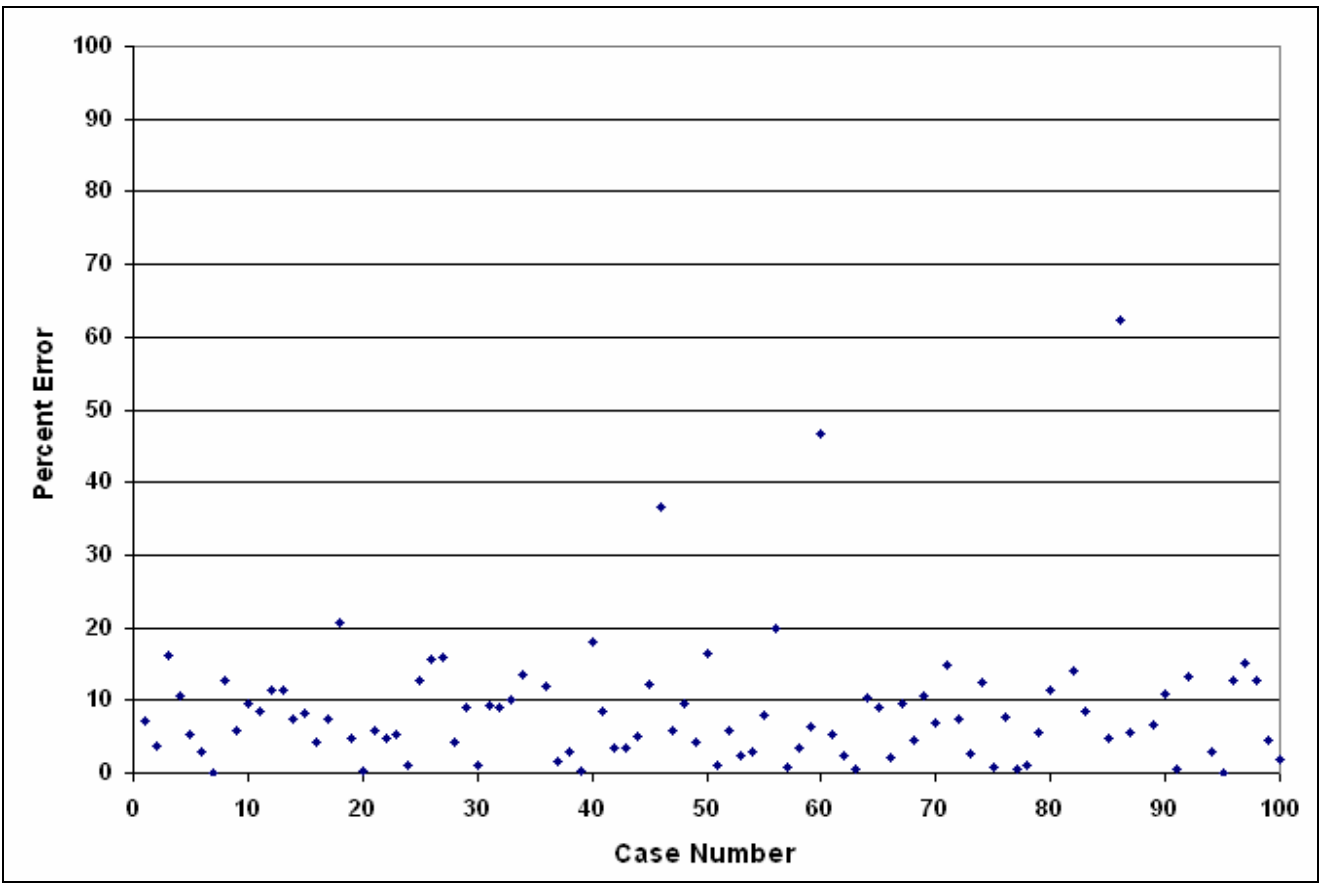

Figure 5.28: Reduced Form, Case 1, Absolute Percent Error between Simulated and Predicted Results

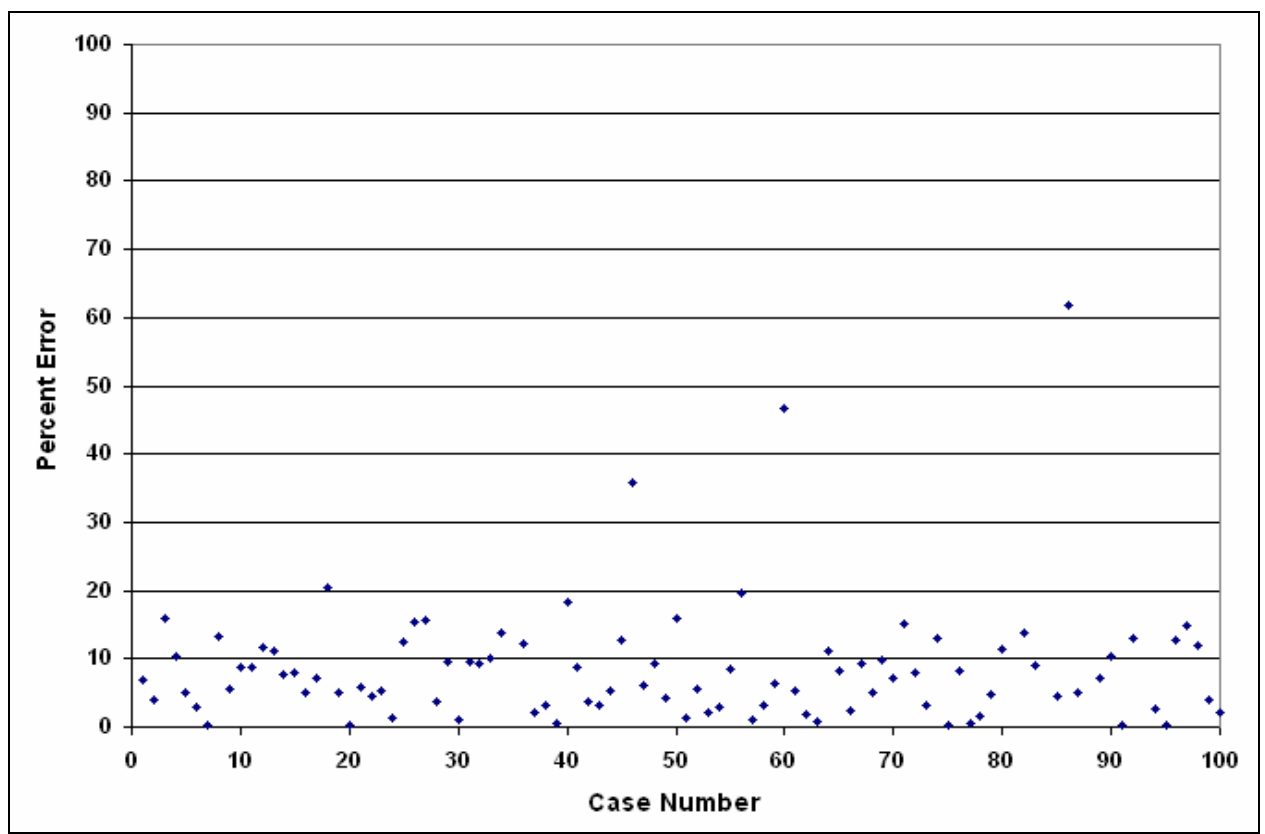

Figure 5.29: Reduced Form, Case 2, Absolute Percent Error between Simulated and Predicted Results 


\subsection{Predictive Models for $\mathrm{CO}_{2}$ Trapping Mechanisms in Deep Saline Carbonate Aquifers}

There are three $\mathrm{CO}_{2}$ trapping mechanisms, hydrodynamic trapping, solubility trapping and mineral trapping. When $\mathrm{CO}_{2}$ is injected into the formation, it moves laterally due to the pressure exerted by the injection well and moves up due to the buoyancy until it reaches impermeable layer, cap rock. Some part of the $\mathrm{CO}_{2}$ injected into the formation remains as a free gas under this impermeable layer. Trapping as free gas is called hydrodynamic trapping. When $\mathrm{CO}_{2}$ contacts formation water, it dissolves into formation water (solubility trapping) and reacts with formation water to form a weak carbonic acid, $\mathrm{H}_{2} \mathrm{CO}_{3}$, and this weak carbonic acid dissociates into bicarbonate $\left(\mathrm{HCO}_{3}^{-}\right)$and carbonate $\left(\mathrm{CO}_{3}^{2-}\right)$. Bicarbonate ions react with divalent cations such as $\mathrm{Ca}^{2+}$ and $\mathrm{Mg}^{2+}$ to form a mineral $\mathrm{CaCO}_{3}$ and $\mathrm{MgCO}_{3}$ and precipitate (mineralization trapping).

The number of moles of $\mathrm{CO}_{2}$ injected into the formation, remaining as free gas, dissolving into formation water and reacting with divalent cations to form a mineral are calculated to develop predictive models for total injected $\mathrm{CO}_{2}$ and for these trapping mechanisms.

The volume of $\mathrm{CO}_{2}$ injected into the aquifer is known; therefore, the number of moles of $\mathrm{CO}_{2}$ can be easily calculated with an Equation of State for the real gas. Figure 5.30 gives the predictive model fit constructed for injected $\mathrm{CO}_{2}$.

If the predictive model for number of moles of $\mathrm{CO}_{2}$ and predictive model for $\mathrm{CO}_{2}$ volume injected into aquifer are compared, it can be seen that correlation coefficient decreases from 0.81 to 0.78 . The main reason for this decrease can be explained by a small error at $\mathrm{CO}_{2}$ compressibility factor $(z)$ calculation since $z$ factor is calculated with an iterative manner given in Appendix E. 
The number of moles of $\mathrm{CO}_{2}$ precipitates as a mineral is calculated from the concentration of $\mathrm{Ca}\left(\mathrm{HCO}_{3}\right)_{2}$. Before $\mathrm{CO}_{2}$ injection, there is no $\mathrm{Ca}\left(\mathrm{HCO}_{3}\right)_{2}$ mineral due to the absence of $\mathrm{CO}_{2}$ in the aquifer. For this reason, the number of moles of $\mathrm{Ca}\left(\mathrm{HCO}_{3}\right)_{2}$ after the simulation run directly gives the number of moles of $\mathrm{CO}_{2}$ reacting with $\mathrm{CaCO}_{3}$. Figure 5.31 shows the predictive model fit constructed for mineral trapping.

The concentration of $\mathrm{CO}_{2}$ remaining as a free gas under the impermeable layer is exported from CMG STARS and the number of moles of $\mathrm{CO}_{2}$ is calculated with the aforementioned Equation of State. Figure 5.32 shows the predictive model fit constructed for free gas.

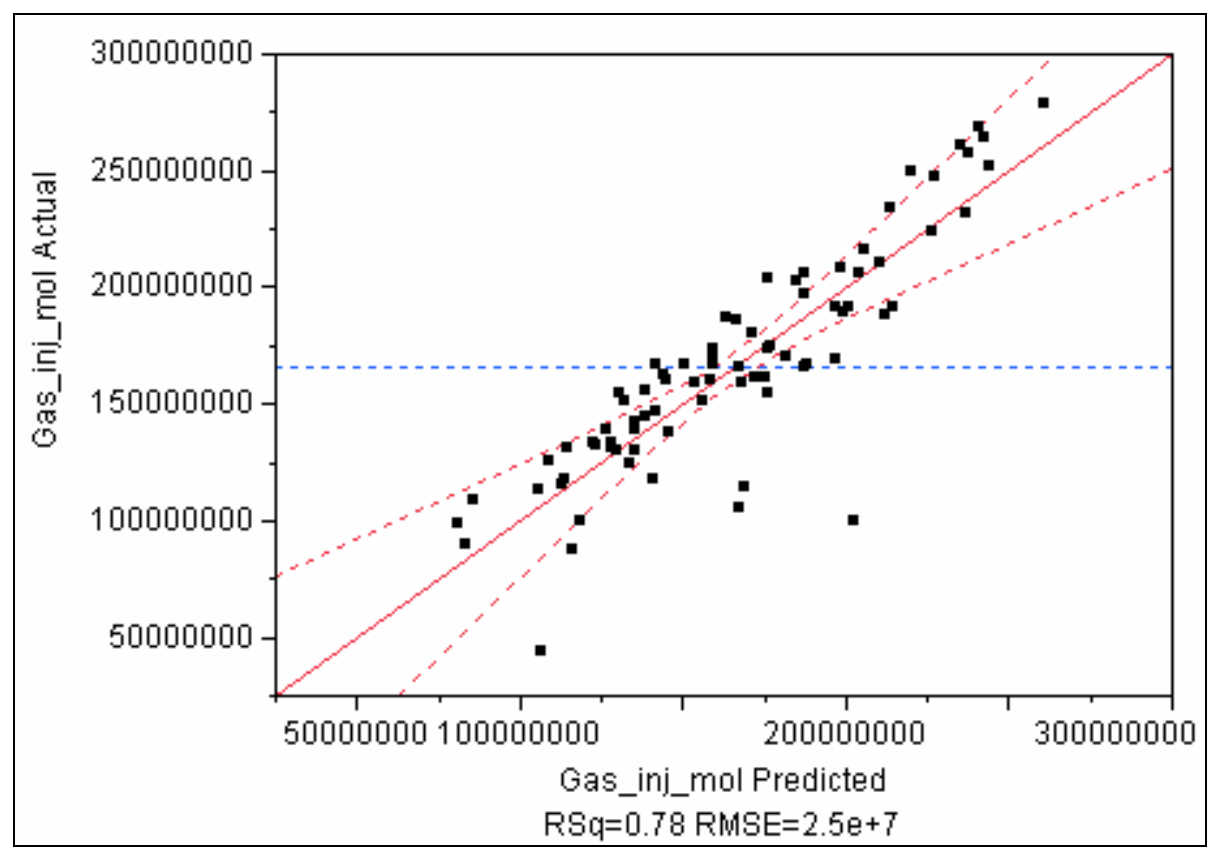

Figure 5.30: Injected $\mathrm{CO}_{2}$ Moles Number, Linear Predictive Model Fit 


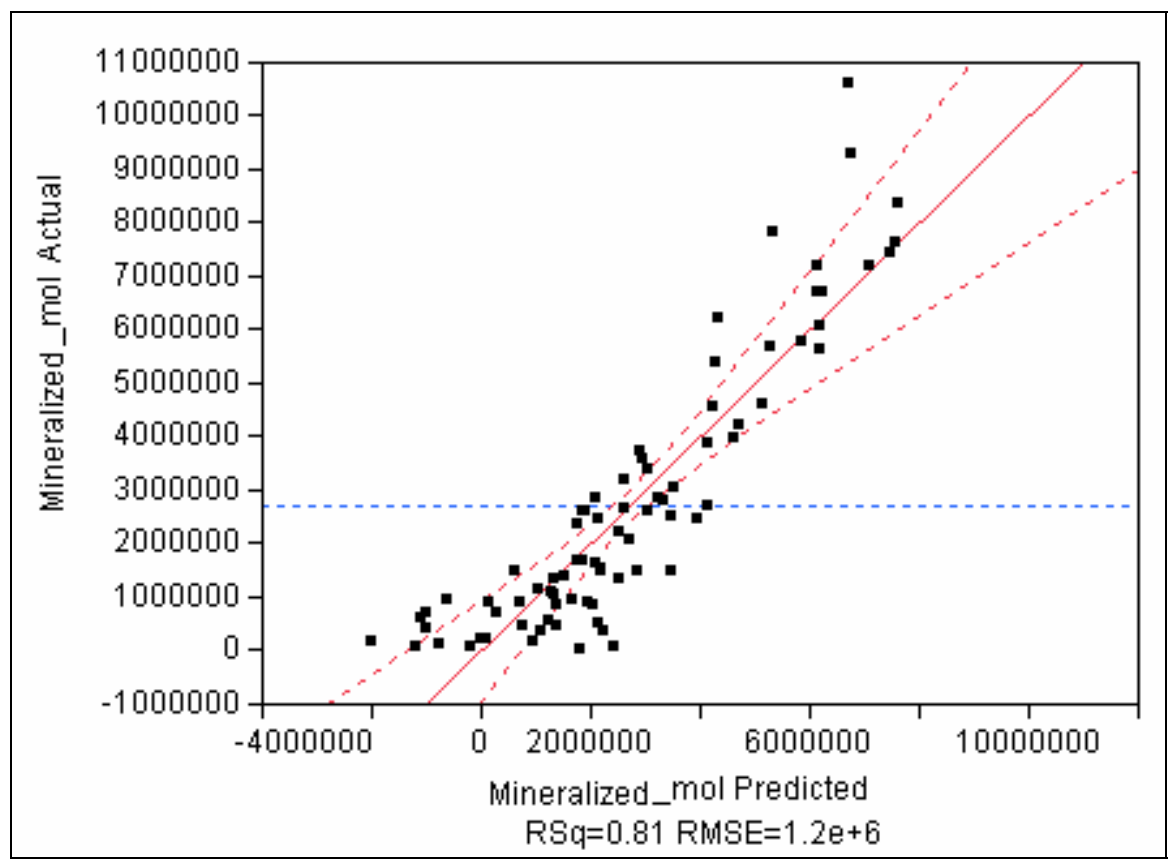

Figure 5.31: Mineralization Trapping, Linear Predictive Model Fit

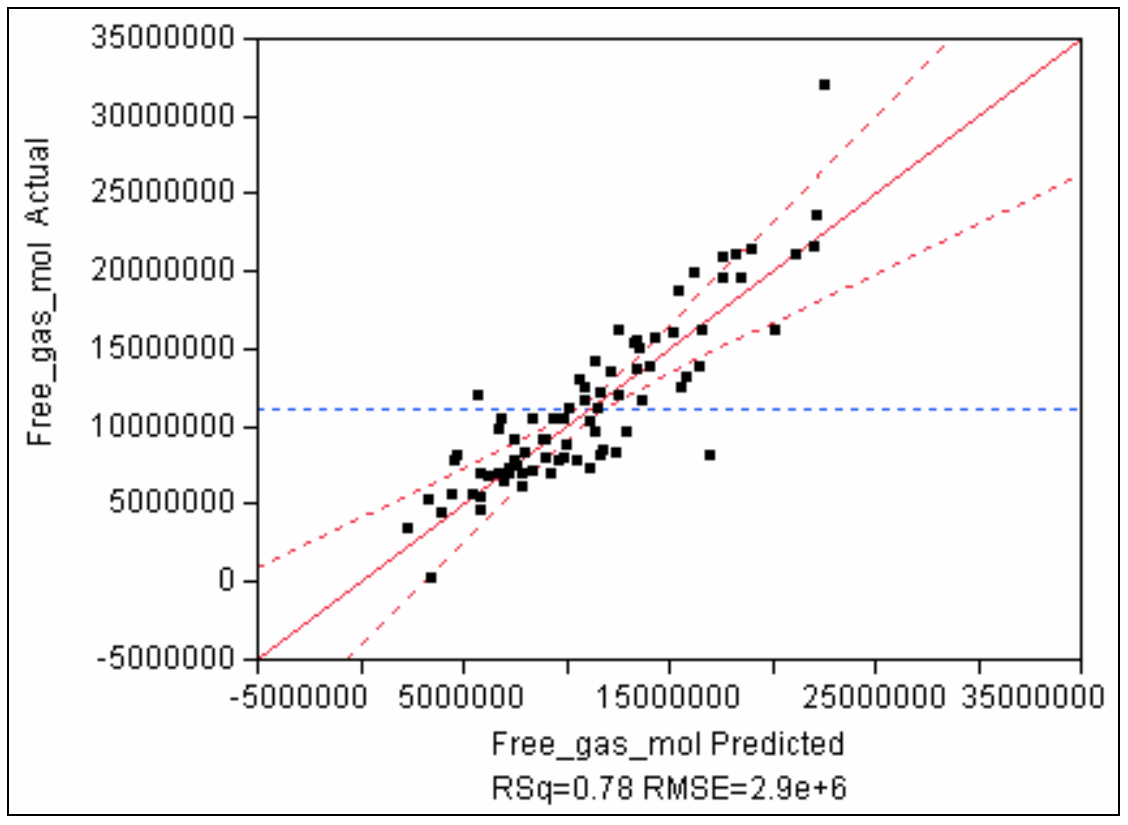

Figure 5.32: Hydrodynamic Trapping, Linear Predictive Model Fit 
The number of moles of $\mathrm{CO}_{2}$ dissolved into formation water is calculated from the difference between the injected moles of $\mathrm{CO}_{2}$ and mineralized and free moles of $\mathrm{CO}_{2}$. The predictive model fit for dissolved $\mathrm{CO}_{2}$ is shown in Figure 5.33.

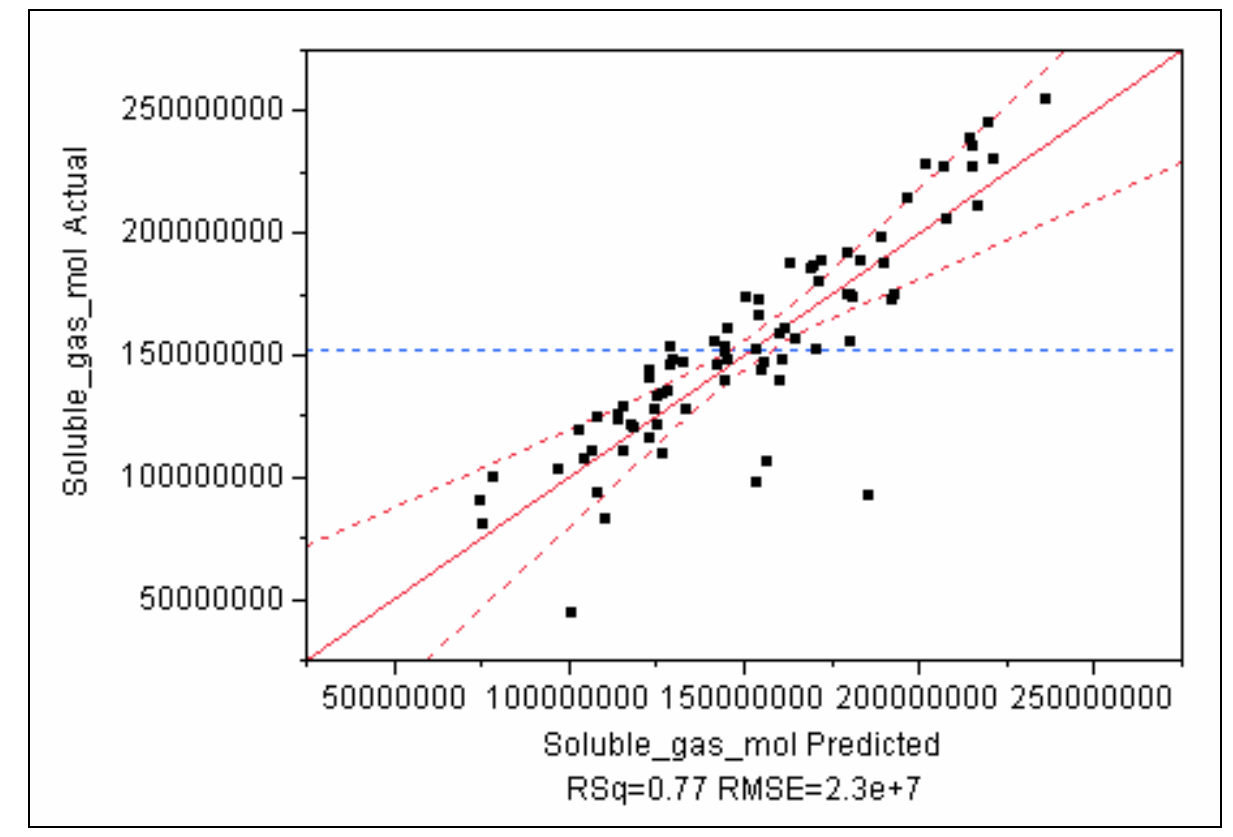

Figure 5.33: Solubility Trapping, Linear Predictive Model Fit

Table 5.7 and Table 5.8 give the statistical analysis of predictive models constructed for injected moles of $\mathrm{CO}_{2}$ and three trapping mechanisms, and predictive equation variable and coefficients. 
Table 5.7: Injected Moles of $\mathrm{CO}_{2}$ and Trapping Mechanisms, Statistical Analysis of Linear Predictive Models

\begin{tabular}{|l|c|c|c|c|}
\cline { 2 - 5 } \multicolumn{1}{c|}{} & $\begin{array}{c}\text { CO2 } \\
\text { injected }\end{array}$ & Mineralization & $\begin{array}{c}\text { Hydrodynamic } \\
\text { Trapping }\end{array}$ & $\begin{array}{c}\text { Solubility } \\
\text { Trapping }\end{array}$ \\
\hline RSquare & 0.777564 & 0.814617 & 0.777063 & 0.771126 \\
\hline Rsquare Adj & 0.721073 & 0.767536 & 0.720444 & 0.712999 \\
\hline $\begin{array}{l}\text { Root Mean Square } \\
\text { Error }\end{array}$ & 25070846 & 1225877 & 2882640 & 22818166 \\
\hline Mean of Response & $1.66 \mathrm{E}+08$ & 2703710 & 11198766 & $1.52 \mathrm{E}+08$ \\
\hline Observations & 80 & 80 & 80 & 80 \\
\hline
\end{tabular}

Table 5.8: Injected Moles of $\mathrm{CO}_{2}$ and Trapping Mechanisms, Linear Predictive Model Variables and Coefficients

\begin{tabular}{|c|c|c|c|c|c|}
\hline \multirow[b]{2}{*}{$i$} & \multirow[b]{2}{*}{ Variable $\left(X_{i}\right)$} & Injected $\mathrm{CO}_{2}$ & Mineralization & $\begin{array}{l}\text { Solubility } \\
\text { Trapping }\end{array}$ & $\begin{array}{l}\text { Hydrodynamic } \\
\text { Trapping }\end{array}$ \\
\hline & & $\begin{array}{c}\text { Coefficient } \\
\left(a_{i}\right)\end{array}$ & $\begin{array}{c}\text { Coefficient } \\
\left(a_{i}\right)\end{array}$ & $\begin{array}{c}\text { Coefficient } \\
\left(a_{i}\right)\end{array}$ & $\begin{array}{c}\text { Coefficient } \\
\left(a_{i}\right)\end{array}$ \\
\hline 1 & Constant & 50533704.5 & -3955886.2 & 56792748.4 & -2303157.7 \\
\hline 2 & Porosity & -1879199.3 & 158146.4 & -1801821.5 & -235524.1 \\
\hline 3 & Permeability & 8614.8 & -581.8 & 8001.8 & 1194.8 \\
\hline 4 & \begin{tabular}{|l|} 
Vertical \\
Permeability
\end{tabular} & -11666.5 & -451.4 & -9300.9 & -1914.1 \\
\hline 5 & $\begin{array}{l}\text { Reference } \\
\text { Depth }\end{array}$ & 51676.8 & 690.4 & 46291.4 & 4695.1 \\
\hline 6 & Pressure & -55283.9 & -819.3 & -47858.8 & -6560.8 \\
\hline 7 & Temperature & -392020.9 & -7177.9 & -404686.9 & 19843.9 \\
\hline 8 & Salinity & -29631412.8 & 1008731.0 & -28037814.0 & -2602329.8 \\
\hline 9 & Swirr & 47538608.6 & 5696890.1 & 38913859.44 & 2927859.1 \\
\hline 10 & krg (end point) & -24280719.8 & -549539.0 & -21148589.1 & -2582591.7 \\
\hline 11 & $\begin{array}{l}\text { Corey Water } \\
\text { Exponent }\end{array}$ & -794076.4 & 193039.9 & 1064012.082 & 76895.8 \\
\hline 12 & \begin{tabular}{|l|} 
Corey Gas \\
Exponent \\
\end{tabular} & 2035312.1 & 326568.6 & 1510601.420 & 198142.1 \\
\hline 13 & $\begin{array}{l}\text { Kozeny-Carman } \\
\text { Coefficient }\end{array}$ & 959559.2 & 123299.6 & 816358.828 & 19900.8 \\
\hline 14 & \begin{tabular}{|l|} 
Diffusion \\
Coefficient \\
\end{tabular} & 150364102 & 183163988.9 & -25911572.2 & -6888314.8 \\
\hline 15 & $\begin{array}{l}\text { Forward } \\
\text { Reaction Rate }\end{array}$ & 15534.8 & 10206.6 & 13381.5 & -8053.3 \\
\hline 16 & $\begin{array}{l}\text { Backward } \\
\text { Reaction Rate }\end{array}$ & 6860.8 & -9139.7 & 2877.9 & 13122.6 \\
\hline 17 & Formation Dip & 1881335.6 & -76265.4 & 1776963.7 & 180637.3 \\
\hline
\end{tabular}


Figure 5.34 shows comparison of the number of moles of $\mathrm{CO}_{2}$ for each trapping mechanism in percent of total $\mathrm{CO}_{2}$ injected in the aquifer. As it is seen from the figure, most part of the injected $\mathrm{CO}_{2}$ dissolves in the formation water. The most effective trapping mechanism is the solubility trapping followed by hydrodynamic trapping. The least effective trapping mechanism is the mineralization due to calcium carbonate formation. This result is consistent with sensitivity analysis since $\mathrm{CO}_{2}$ storage capacity of the aquifer is much more sensitive to the variable affecting the solubility of $\mathrm{CO}_{2}$.

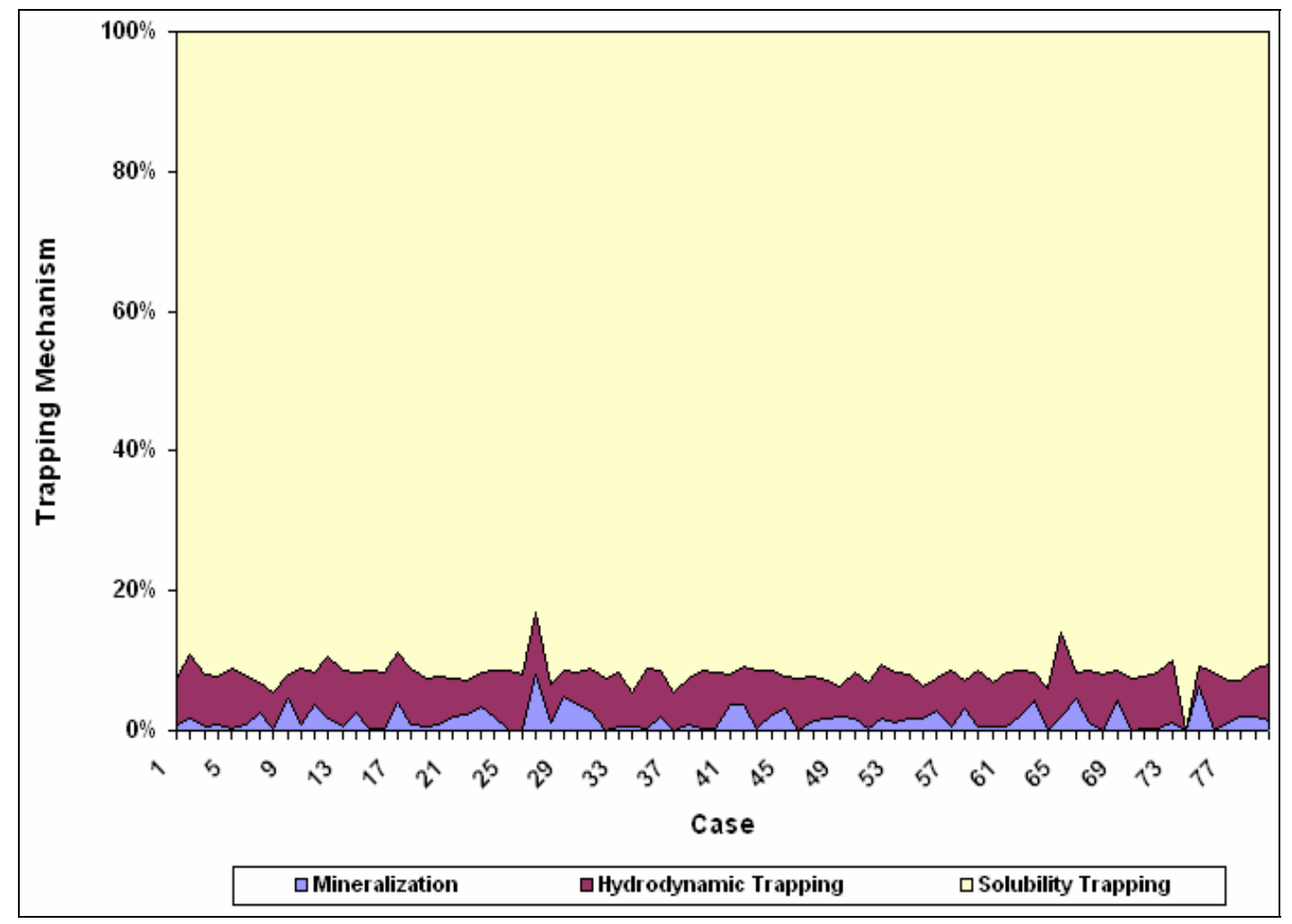

Figure 5.34: $\mathrm{CO}_{2}$ Trapping Mechanisms Comparison 


\subsection{Dimensionless Predictive Model Construction for $\mathrm{CO}_{2}$ Sequestration in Deep Saline Carbonate Aquifers}

Dimensionless Predictive Model is constructed by using the results of the Case 1-2-3 and four analyses are made. In the first analysis, a linear predictive model is constructed with least square method, which is a function of simulation input variables as well as grid dimensions. Figure 5.35 gives the fit of the linear dimensionless predictive model of the first analysis.

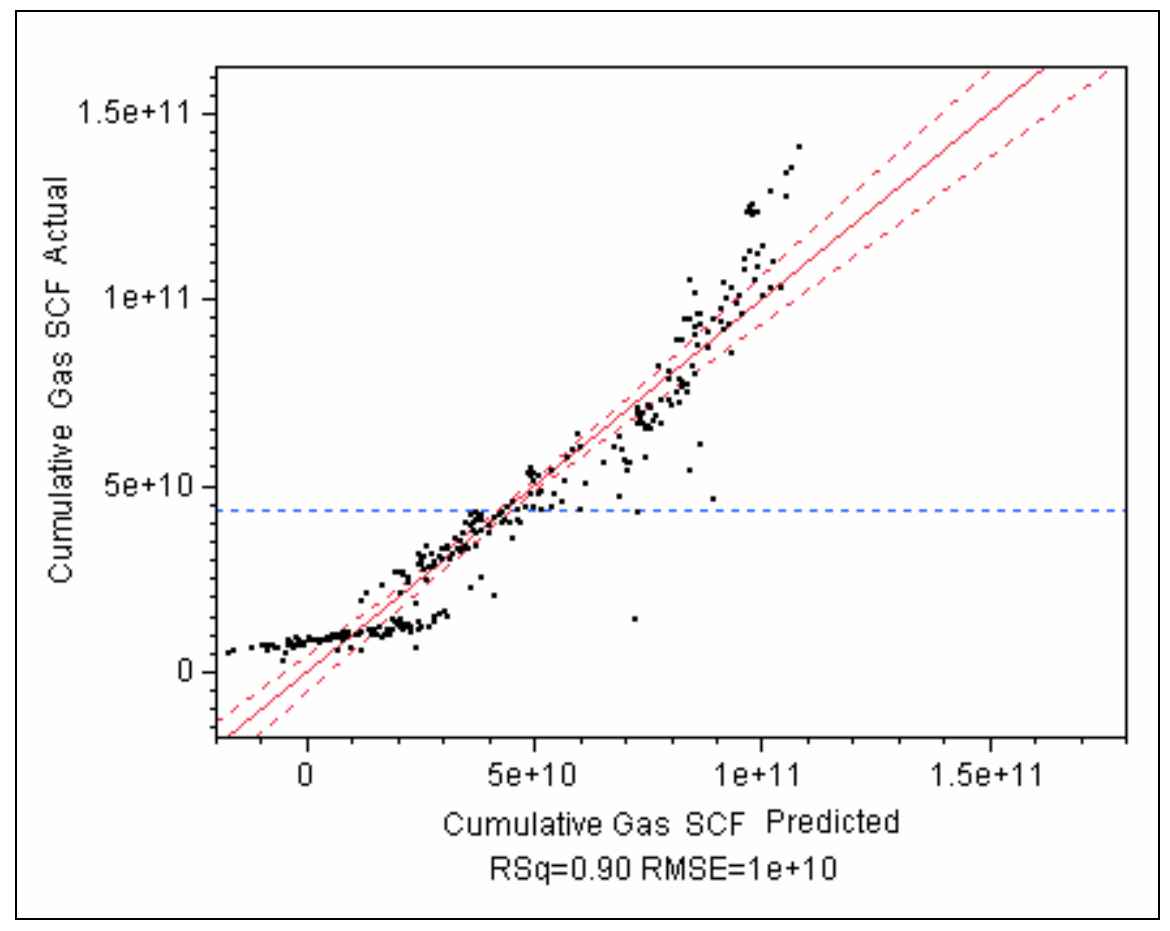

Figure 5.35: Analysis 1, Linear Dimensionless Predictive Model Fit

As it is seen from Figure 5.35, the linear dimensionless predictive model (Table 5.9) overestimates the lower $\mathrm{CO}_{2}$ storage capacities and underestimates higher $\mathrm{CO}_{2}$ storage capacities of the aquifer. The curvature of estimate can be defined with nonlinear equations if simulation results are 
divided by pore volume and the linear equation (Table 5.9, Analysis 2) defined as $x$. The nonlinear predictive model, $y$ can be written in terms of $x$ given in Eqn. 5.3.

$y=3.5058 \times 10^{-8} x^{3}-2.2631 \times 10^{-5} x^{2}+0.1163 x+726.6931$

Table 5.9: Analysis 1 and Analysis 2, Dimensionless Predictive Model

Variables and Coefficients

\begin{tabular}{|r|l|r|r|}
\hline \multirow{2}{*}{$i$} & \multicolumn{1}{|c|}{ Variable $\left(x_{i}\right)$} & \multicolumn{1}{c|}{ Analysis 1 } & \multicolumn{1}{c|}{ Analysis 2 } \\
\cline { 3 - 4 } & & \multicolumn{1}{c|}{ Coefficient $\left(a_{i}\right)$} & Coefficient $\left(a_{i}\right)$ \\
\hline 1 & Constant & -32013177401.954 & 3299.06640 \\
\hline 2 & Porosity & -497495635.120 & -283.57020 \\
\hline 3 & Permeability & -1332393.912 & -0.51912 \\
\hline 4 & Vertical Permeability & 11883989.418 & 0.09775 \\
\hline 5 & Reference Depth & -13410782.421 & -0.11152 \\
\hline 6 & Pressure & -79969212.080 & 11.59211 \\
\hline 7 & Temperature & -6870826949.203 & 429.13760 \\
\hline 8 & Salinity & 7290567571.994 & 170.71546 \\
\hline 9 & Swirr & -4876751501.369 & 100.63053 \\
\hline 10 & krg (end point) & -393253788.739 & 11.77446 \\
\hline 11 & Corey Water Exponent & 797631291.346 & 6.19960 \\
\hline 12 & Corey Gas Exponent & 262551481.143 & 22.23347 \\
\hline 13 & Kozeny-Carman Coefficient & -96888171475.011 & 3686.13301 \\
\hline 14 & Diffusion Coefficient & 9512974.528 & 0.17893 \\
\hline 15 & Forward Reaction Rate & -5035855.322 & 0.57113 \\
\hline 16 & Backward Reaction Rate & 1627440425.888 & 76.03600 \\
\hline 17 & Formation Dip & 154582.381 & - \\
\hline 18 & Area & &
\end{tabular}

Figure 5.36 and Figure 5.37 give the fit of $\mathrm{CO}_{2}$ storage capacity of the aquifer obtained from simulation (actual) and the Eqn. 5.3. (predicted), and absolute percent error between actual and predicted values, respectively. 


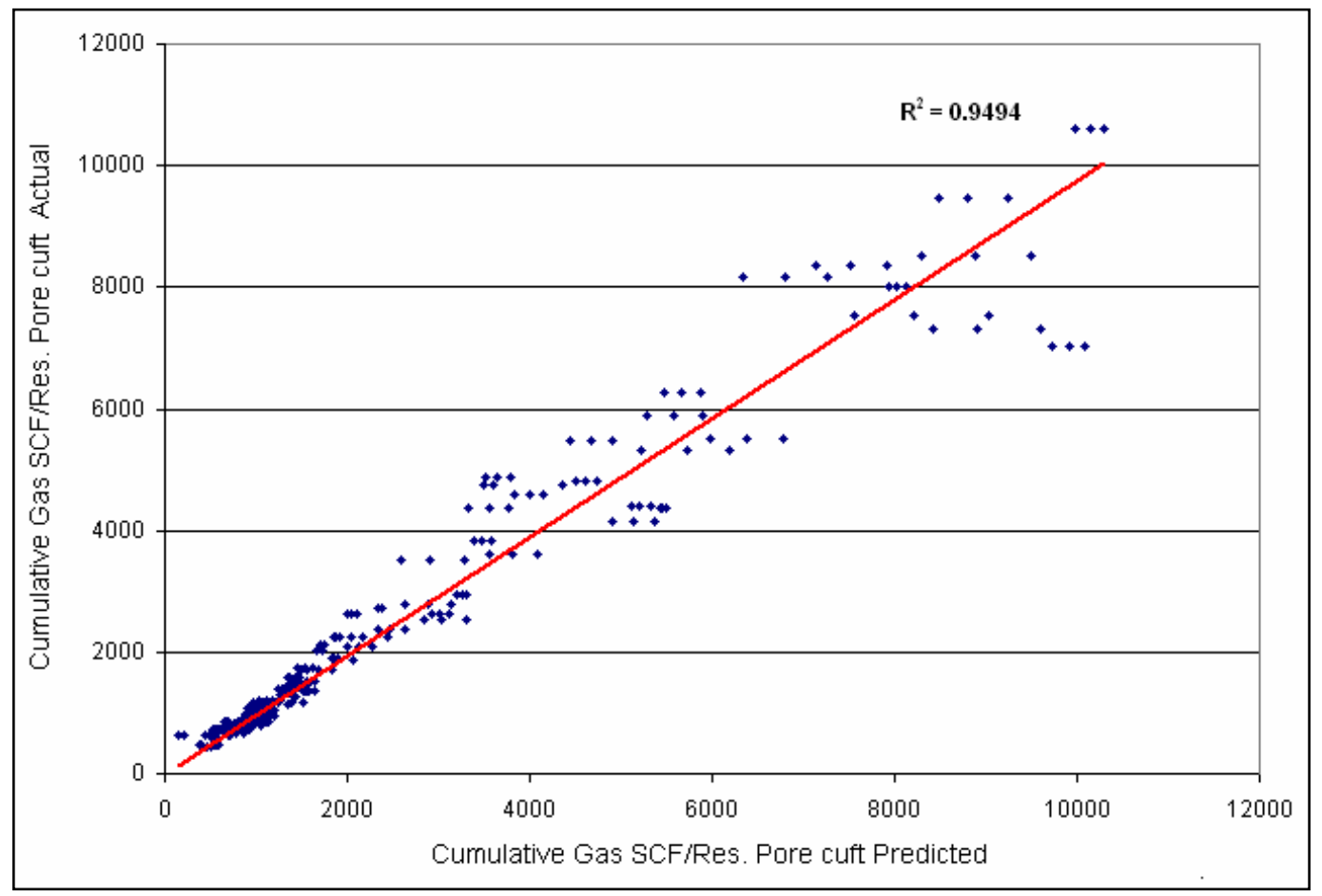

Figure 5.36: Analysis 2, Nonlinear Dimensionless Predictive Model Fit

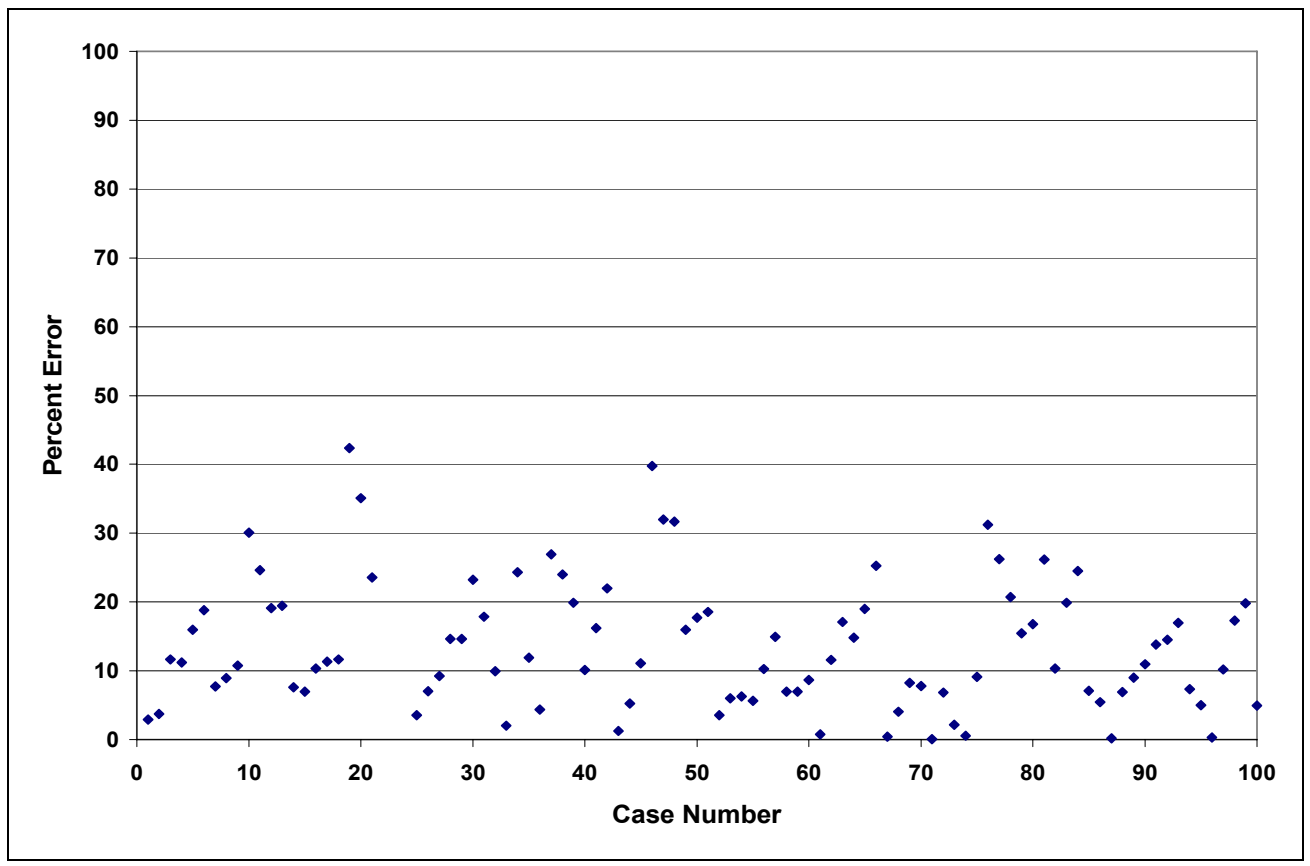

Figure 5.37: Analysis 2, Nonlinear Dimensionless Predictive Model, Absolute Percent Error between Simulated and Predicted Results 
In the third analysis, a linear dimensionless predictive model independent of bulk volume of the aquifer is constructed and finally, in last analysis, a nonlinear dimensionless predictive model independent of pore volume of the aquifer (Eqn. 5.4) is constructed to estimate the $\mathrm{CO}_{2}$ storage capacity of the aquifer. Figure 5.38 and Figure 5.39 give the predictive model fit for independent aquifer bulk volume and independent aquifer pore volume cases, respectively. Table 5.10 gives the statistical analysis of these two dimensionless predictive models. Figure 5.40 and 5.41 give the absolute error for these two analyses, and Table 5.11 gives the predictive model variables and corresponding coefficients for these two analyses.

$y=a_{0}+\sum_{i=1}^{17} a_{i} x_{i}+a_{18}\left(x_{17}-a_{17}\right)+a_{19}\left(x_{17}-a_{17}\right)^{2}+a_{20}\left(x_{17}-a_{17}\right)^{3}$

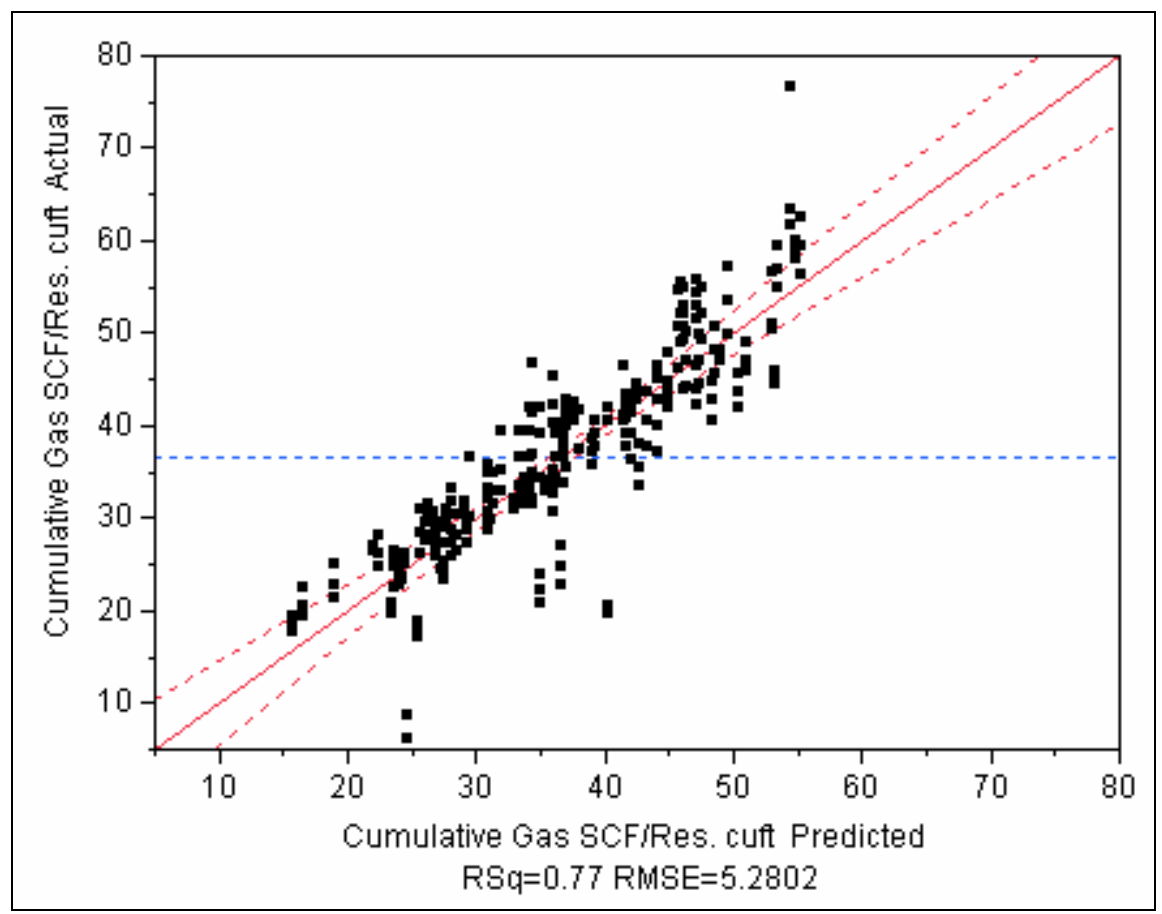

Figure 5.38: Analysis 3, Linear Dimensionless Predictive Model Fit (Independent of Bulk Volume of the Aquifer) 


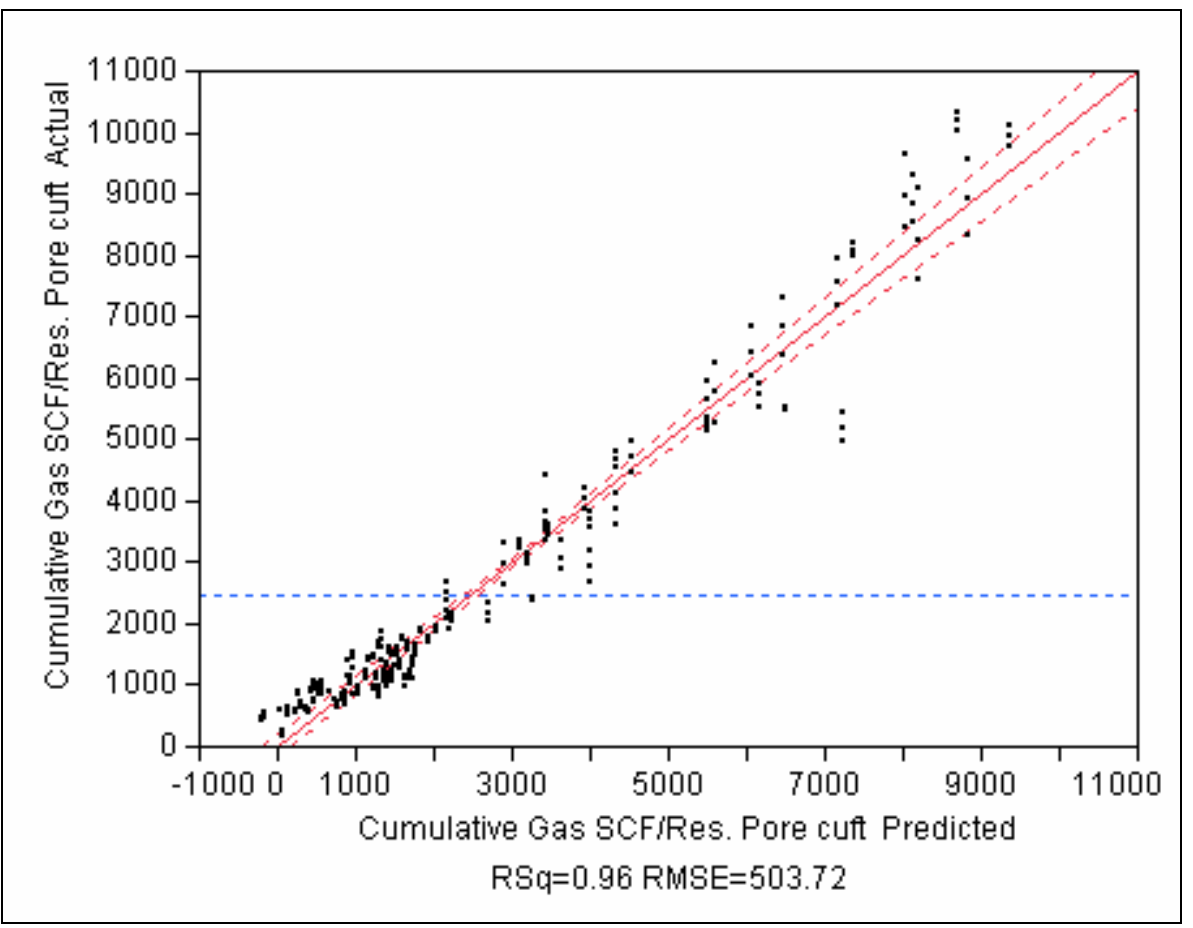

Figure 5.39: Analysis 4, Nonlinear Dimensionless Predictive Model Fit (Independent of Pore Volume of Aquifer)

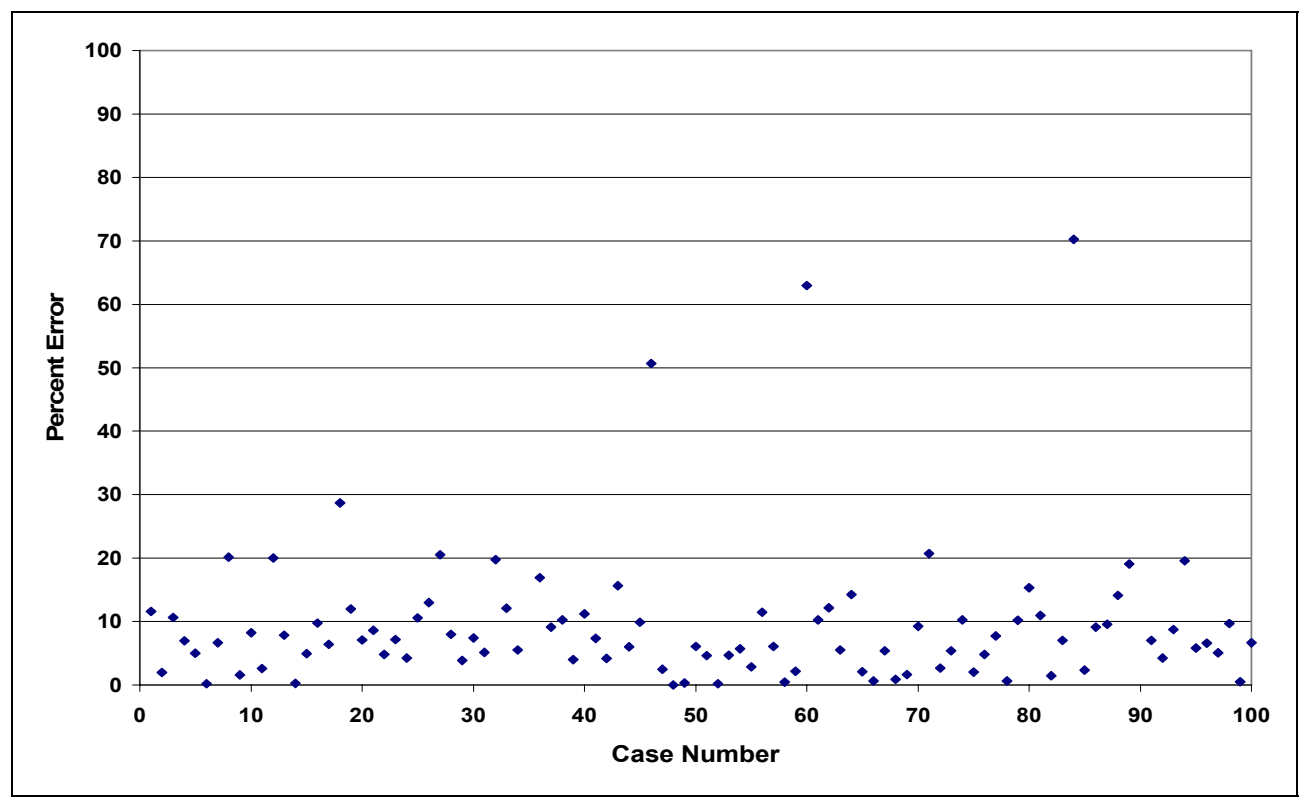

Figure 5.40: Analysis 3, Linear Dimensionless Predictive Model, Absolute Percent Error between Simulated and Predicted Results 


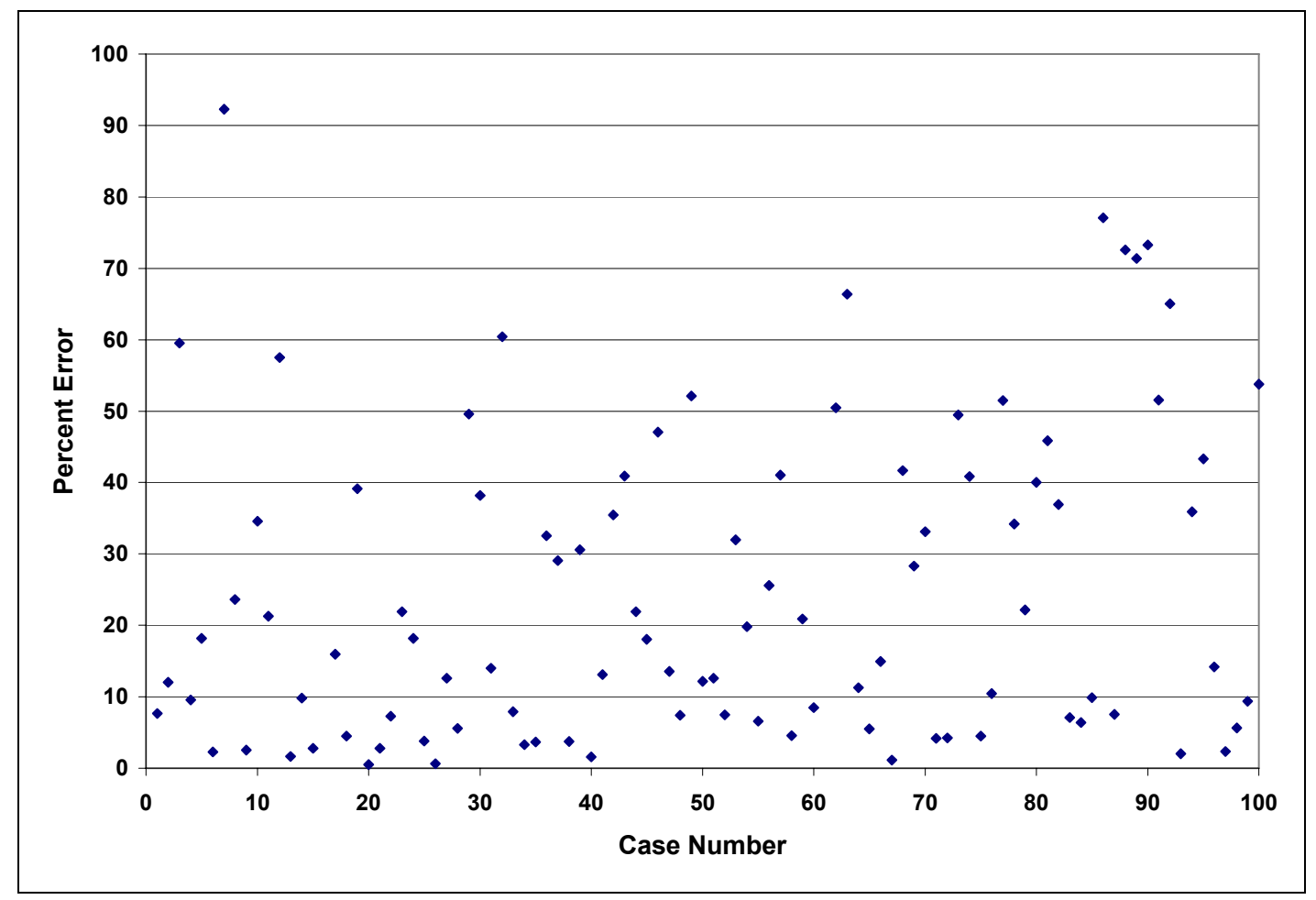

Figure 5.41: Analysis 4, Nonlinear Dimensionless Predictive Model, Absolute Percent Error between Simulated and Predicted Results

Table 5.10: Analysis 3 and Analysis 4, Statistical Analysis of Dimensionless Predictive Models

\begin{tabular}{|l|r|r|}
\cline { 2 - 3 } \multicolumn{1}{c|}{} & Analysis 3 & Analysis 4 \\
\hline RSquare & 0.773552 & 0.960151 \\
\hline RSquare Adj & 0.760328 & 0.957514 \\
\hline Root Mean Square Error & 5.280195 & 503.7188 \\
\hline Mean of Response & 36.45174 & 2480.128 \\
\hline Observations & 291 & 291 \\
\hline
\end{tabular}

The correlation coefficient of Analysis 4 is more than that of Analysis 3; it seems that the $\mathrm{CO}_{2}$ storage capacity of the aquifer is more accurately estimated with nonlinear dimensionless predictive model independent of aquifer pore volume. However; if absolute percent error between the simulated and predicted values are compared for these two analyses, the 
$\mathrm{CO}_{2}$ storage capacity of the aquifer is best predicted with linear dimensionless predictive model obtained from Analysis 3 since the error term is less compared with Analysis 4. The reason of better correlation coefficient can be explained with greater predicted values acts as outliner points and improve the correlation coefficient.

Table 5.11: Analysis 3 and Analysis 4, Dimensionless Predictive Model Variables and Coefficients

\begin{tabular}{|l|l|r|r|}
\hline \multirow{2}{*}{$i$} & \multicolumn{1}{|c|}{ Variable $\left(x_{i}\right)$} & \multicolumn{1}{c|}{ Analysis 3 } & \multicolumn{1}{c|}{ Analysis 4 } \\
\cline { 3 - 4 } & & Coefficient $\left(a_{i}\right)$ & Coefficient $\left(a_{i}\right)$ \\
\hline 1 & Constant 1 & 11.43112529 & 778.77266945 \\
\hline 2 & Permeability & -0.40221297 & -0.02028646 \\
\hline 3 & Vertical Permeability & 0.00075363 & -0.27349870 \\
\hline 4 & Reference Depth & -0.00126850 & 0.37179449 \\
\hline 5 & Pressure & 0.01019629 & -0.38174254 \\
\hline 6 & Temperature & -0.01180306 & 2.08025196 \\
\hline 7 & Salinity & -0.06311432 & 43.11413125 \\
\hline 8 & Swirr & -7.27119842 & -201.37114538 \\
\hline 9 & krg (end point) & 5.65901406 & -337.65758359 \\
\hline 10 & Corey Water Exponent & -4.20455360 & 6.18790000 \\
\hline 11 & Corey Gas Exponent & -0.27677962 & 53.31466514 \\
\hline 12 & Kozeny-Carman Coefficient & 0.63997660 & 27.26588807 \\
\hline 13 & Diffusion Coefficient & 0.22859101 & 9731.18218765 \\
\hline 14 & Forward Reaction Rate & -81.26890047 & 0.64070592 \\
\hline 15 & Backward Reaction Rate & 0.00773779 & 0.50812745 \\
\hline 16 & Formation Dip & -0.00389108 & 31.47556750 \\
\hline 17 & Porosity & 1.06320032 & -128.82352757 \\
\hline 18 & Constant 2 & - & 24.59572018 \\
\hline 19 & Constant 3 & - & -13.06206394 \\
\hline 20 & Constant 4 & - & -1.66188793 \\
\hline & & \multicolumn{2}{|c}{} \\
\hline
\end{tabular}




\section{CHAPTER 6}

\section{CONCLUSION}

To develop a predictive model, Latin Hypercube Space Filling Design is constructed with 16 input variables affecting the storage capacity of the deep saline carbonate aquifer found from the literature. Hypothetical confined aquifer is created. By using the simulation input variables instead of design input variables, linear predictive models are constructed for three cases in which grid dimensions are $250 \mathrm{ft}, 500 \mathrm{ft}$ and $750 \mathrm{ft}$ in $\mathrm{x}$ and y directions while keeping the grid dimension constant in $\mathrm{z}$ direction, $80 \mathrm{ft}$, with correlation coefficients $0.81,0.79$ and 0.78 , respectively. The decrease in correlation coefficients with increasing grid dimensions is explained by numerical diffusion due to the sudden equilibrium of $\mathrm{CO}_{2}$ in grid block.

Sensitivity analyses are conducted to understand the effect of each variable on $\mathrm{CO}_{2}$ sequestration capacity of the aquifer. The most sensitive variable is reference depth since the difference between fracture pressure and formation pressure increases with depth that in turn positively affects the $\mathrm{CO}_{2}$ storage capacity of the aquifer. The second most sensitive variable is found to be porosity. $\mathrm{CO}_{2}$ storage capacity of the aquifer decreases with increasing porosity, which is opposite to the general trend due to the confined aquifer assumption. Formation temperature and salinity of the formation water are the other important variables. The less sensitive variables are found to be forward and backward reaction rates of carbonate deposition and dissolution. Since it is difficult to obtain values of the variables used in the predictive models, a reduced form of the predictive model is developed by using the 
most sensitive 6 and 7 variables both with least square method with correlation coefficients of 0.79 .

To find the most effective trapping mechanism, the numbers of moles of $\mathrm{CO}_{2}$ remaining as a free gas under the impermeable layer, reacting with divalent cation to form a mineral and dissolving in the formation water are calculated and compared. The most effective trapping mechanism is found to be solubility trapping. This result is consistent with the sensitivity analysis since the variables affecting the dissolution of $\mathrm{CO}_{2}$ in the formation water have more effect on $\mathrm{CO}_{2}$ storage capacity of the aquifer than the other variables effects. Furthermore, linear predictive models are constructed for solubility trapping, hydrodynamic trapping and mineral trapping with correlation coefficients $0.77,0.78$ and 0.81 , respectively.

By using simulation results of three cases, four analyses are conducted to find linear or nonlinear dimensionless predictive models which are valid for carbonate deep saline aquifers with area between $27562500 \mathrm{ft}^{2}$ and $248062500 \mathrm{ft}^{2}$. The best predictive models are found in the second and third analysis in which nonlinear predictive model function of grid dimensions and linear predictive model independent of aquifer reservoir volume are found with correlation coefficients 0.95 and 0.77 , respectively. 


\section{CHAPTER 7}

\section{RECOMMENDATIONS}

Most of the studies related to $\mathrm{CO}_{2}$ sequestration in deep saline aquifers are case studies conducted to understand the $\mathrm{CO}_{2}$ distribution in the formation and estimate the storage capacity of the formation. Only few studies are available in the literature related to the sensitivity of parameters such as pressure, temperature and salinity for the $\mathrm{CO}_{2}$ storage capacity and these studies are also specific to the formation simulated.

The predictive model developed in this study can be said to be very simple since some factors are not taken into account. For example, in this study, there is only one injection well at the center of the reservoir, half part of the well is perforated and initial injection rate is assumed to be constant for all simulation cases. Nevertheless, the distribution of $\mathrm{CO}_{2}$ also depends on well location, perforation interval and perforation location and initial injection rate. Moreover, the formation is assumed to be homogenous. Therefore the rock and fluid properties are same for all grid blocks. In reality, all formations are heterogeneous. In other words, rock and fluid properties change with location.

The common distribution for rock and fluid properties, and range of these distribution parameters such as mean and variance should be found from the literature to define the heterogeneity. By taking well location, perforation interval and perforation location, injection rate and heterogeneity of the aquifer into account, a more realistic and accurate predictive model valid for 
all deep saline aquifers should be developed. Since simulations are very expensive and time consuming, developing predictive model can be very useful to quickly estimate $\mathrm{CO}_{2}$ storage capacity of a deep saline aquifer. 


\section{REFERENCES}

[1] Bryant, E.: "Climate process and change", Cambridge, UK: Cambridge University Press, 1997. p.209

[2] IPCC, 2007: Summary for Policymakers. In: Climate Change 2007: The Physical Science Basis. Contribution of Working Group I to the Fourth Assessment Report of the International Panel on Climate Change [Solomon, S., D. Qin, M. Manning, Z. Chen, M. Marquis, K.B. Averyt, M. Tignor and H.L. Miller (eds)]. Cambridge University Press, Cambridge, United Kingdom and New York, NY, USA.

[3] Bachu, S.: "Sequestration of $\mathrm{CO}_{2}$ in geological media: criteria and approach for site selection in response to climate change", Energy Conversion \& Management 2000; 41: 953-970.

[4] Jempa, C., Munasinghe M.: "Climate Change Policy", New York, NY: Cambridge University Press; 1998, p.331

[5] Bajura, RA.: "The role of carbon dioxide sequestration in the long term energy future", Fifth International Greenhouse Gas Technologies Conference, Cairns, Australia, Collingwood. VIC, AU: CSIRO Publishing; 2001. p: 52-8.

[6] IPPC Special Report on Carbon Dioxide Capture and Storage, chapter 5, available at http://www.ipcc.ch/, accessed @ 16/4/2009.

[7] Tore A Torp., John Gale: "Demonstrating storage of $\mathrm{CO}_{2}$ in geological reservoirs: The Sleipner and SACS projects", Energy 2004, 29: 13611369.

[8] Hovorka, S., D., Collins, D., Benson, S., Myer, L., Byrer, C, Cohen, K.: "Update on the Frio Brine Pilot: Eight month after injection", Fourth Annual Conference on Carbon Capture and Sequestration DOE/NETL, May 2-5, 2005. 
[9] Flett M., Gurton R., and Taggart I.: The Function of Gas-Water Relative Permeability Hysteresis in the Sequestration of Carbon Dioxide in Saline Formations, SPE 88485, SPE Asia Pacific Oil and Gas Conference and Exhibition, Pert, Australia, 18-20 October 2004.

[10] Zhang, K., Doughty, C., Wu, Y.S., and Pruess, K.: "Efficient Parallel Simulation of $\mathrm{CO}_{2}$ Geological Sequestration in Saline Aquifers", SPE 106026, SPE Reservoir Simulation Symposium, Houston, Texas, USA, 26-28 February 2007.

[11] Van Der Meer, L. G. H.: "The Conditions Limiting $\mathrm{CO}_{2}$ Storage in Aquifers”, Energy Conversion \& Management 1993, 34: 9-11, 959-966.

[12] Holt, T., Jensen, J., and Lindeberg, E.: "Underground Storage of $\mathrm{CO}_{2}$ in Aquifers and Oil Reservoirs". Energy Conversion \& Management 1995, 36: 535-538.

[13] Law, H. S. and Bachu, S.: "Hydrological and Numerical Analysis of $\mathrm{CO}_{2}$ disposal in deep aquifer systems in the Alberta sedimentary basin", Energy Conversion \& Management 1966, 37: 6-8, 1167-1174.

[14] Hurter, S., Labregere, D., and Berge, J.: "Simulation for $\mathrm{CO}_{2}$ Injection Projects with Compositional Simulator", SPE 108540, Offshore Europe, Aberdeen, Scotland, U.K., 4-7 September 2007.

[15] Subodh, G.:"What Are Our Options for Sequestration of Atmospheric $\mathrm{CO}_{2}$-Some Thoughts", SPE 109815, SPE Annual Conference and Exhibition, Anaheim, California, USA, 11-14 November 2007.

[16] Office of Science, Office of Fossil Energy and U.S. Department of Energy:" Carbon Sequestration Research and Development", December 1999.

[17] Wisniewski, J., Dixon, R.K., Kinsman, J.D., Sampson, R.N., and Lugo, A.E.:" Carbon dioxide sequestration in the terrestrial ecosystems", Climate Research, Vol.3: 1-5, 1993.

[18] Brewer, P.G., Peltzer, E.T., and Orr, F.M., Jr.:“ Direct Experiments on the Ocean Disposal of Fossil Fuel $\mathrm{CO}_{2}$ " , SPE 71454, SPE Annual Technical Conference and Exhibition, New Orleans, LA, Sept. 30-Oct. 3, 2001. 
[19] Peltzer, E.T., Brewer, P.G., Friederich, G. and Rehder, G.: "Direct Observation of the Fate of Oceanic Carbon Dioxide Release at $800 \mathrm{~m}$ ", Preprints of Papers, American Chemical Society, Division of Fuel Chemistry 45(4), 794-798, 2000.

[20] Brewer, P.G., Friederich, G., Peltzer, E.T., and Orr, F.M., Jr.: "Direct Experiment on the Ocean Disposal of Fossil Fuel $\mathrm{CO}_{2}$ ", Science 284, 943-954, 1999.

[21] Mathiassen, O.M.: " $\mathrm{CO}_{2}$ as Injection Gas for Enhanced Oil Recovery and Estimation of the Potential on the Norwegian Continental Shelf", NTNU-Norwegian University of Science and Technology Department of Petroleum Engineering and Applied Geophysics, May 2003.

[22] Moritis, G.: “1998 Worldwide EOR Survey”, Oil Gas J, 20:49-97, 1998.

[23] Jessen, K., Kovscek, A.R., Orr, F.M., Jr.: "Increasing $\mathrm{CO}_{2}$ Storage in Oil Recovery", Energy and Conversion and Management, 46:293-311, 2005.

[24] Thiez, P.L, Mosditchian, G., Torp, T., Feron, P., Ritsema, I., Zweigel, P., Lindeberg, E.: "An Innovative European Integrated Project: CASTOR $\mathrm{CO}_{2}$ from Capture to Storage", available at https://www.co2castor.com, accessed @ 16/3/2009.

[25] Meer, V.D., Kreft, E., Geel, C.R., Hoore, D.D., Hartman, J.: " $\mathrm{CO}_{2}$ Storage and Testing Enhanced Gas Recovery in the K12-B Reservoir", $23^{\text {rd }}$ World Gas Conference, Amsterdam, 2006.

[26] Akintunde, O.M.,: "Monitoring Coal Bed Methane Production: A Case Study from the Powder River Basin, Wyoming, United States of America", Department of Geophysics, Stanford University, 2005.

[27] Stevens, S.H., Spector, D., Riemer, P.: "Enhanced Coalbed Methane Recovery Using $\mathrm{CO}_{2}$ Injection: Worldwide Resources and $\mathrm{CO}_{2}$ Sequestration Potential", SPE 48881, SPE International Conference and Exhibition, Beijing, China, 2-6 November 1998.

[28] Hellevang, H., Khattri, S.K., Fladmark, G.E., Kvamme, B.: " $\mathrm{CO}_{2}$ Storage in the Utsira Formation - ATHENA 3D Reactive Transport Simulations", Paper D, Submitted to Basin Research. 
[29] Hovorka, S.D., Knox, P.R., 2003, Frio Brine Sequestration Pilot in the Texas Gulf Coast, in Gale, J., and Kaya, Y., Greenhouse Gas Control Technologies: Proceedings, $6^{\text {th }}$ International Conference on Greenhouse Gas Control Technologies, October 1-4, Kyoto, Japan: New York, Pergamon, p.583-587. GCCC Digital Publication Series \#03-01.

[30] Hovorka, S.D., Doughty, C., Knox, P.R., Green, C.T., Pruess, K., Benson, S.M.: "Evaluation of Brine-Bearing Sands of the Frio Formation, Upper Texas Gulf Coast for Geological Sequestration of $\mathrm{CO}_{2}$ ", First National Conference on Carbon Sequestration, May 14-17, Washington DC, National Energy Technology Laboratory, 2001.

[31] Piri, M., Prévost, J.H., and Fuller, R.: "Carbon Dioxide in Saline Aquifers: Evaporation, Precipitation and Compressibility Effects", Conference Proceedings, Fourth Annual Conference on Carbon Capture and Sequestration DOE/NETL, May 2-5, 2005.

[32] Lagneau, V., Pipart, A., and Catalette, H.: "Reactive Transport Modeling of $\mathrm{CO}_{2}$ Sequestration in Deep Saline Aquifers", Oil \& Gas Science and Technology - Rev. IFT, Vol.60, No.2, pp. 231-247, 2005.

[33] Hangx, S.J.T.: "Subsurface Mineralization: Rate of $\mathrm{CO}_{2}$ mineralization and geomechanical effects on host and seal formations, Behavior of the $\mathrm{CO}_{2}-\mathrm{H}_{2} \mathrm{O}$ system and preliminary mineralization model and experiments", CATO Workpackage WP 4.1, December 2005.

[34] Thibeau, S., Nghiem, L.X., and Ohkuma, H.: "A Modeling Study of the Role of Selected Minerals in Enhancing $\mathrm{CO}_{2}$ Mineralization During $\mathrm{CO}_{2}$ Aquifer Storage", SPE 109739, SPE Annual Technical Conference and Exhibition, Anaheim, California, USA, 11-14 November 2007.

[35] Nghiem, L., Sammon, P., Grabenstetter, J., and Ohkuma, H.: "Modeling $\mathrm{CO}_{2}$ Storage in Aquifers with a Fully-Coupled Geochemical EOS Compositional Simulator", SPE 89474, SPE/DOE Fourteenth Symposium on Improved Oil Recovery, Tulsa, Oklahoma, USA, 17-21 April 2004.

[36] Doughty, C.: "Modeling Geologic Storage of Carbon Dioxide: Comparison of Non-Hysteretic and Hysteretic Characteristic Curves", Proceedings, TOUGH Symposium 2006, Lawrence Berkeley National Laboratory, Berkeley, California, May 15-17, 2006. 
[37] Ennis-King, J., Gibson-Poole, C.M., Lang, S.C., and Paterson, L.: "LongTerm Numerical Simulation of Geological Storage of $\mathrm{CO}_{2}$ in the Petrel Sub-Basin, North West Australia",

[38] İzgeç, Ö., Demiral, B., Bertin, H., and Akın,S.: " $\mathrm{CO}_{2}$ Injection into Saline Carbonate Aquifer Formations I: Laboratory Investigation", Transp. Porous Med, 72:1-24, 2008.

[39] İzgeç, Ö., Demiral, B., Bertin, H., and Akın,S.: " $\mathrm{CO}_{2}$ Injection into Saline Carbonate Aquifer Formations I: Comparison of Numerical Simulation to Experiments", Transp. Porous Med, 73:57-74, 2008.

[40] Ozah, R.C., Lakshminarasimhan, S., Pope, G.A., Sepehmoori, K., and Bryant, S.L.: "Numerical Simulation of the Storage of Pure $\mathrm{CO}_{2}$ and $\mathrm{CO}_{2}-\mathrm{H}_{2} \mathrm{~S}$ Gas Mixtures in Deep Saline Aquifers", SPE 97255, SPE Annual Technical Conference and Exhibition, Dallas, Texas, USA, 9-12 October 2005.

[41] Mo, S., Zweigel, P., Lindeberg, E., and Akervoll, I.: "Effect of Geological Parameters on $\mathrm{CO}_{2}$ Storage in Deep Saline Aquifers", SPE 93952, SPE Europec/EAGE Annual Conference, Madrid, Spain, 13-16 June 2005.

[42] Kumar, A., Noh, M., Pope, G.A., Sepehrnoori, K., Bryant, S., and Lake, L.W.: "Reservoir Simulation of $\mathrm{CO}_{2}$ Storage in Deep Saline Aquifers", SPE 89343, SPE/DOE Fourteenth Symposium on Improved Oil Recovery, Tulsa, Oklahoma, USA, 17-21 April 2004.

[43] Saripalli, P., and McGrail, P.: "Semi-Analytical Approaches to Modeling Deep Well Injection of $\mathrm{CO}_{2}$ for Geological Sequestration", Energy Conversion and Management, 43: 185- 198, 2002.

[44] Bachu, S., and Adams, J.J.: "Sequestration of $\mathrm{CO} 2$ in Geological Media in Response to Climate Change: Capacity of Deep Saline Aquifers to Sequester $\mathrm{CO}_{2}$ in Solution", Energy Conversion and Management, 44: 3151-3175, 2003.

[45] Siomina, I., and Ahlinder, S.: "Lean optimization using supersaturated experimental design", Applied Numerical Mathematics 2008, 58: 1-15.

[46] Cioppa, T. M.: "Efficient Nearly Orthogonal and Space Filling Designs for High-Dimensional Complex Models", 2002, Naval Postgraduate School, Monterey, California. 
[47] Fang, K.T. and Wang, Y.:"Number-Theoretic Methods in Statistics", Chapman and Hall, London, 1994.

[48] Fang, K.T., Ma, C., and Winker, P.: "Centered $L_{2}$-Discrepancy of Random Sampling and Latin Hypercube Design, and Construction of Uniform Designs", Mathematics of Computation, Vol. 71, No. 237, p. 275-296, 2000.

[49] JMP User Guide, Release 8 Copyright @ 2008 , SAS Institute Inc., Cary, NC, USA, ISBN 978-1-59994-924-6

[50] McKay, M.D., Beckman, R.J., and Conover, W.J.:"A Comparison of Three Methods for Selecting Values in the Analysis of Output from a Computer Code", Technometrics, Vol.21, No.2, p.239-245, May 1979.

[51] Tang, B."Orthogonal Array-Based Latin Hpercubes", Journal of the American Statistical Association: Theory and Methods, Vol.88, No.424, p.1392-1397, December 1993.

[52] Sacks, J., Welch, W.J., Mitchell, T.J., and Wynn, H.P.: "Design and Analysis of Computer Experiments", Statistical Science, Vol.4, No.4, p.409-422, 1989

[53] Computer Modeling Group (CMG): CMG STARS User's Guide. Computer Modeling Group LTD, 2007.

[54] Abou-Kassem, J.H., Ertekin, T., King, G.R.: "Basic Applied Reservoir Simulation”, SPE Textbook Series Vol.7, pp. 134-138, 142-143, 2001.

[55] William, P.H., Brian, F.P, Saul, T.A., William, V.T: "Numerical Recipes in FORTRAN 77: The Art of Scientific Computing", Cambridge University Press, pp. 34-42, 1992.

[56] Wellman, T.P., Grigg, R.B., McPherson, B.J., Svec, R.K, and Lichtner, P.C.: "Evaluation of $\mathrm{CO}_{2}$-Brine-Reservoir Rock Interaction with Laboratory Flow Tests and Reactive Transport Modelling", SPE 80228 , SPE International Symposium on Oilfield Chemistry, Houston, Texas, USA, 5-7 February 2003.

[57] Zerai, B., Saylor, B.Z., and Matisoff, G: "Computer Simulation of $\mathrm{CO}_{2}$ Trapped through Mineral Precipitation in the Rose Run Sandstone, Ohio, Applied Geochemistry v. 21, pp. 223-240, 2006. 
[58] Bennion, D.B., and Bachu, S.: "Dependence on Temperature, Pressure, and Salinity of the IFT and Relative Permeability Displacement Characteristics of $\mathrm{CO}_{2}$ Injected in Deep Saline Aquifers", SPE 102138, SPE Annual Technical Conference and Exhibition, San Antonio, Texas, USA, 24-27 September 2008.

[59] Bennion, D.B., and Bachu, S.: "Drainage and Imbibition Relative Permeability Relationships for Supercritical $\mathrm{CO}_{2} /$ Brine and $\mathrm{H}_{2} \mathrm{~S} /$ Brine Systems in Intergranular Sandstones, Carbonate, Shale, and Anhydrite Rocks", SPE 99326, SPE Europec, Vienna, Austria, 12-15 June 2006.

[60] Ennis-King, J., and Paterson, L.: "Engineering Aspects of Geological Sequestration of Carbon Dioxide", SPE 77809, Asia Pacific Oil and Gas Conference and Exhibition, Melbourne, Australia, 8-10 October 2002.

[61] Yuanhui, J., Xiaoyan, J., Xin, F., Chang, L., Linghong, L.: "Progress in the Study on the Phase Equilibria of the $\mathrm{CO}_{2}-\mathrm{H}_{2} \mathrm{O}$ and $\mathrm{CO}_{2}-\mathrm{H}_{2} \mathrm{O}-\mathrm{NaCl}$ Systems", Chin. J. Chem. Eng., 15(3), pp.439-448, 2007.

[62] Tewes, F. and Boury, F.: "Formation and Rheological Properties of the Supercritical $\mathrm{CO}_{2}$-Water Pure Interface", J. Phys. Chem. B, 109, 39903997, 2005.

[63] Jalalh, A.A.: "Compressibility of Porous Rocks: Part II. New Relationship", Acta Geophysica, vol.54, no.4, pp.399-412, DOI 10.2478/s11600-006-0029-4, 2006.

[64] Timur, A.: "An Investigation of Permeability, Porosity, \& Residual Water Saturation Relationships for Sandstones Reservoirs", $9^{\text {th }}$ Annual SPWLA Logging Symposium, New Orleans, Louisiana, 1968.

[65] Fei, Y.: "Thermal Expansion, Mineral Physics and Crystallography, A Handbook of Physical Constants", AGU Reference Shelf 2, the American Geophysical Union, 1995.

[66] http://www.engineeringtoolbox.com, accessed @ 10/3/2009.

[67] Clauser, C. and Huenges, E.: "Thermal Conductivity of Rocks and Minerals, Rock Physics and Phase Relations, A Handbook of Physical Constants", AGU Reference Shelf 3, the American Geophysical Union, 1995. 
[68] Comerlati, A., Gambolati, G., Putti, M., and Teatini, P.: "A Preliminary Numerical Model of $\mathrm{CO}_{2}$ Sequestration in a Normally Consalidated Sedimentary Basin", Dev. Water Science, 47, vol.1, Elsevier, Amsterdam, pp.217-224, 2002.

[69] Morey, G.W.: "The Action of Water on Calcite, Magnesite and Dolomite", Mineralogical Notes, The American Mineralogist, vol.47, NovemberDecember, 1962.

[70] Pinho, S.P. and Macedo, E.A.: "Solubility of $\mathrm{NaCl}, \mathrm{NaBr}$, and $\mathrm{KCl}$ in Water, Methanol, Ethanol, and Their Mixed Solvents", J. Chem. Eng. Data, vol.50, pp.29-32, 2005.

[71] Eaton, B.A.: "Fracture Gradient Prediction and Its Application in Oilfield Operations", SPE 2163, SPE $43^{\text {rd }}$ Annual Fall Meeting, Houston, Texas, June 26, 1969.

[72] Hubbert, M.K., and Willis, D.G.: "Mechanism of Hydraulic Fracturing", Trans., AIME 210, pp.153-166, 1957.

[73] Duan, Z., Møller, N., and Weare, J.H.: "An Equation of State for the $\mathrm{CH}_{4-}$ $\mathrm{CO}_{2}-\mathrm{H}_{2} \mathrm{O}$ system: I. Pure Systems from 0 to $1000{ }^{\circ} \mathrm{C}$ and 0 to 8000 bar", Geochimica et Cosmochimica Acta, vol.56, pp.2605-2617,1992.

[74] Camper, D., Becker, C., Koval, C., and Noble, R.: "Diffusion and Solubility Measurements in Room Temperature lonic Liquids", Ind. Eng. Chem. Res., vol.45, pp.445-450, 2006. 


\section{APPENDIX A}

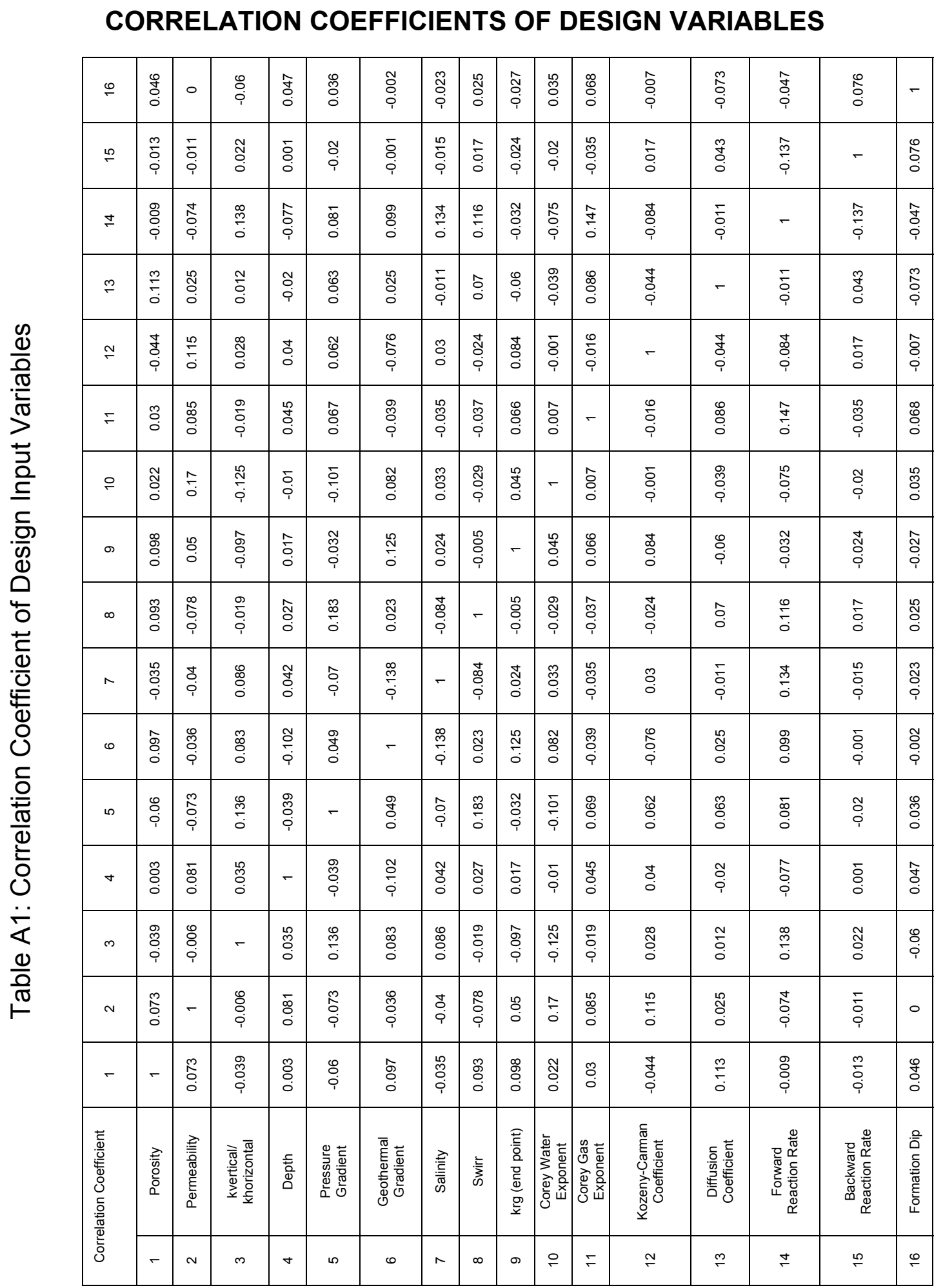




\section{APPENDIX B}

\section{DISTRIBUTION OF SIMULATION INPUT VARIABLES}

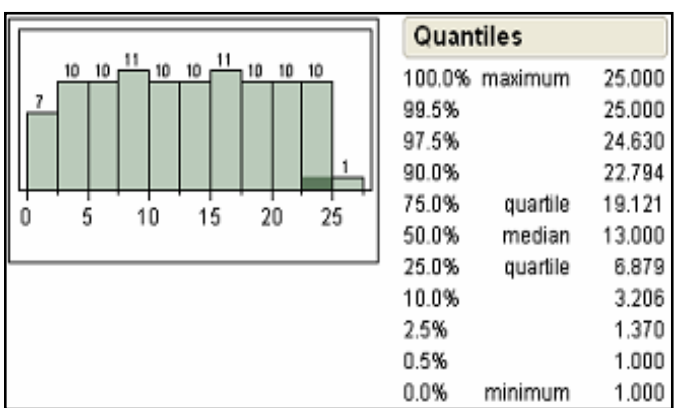

Figure B.1: Porosity (\%) Distribution

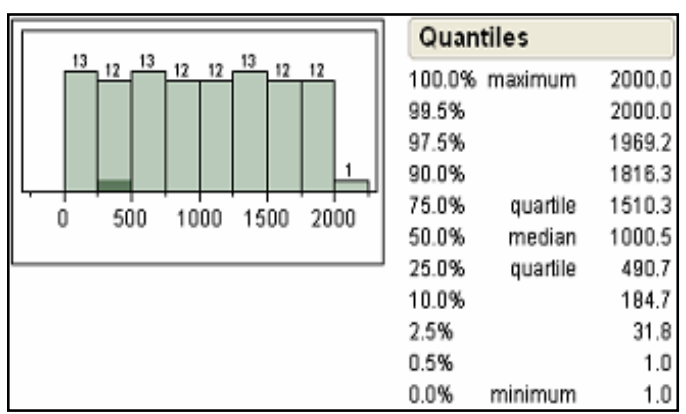

Figure B.2: Permeability (mD) Distribution

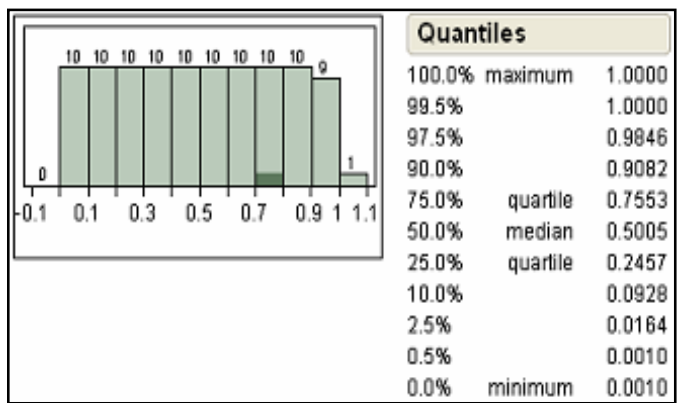

Figure B.3: Horizontal to Vertical Permeability Ratio Distribution

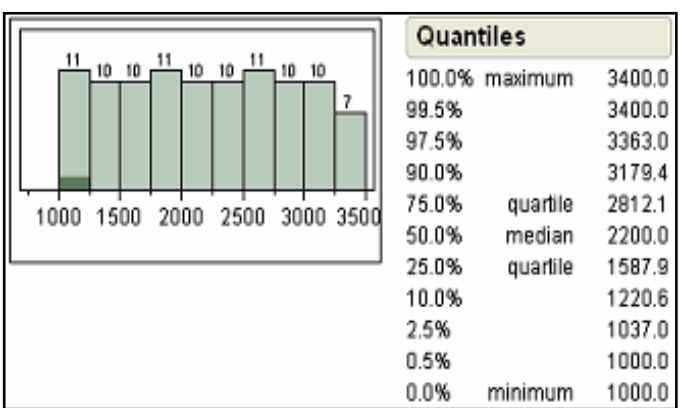

Figure B.4: Reference Depth (m) Distribution

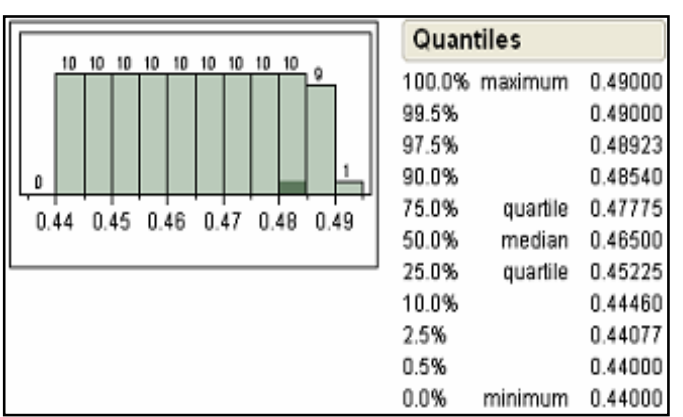

Figure B.5: Pressure Gradient (psi/ft)

Distribution

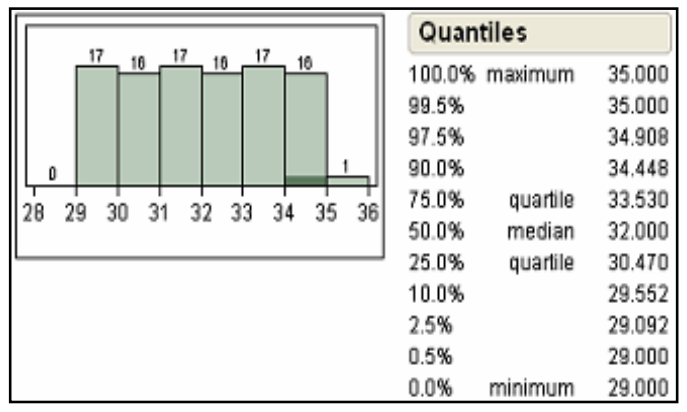

Figure B.6: Geothermal Gradient $\left({ }^{\circ} \mathrm{C} / \mathrm{km}\right)$

Distribution 


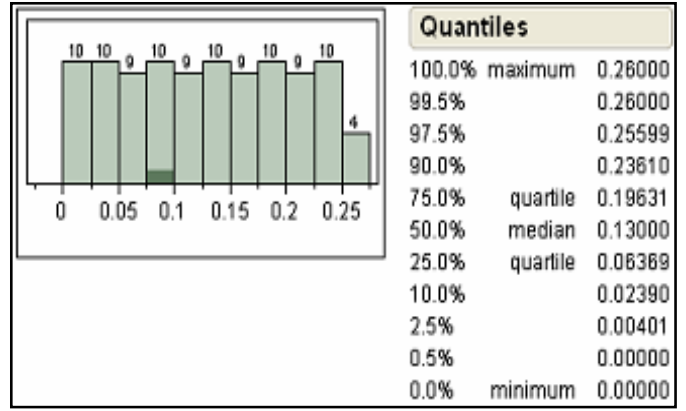

Figure B.7: Salinity (weight fraction)

Distribution

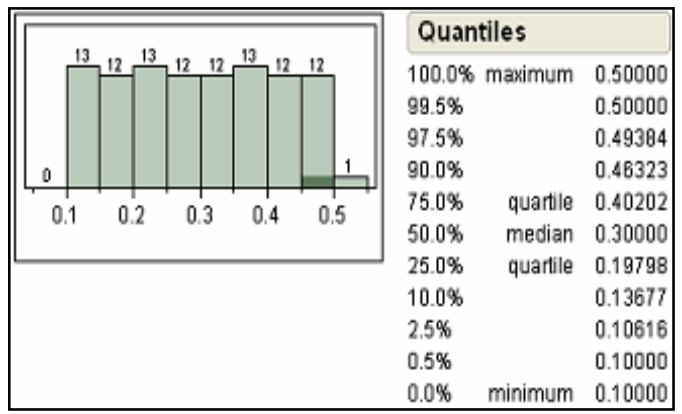

Figure B.8: Irreducible Water Saturation (fraction) Distribution

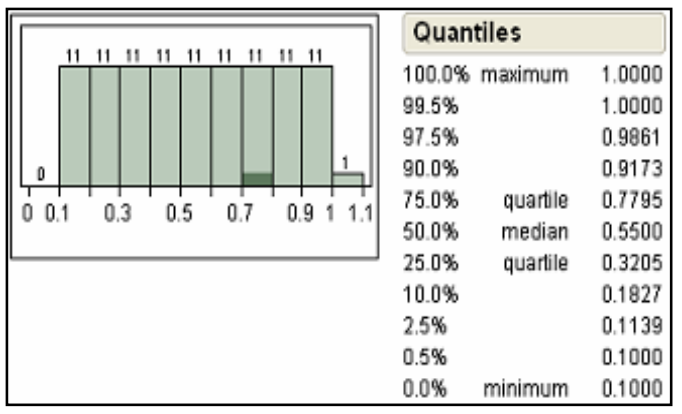

Figure B.9: Gas Relative Permeability End

Point Distribution

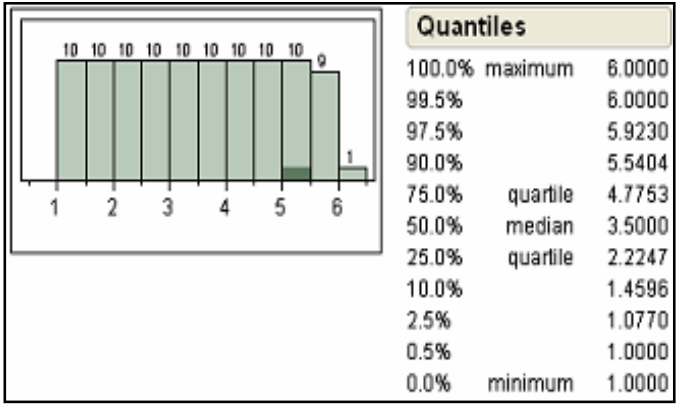

Figure B.10: Corey Water Coefficient Distribution

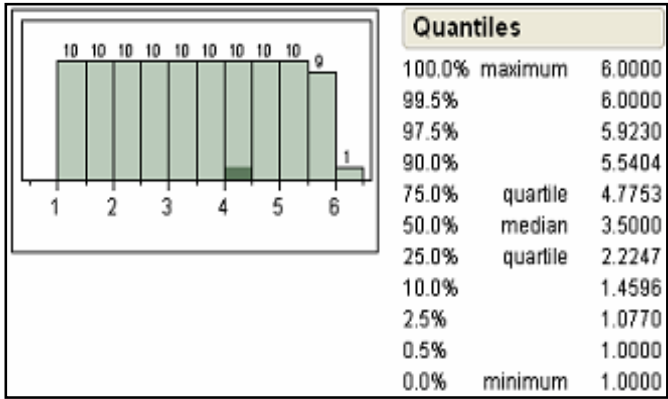

Figure B.11: Corey Gas Coefficient Distribution

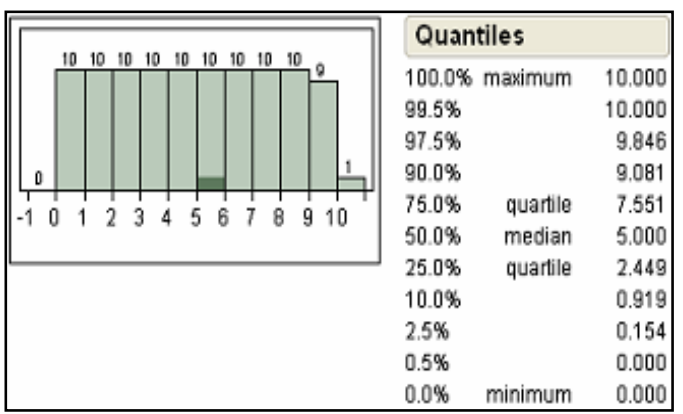

Figure B.12: Kozeny-Carman Coefficient

Distribution 


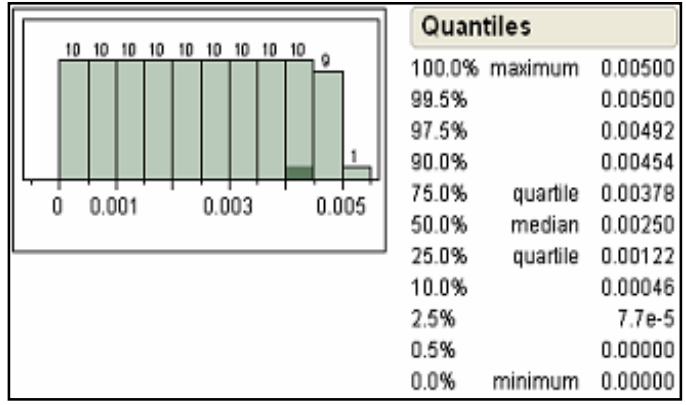

Figure B.13: Diffusion Coefficient ( $\mathrm{ft}^{2} /$ day)

Distribution

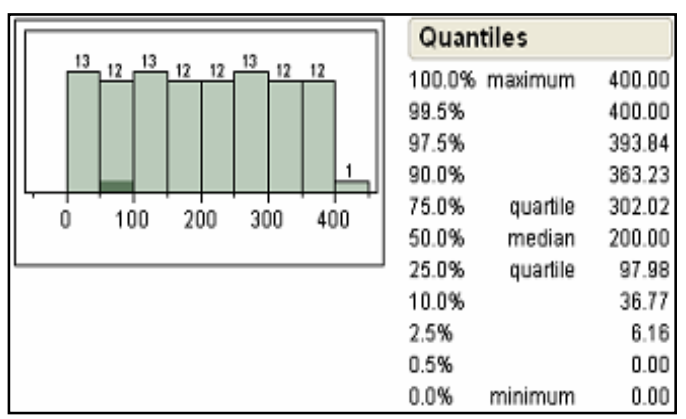

Figure B.14: Forward Reaction Rate (1/day)

Distribution

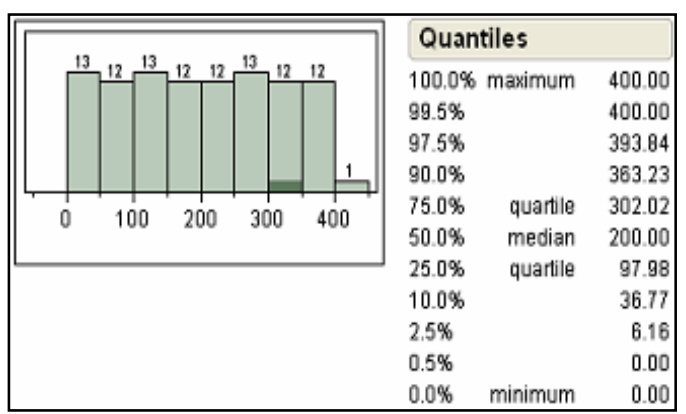

Figure B.15: Backward Reaction Rate (1/day)

Distribution

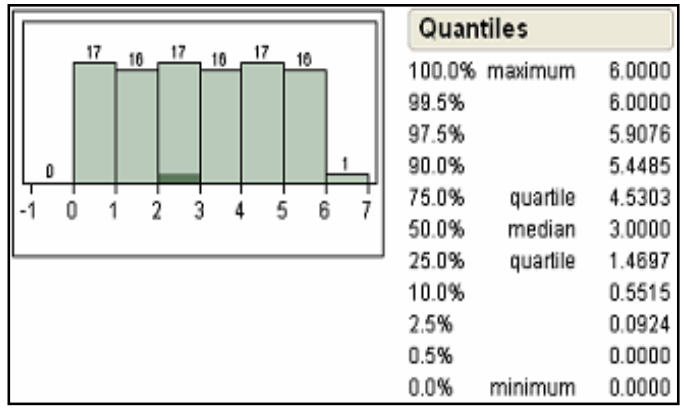

Figure B.16: Formation Dip (degree) Distribution 


\section{APPENDIX C}

\section{PROJECTED DISTRIBUTION OF DESIGN POINTS}

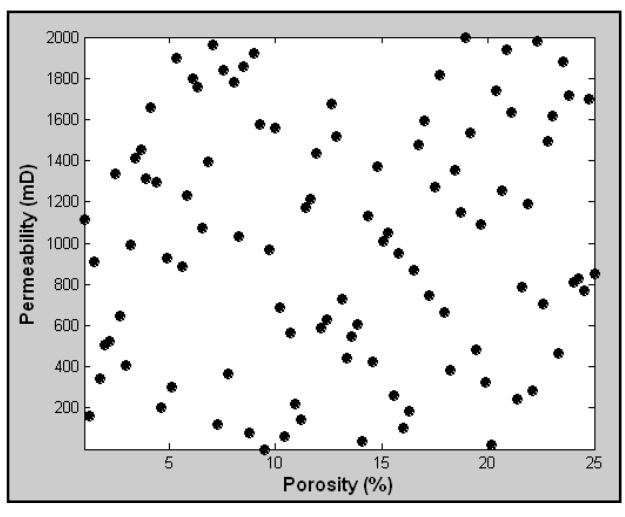

Figure C.1: Porosity vs. Permeability

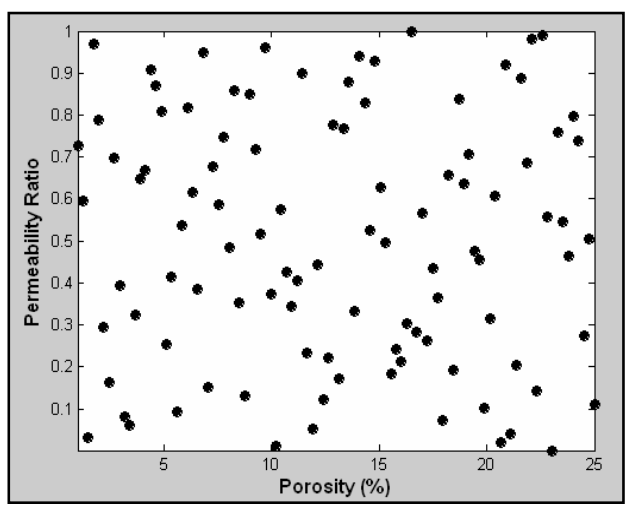

Figure C.2: Porosity vs. Horizontal to Vertical Permeability Ratio

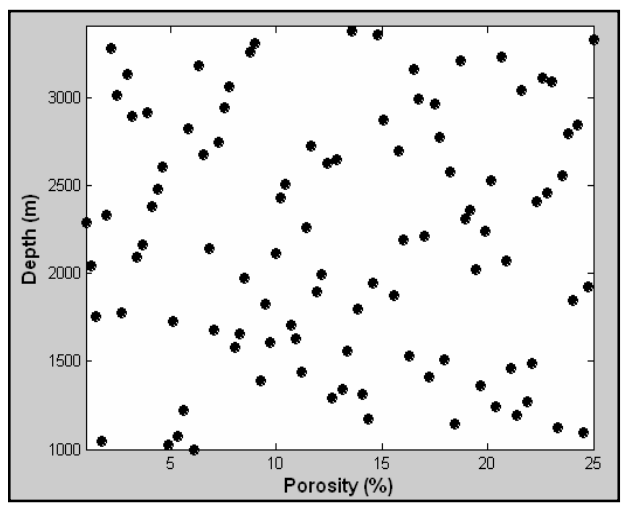

Figure C.3: Porosity vs. Reference Depth

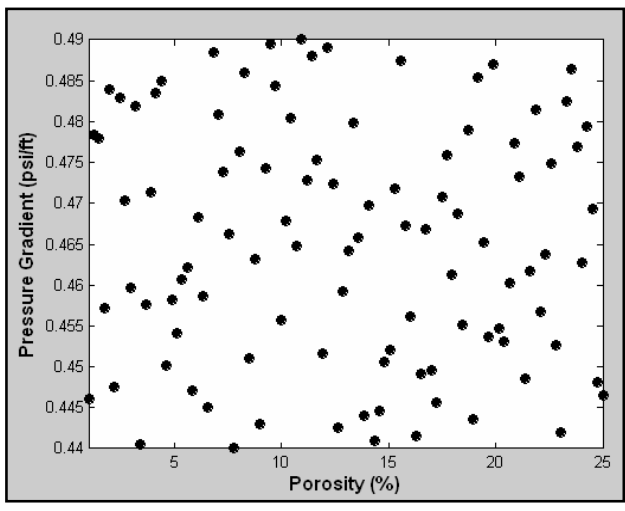

Figure C.4: Porosity vs. Pressure Gradient

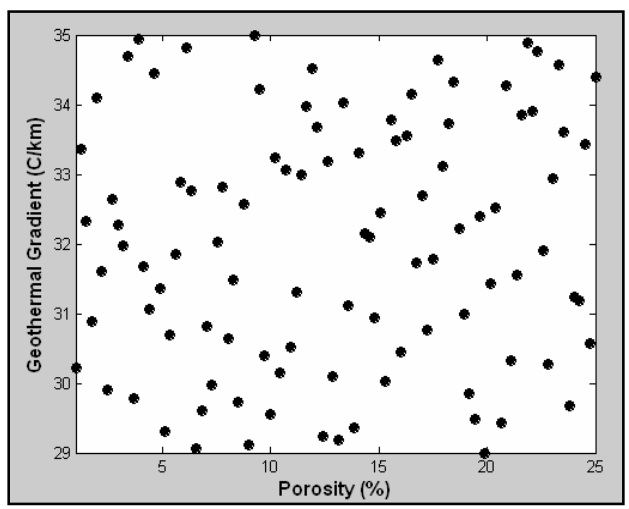

Figure C.5: Porosity vs. Geothermal Gradient

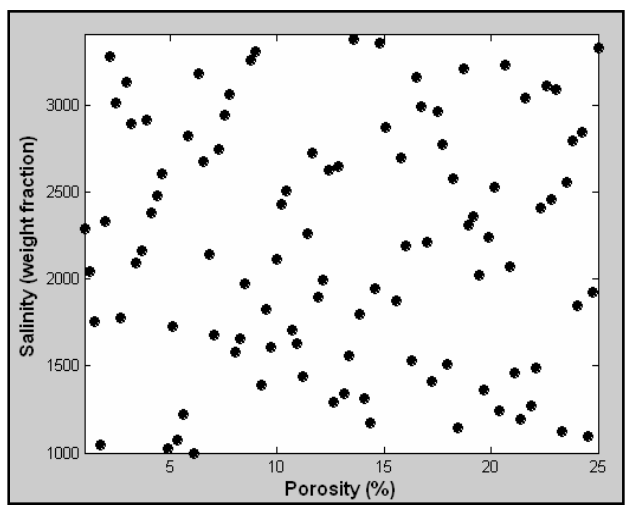

Figure C.6: Porosity vs. Salinity 


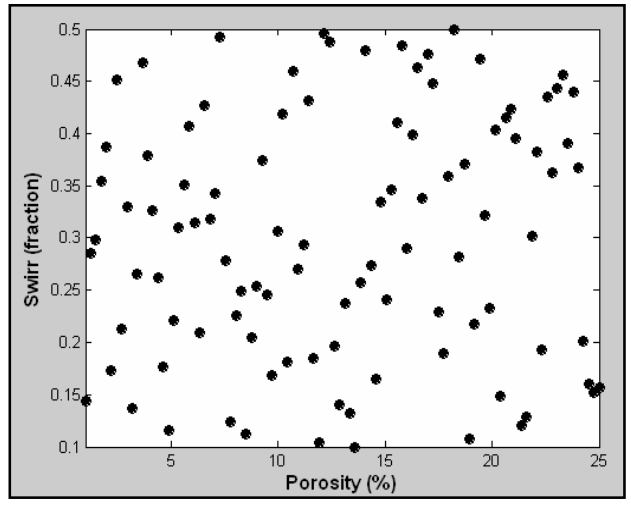

Figure C.7: Porosity vs. Irreducible Water Saturation

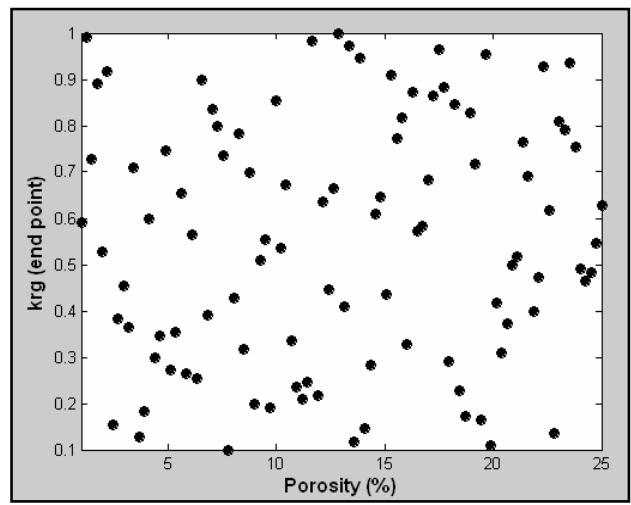

Figure C.8: Porosity vs. Gas Relative Permeability End Point

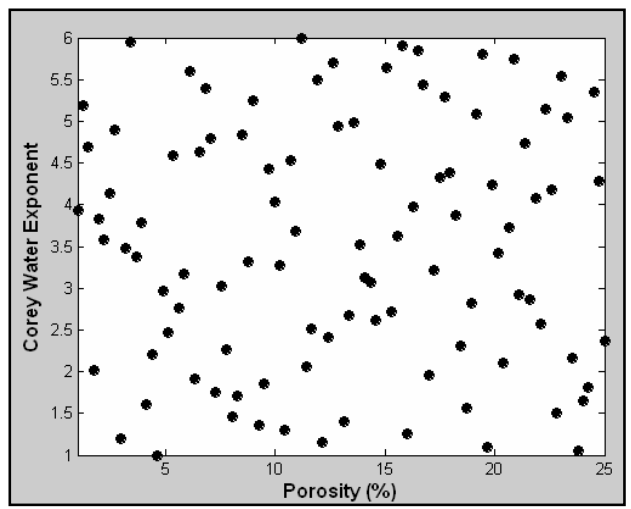

Figure C.9: Porosity vs. Corey Water Exponent

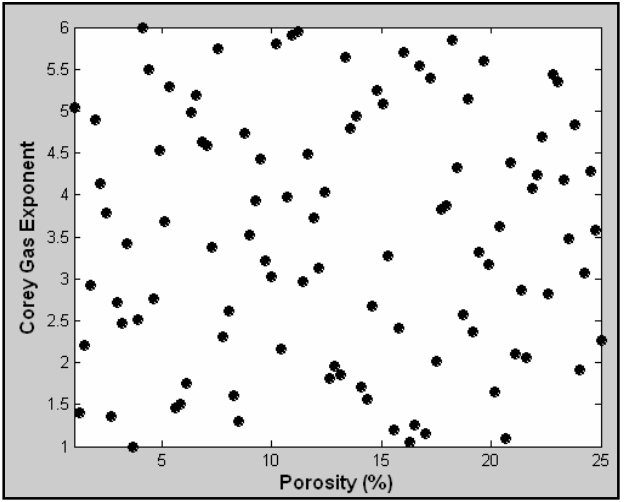

Figure C.10: Porosity vs. Corey Gas Exponent

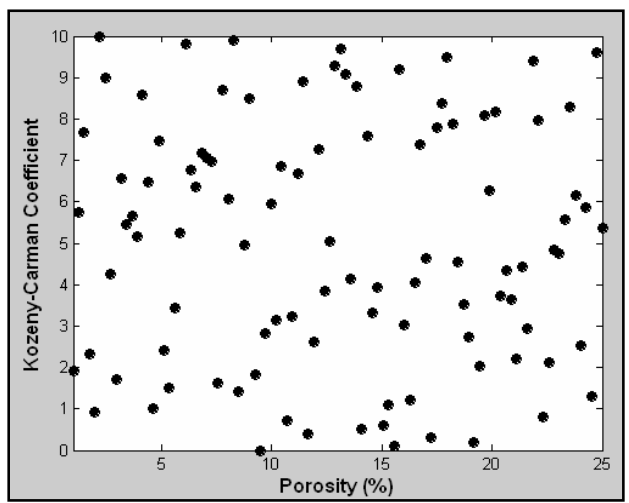

Figure C.11: Porosity vs. Kozeny-Carman Coefficient

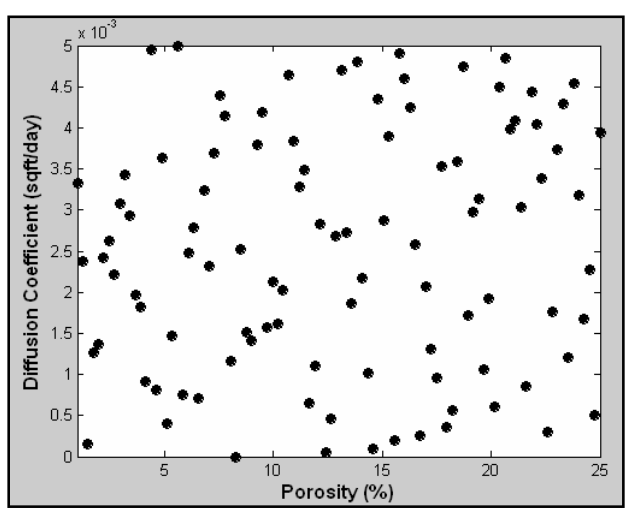

Figure C.12: Porosity vs. Diffusion Coefficient 


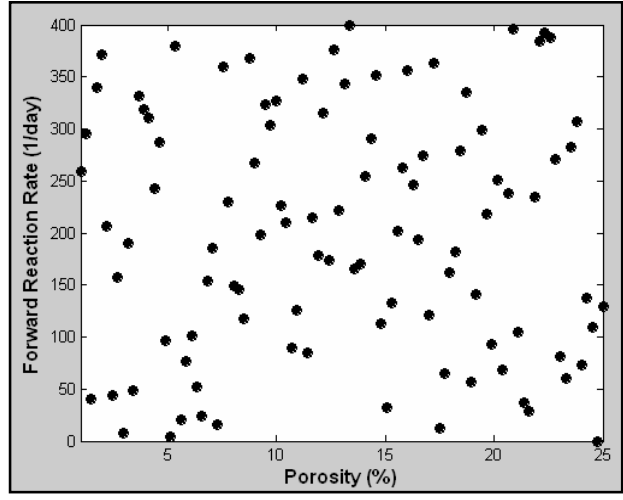

Figure C.13: Porosity vs. Forward Reaction Rate

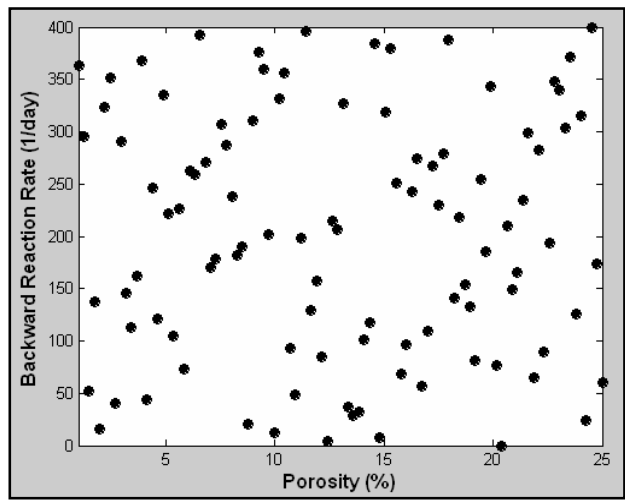

Figure C.14: Porosity vs. Backward Reaction Rate

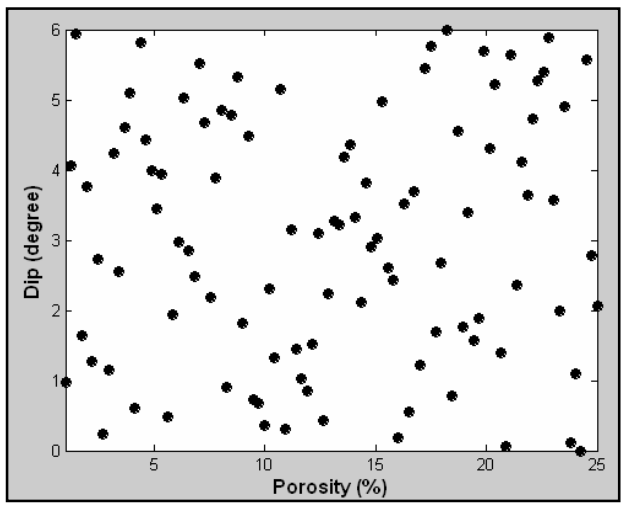

Figure C.15: Porosity vs. Formation Dip

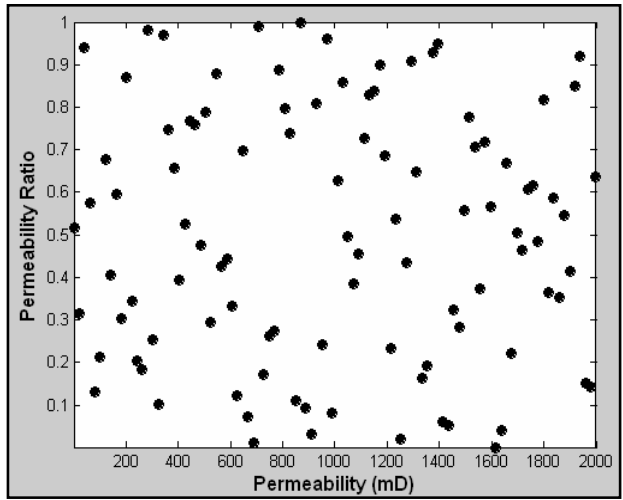

Figure C.16: Permeability vs. Horizontal to Vertical Permeability Ratio

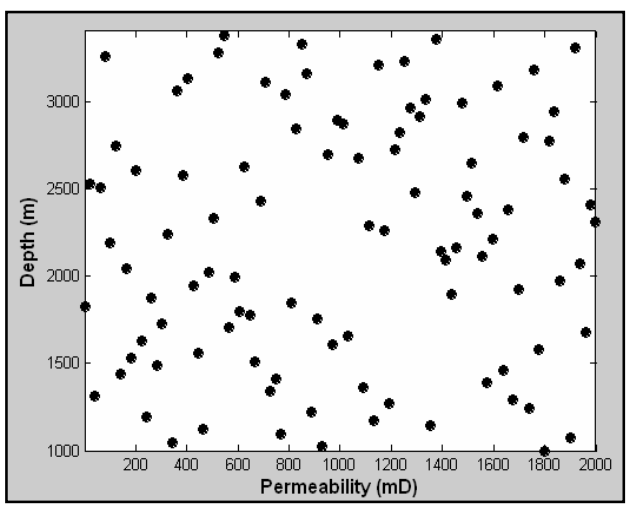

Figure C.17: Permeability vs. Reference Depth

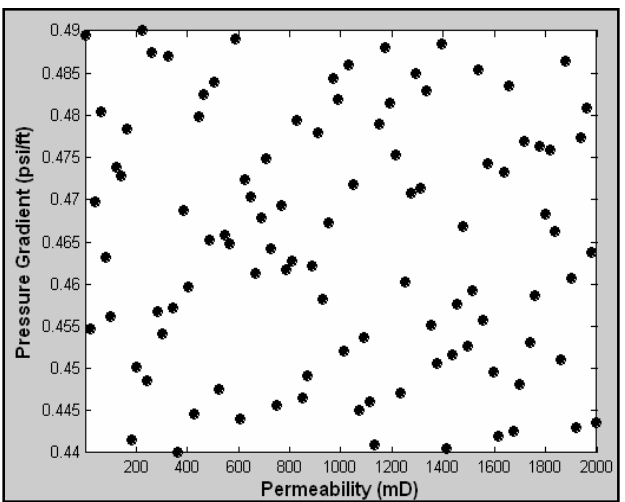

Figure C.18: Permeability vs. Pressure

Gradient 


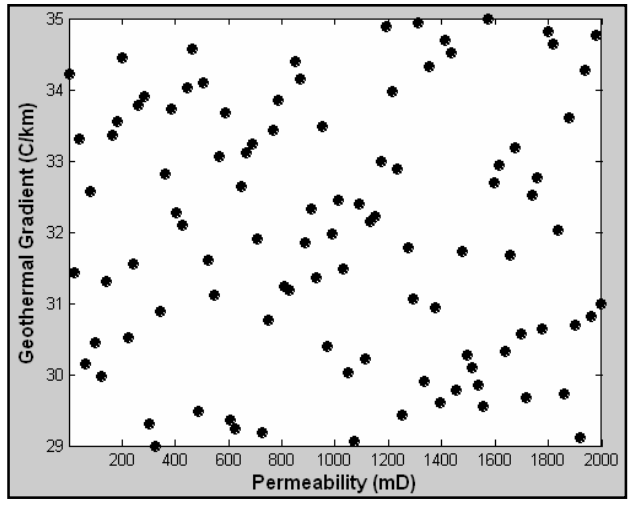

Figure C.19: Permeability vs. Geothermal Gradient

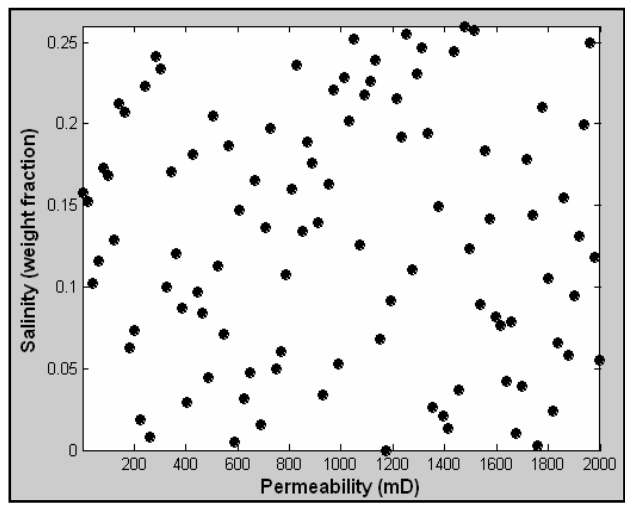

Figure C.20: Permeability vs. Salinity

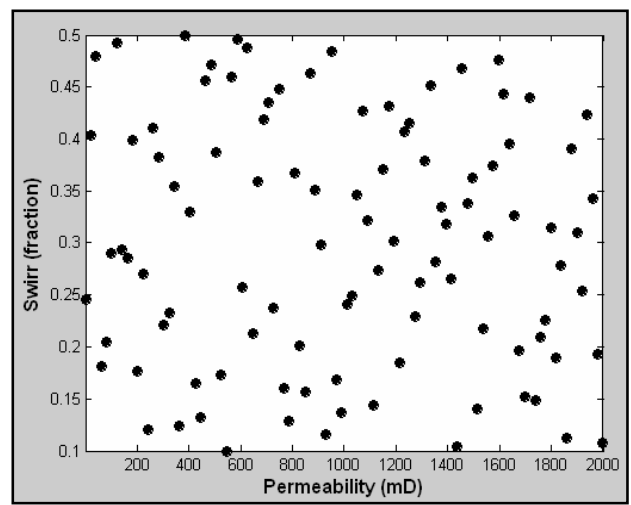

Figure C.21: Permeability vs. Irreducible Water Saturation

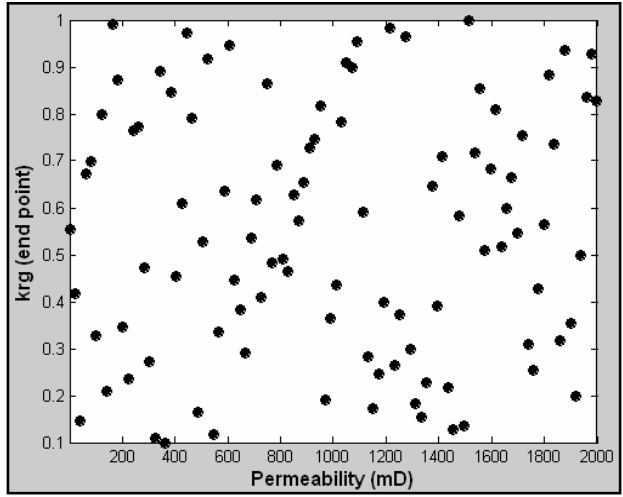

Figure C.22: Permeability vs. Gas Relative Permeability End Point

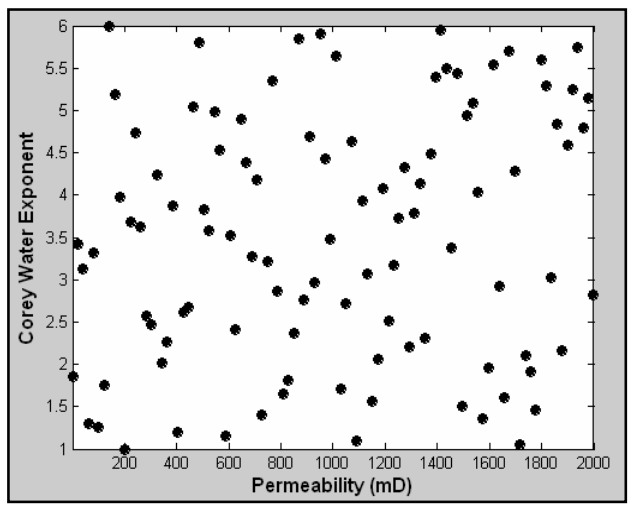

Figure C.23: Permeability vs. Corey Water Exponent

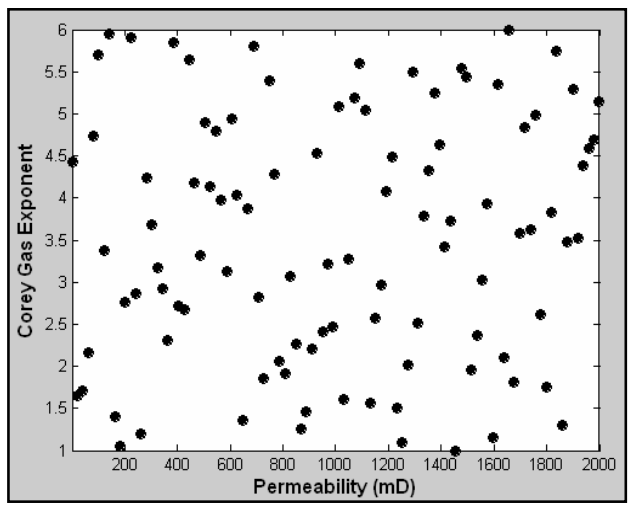

Figure C.24: Permeability vs. Corey Gas Exponent 


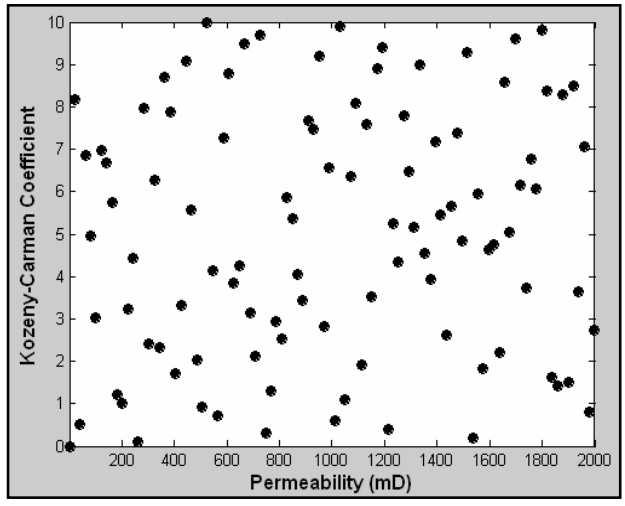

Figure C.25: Permeability vs. Kozeny-Carman Coefficient

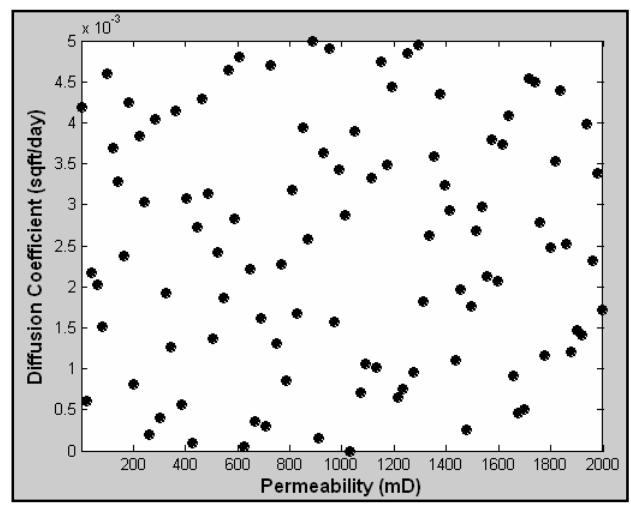

Figure C.26: Permeability vs. Diffusion Coefficient

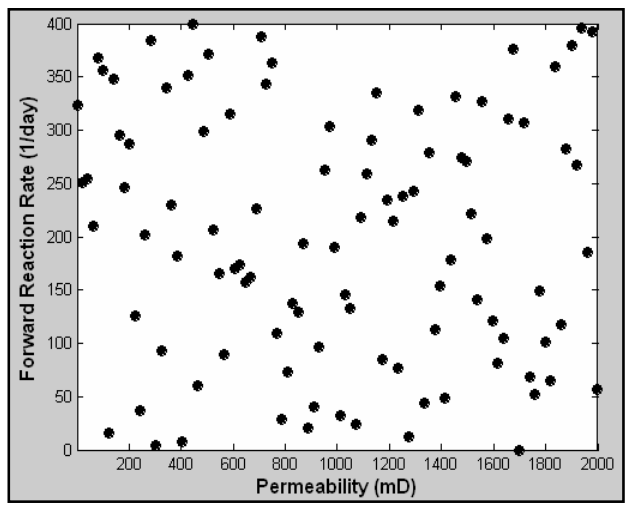

Figure C.27: Permeability vs. Forward Reaction Rate

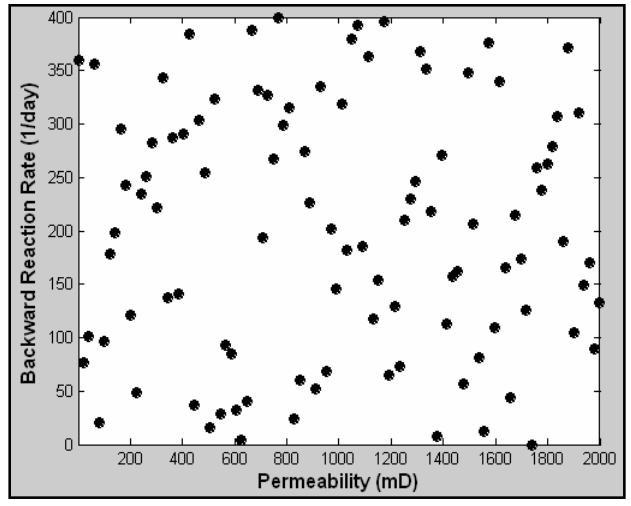

Figure C.28: Permeability vs. Backward Reaction Rate

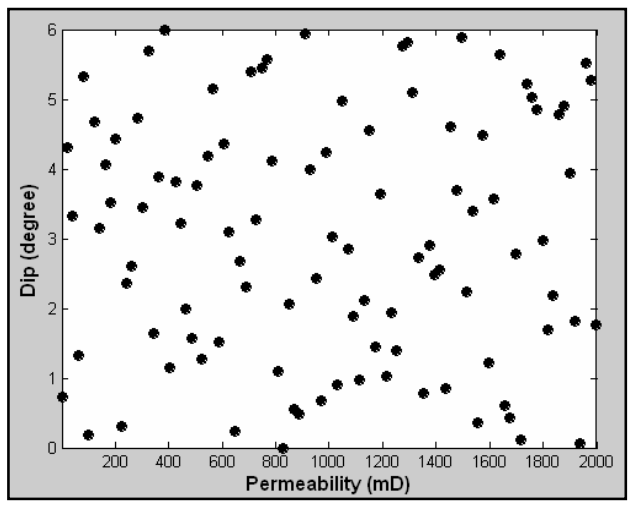

Figure C.29: Permeability vs. Formation Dip

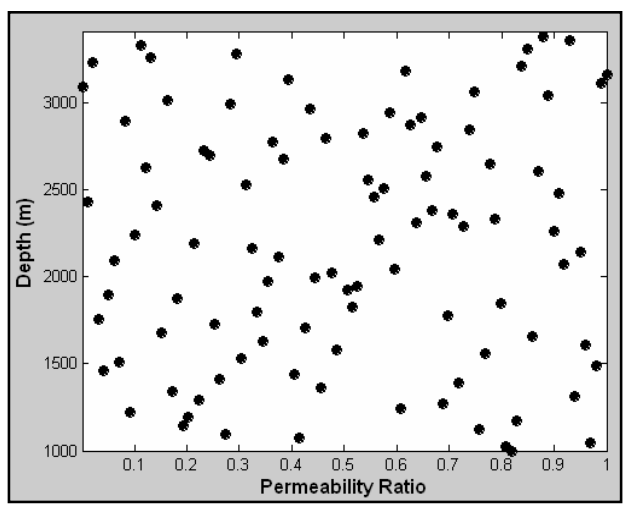

Figure C.30: Horizontal to Vertical Permeability Ratio vs. Reference Depth 


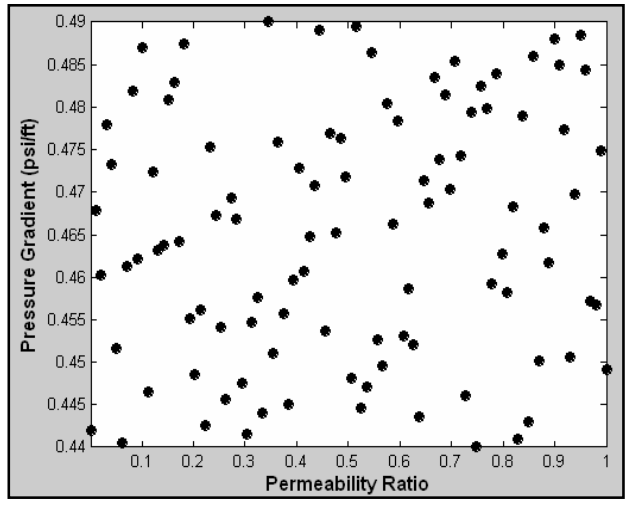

Figure C.31: Horizontal to Vertical Permeability Ratio vs. Pressure Gradient

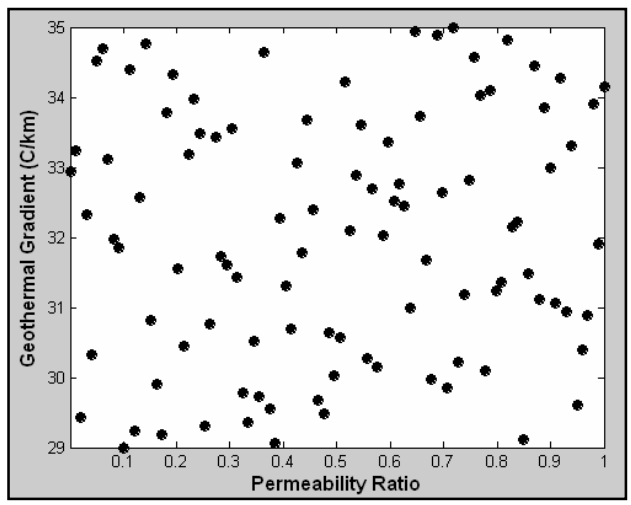

Figure C.32: Horizontal to Vertical Permeability Ratio vs. Geothermal Gradient

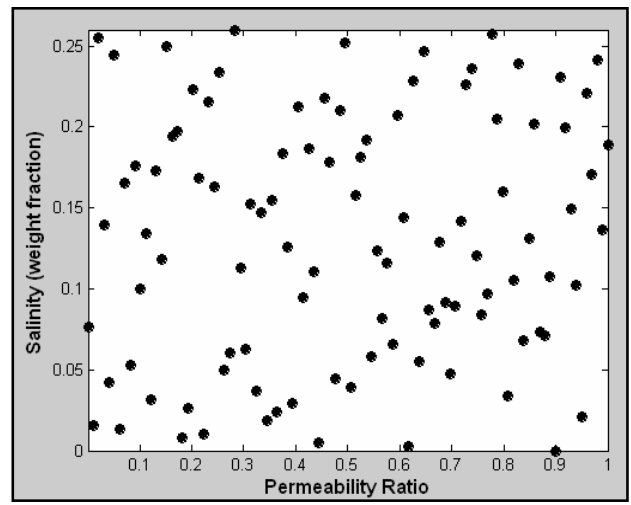

Figure C.33: Horizontal to Vertical Permeability Ratio vs. Salinity

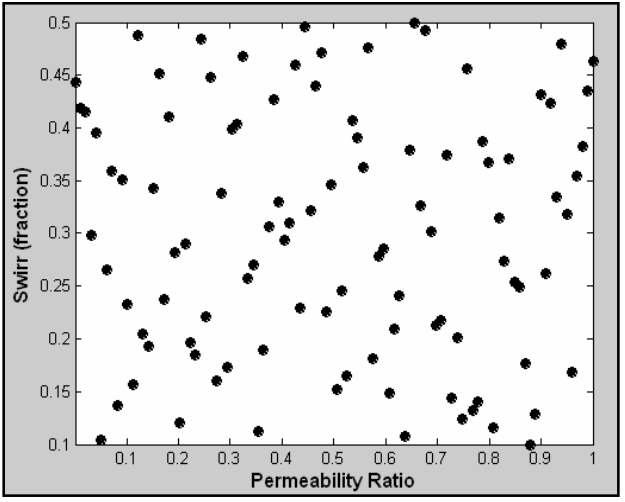

Figure C.34: Horizontal to Vertical Permeability Ratio vs. Irreducible Water Saturation

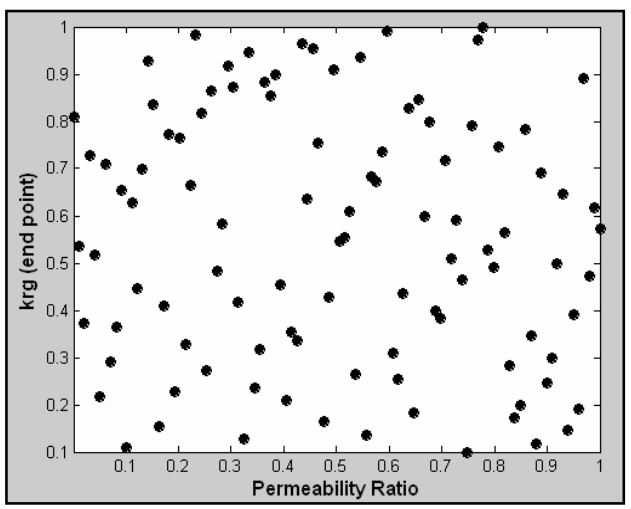

Figure C.35: Horizontal to Vertical Permeability Ratio vs. Gas Relative Permeability End Point

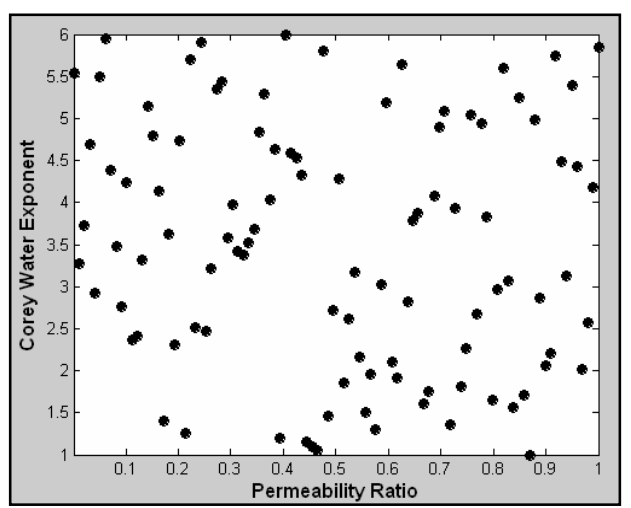

Figure C.36: Horizontal to Vertical Permeability Ratio vs. Corey Water Exponent 


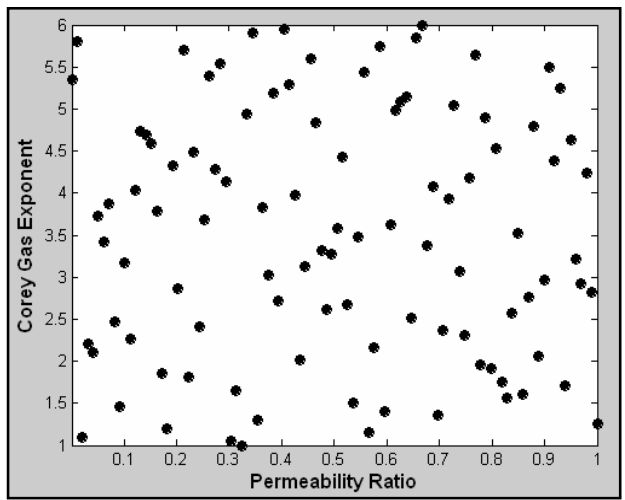

Figure C.37: Horizontal to Vertical Permeability Ratio vs. Corey Gas Exponent

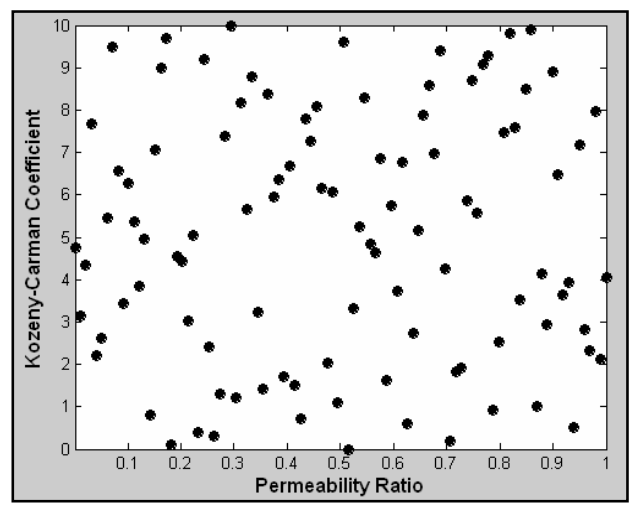

Figure C.38: Horizontal to Vertical Permeability Ratio vs. Kozeny-Carman Coefficient

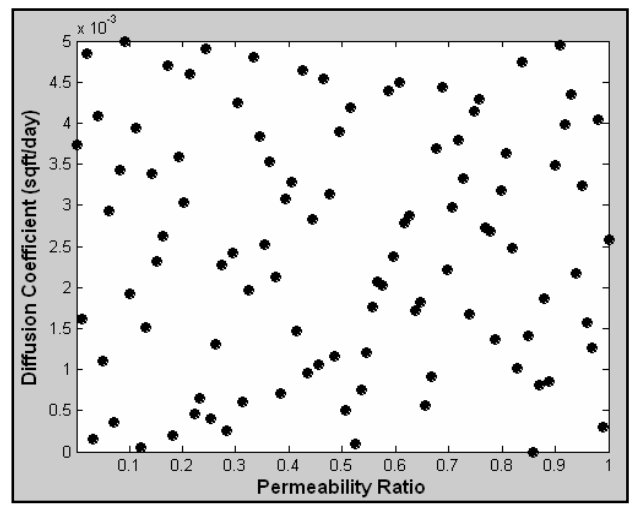

Figure C.39: Horizontal to Vertical Permeability Ratio vs. Diffusion Coefficient

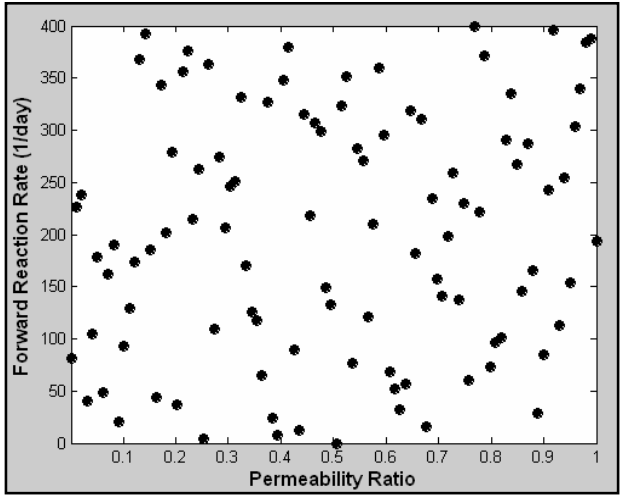

Figure C.40: Horizontal to Vertical Permeability Ratio vs. Forward Reaction Rate

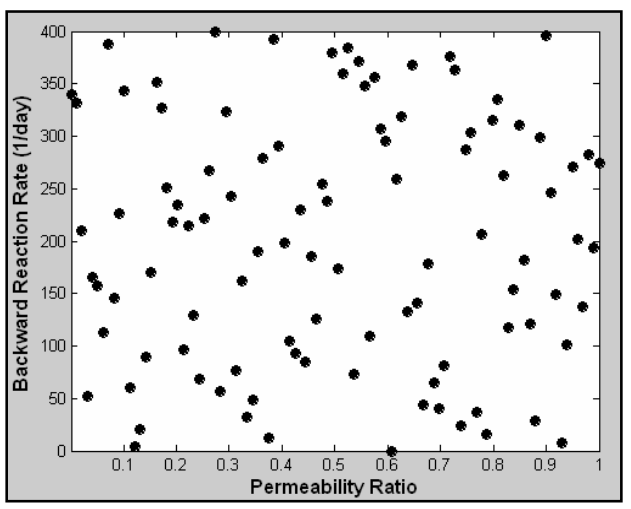

Figure C.41: Horizontal to Vertical Permeability Ratio vs. Backward Reaction Rate

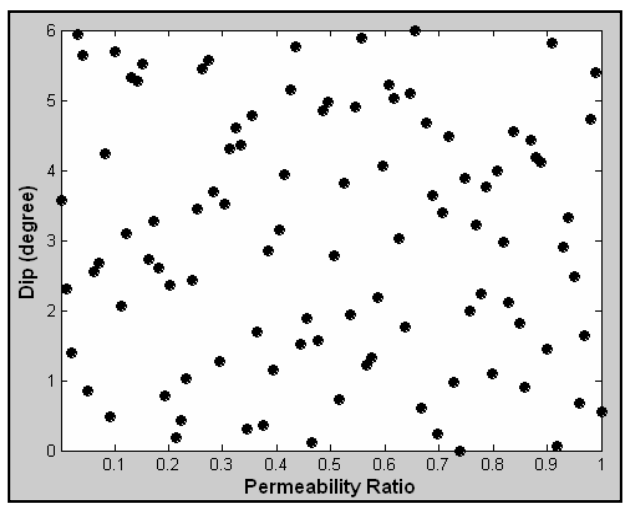

Figure C.42: Horizontal to Vertical Permeability Ratio vs. Formation Dip 


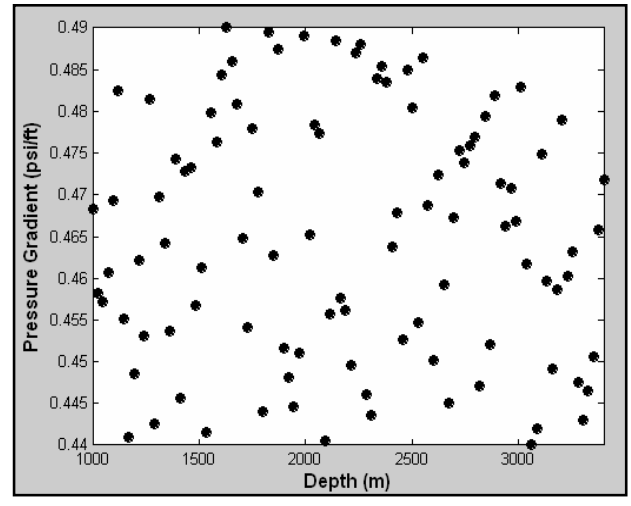

Figure C.43: Reference Depth vs. Pressure Gradient

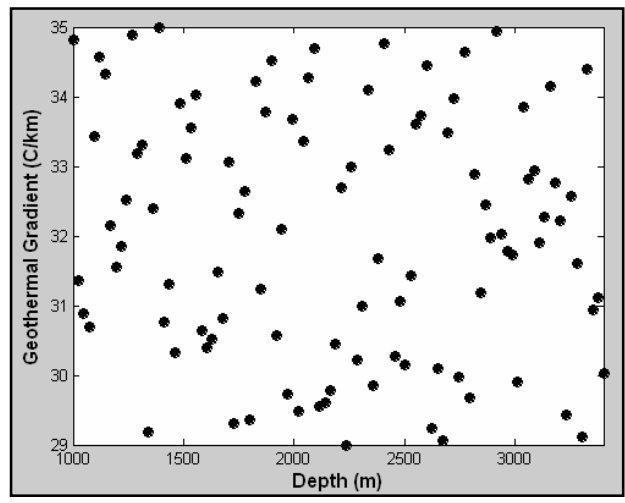

Figure C.44: Reference Depth vs. Geothermal Gradient

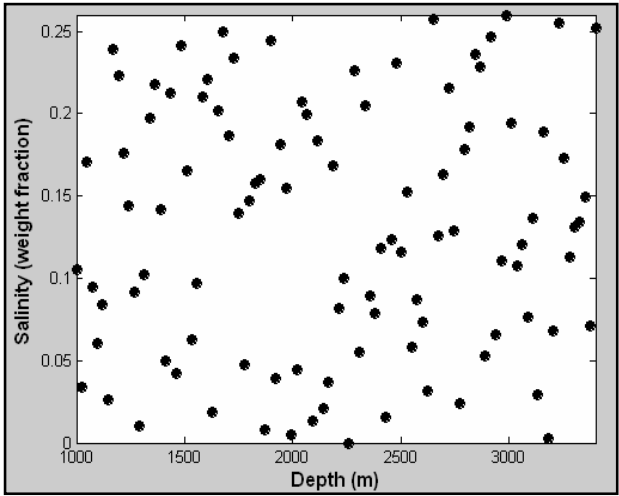

Figure C.45: Reference Depth vs. Salinity

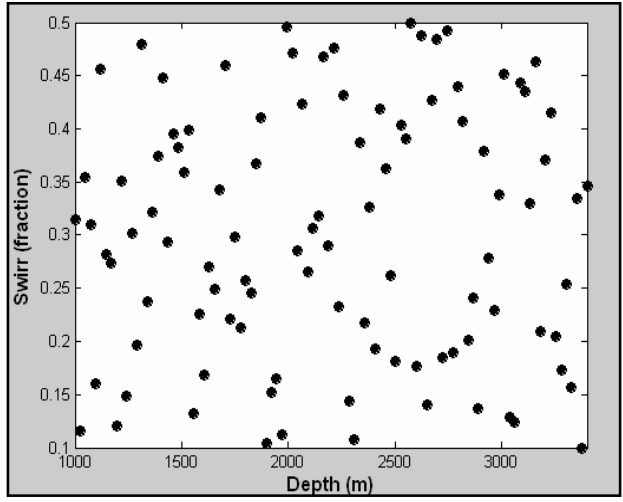

Figure C.46: Reference Depth vs. Irreducible Water Saturation

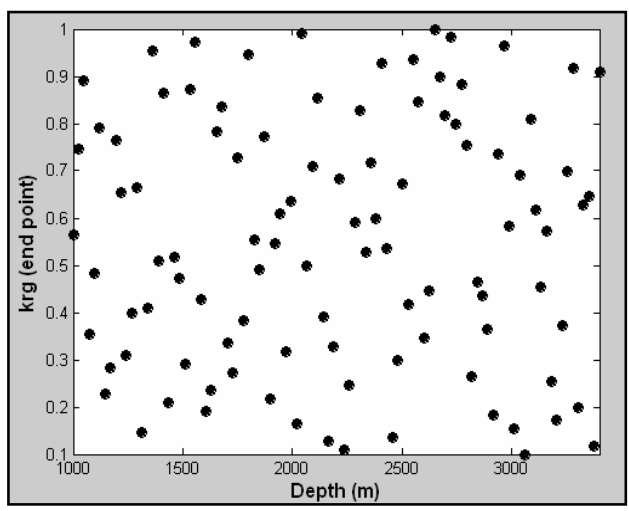

Figure C.47: Reference Depth vs. Gas Relative Permeability End Point

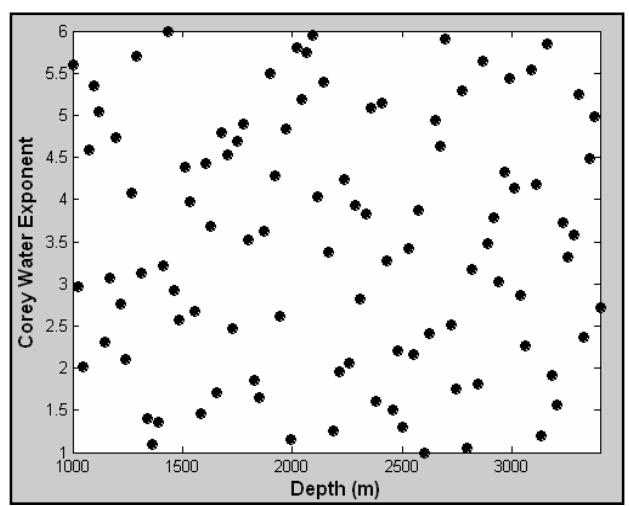

Figure C.48: Reference Depth vs. Corey Water Exponent 


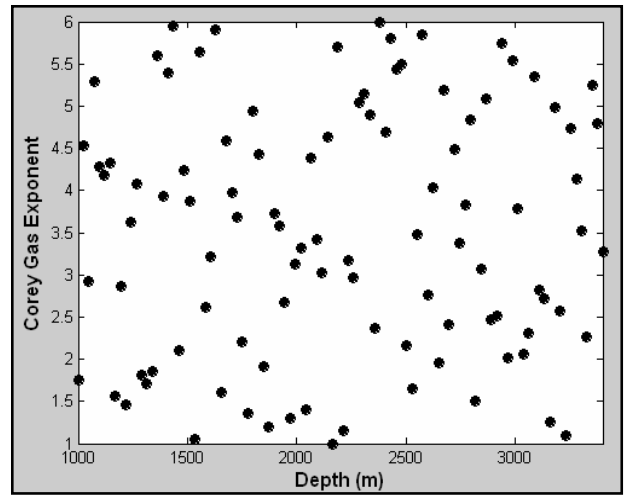

Figure C.49: Reference Depth vs. Corey Gas Exponent

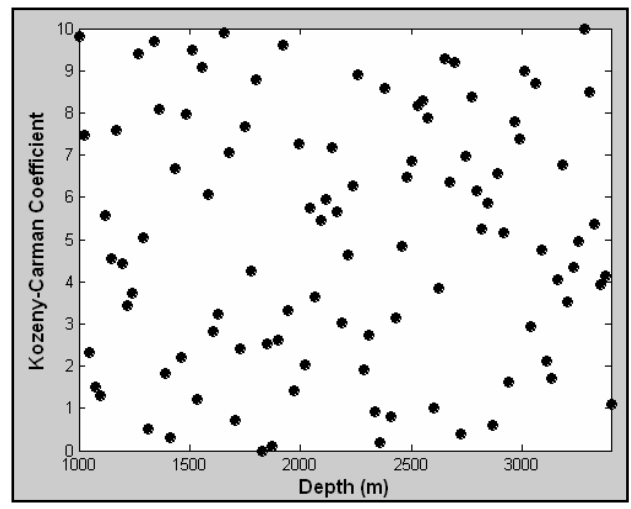

Figure C.50: Reference Depth vs. KozenyCarman Coefficient

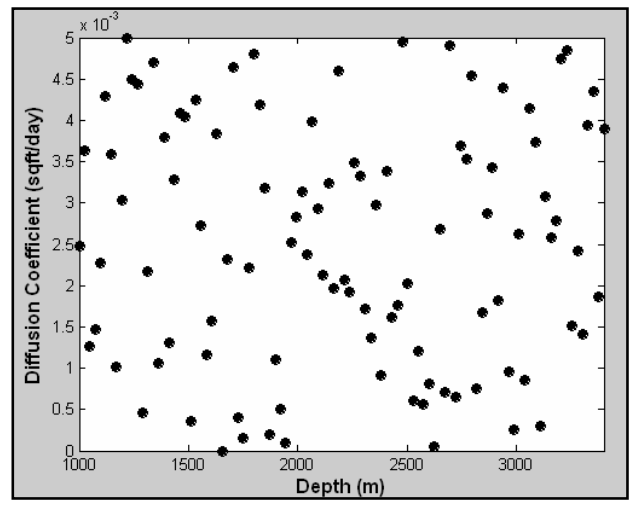

Figure C.51: Reference Depth vs. Diffusion Coefficient

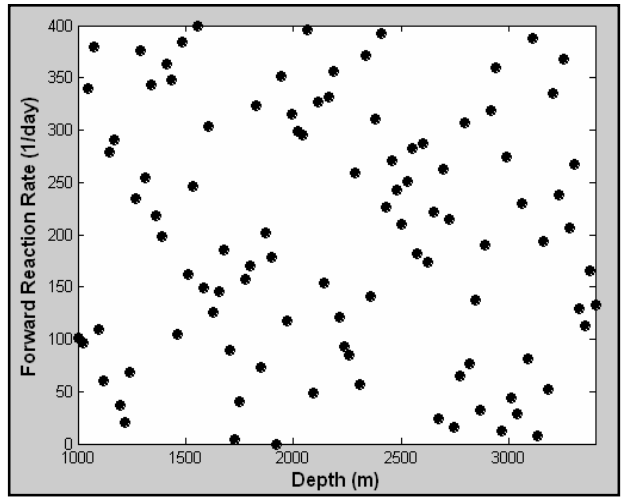

Figure C.52: Reference Depth vs. Forward Reaction Rate

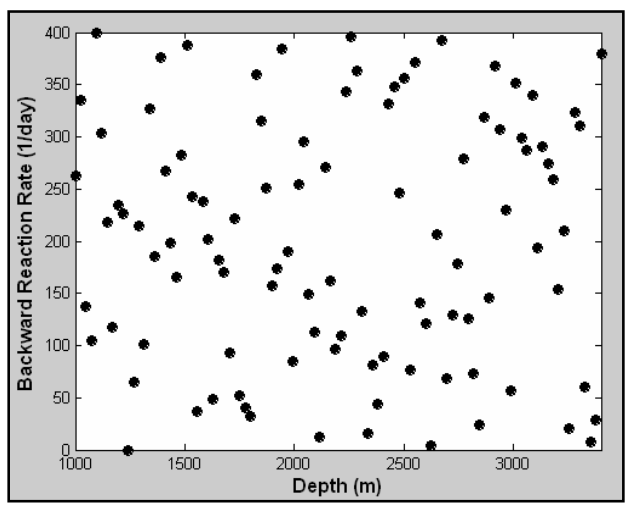

Figure C.53: Reference Depth vs. Backward Reaction Rate

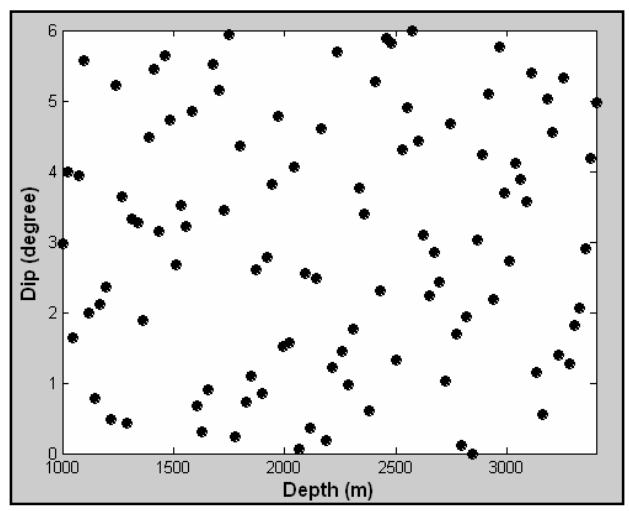

Figure C.54: Reference Depth vs. Formation Dip 


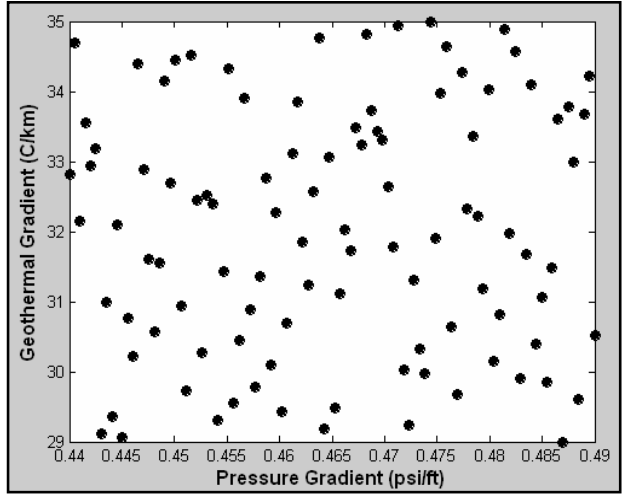

Figure C.55: Pressure Gradient vs. Geothermal Gradient

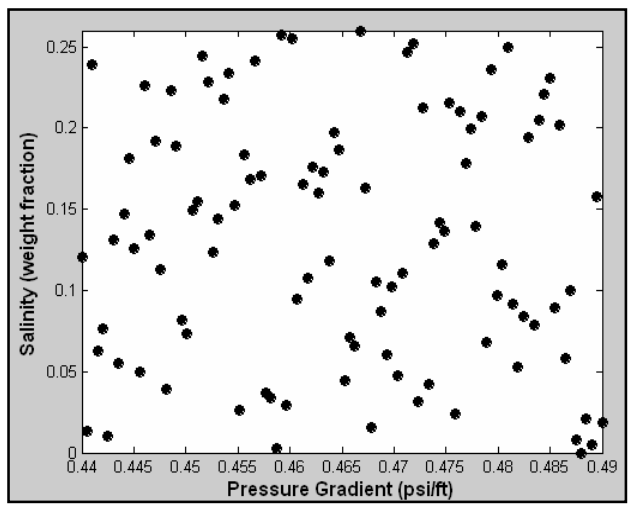

Figure C.56: Pressure Gradient vs. Salinity

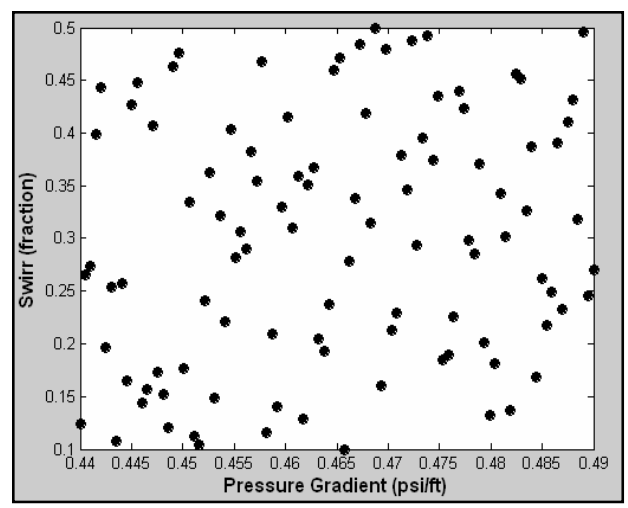

Figure C.57: Pressure Gradient vs. Irreducible Water Saturation

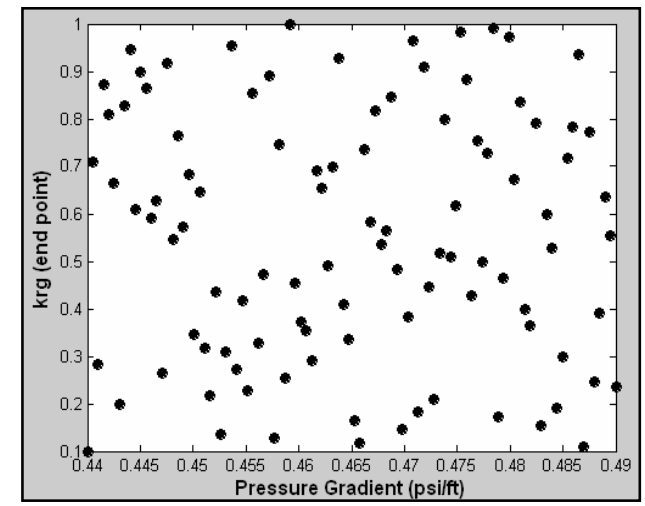

Figure C.58: Pressure Gradient vs. Gas

Relative Permeability End Point

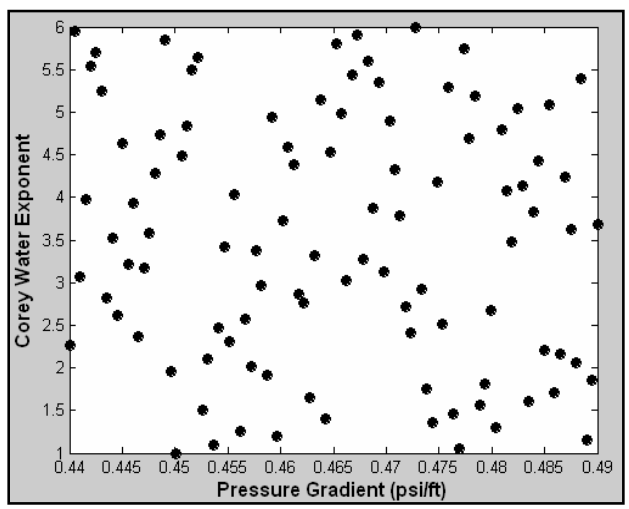

Figure C.59: Pressure Gradient vs. Corey Water Exponent

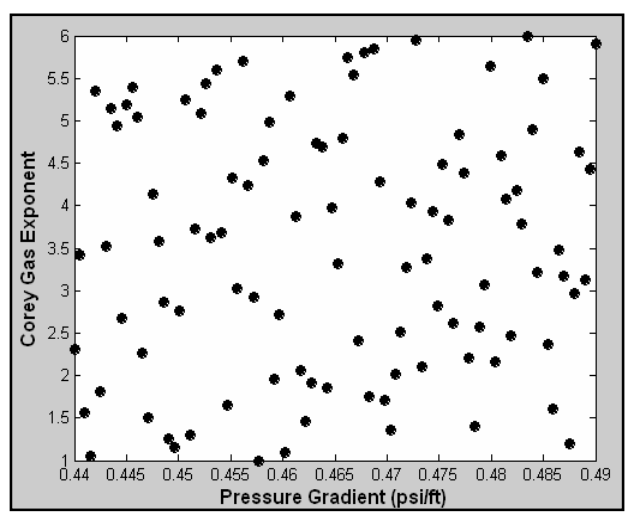

Figure C.60: Pressure Gradient vs. Corey Gas Exponent 


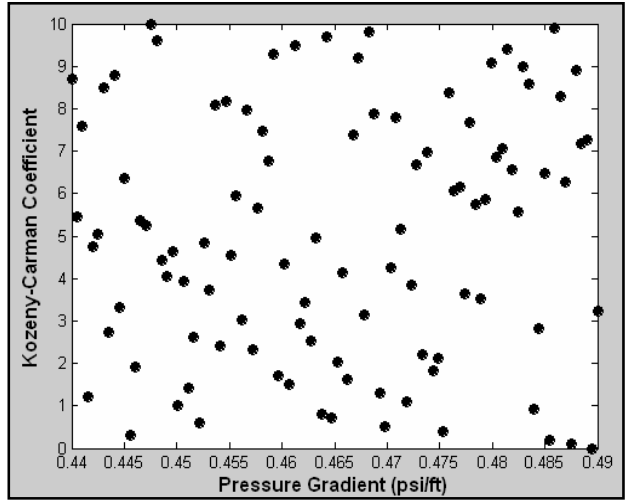

Figure C.61: Pressure Gradient vs. KozenyCarman Coefficient

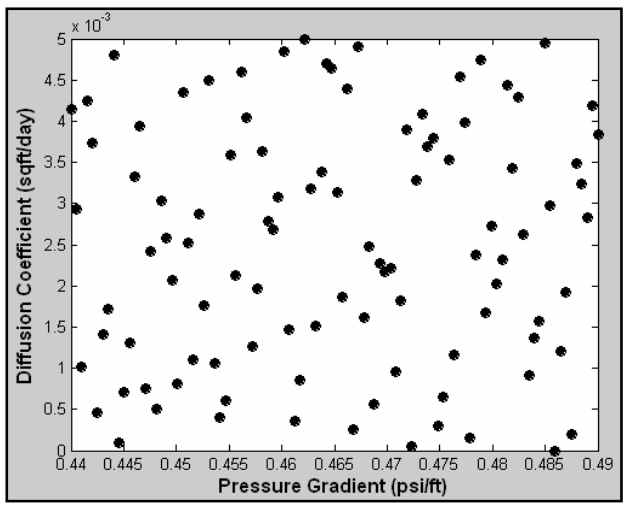

Figure C.62: Pressure Gradient vs. Diffusion Coefficient

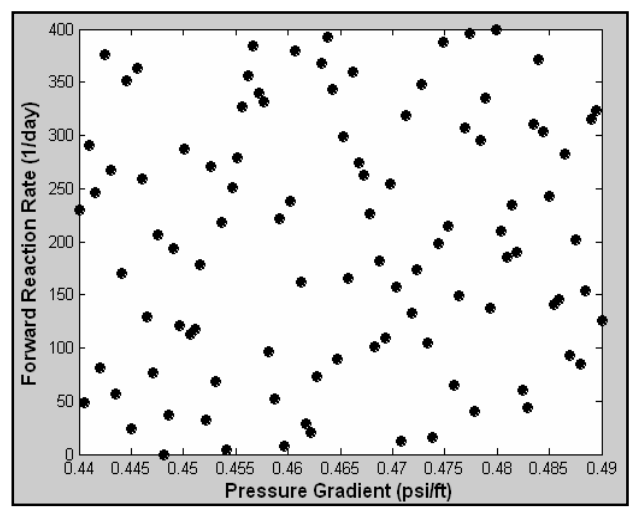

Figure C.63: Pressure Gradient vs. Forward Reaction Rate

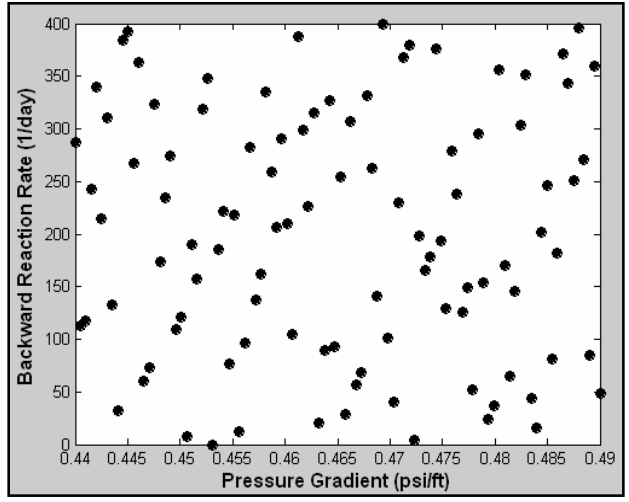

Figure C.64: Pressure Gradient vs. Backward Reaction Rate

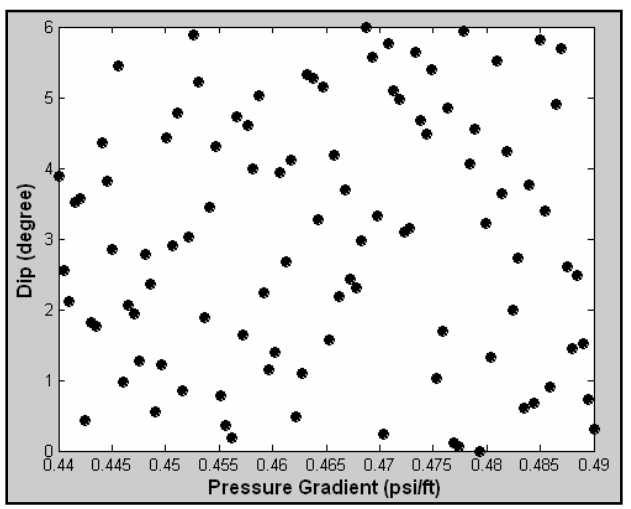

Figure C.65: Pressure Gradient vs. Formation Dip

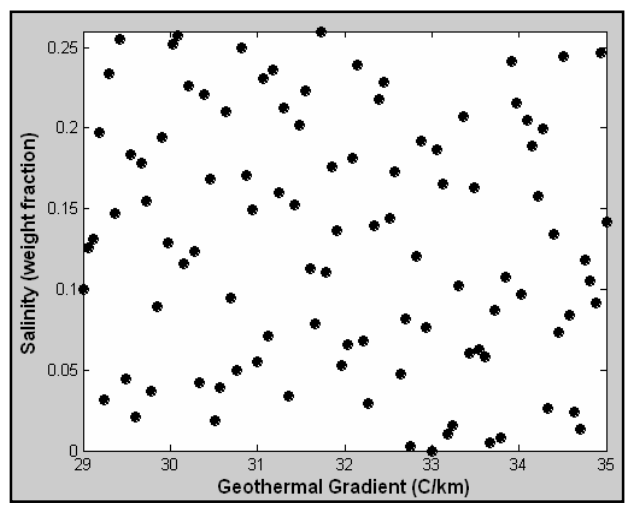

Figure C.66: Geothermal Gradient vs. Salinity 


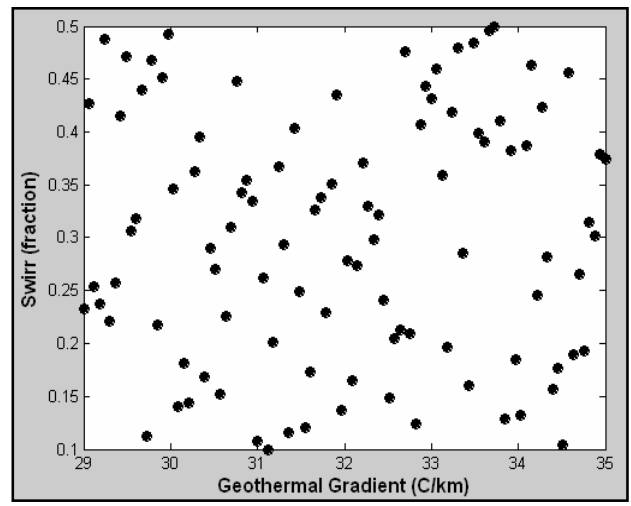

Figure C.67: Geothermal Gradient vs. Irreducible Water Saturation

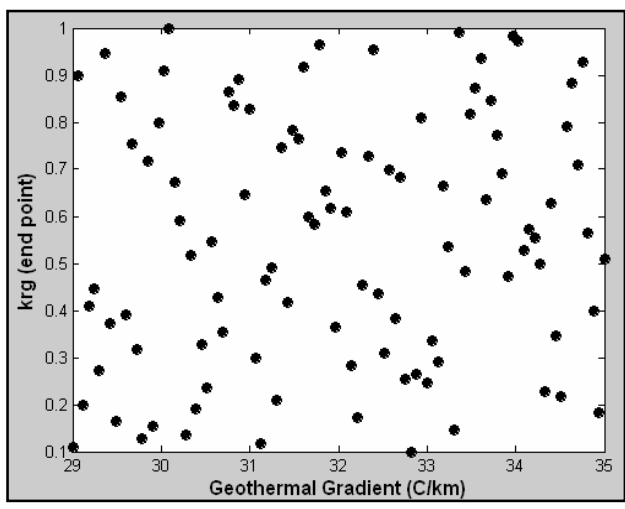

Figure C.68: Geothermal Gradient vs. Gas

Relative Permeability End Point

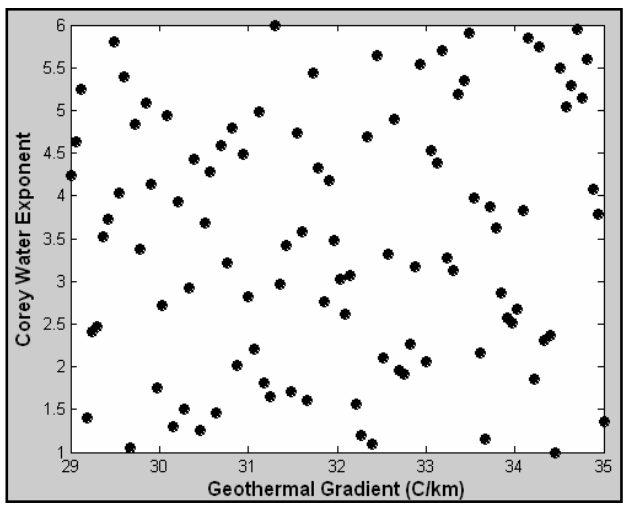

Figure C.69: Geothermal Gradient vs. Corey Water Exponent

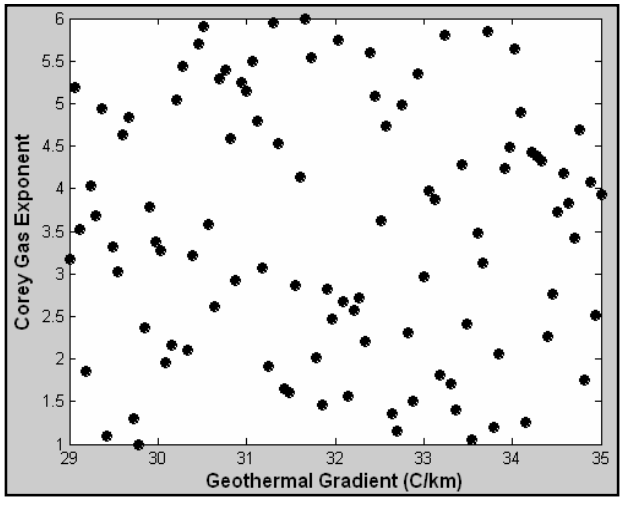

Figure C.70: Geothermal Gradient vs. Corey Gas Exponent

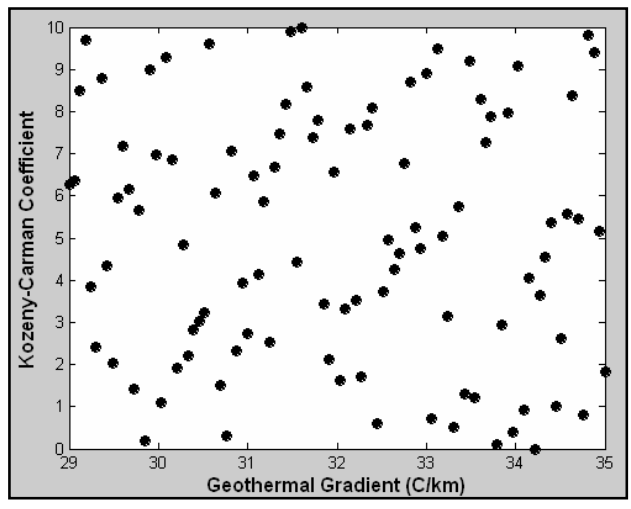

Figure C.71: Geothermal Gradient vs. KozenyCarman Coefficient

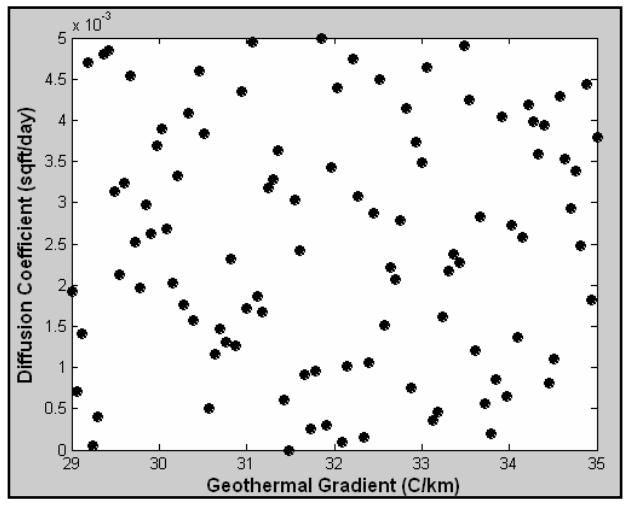

Figure C.72: Geothermal Gradient vs. Diffusion Coefficient 


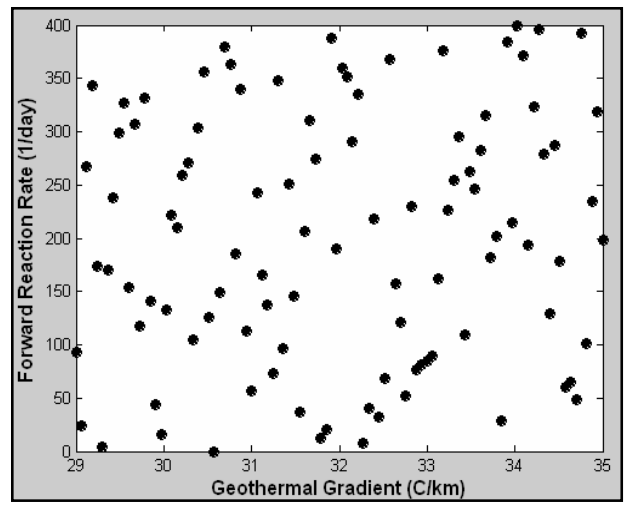

Figure C.73: Geothermal Gradient vs. Forward Reaction Rate

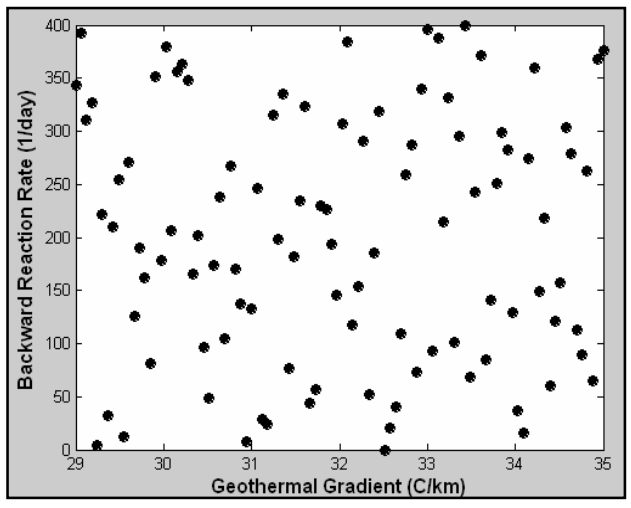

Figure C.74: Geothermal Gradient vs. Backward Reaction Rate

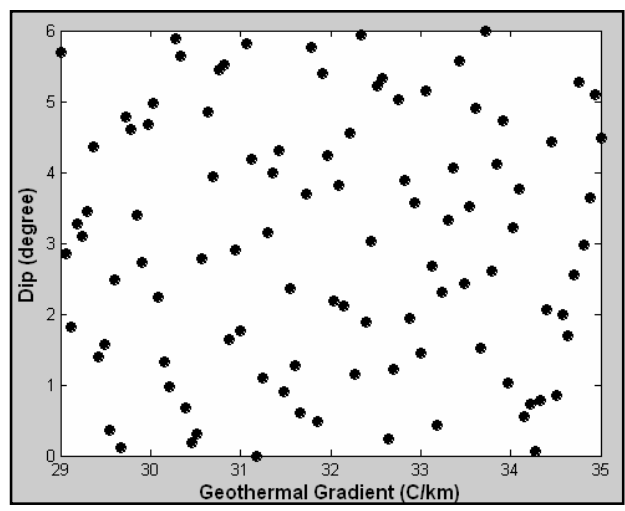

Figure C.75: Geothermal Gradient vs.

Formation Dip

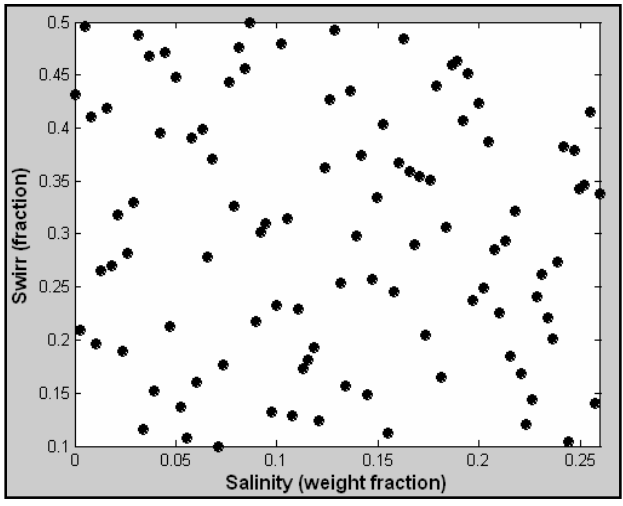

Figure C.76: Salinity vs. Irreducible Water Saturation

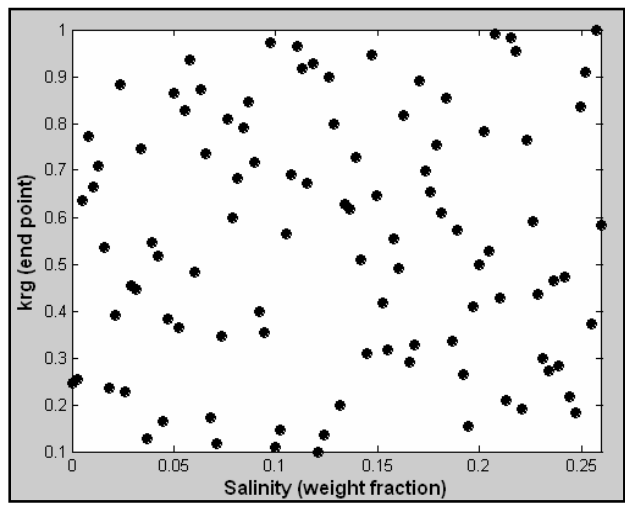

Figure C.77: Salinity vs. Gas Relative Permeability End Point

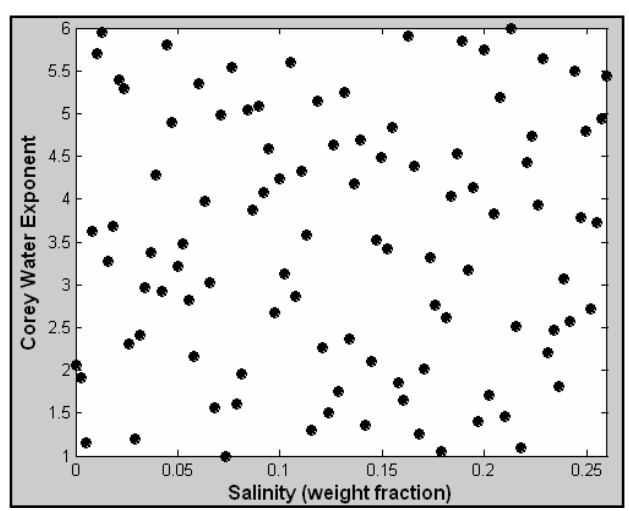

Figure C.78: Salinity vs. Corey Water Exponent 


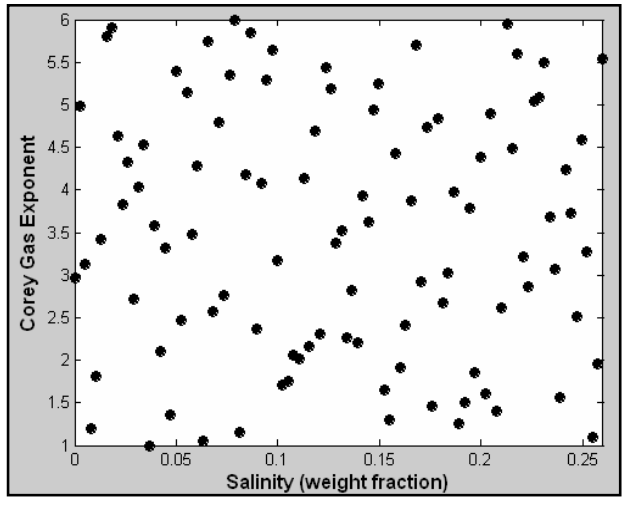

Figure C.79: Salinity vs. Corey Gas Exponent

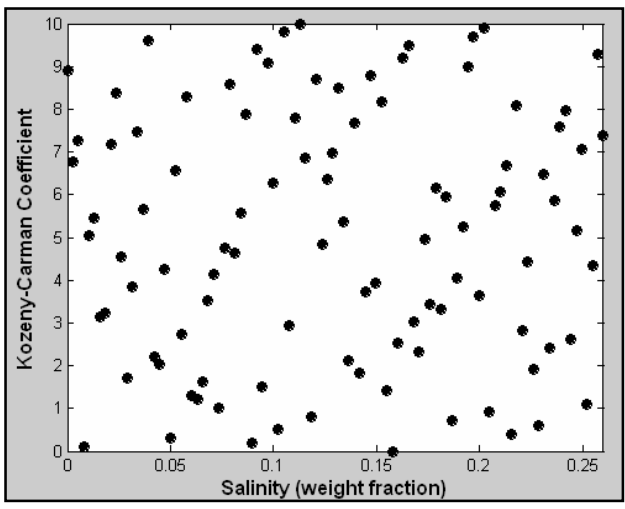

Figure C.80: Salinity vs. Kozeny-Carman Coefficient

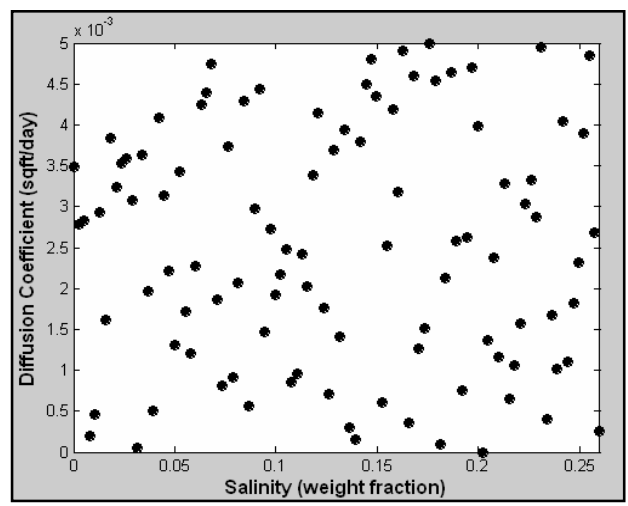

Figure C.81: Salinity vs. Diffusion Coefficient

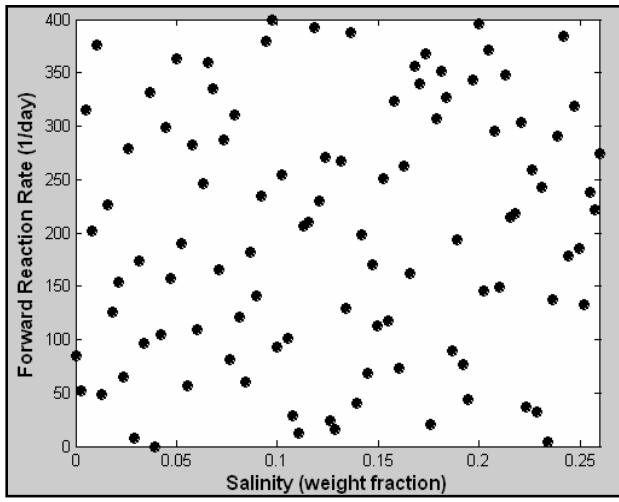

Figure C.82: Salinity vs. Forward Reaction Rate

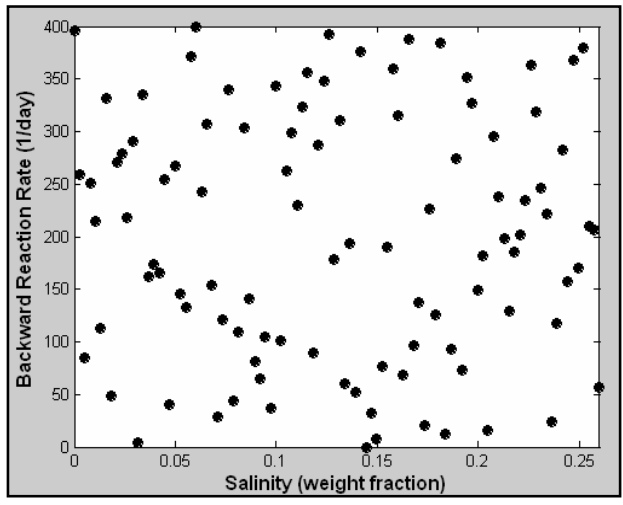

Figure C.83: Salinity vs. Backward Reaction Rate

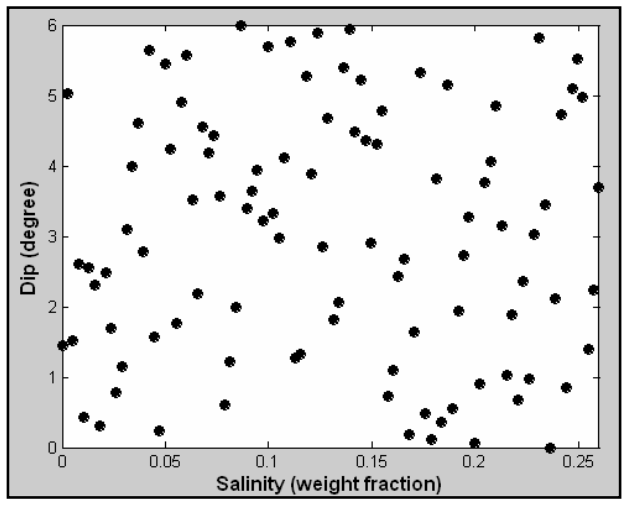

Figure C.84: Salinity vs. Formation Dip 


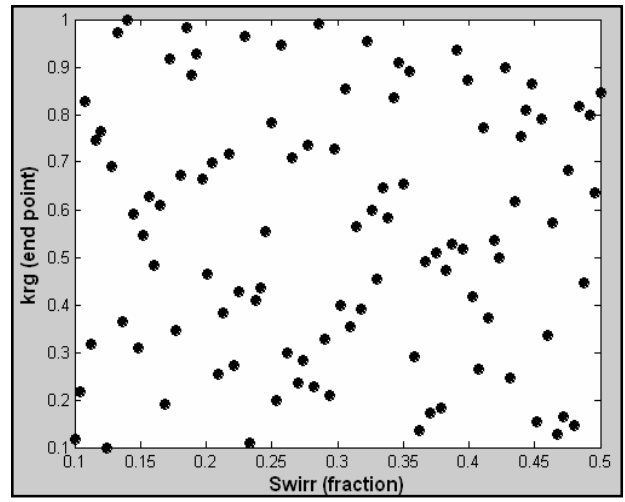

Figure C.85: Irreducible Water Saturation vs.

Gas Relative Permeability End Point

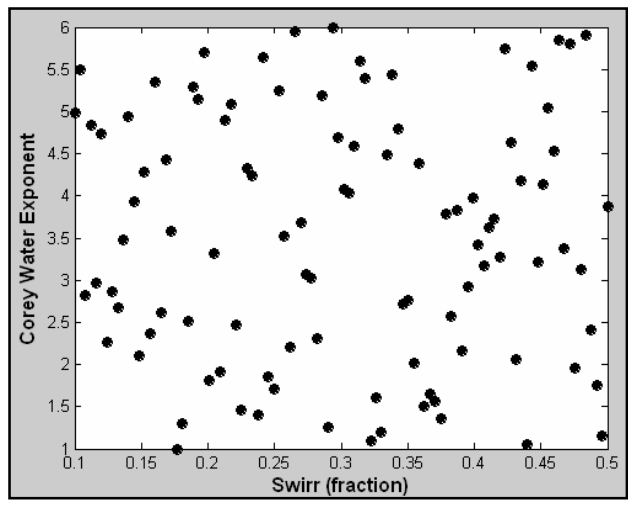

Figure C.86: Irreducible Water Saturation vs. Corey Water Exponent

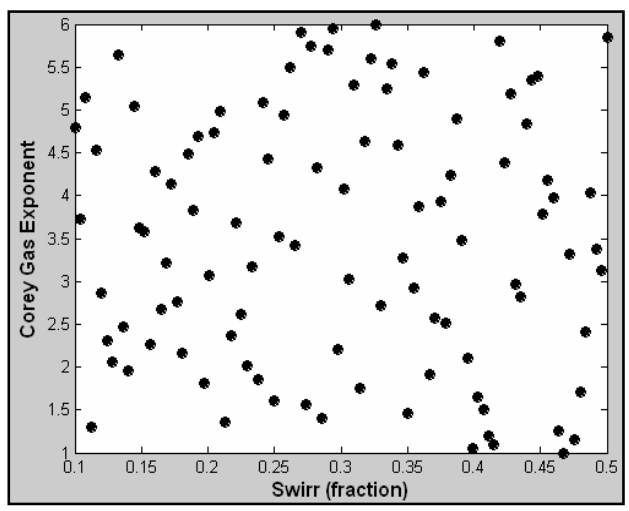

Figure C.87: Irreducible Water Saturation vs. Corey Gas Exponent

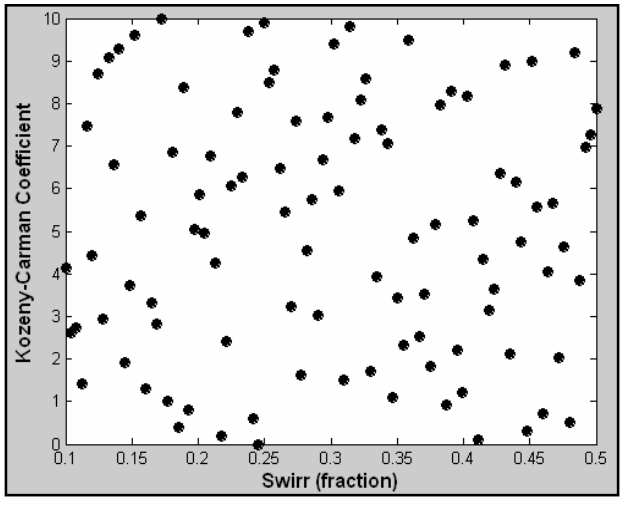

Figure C.88: Irreducible Water Saturation vs. Kozeny-Carman Coefficient

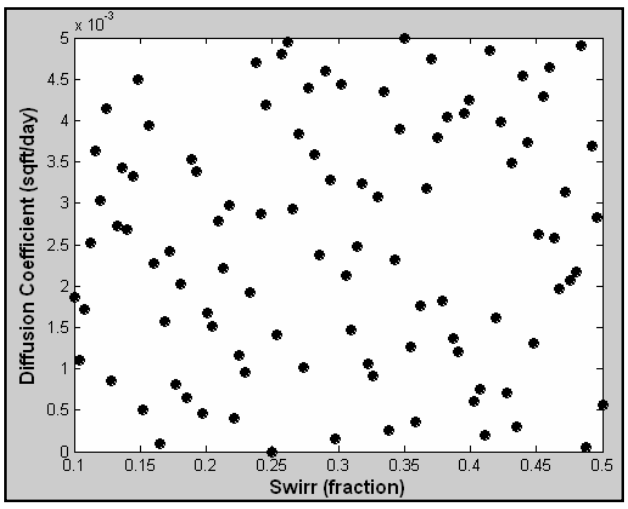

Figure C.89: Irreducible Water Saturation vs. Diffusion Coefficient

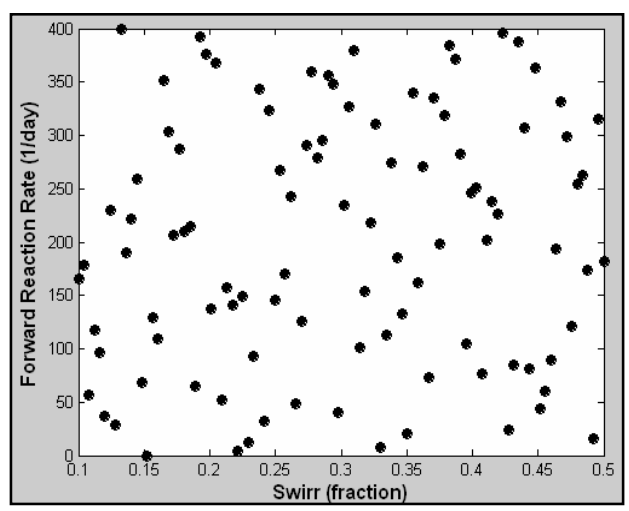

Figure C.90: Irreducible Water Saturation vs.

Forward Reaction Rate 


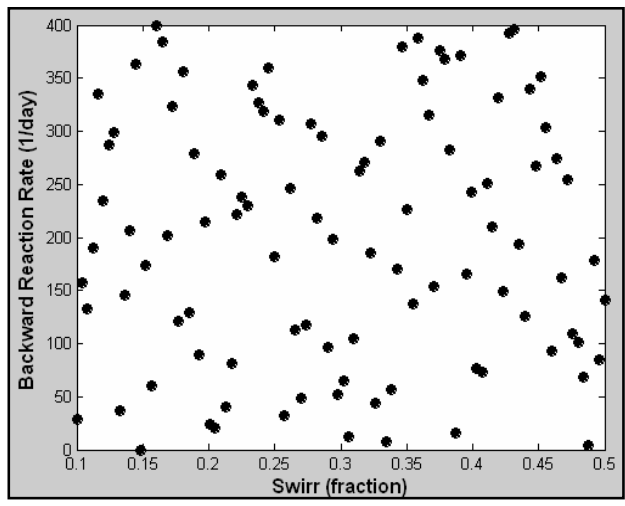

Figure C.91: Irreducible Water Saturation vs. Backward Reaction Rate

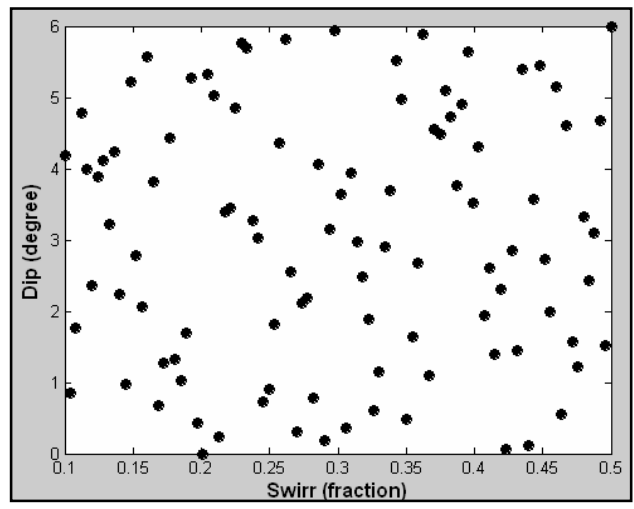

Figure C.92: Irreducible Water Saturation vs.

Formation Dip

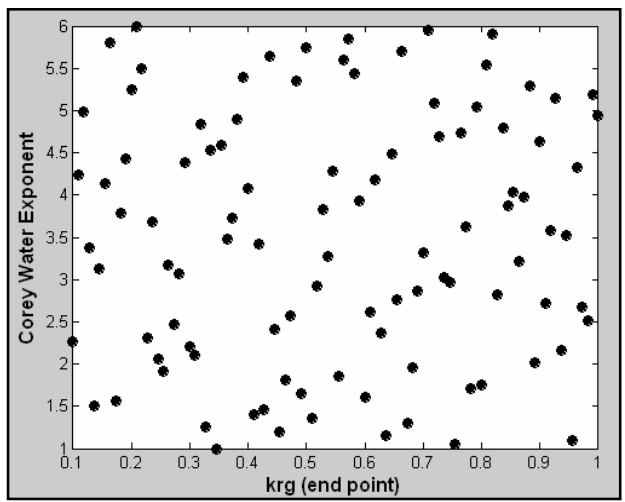

Figure C.93: Gas Relative Permeability End Point vs. Corey Water Exponent

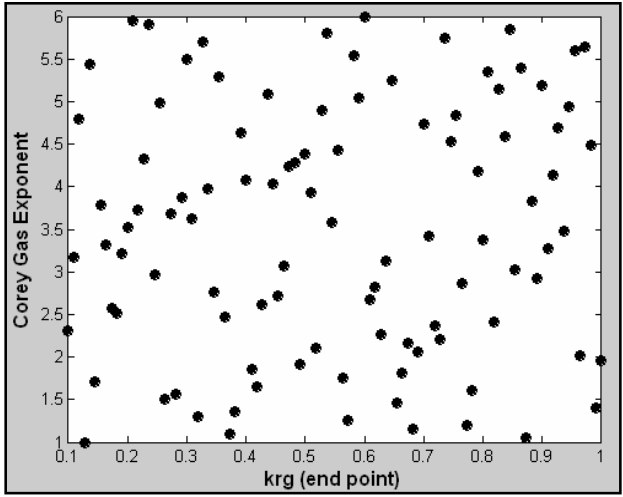

Figure C.94: Gas Relative Permeability End Point vs. Corey Gas Exponent

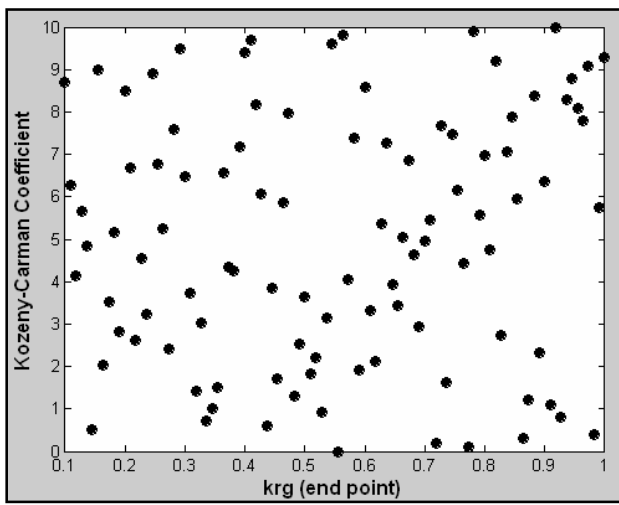

Figure C.95: Gas Relative Permeability End Point vs. Kozeny-Carman Coefficient

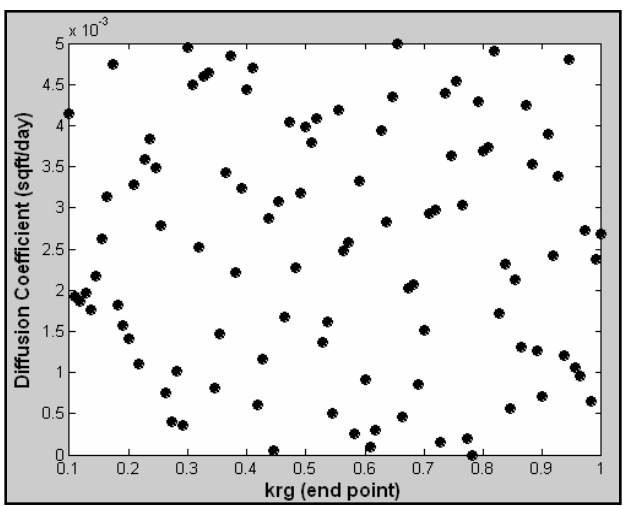

Figure C.96: Gas Relative Permeability End Point vs. Diffusion Coefficient 


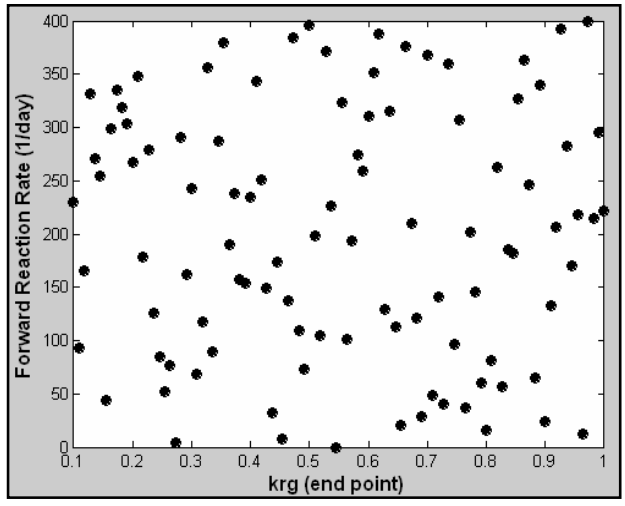

Figure C.97: Gas Relative Permeability End Point vs. Forward Reaction Rate

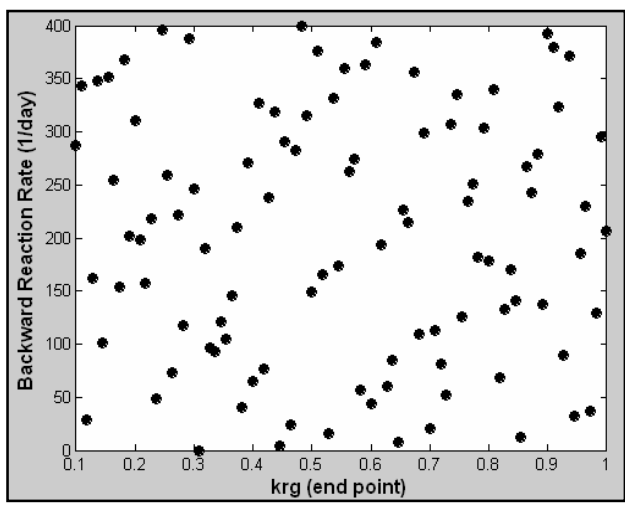

Figure C.98: Gas Relative Permeability End

Point vs. Backward Reaction Rate

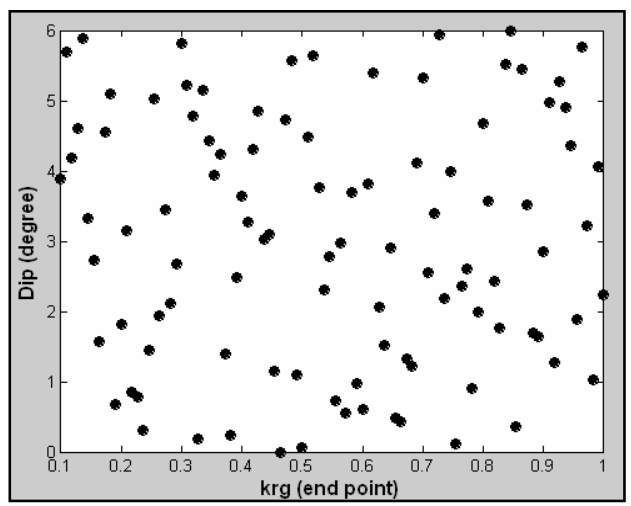

Figure C.99: Gas Relative Permeability End Point vs. Formation Dip

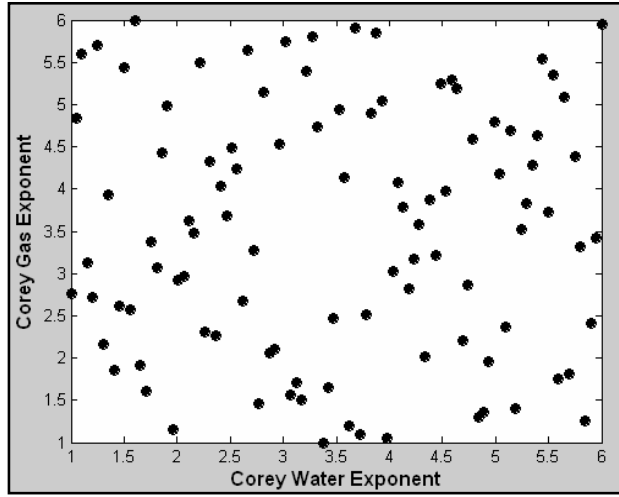

Figure C.100: Corey Water Exponent vs. Corey Gas Exponent

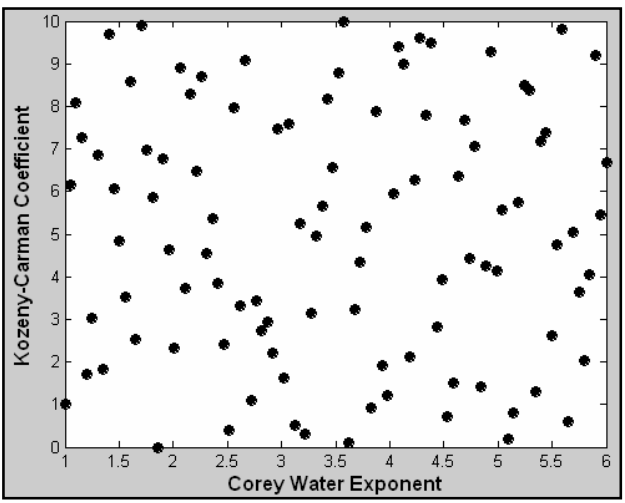

Figure C.101: Corey Water Exponent vs. Kozeny-Carman Coefficient

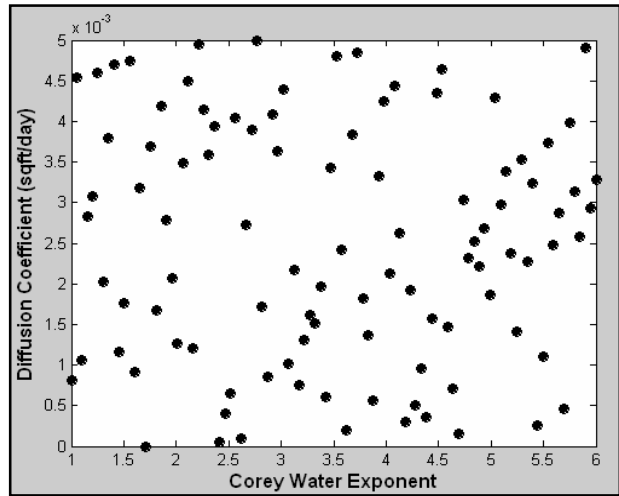

Figure C.102: Corey Water Exponent vs. Diffusion Coefficient 


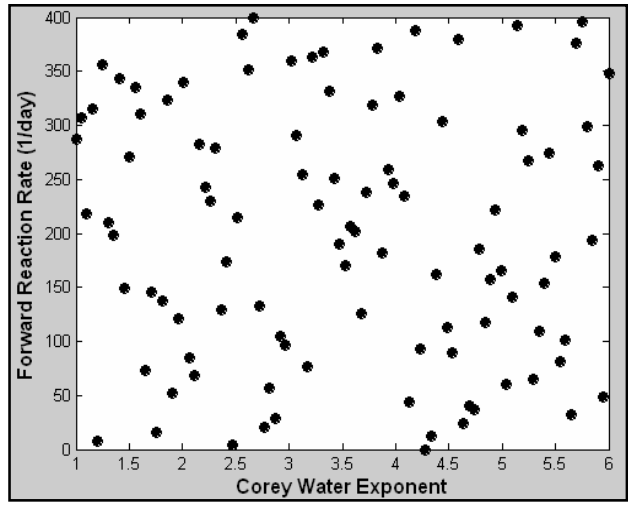

Figure C.103: Corey Water Exponent vs. Forward Reaction Rate

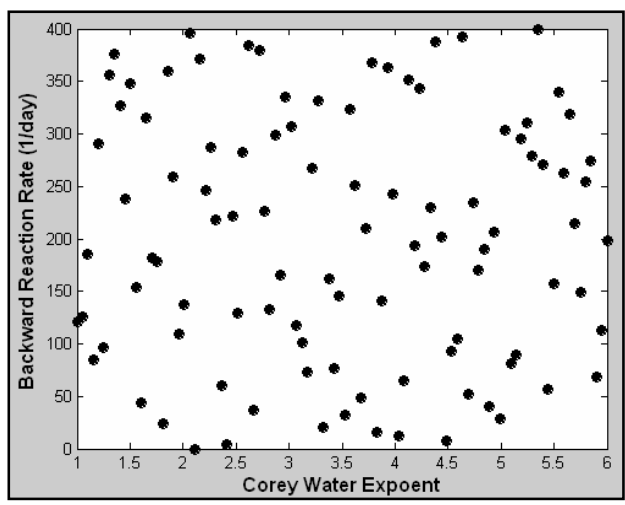

Figure C.104: Corey Water Exponent vs. Backward Reaction Rate

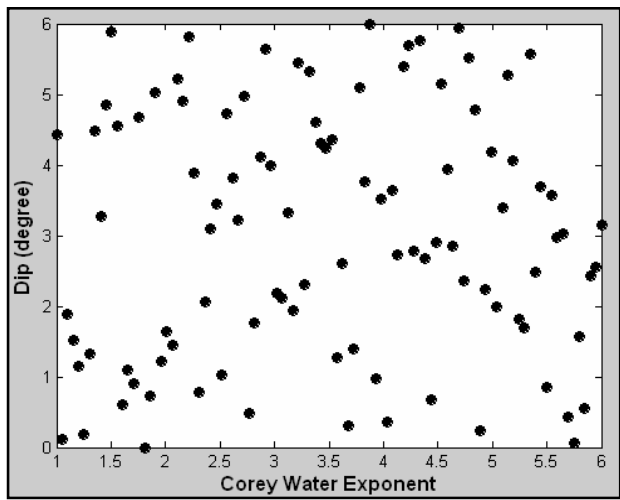

Figure C.105: Corey Water Exponent vs.

Formation Dip

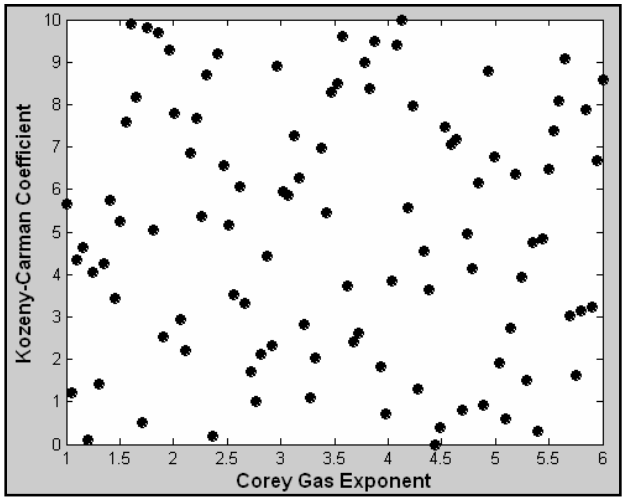

Figure C.106: Corey Gas Exponent vs. Kozeny-Carman Coefficient

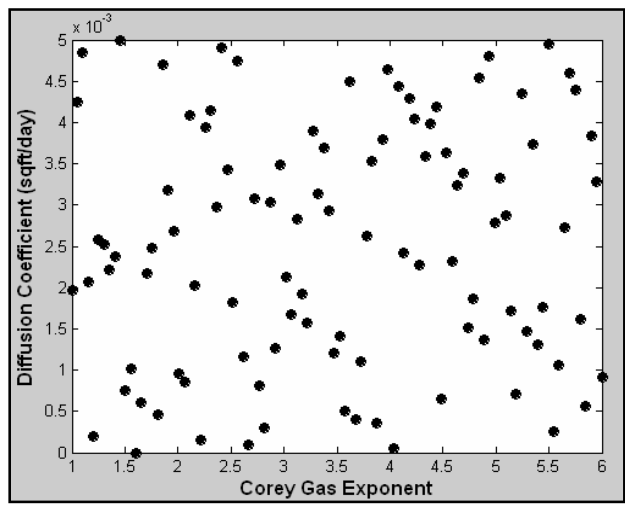

Figure C.107: Corey Gas Exponent vs. Diffusion Coefficient

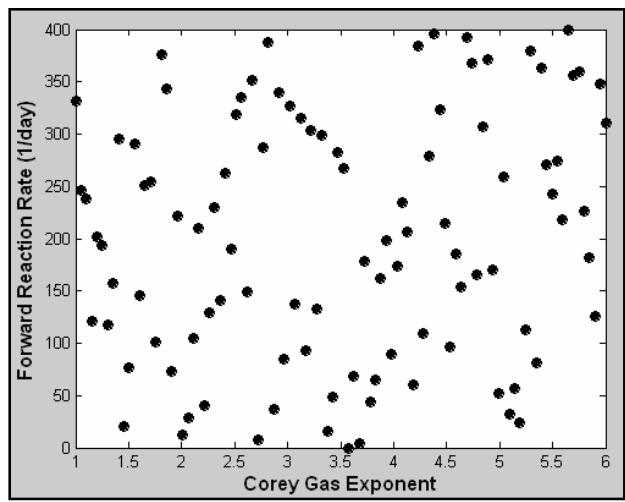

Figure C.108: Corey Gas Exponent vs. Forward Reaction Rate 


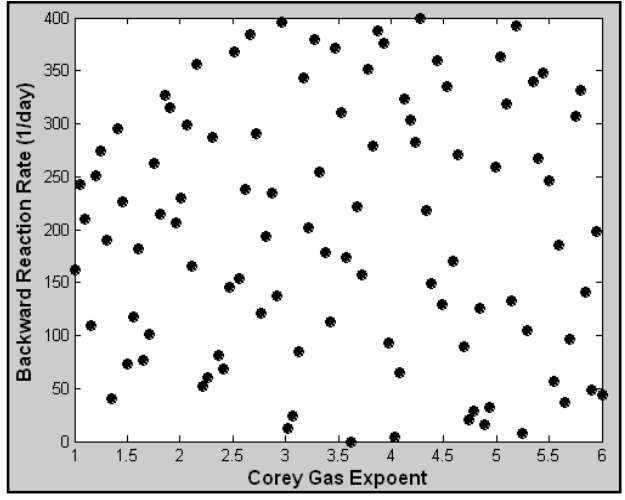

Figure C.109: Corey Gas Exponent vs. Backward Reaction Rate

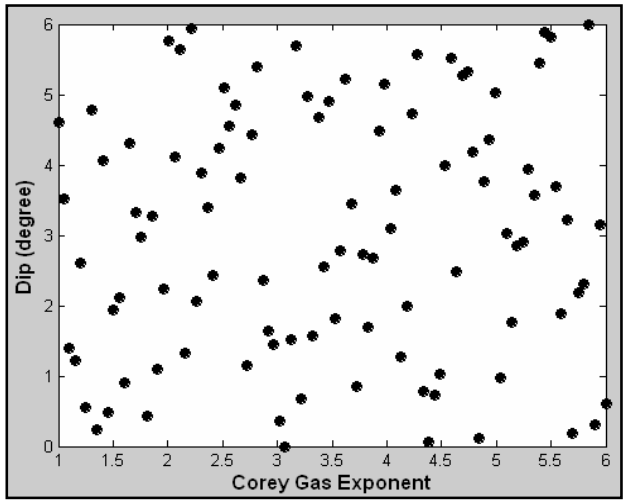

Figure C.110: Corey Gas Exponent vs.

Formation Dip

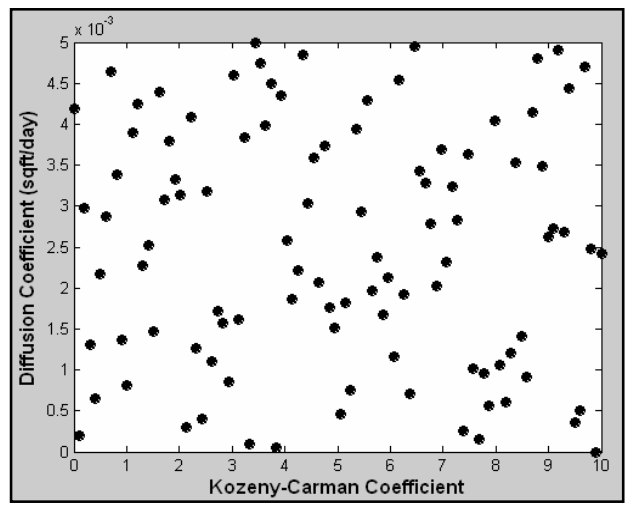

Figure C.111: Kozeny-Carman Coefficient vs. Diffusion Coefficient

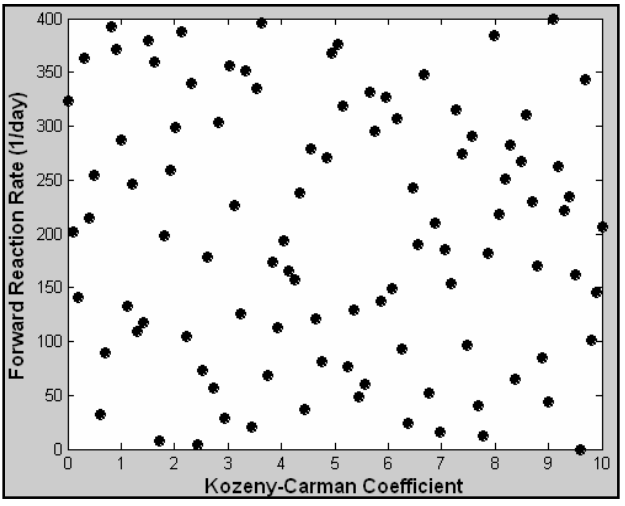

Figure C.112: Kozeny-Carman Coefficient vs.

Forward Reaction Rate

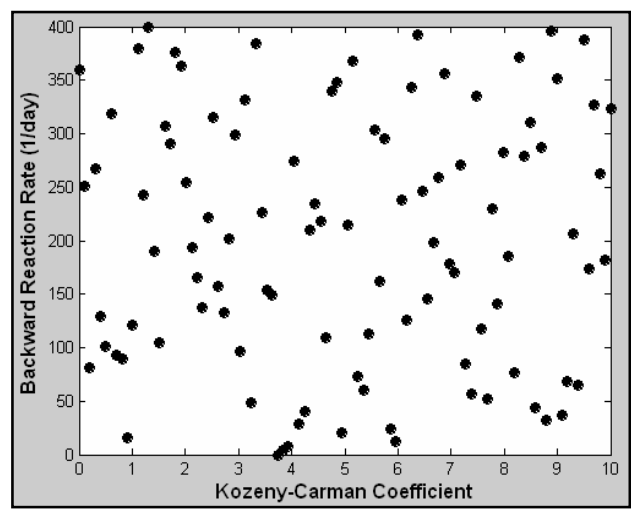

Figure C.113: Kozeny-Carman Coefficient vs. Backward Reaction Rate

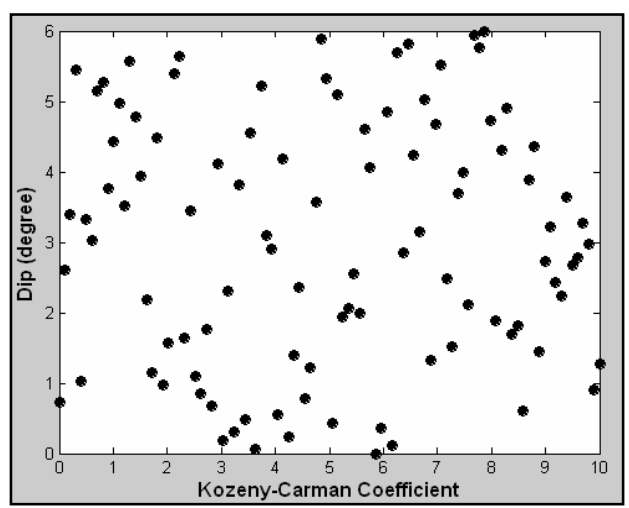

Figure C.114: Kozeny-Carman Coefficient vs.

Formation Dip 


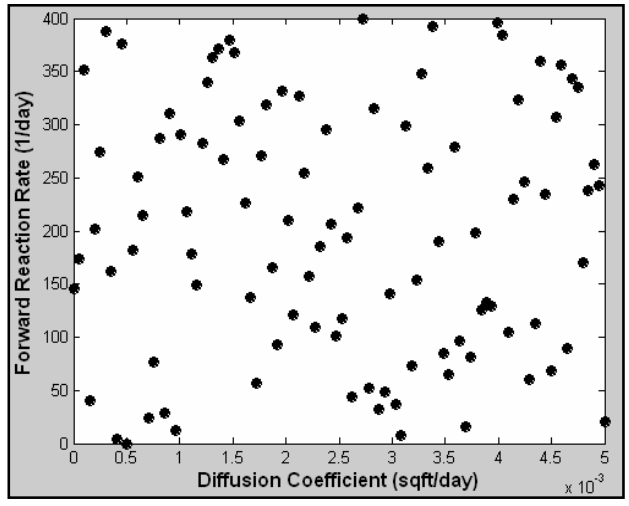

Figure C.115: Diffusion Coefficient vs. Forward Reaction Rate

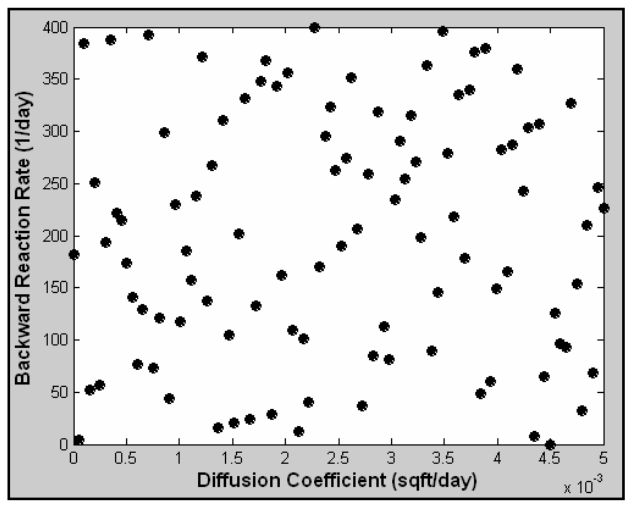

Figure C.116: Diffusion Coefficient vs. Backward Reaction Rate

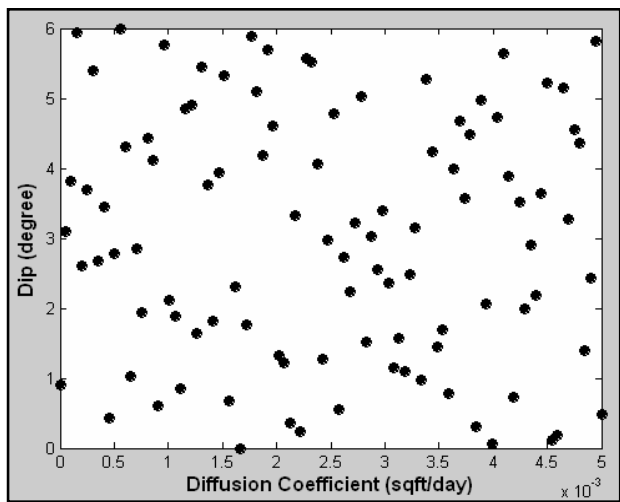

Figure C.117: Diffusion Coefficient vs.

Formation Dip

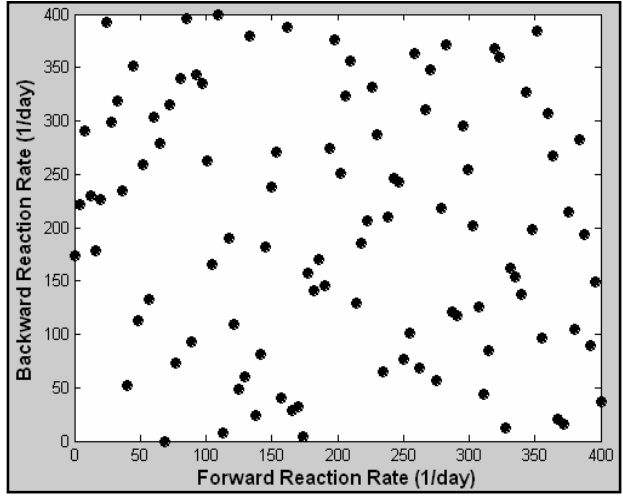

Figure C.118: Forward Reaction Rate vs. Backward Reaction Rate

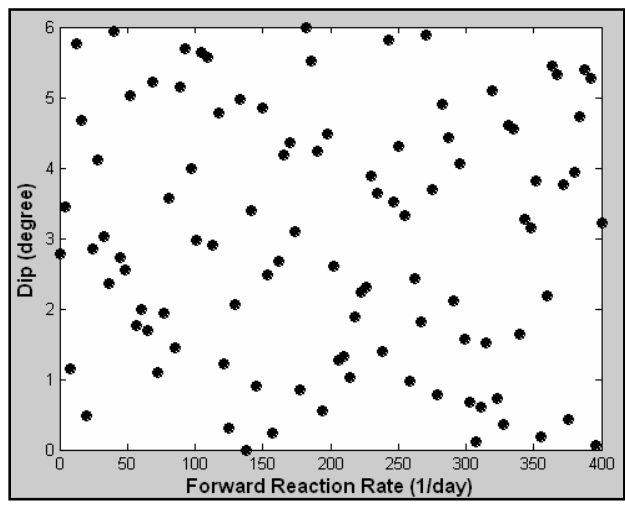

Figure C.119: Forward Reaction Rate vs.

Formation Dip

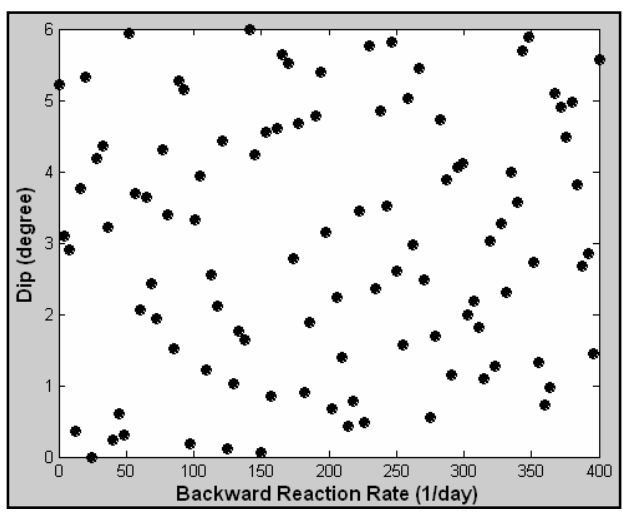

Figure C.120: Backward Reaction Rate vs. Formation Dip 


\section{APPENDIX D}

\section{SIMULATION TEXT FILE}

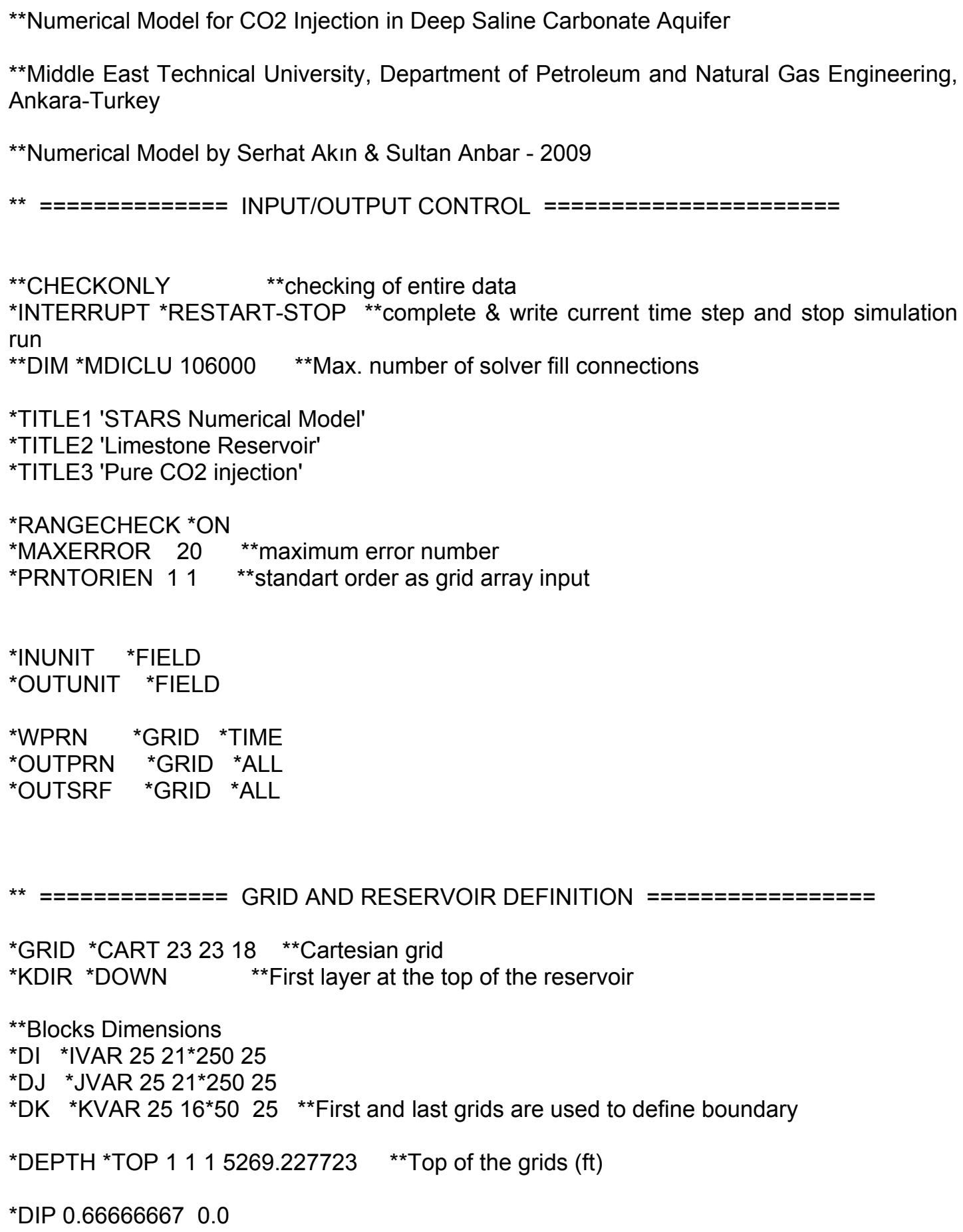




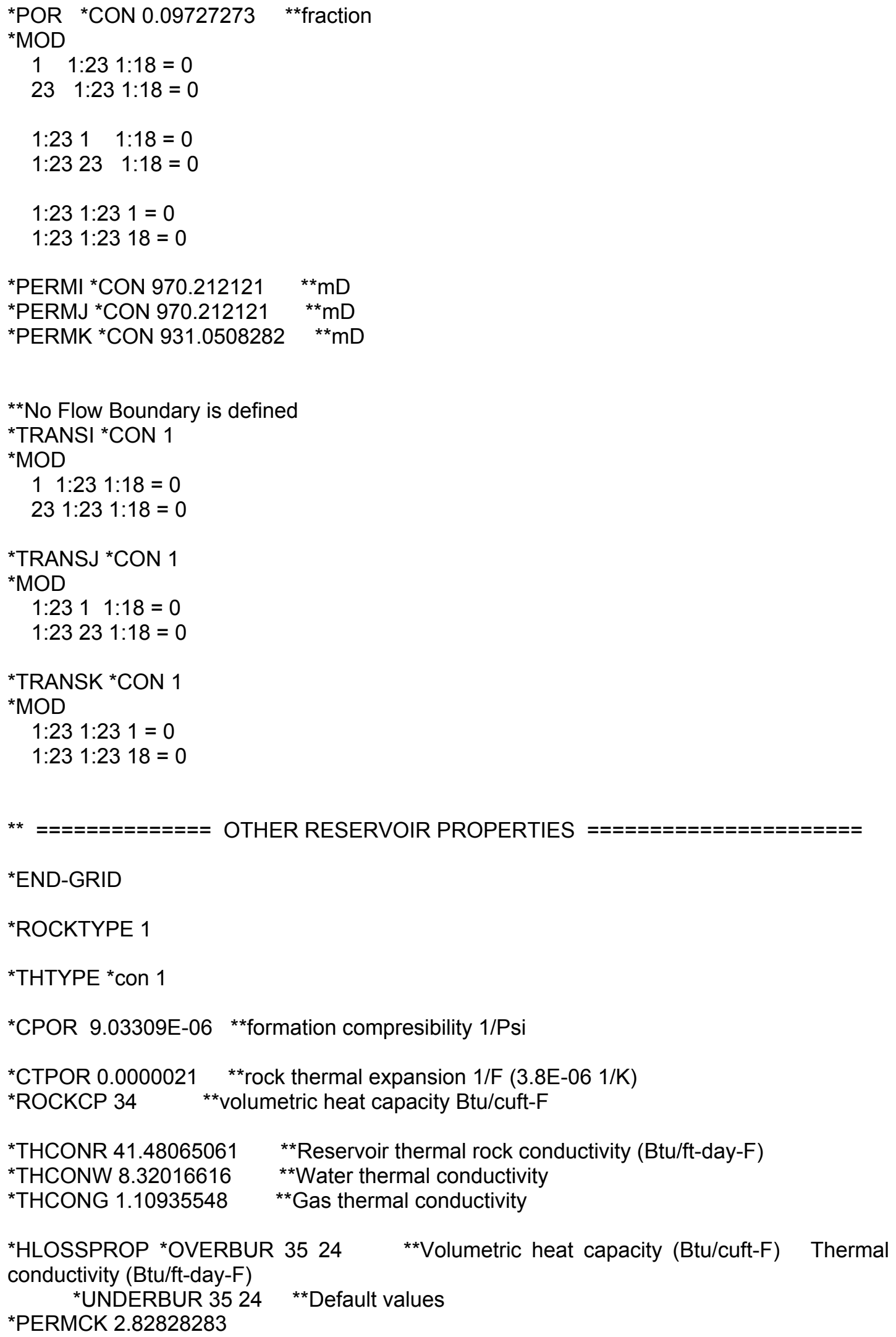




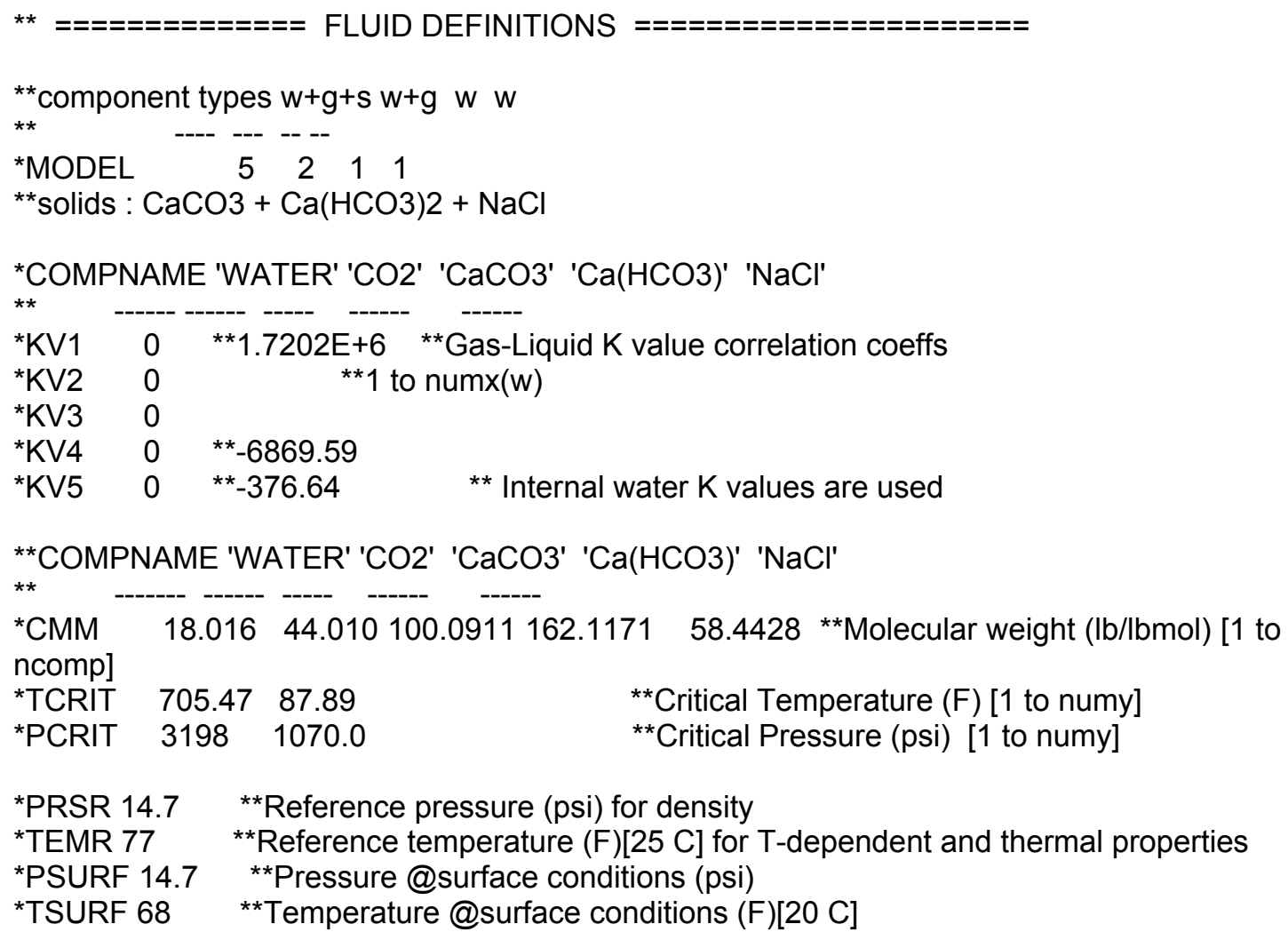




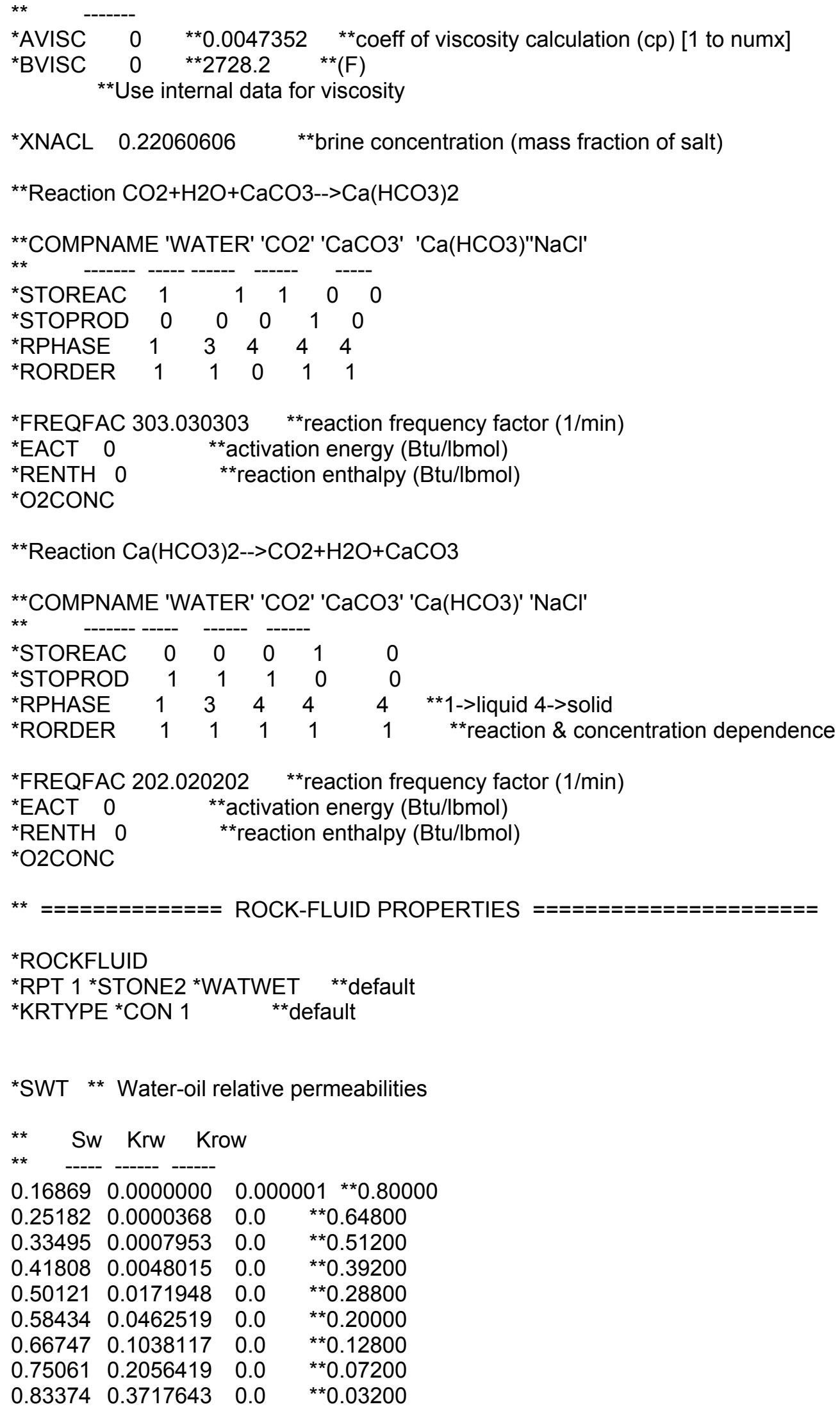




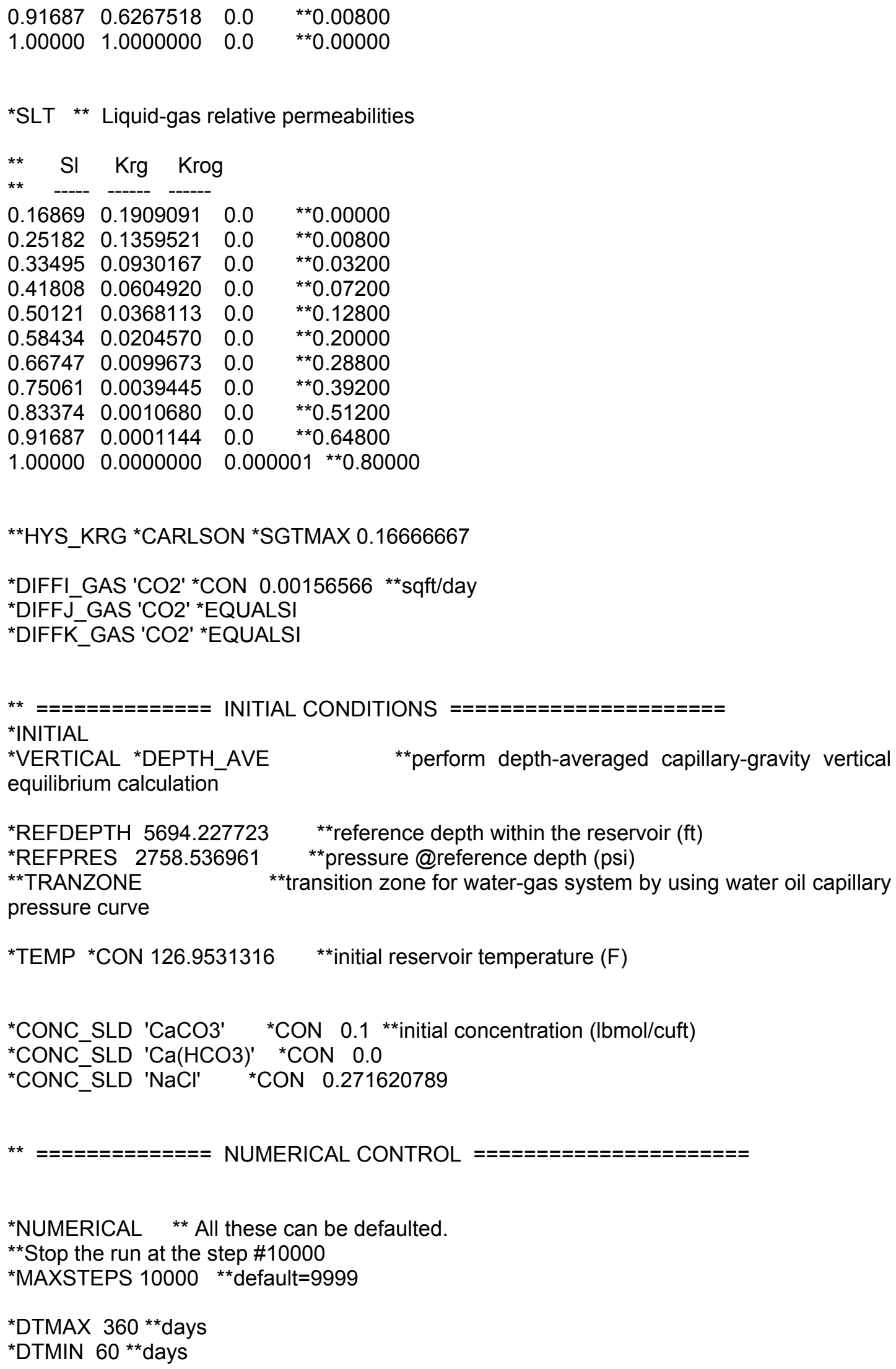


*TFORM *ZT

*ISOTHERMAL

${ }^{*}$ NCUTS 20

** ================ WELL \& RECURRENT DATA =========================

${ }^{*} \mathrm{RUN}$

*TIME0

${ }^{*}$ DTWELL $140 \quad$ **Timestep size (days)

** -----WELL SPECIFICATION W1

*WELL 1 'W1' *VERT 1212 **Well location $(\mathrm{i}, \mathrm{j})$

*INJECTOR *MOBWEIGHT *IMPLICIT 1

${ }^{* *}$ COMPNAME 'WATER' 'CO2' 'CaCO3' 'Ca(HCO3)' 'NaCl'

*INCOMP *GAS $0.0 \quad 1.0$

*TINJW 126.9531316 **supercritic condition (F)

*PINJW $3260.868432 \quad{ }^{* *}$ supercritic condition (psia)

*OPERATE *MAX *STG 1000000. *CONT $\quad{ }^{* *}$ scf/day

*OPERATE *MAX *BHP $3614.423825{ }^{*}$ CONT $\quad{ }^{* *}$ psia

*MONITOR *MIN *STG 100. *SHUTIN

** rad geofac wfrac skin

** (rw-ft) (Appendix A)

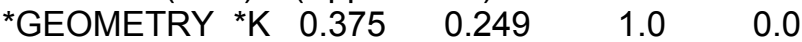

*PERF *GEO 1

** $\mathrm{i}$ j $\mathrm{k}$ ff status

$1212 \quad 10: 17 \quad 1$ *OPEN

*TIME 360

*TIME 720

*TIME 1080

*TIME 1440

*TIME 1800

*TIME2160

*TIME 2520

*TIME 2880

*TIME 3240

*TIME 3600

*TIME 3960

*TIME4320

*TIME 4680

*TIME 5040

*TIME 5400

*TIME5760 
*TIME6120

*TIME 6480

*TIME 6840

*TIME 7200

*TIME 7560

*TIME 7920

*TIME 8280

*TIME 8640

*TIME 9000

*TIME 9360

*TIME 9720

*TIME 10080

*TIME 10440

*TIME 10800

*TIME 11160

*TIME 11520

*TIME 11880

*TIME 12240

*TIME 12600 $\vdots \quad \vdots$

*TIME 106560

*TIME 106920

*TIME 107280

*TIME 107640

*TIME 108000

${ }^{*}$ STOP ${ }^{* *}$ Run (600 years) ends here 


\section{APPENDIX E}

\section{FILE FOR GAS COMPRESSIBILITY FACTOR CALCULATION}

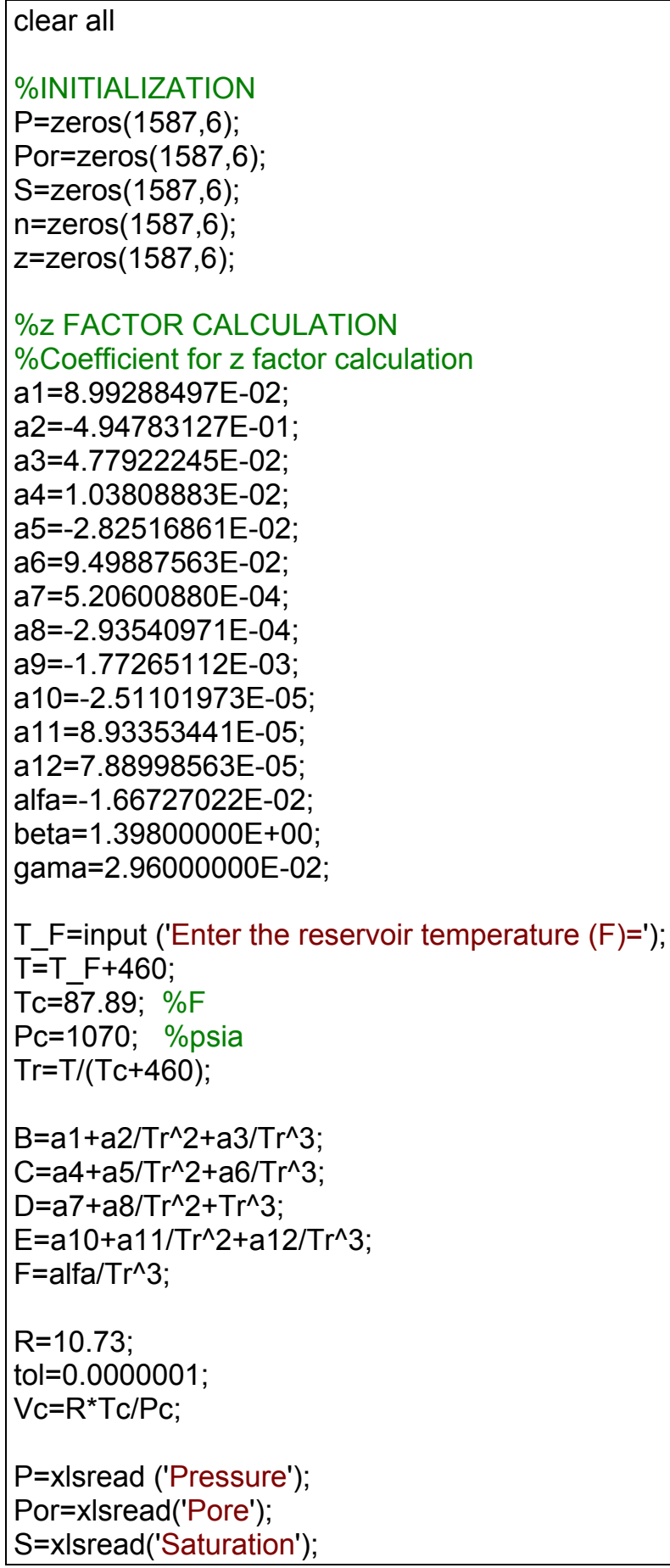




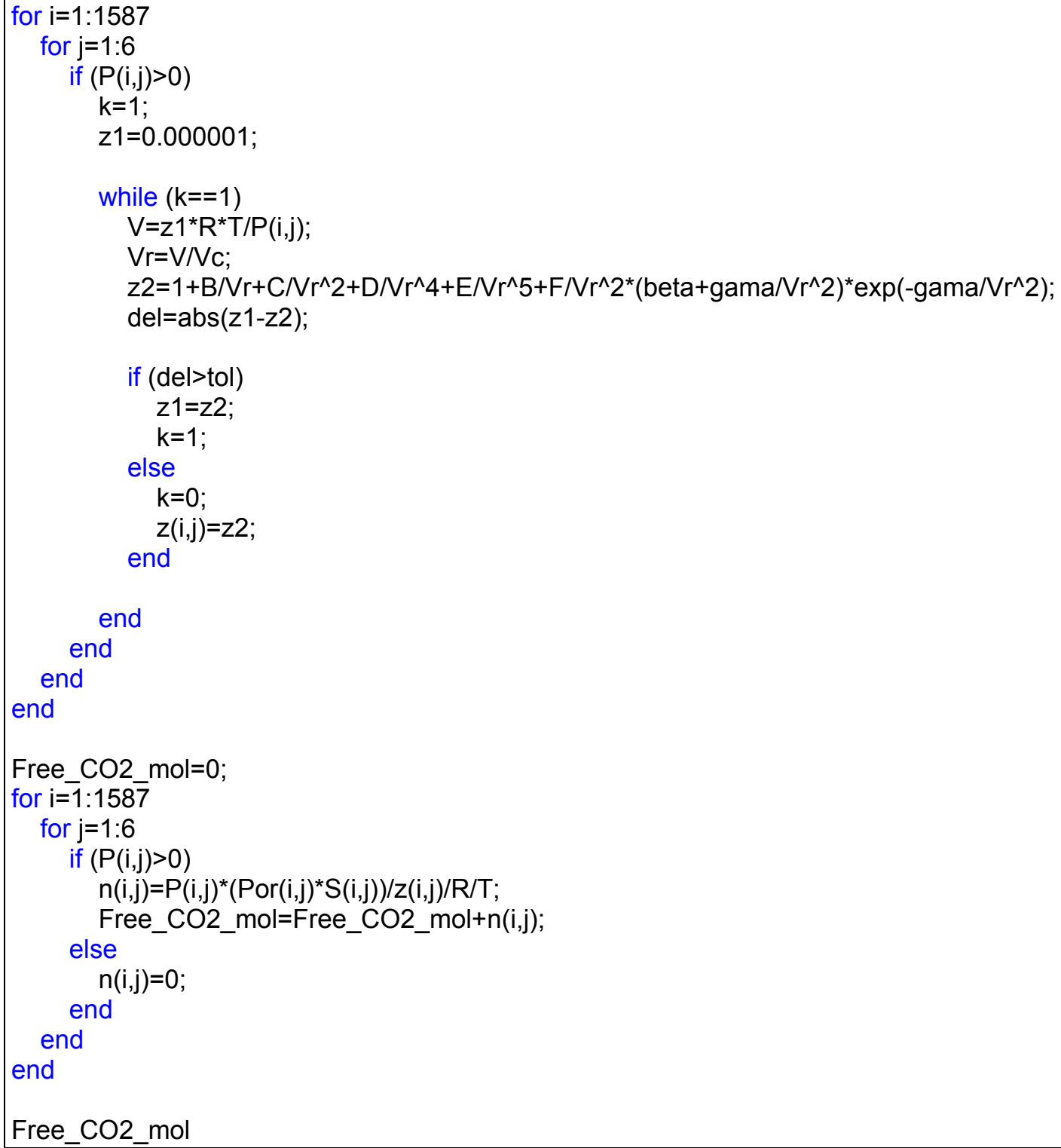

